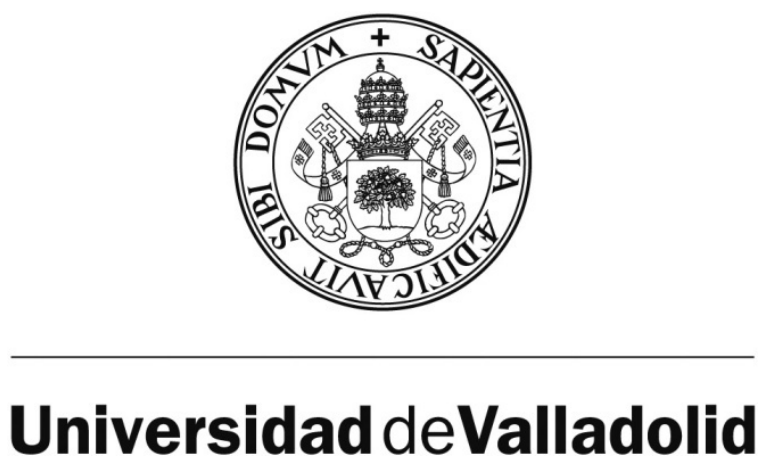

FACULTAD DE MEDICINA

DEPARTAMENTO DE BIOQUÍMICA Y BIOLOGÍA MOLECULAR Y FISIOLOGÍA

TESIS DOCTORAL:

\title{
Relación de Apolipoproteína D y sus homólogos en Drosophila con las membranas biológicas. Estudio de su función en diferentes procesos celulares y de su localización y efectos sobre las balsas lipídicas.
}

Presentada por MANUELA DEL CAÑO ESPINEL para optar al grado de doctor por la Universidad de Valladolid

Dirigida por:

Dra. María Dolores Ganfornina Álvarez Dr. Diego Sánchez Romero 
A mi madre, para mi abuelita 


\section{SUMMARY/RESUMEN}

Apolipoprotein $D(A p o D)$ is a Lipocalin secreted mainly by glialcells whose expression increases with aging and neurodegeneration. Glial Lazarillo (GLaz) and Neural Lazarillo (NLaz) are Drosophila homologues of ApoD. ApoD protects against oxidative stress and promotes axon regeneration after injury, but its mechanism of action is unknown. ApoD stands among a small set of genes whose over-expression upon nervous system aging is conserved throughout evolution, and its over-expression is extensively correlated with a wide spectrum of nervous system damage, like stroke, psychiatric disorders, and neurodegenerative diseases like Alzheimer, Parkinson, Huntington or Niemann Pick. These neuroprotective functions are proposed to be mediated by counteracting lipid peroxidation.

In this Thesis it is hypothesized that GLaz/NLaz/ApoD modulates membrane composition, dynamics and oxidation. To contrast this hypothesis the effects of these lipocalins on different processes in which the membrane plays an important role have been studied.

Physiological aging and neurodegeneration share their two major causal factors (1) reactive oxygen species (ROS)-mediated damage and (2) deterioration of protein and organelle quality control systems. GLaz is able to counteract some of the neurodegenerative effects of a primarily mitochondrial dysfunction disease with a redox imbalance, Friedreich ataxia, reducing the level of lipid peroxidation and free fatty acids. The first objective of this work is to study the effect of these Lipocalins on the second factor, the impairment of the protein and organelle quality control systems. A Drosophila retinal degeneration model based on a poly- $Q$ triggered disease, the Type I Spinocerebellar Ataxia (SCA1), combined with various forms of over-expressing NLaz and GLazwas used. Until now, no Lipocalin has been tested for its ability to modify poly-Q-based neurodegeneration. Both Lipocalins have proved to be part of the endogenous transcriptional protective response against poly-Q-based neurodegeneration.GLaz and NLaz overexpression rescues neurodegeneration and their beneficial effects persist throughout aging and take place in an autocrine and paracrine manner. GLaz gain-of-function in this model promotes clearance of ubiquitinated proteins, reduces the accumulation of the autophagy cargo receptor $\mathrm{p} 62$ and thereby reduces apoptotic cell death. GLaz achieves this protection by promotingflow of the last steps of autophagy, not its induction, even when combining SCA1-dependent with pharmacological inductions of autophagy. In addition, GLaz decreases the SCA1-dependent induction of Gsts1, a SCA1 genetic modifier contributing to the clearance of lipid peroxides, whereby the beneficial effects of GLaz are linked to lipid peroxide clearance.

These results suggest that GLaz enters the degenerating neurons by endocytosis and promotes the resolution of autophagy, increasing its flow and helping to clear poly-Q-induced protein aggregates. The study of the internalization of ApoD in cultured astrocytes has revealed that ApoD is endocytosed and localized in lysosomes where it can act on processes occurring inside the cell like autophagy flow.

Since there is an ApoD homolog bound to the membrane through a GPI membrane binding domain, the grasshopper Lazarillo, whose loss causes a defect in axon growth, the 
conservation of this phenotype in the secreted homologues was the next target of this work. The analysis of axonal growth in Drosophila primary neuronal cultures in the absence of NLaz and GLaz has revealed a decrease in the length of axons compared to control cultures, and a decrease in the number of established synapses and their area. This result confirms the existence of a conserved mechanism of action strongly associated with membranes.

Given the conserved phenotype of GPI-membrane bound Lazarillo and its secreted homologues, lysosomal membranes are rich in lipid rafts, and the GPI-proteins are usually found attached to these domains suggests that ApoD and its secreted homologues may be linked specifically to the membrane lipids rafts. The last part of this work was focused in the possible ApoD-membranes interaction and the effect of the lipocalin on them.

Despite being a secreted protein, ApoD has a strong interaction with membranes. ApoD behaves as a peripheral membrane protein associated to detergent-resistant membrane domains in a stable and independent of species manner. Specifically ApoD appears linked to membrane domains extracted by Triton X-114 characterized as cellular membrane domains rich in gangliosides. No differences were observed in the amounts of cholesterol or sphingomyelin when comparing lipid rafts of WT and ApoD-KO membranes. Similarly, no notable differences exist in the protein profile from the lipid raft fractions in the absence of ApoD. However, the analysis of raft fractions with Raman spectroscopy shows conformational changes in their molecular structures and molecular disorder due to lack of ApoD. A lipidomic study with UPLC-mass spectrometry shows significant changes in lipid composition between WT and ApoD-KO raft fractions of mouse hippocampi treated with the pro-oxidant drug paraquat. ApoD specifically modified ganglioside metabolism in response to oxidative stress resulting in modifications of the composition of monohexosilceramides, sphingomyelin and ceramides that constitute lipid rafts. These results confirm a direct relationship between a secreted protein, ApoD, and membrane composition, and specifically link ApoD function to lipid rafts, a membrane domain involved in a vast number of signalling processes conditioning cell fate.

This new location of ApoD and its amazing interaction with membranes opens new research lines approaching the mechanism of action of ApoD to both the plasma and intracellular membranes. It also points to the processes where these structures are involved, conferring ApoD a broad spectrum of possibilities to exert its protective function and converting ApoD in a versatile research tool. 


\section{INDEX}

\section{SUMMARY}

II. INTRODUCTION

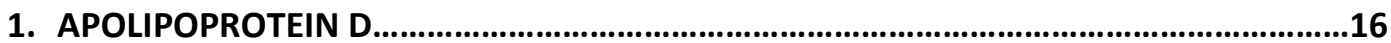

1.1. STRUCTURE

1.2. LIGAND

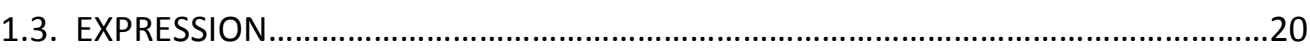

1.4. ApoD HOMOLOGOUS GENES. THE LIPOCALIN FAMILY......................................23

1.4.1. LAZARILLO (Laz) AND OTHER LIPOCALINS WITH MEMBRANES ANCHOR

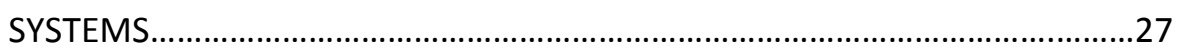

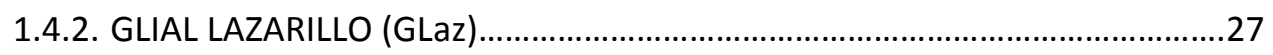

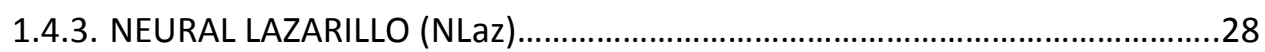

1.5. LOSS-OF FUNCTIONS AND GAIN-OF-FUNCTION MODELS...................................28

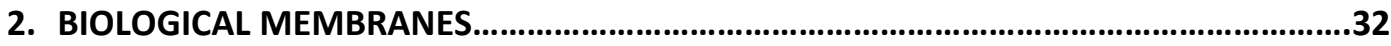

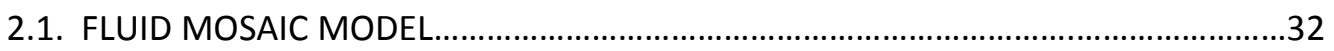

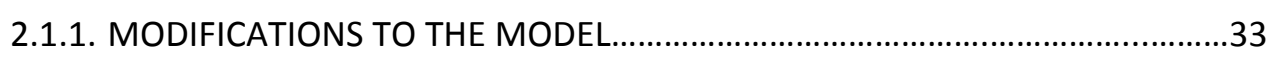

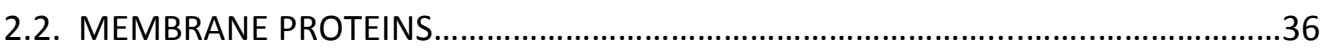

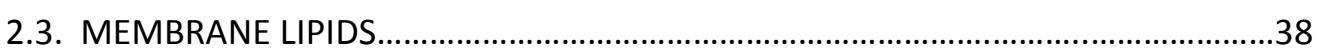

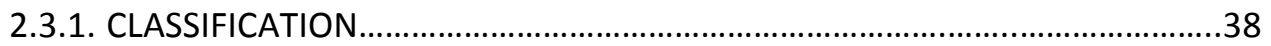

2.3.2. MEMBRANELIPIDSIN DROSOPHILA............................................................45

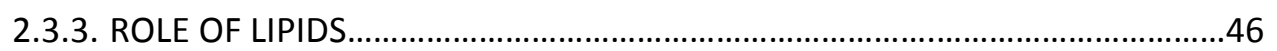

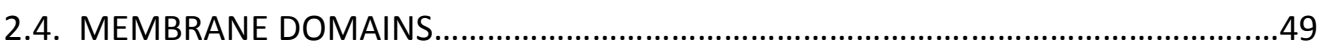

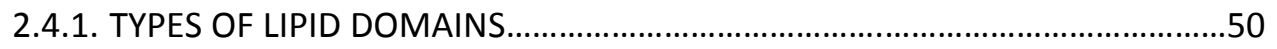

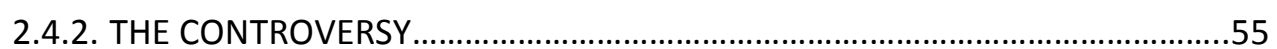

2.4.3. ANALYTICAL TECHNIQUES. EVIDENCES OF THEIR EXISTENCE......................56

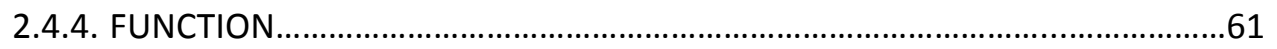

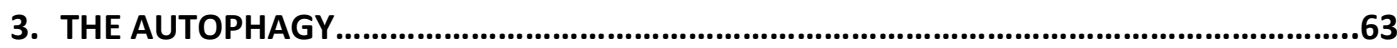

3.1. DEFINITION. TYPES

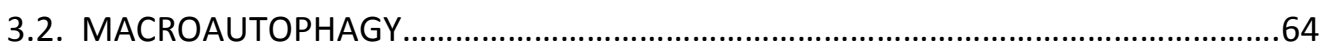

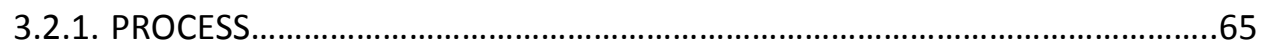

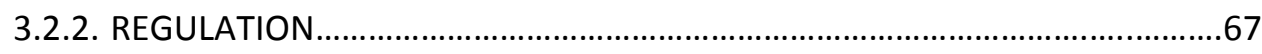

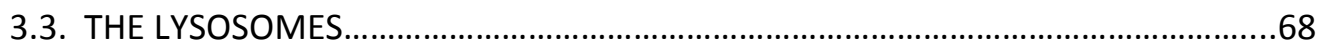

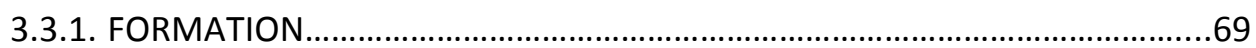

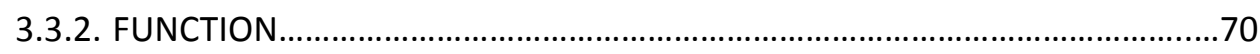

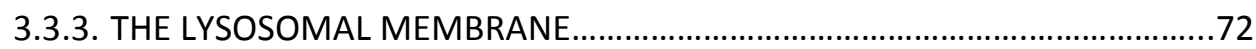

3.4. ROLE OF AUTOPHAY IN CELLULAR HOMEOSTASIS AGAINST OXIDATIVE STRESS.

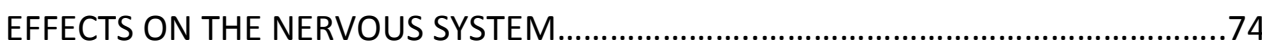

4. OXIDATIVE STRESS. EFFECTS ON THE NERVOUS SYSTEM..............................................77

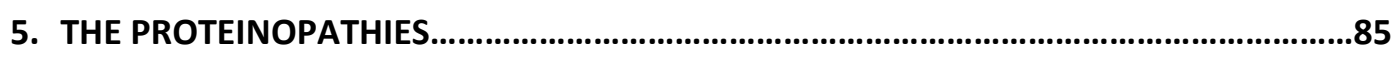

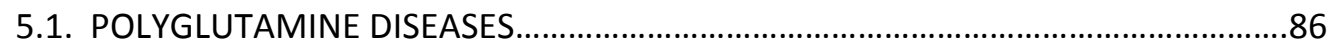

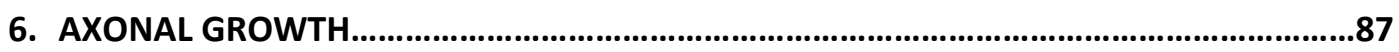




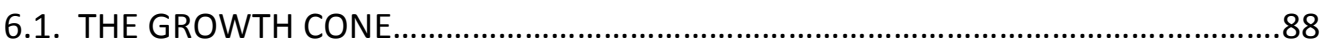

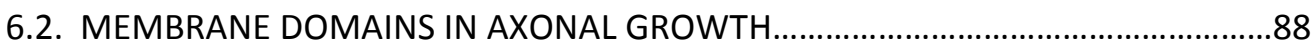

III. OBJETIVES

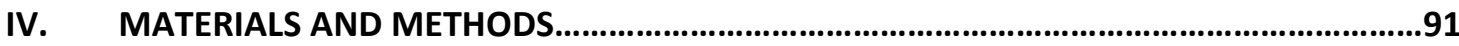

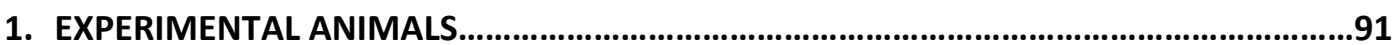

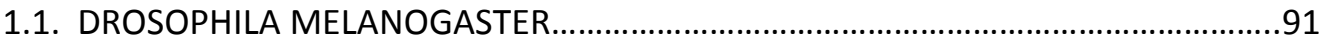

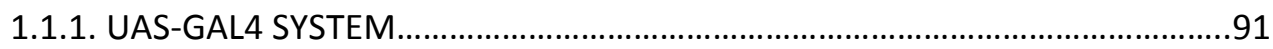

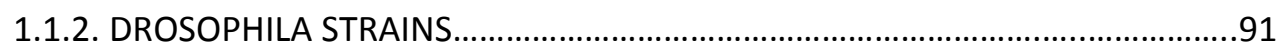

1.1.2.1. GAIN-OF-FUNCTION AND LOSS-OF-FUNCTION OF GLaz AND NLaz..91

1.1.2.2. SCA1 MODEL IN THE FLY RETINA.........................................................92

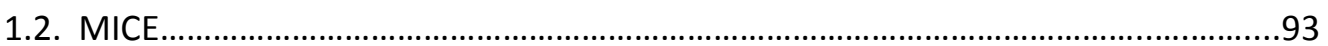

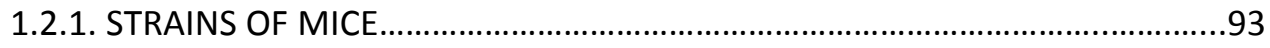

1.2.2. CHRONIC TREATMENT WHITH PARAQUAT (PQ)..........................................93

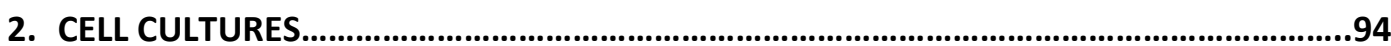

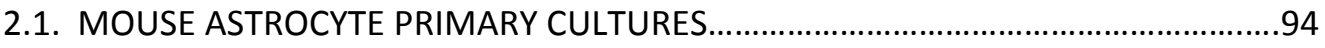

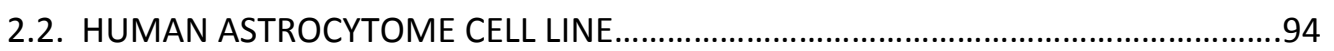

2.3. DROSOPHILA NEURONS PRIMARY CULTURES. AXONAL GROWTH......................94

3. MORPHOLOGICAL ANALYSIS OF DROSOPHILA EYE SURFACE.......................................95

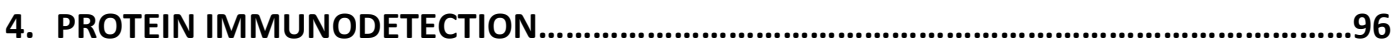

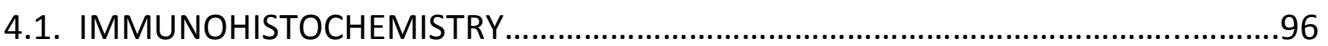

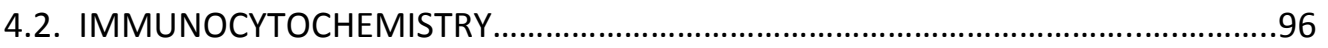

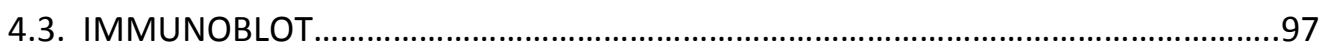

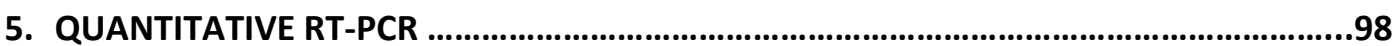

6. ISOLATION OF DETERGENT RESISTANT MEMBRANE DOMAINS.................................99

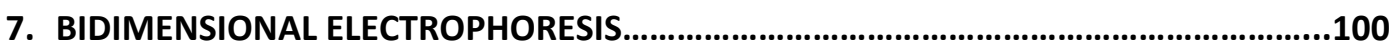

8. QUANTIFICATION OF CHOLESTEROL AND SPHINGOMYELIN.....................................100

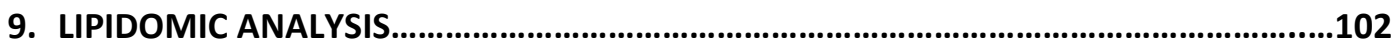

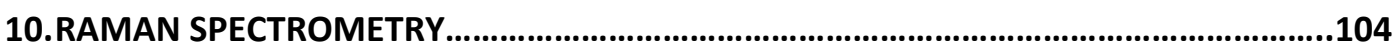

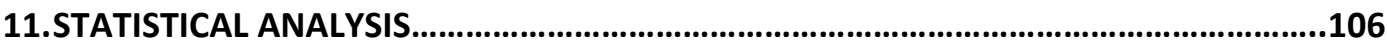

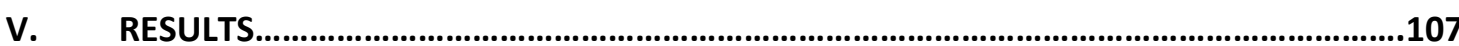

1. CHAPTER1. STUDY OF THE ROLE OF APOD IN A PROTEINOPATHY: THE SPINOCEREBELLAR ATAXIA TYPE I (SCA1)

1.1. GLaZ IS OVEREXPRESSED UPON POLYGLUTAMINATED HUMAN ATAXIN-1 EXPRESSION IN DROSOPHILA RETINA (SCA1 MODEL).

1.2. GLaz REDUCES THE PHOTORECEPTOR DEGENERATION CAUSED BY POLYGLUTAMINATED HUMAN ATAXIN-1

1.3. GLaz RESCUES DEGENERATION OF PHOTORECEPTOR NEURONS IN A STABLE MANNER WHEN PRODUCED BY ITS NATIVE CELL EXPRESSION DOMAIN............112

1.4. NLaz IS UP-REGULATED BY PATHOGENIC POLY-Q ATAXIN1 EXPRESSED IN THE FLY RETINA, AND RESCUES PHOTORECEPTOR NEURODEGENERATION. 
1.5. OVER-EXPRESSION OF GLaz DECREASES APOPTOTIC CELL DEATH IN THE PRESENCE OF EXPANDED HUMAN ATAXIN1...

1.6. GLaZ ALTERS THE EXPRESSION OF A SCA1 PHENOTYPE-MODIFIER CONTROLLING

LIPID PEROXIDE CLEARANCE.

1.7. GLaZ REDUCES THE SCA1-DEPENDENT ACCUMULATION OF UBIQUITINATED PROTEINS.

1.8. OVER-EXPRESSION OF GLaz REDUCES SCA1-DEPENDEN AUTOPHAGY INDUCTION.

1.9. GLaz PREVENTS p62 ACCUMULATION UPON SCA1-DEPENDENT AND RAPAMYCINSTIMULATED AUTOPHAGY...

1.10. THE ABSENCE OF GLaz IMPAIRS AUTOPHAGY FLUX BUT NOT AUTOPHAGY INITIATION

1.11. ApoD INTRACELLULAR LOCATION.

1.11.1.1. ENDOCYTOSED ApoD IS FOUND IN LYSOSOMES 124

2. CHAPTER 2. THE ROLE OF GLaz AND NLaz IN AXONAL GROWTH AND SYNAPTOGENESIS

2.1. LACK OF GLaz CAUSES A DECREASE IN AXON LENGTH BUT NOT IN THE AMOUNT OF FILOPODIA OF DROSOPHILA NEURONS IN CULTURE. .126

2.2. LACK OF GLaz AND NLaz REDUCES THE NUMBER OF SINAPSIS ESTABLISHED BY DROSOPHILA NEURONS CULTURES

3. CHAPTER 3. APOD AND MEMBRANES

3.1. ApoD IS LOCATED IN DETERGENT RESISTANT MEMBRANE DOMAINS AND THIS ASSOCIATION IS CONSERVED BETWEEN MOUSE AND HUMAN MEMBRANES 130

3.2. LACK OF APOD DOES NOT CHANGE THE AMOUNT OF CHOLESTEROL OR SPHINGOMYELIN IN MOUSE BRAIN DETERGENT RESISTANT MEMBRANE DOMAINS.

3.3. LACK OF APOD DOES NOT SUBSTANTIALLY MODIFY THE PROTEIN PATTERN OF MOUSE-BRAIN DETERGENT RESISTANT MEMBRANE DOMAINS

3.4. LACK OF APOD CAUSES CONFORMATIONAL CHANGES IN LIPIDS OF MOUSE-BRAIN DETERGENT RESISTANT MEMBRANE DOMAINS.

3.5. ApoD DOES NOT MODIFY THE LIPID RAFTS GENERIC MAKER FLOTILIN DISTRIBUTION.

3.6. LACK OF ApOD ALTERS THE LIPIDS-COMPOSITION RESPONSE TO OXIDATIVESTRESS IN THE MOUSE HIPPOCAMPAL DETERGENT RESISTANT MEMBRANE DOMAINS.

3.6.1. MOUSE HIPPOCAMPAL TRITON X-114 RESISTANT MEMBRANE DOMAINS ARE HIGHLY SENSITIVE TO OXIDATIVE STRESS AND THEIR COMPOSITION DEPENDS ON ApOD ONLY UNDER OXIDATIVE STRESS 136

3.6.2. LACK OF APOD CAUSES AN INCREASE OF MONOHEXOSILCERAMIDES IN DETERGENT RESISTANT MEMBRANE DOMAINS UNDER OXIDATIVE STRESS 


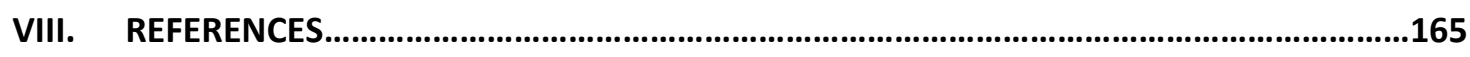

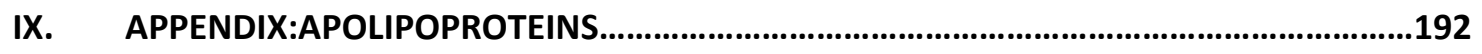

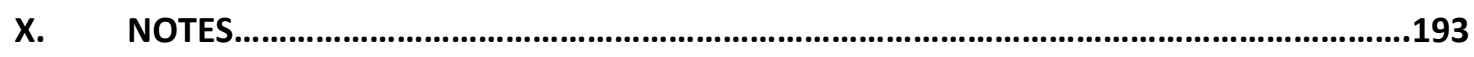




\section{ÍNDICE}

I. RESUMEN

II. INTRODUCCIÓN

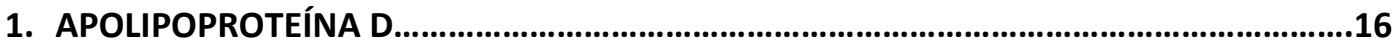

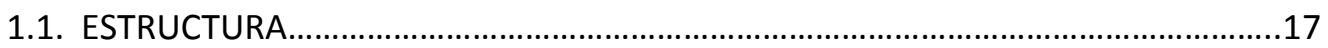

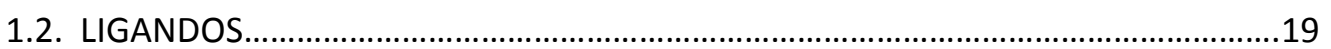

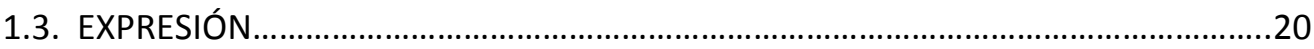

1.4. HOMOLOGOS DE ApoD. LA FAMILIA DE LAS LIPOCALINAS..................................23

1.4.1. LAZARILLO (Laz) Y OTRAS LIPOCALINAS CON SISTEMAS DE ANCLAJE A MEMBRANAS. .27

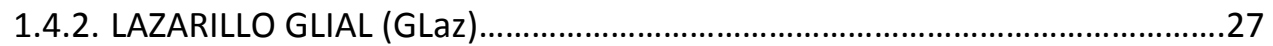

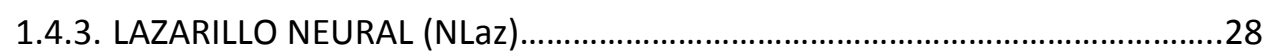

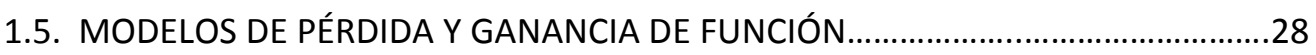

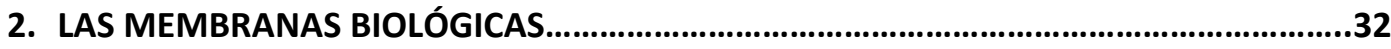

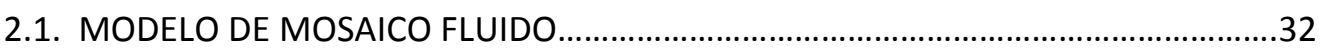

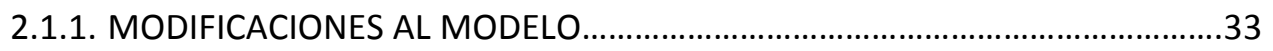

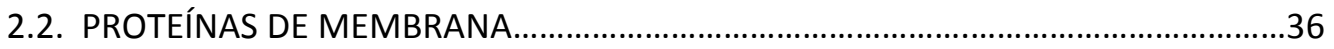

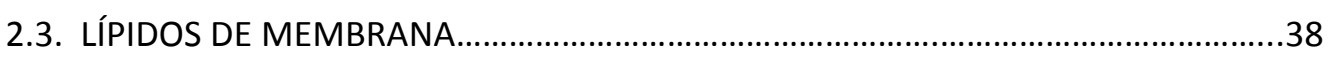

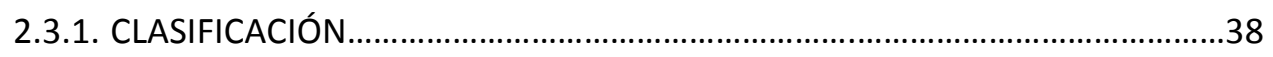

2.3.2. LÍPIDOS DE MEMBRANA EN DROSOPHILA .....................................................45

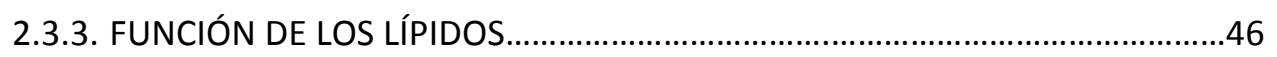

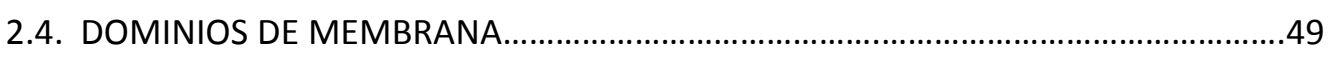

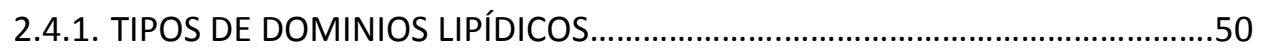

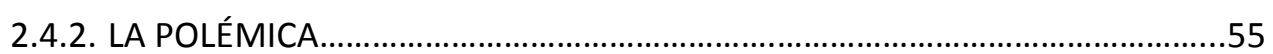

2.4.3. TÉCNICAS DE ANÁLISIS. EVIDENCIAS DE SU EXISTENCIA .............................56

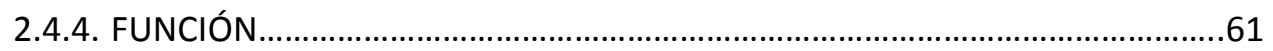

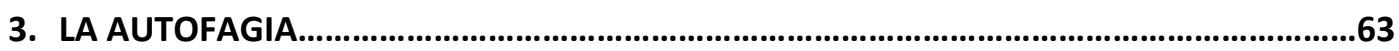

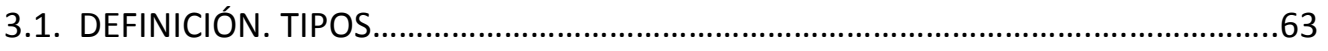

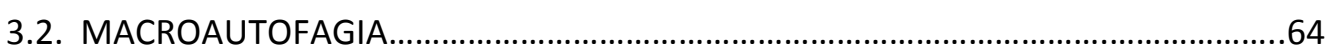

3.2.1. PROCESO

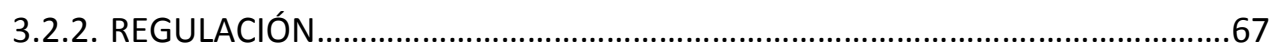

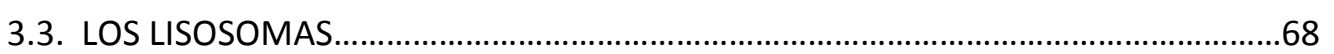

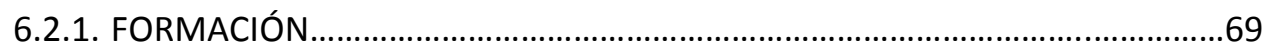

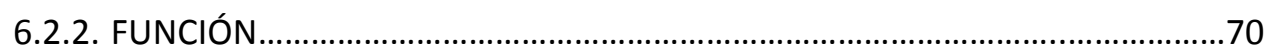

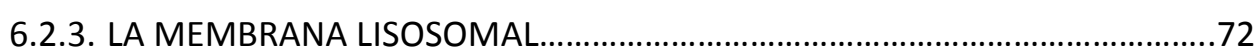

3.4. PAPEL DE LA AUTOFAGIA EN LA HOMEOSTASIS CELULAR Y ANTE EL ESTRÉS....74

4. EL ESTRÉS OXIDATIVO. SUS EFECTOS SOBRE EL SISTEMA NERVIOSO...........................77

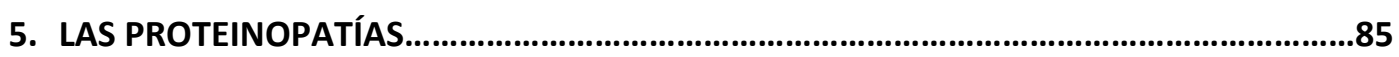

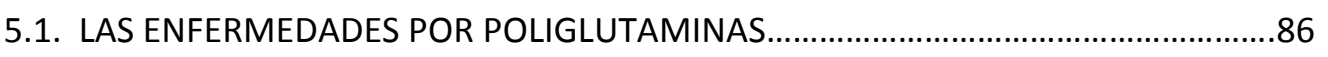

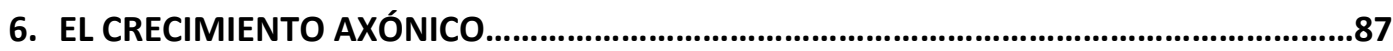

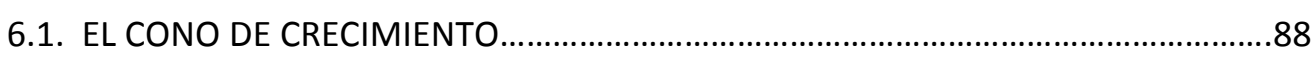

6.2. LOS DOMINIOS DE MEMBRANA EN EL CRECIMIENTO AXONAL.............................88 


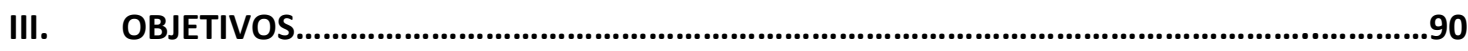

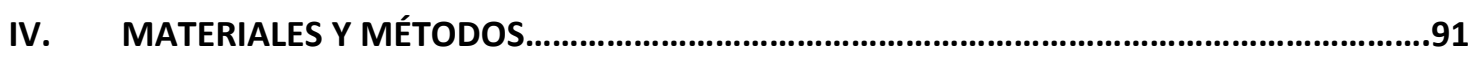

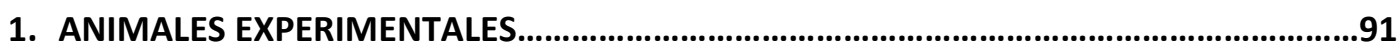

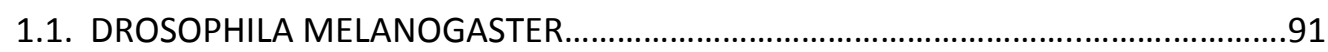

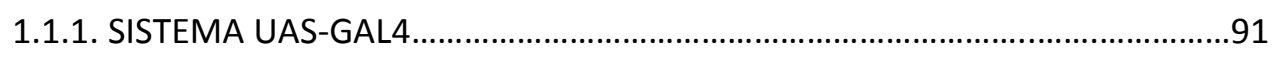

1.1.2. ESTIRPES DE DROSOPHILA .....................................................................91

11.1.1.1. GLaz y NLaz, GANANCIA Y PÉRDIDA DE FUNCIÓN.........................91

11.1.1.2. MODELO DE SCA1 EN LA RETINA.......................................................92

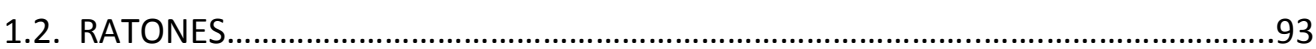

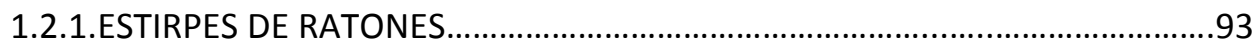

1.2.2.TRATAMIENTO CRÓNICO CON PARAQUAT (PQ)...........................................93

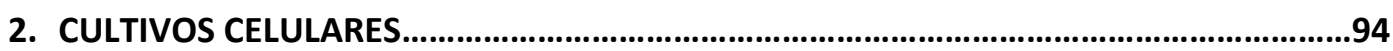

2.1. CULTIVOS PRIMARIOS DE ASTROCITOS DE RATÓN............................................94

2.2. LÍNEA CELULAR DE ASTROCITOMA HUMANA...................................................94

2.3. CULTIVOS PRIMARIOS DE NERONAS DE DROSOPHILA. CRECIMIENTO

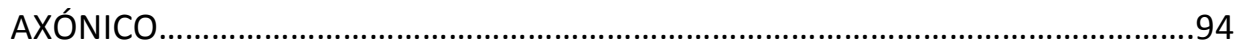

3. ANÁLISIS MORFOLÓGICO DE LA SUPERFICIE DEL OJO DE DROSOPHILA......................95

4. INMUNODETECCIÓN DE PROTEÍNAS........................................................................96

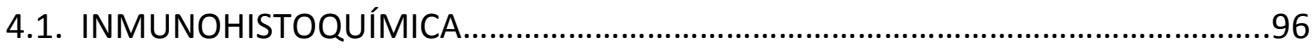

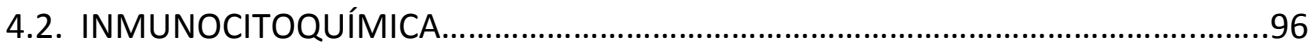

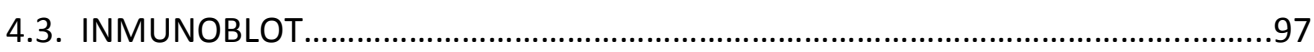

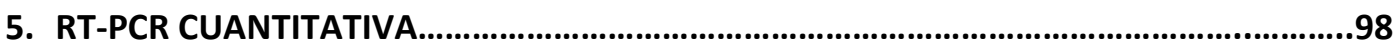

6. AISLAMIENTO DE DOMINIOS DE MEMBRANA RESISTENTES A DETERGENTE.............99

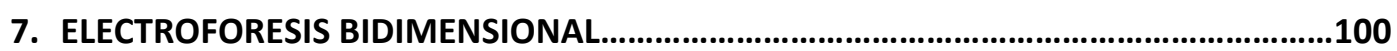

8. CUANTIFICACIÓN DE COLESTEROL Y ESFINGOMIELINA............................................100

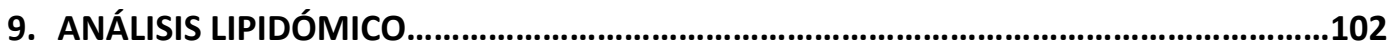

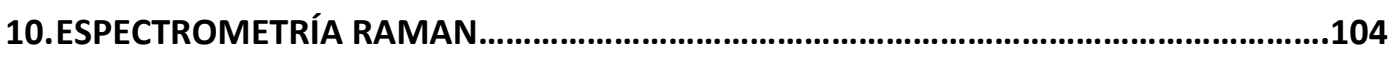

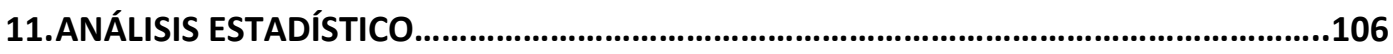

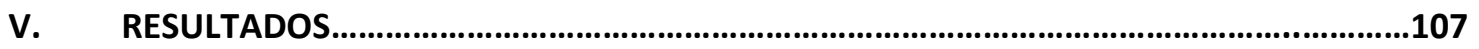

1. CAPítUlO 1: ESTUdio de LA FUNCIÓN DE Apod EN UNA PROTEINOPATÍA: LA ATAXIA ESPINOCEREBELOSA TIPO I (SCA1)

1.1. GLaz SE SOBREEXPRESA ANTE LA EXPRESIÓN DE LA PROTEÍNA ATAXINA-1 HUMANA POLIGLUTAMINADA EN LA RETINA DE DROSOPHILA (MODELO DE SCA1). .108

1.2. GLaz REDUCE LA DEGENERACIÓN DE LOS FOTORRECEPTORES PROVOCADA POR ATAXINA-1 HUMANA POLIGLUTAMINADA .......................................................109

1.3. GLaz PRODUCIDA EN SU DOMINIO DE EXPRESIÓN NATIVO RESCATA LA DEGENERACIÓN DE MANERA ESTABLE..

1.4. NLaz TAMBIÉN SE SOBREEXPRESA ANTE LA EXPRESIÓN DE ATAXINA-1 HUMANA POLIGLUTAMINADA EN LA RETINA DE DROSOPHILA Y RESCATA LA NEURODEGENERACIÓN.. 
1.5. LA SOBREEXPRESIÓN DE GLaZ DISMINUYE LA MUERTE POR APOPTOSIS EN PRESENCIA DE ATAXINA-1 HUMANA POLIGLUTAMINADA

1.6. GLaz ALTERA LA EXPRESIÓN DE UN GEN RESCATADOR DEL FENOTIPO DE SCA1 INVOLUCRADO EN LA ELIMINACIÓN DE LÍPIDOS PEROXIDADOS

1.7. GLaz REDUCE LA ACUMULACIÓN DE PROTEÍNAS UBIQUITINADAS DEPENDIENTE DE ATAXINA-1 HUMANA POLIGLUTAMINADA

1.8. GLaz REDUCE LA INDUCCIÓN DE LA AUTOFAGA DEPENDIENTE DE ATAXINA-1 HUMANA POLIGLUTAMINADA

1.9. GLaz PREVIENE LA ACUMULACION DE P62 EN LA AUTOFAGIA ESTIMULADA POR ATAXINA-1 HUMANA POLIGLUTAMINADA Y RAPAMICINA.

1.10. LA AUSENCIA DE GLaz DETERIORA EL FLUJO DE LA AUTOFAGIA PERO NO SU INICIACIÓN .122

1.11. LOCALIZACIÓN INTRACELULAR DE ApoD .123

1.11.1.1. ApoD ENDOCITADO SE DIRIGE A LOS LISOSOMAS .124

2. CAPÍtULO 2. ESTUdIO DE GLaz Y NLaz EN EL CRECIMIENTO AXONAL Y LA SINAPTOGÉNESIS

2.1. LA FALTA DE GLaz Y NLaz PROVOCA LA DISMINUCIÓN DE LA LONGITUD DEL AXÓN PERO NO DEL NÚMERO DE FILOPODIOS DE NEURONAS DE DROSOPHILA EN CULTIVO. .126

2.2. LA FALTA DE GLaz Y NLaz DISMINUYE EL NÚMERO DE SINAPSIS ESTABLECIDAS EN NEURONAS DE DROSOPHILA EN CULTIVO.

3. CAPÍTULO 3. APOD Y LAS MEMBRANAS. .129

3.1. ApoD SE ENCUENTRA EN LOS DOMINIOS DE MEMBRANAS RESISTENTES A DETERGENTEY ESTA ASOCIACIÓN ESTÁ CONSERVADA EN LAS MEMBRANAS DE RATÓN Y HUMANAS 130

3.2. LA FALTA DE ApoD NO MODIFICA LA CANTIDAD DE COLESTEROL $Y$ ESFINGOMIELINA DE LOS DOMINIOS DE MEMBRANA RESISTENTES A DEGERGENTE DE CEREBROS DE RATÓN. 131

3.3. LA FALTA DE APOD NO MODIFICA SUSTANCIALMENTE EL PATRÓN PROTEICO DE LOS DOMINIOS DE MEMBRANA RESISTENTES A DETERGENTE DE CEREBROS DE RATÓN. 132

3.4. LA FALTA DE ApOD PROVOCA CAMBIOS CONFORMACIONALES EN LA ESTRUCTURA DE LOS DOMINIOS DE MEMBRANA RESISTENTES A DETERGENTE DE CEREBROS RATÓN.

3.5. ApoD NO MODIFICA LA DISTRIBUCIÓN DEL MARCADOR GENÉRICO DE BALSAS LIPÍDICAS FLOTILINA. .135

3.6. LA FALTA DE ApoD MODIFICA LA RESPUESTA ANTE EL ESTRÉS OXIDATIVO DE LOS LÍPIDOS DE LOS DOMINIOS DE MEMBRANA RESISTENTES A DETERGENTE DE HIPOCAMPOS DE RATÓN. .136

3.6.1. LOS DOMINIOS DE MEMBRANA RESISTENTES A TRITON X-114 DE HIPOCAMPO DE RATÓN SON ALTAMENTE SENSIBLES AL ESTRÉS OXIDATIVO Y SU COMPOSICION VARÍA ANTE LA FALTA DE APOD ÚNICAMENTE BAJO ESTRÉS OXIDATIVO 
3.6.2. LA FALTA DE APOD PROVOCA UN AUMENTO DE MONOHEXOSILCERAMIDAS EN LOS DOMINIOS DE MEMBRANA RESISTENTES A DETERGENTE DE HIPOCAMPOS DE RATONES SOMETIDOS A ESTRÉS OXIDATIVO. .137

VI. DISCUSIÓN 150

VII. CONCLUSIONES 163

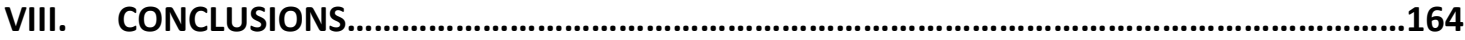

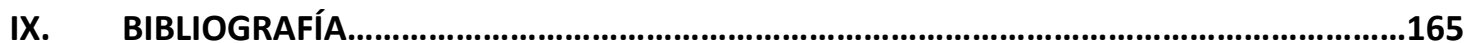

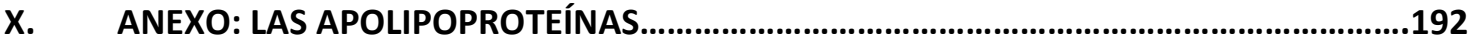

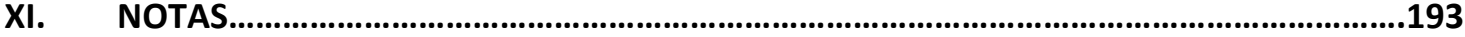




\section{ABREVIATURAS}

4HNE: 4-hidroxi-2-nonenal

$\boldsymbol{\alpha}_{1} \mathbf{M}: \boldsymbol{\alpha}_{1}$-microglobulina

AA: Ácido araquidónico

AD: Alzheimer disease

ADCAs: Ataxias cerebelosas autosómicas dominantes

AFM: Microscopía de fuerza atómica

AGP: $\alpha_{1}$-glicoproteína ácida

ApoD: Apolipoproteína D

ApoE: Apolipoproteína E

ApoM: Apolipoproteína M

APF: Después de la fase de pupa

APP: Proteína transmembrana precursora del amiloide

ASMasa: Esfingomielinasa ácida

Asn: Asparagina

AtTIL: Arabidopsis thaliana Temperature-induced lipocalin

BHT: Butilhidroxitolueno

BMP/LBPA: Lípido bis-monoacilglicerofosfato

C1P: Ceramida-1-fosfato

CAMs: Moléculas de adhesión

CAG: Glutamina

Cer: Ceramida

CerS: Ceramida sintasa

CHOX: Colesterol oxidasa

CMA: Autofagia mediada por chaperonas

CMH: Monohexosilceramidas 
Cys: Cisteinas

DAG: Diacilglicerol

DHA: Ácido docosahexaenoico

DIGs: Dominios ricos en glicolípidos insolubles en detergentes

Dpi: Puntos por pulgada

DRM: Membranas resistentes a detergentes

EA: Ataxias episódicas

EBSS: Earle's Balanced Salt Solution

EGF-R: Receptor del factor de crecimiento epidérmico

El: Ionización por impacto electrónico

EPA: Ácido eicosapentaenoico

ERC: Vía enodosomal de reciclaje perinuclear

ESI: Ionización por electrospray

ESR: Resonancia de spin electrónico

FBS: Suero bovino fetal

FLot: Flotilina

FPALM: Microscopía de Localización por Fotoactivación Fluorescente

FRET: Transferencia de energía de resonancia de Förster

GC: Cromatografía de gases

GEMs: Membranas enriquecidas en glicolípidos

GMR: Glass multimer reporter

GLaz: Lazarillo Glial

GPI: Glicosilfosfatilinositol

GSH: Glutatión reducido

GSLs: Glucoesfingolípidos

GSP: Glutatión peroxidasa

GST: Glutatión-S-transferasa 
hApoD: ApoD humana

HD: Enfermedad de Huntington

HDL: Lipoproteínas de alta densidad

HETEs: Ácido hidroeicosatetraenoico

HpETEs: Ácido hidroperoxieicosatetraenoico

HRP: Peroxidasa de rabanillo

HVA: Ácido homovanílico

IPG: Gradiente de pH inmovilizado

IPs: Inositol Trifosfato

IR: Infrarrojo

IUPAC: International Union of Pure and Applied Chemistry

JNK: c-Jun N-terminal kinases

LAMP1: Proteína lisosomal asociada a la membrana 1

LAMP2: Proteína lisosomal asociada a la membrana 2

Laz: Lazarillo

LC: Cromatografía líquida

LCAT: Lecitin Colesterol Acil Transferasa

Lcn2: Siderocalina o Lipocalina2

LDTI: Complejos insolubles en Triton de baja intensidad

Lo: Fases líquidas ordenadas

LPA: Ácido Lisofosfatídico

LPC: Lisofosfatidilcolina

LPL: Lipoproteinlipasa

MAC: Complejo de ataque a la membrana

MAG: Glucoproteina asociada a la mielina

MALDI: Desorción/ionización láser asistida por matriz

MAN-6-P: Manosa-6-fosfato 
M $\beta C D$ : Metil- $\beta$-ciclodextrina

MD: Dominios de membrana

Met: Metioninas

MetSO: Metionina sulfóxido

MrsA: Metionina sulfóxido reductasa A

MrsB: Metionina sulfóxido reductasa B

MS: Espectrometría de masas

mTOR: Mammalian target of Rapamycin

MT: Microtúbulos

MVBs: Cuerpos multivesiculares

Neo: Neomicina

NFKB: Factor nuclear kappa B

NLaz: Lazarillo Neural

NOS: Óxido nítrico sintasa

NPC1: Enfermedad de Niemann-Pick tipo C1

OBP: Odorant Binding Protein

PA: Ácido fosfatídico

PAS: Estructura preautofagosómica

PBS: Tampón fosfato salino

PC: Fosfatidilcolina

PCL: Prenilcisteinaliasa

Pdro: Proteína asociada a DRMs y endosomas

PE: Fosfatidiletanilamina

PG: Fosfatidilglicerol

PGD2: Prostaglandina D2

PH: Dominio homólogo a pleckstrina

PI: Fosfatidilnositol 
PI3K: Fosfoinositol 3-quinasa

PIP: Fosfoinosítidos

PIPz: Fosfatidilinositolbifosfato

PKA: Proteína Quinasa A

PKC: Proteína Quinasa C

PLA: Fosfolipasa

PLA2: Fosfolipasa A2

PLB: Fosfolipasa B

PLC: Fosfolipasa C

PLD: Fosfolipasa D

PPT1: Tioesterasa palmitoilada

PQ: Paraquat

PRE: Progesterone-responsive element

PrPc: Proteína priónica

PS: Fosfatidilserina

Ptdlns3P: Fosfatidilinositol 3-P

PVDF: Membrana de polifluoruro de vinilideno

RBP: Retinol Binding protein

R-COOH: Grupo carboxilo

RNS: Especies Reactivas de Nitrógeno

ROS: Especies Reactivas de Oxígeno

S1P: Esfingosina-1-fosfato

SCA1: Ataxia espinocerebelosa 1

SDS: Dodecilsulfato sódico

SM: Esfingomielina

SMasa: Esfingomielinasa

SMSs: Esfingomielinasintasas 
SNP: Sistema nervioso periférico

SOD: Superóxidodismutasa

SPC: Esfingosilfosforilcolina

Sph: Esfingosina

SPT: Serina palmitoil transferasa

SQSTM1: Adaptador proteico P62 o Sequestosome 1

TL: Tear Lipocalin

TOF: Tiempo de vuelo

TOR: Target of rapamycin

TRE: Elemento de respuesta a la hormona tiroidea

TUNEL: Terminal deoxynucleotidyl transferase dUTP nick end labeling

UPLC: Cromatografía Líquida de Ultrarrendimiento

VDL: Lipoproteínas de muy baja densidad

Vib: Vibrator 


\section{INTRODUCCIÓN}

\section{APOLIPOPROTEÍNA D}

Apolipoproteína D (ApoD) fue presentada al mundo científico en 1991 como una apolipoproteína atípica. Inicialmente fue denominada apolipoproteína por ser la cuarta proteína descubierta unida a las lipoproteínas de alta densidad $(\mathrm{HDL})^{1}$ del plasma sanguíneo (Ver Anexo Lipoproteínas) [2]. Sin embargo, tras el estudio de su secuencia y estructura, ApoD se clasificó como un miembro de una familia de proteínas llamadas Lipocalinas, debido a sus similitudes con la $\alpha 1$-microglobulina y a su homología estructural con la proteína RBP (Retinol Binding Protein $\left.{ }^{2}\right)[4,5]$. Las Lipocalinas son pequeñas proteínas extracelulares (160-180 residuos) que comparten una estructura de barril $\beta$ que conforma un bolsillo generalmente hidrofóbico y ciertas propiedades comunes: la unión a pequeños ligandos hidrofóbicos, la unión a receptores específicos de la superficie celular y la formación de complejos covalentes y no covalentes con otras macromoléculas solubles. Han sido clasificadas como proteínas transportadoras aunque actualmente se conocen una amplia variedad de funciones diferentes para muchos de sus miembros [6, 7]. ApoD comparte esta misma estructura aunque no se conoce ni ligando ni receptor específico para ella. La proteína a 1-microglobulina, uno de los tres miembros originales de la familia de las Lipocalinas, posee una cisteína libre a la entrada del bolsillo con actividad reductasa y recolectora de radicales que también está presente en la estructura de ApoD $[8,9]$.

En las HDL del plasma sanguíneo, ApoD se encontró asociada a la enzima LCAT (Lecitin Colesterol Acil Transferasa) [2]. LCAT es una enzima secretada por el hígado y el cerebro que cataliza una reacción reversible de tras-esterificación. Transfiere un ácido graso de la fosfatidilcolina a una molécula de colesterol libre, generando así un éster de colesterol y lisofosfatidilcolina. Además, el bolsillo de ApoD mostró afinidad de unión por la progesterona y otros esteroles. Estos hechos llevaron a proponer a ApoD bien como un vehículo presentador de los sustratos de LCAT: colesterol o fosfatidilcolina, o bien como un transportador de los productos finales de dicha reacción: lisofosfolípidos o colesteril ésteres [2, 10].

\footnotetext{
${ }^{1}$ Las lipoproteínas son complejos macromoleculares esféricos cuya función es el transporte de lípidos. Están formadas por un núcleo de lípidos apolares (colesterol esterificado y triglicéridos) rodeados de una capa de fosfolípidos y colesterol libre (polares) que se orientan según su carácter anfipático y que, a su vez, se recubren de proteínas con los dominios polares hacia el exterior para aislarse del medio acuoso y hacerse solubles en el. Sus componentes están unidos por interacciones fisicoquímicas débiles, lo que permite el intercambio de los más superficiales con las membranas. Cada tipo de lipoproteína tiene una composición y una proporción característica de las proteínas denominadas apolipoproteínas o apoproteínas. Las lipoproteínas se clasifican en función de su densidad (a mayor densidad, mayor contenido en proteínasy, a mayor diámetro, mayor contenido de lípidos): lipoproteínas de muy baja densidad (VLDL), lipoproteínas de densidad intermedia (IDL), lipoproteínas de baja densidad (LDL), lipoproteínas de alta densidad (HDL) (1. Arai, H., Oxidative modification of lipoproteins. Subcell Biochem, 2014. 77: p. 103-14.)

${ }^{2}$ El retinol es una molécula liposoluble de estructura plana que contiene un anillo cíclico hexénico y una cadena hidrocarbonada con cuatro dobles enlaces en posición trans. Es uno de los posibles isómeros de la vitamina A con poder antioxidante (3. O'Byrne, S.M. and W.S. Blaner, Retinol and retinyl esters: biochemistry and physiology.J Lipid Res. 54(7): p. 1731-43.).
} 
Los primeros estudios sobre su expresión determinaron que la síntesis de ApoD estaba restringida a unos pocos tipos celulares (fundamentalmente fibroblastos del endoneuro ${ }^{3} \mathrm{o}$ células gliales dispersas). Sin embargo, la proteína aparecía en gran cantidad de tipos celulares y, especialmente, en los que menos expresión génica mostraban. Por lo tanto, se sugirió que ApoD podría estar siendo endocitada y acumulada en células que no la producen [5].

\subsection{ESTRUCTURA}

\section{ESTRUCTURA PRIMARIA}

El cromosoma 3 del genoma humano (el 16 del ratón y el 2 en sus homólogos en Drosophila; ver sección 1.5) contiene una secuencia de $20 \mathrm{kpb}$ divididas en 5 exones, de las cuales $855 \mathrm{pb}$ codifican para la proteína ApoD. Tanto la organización exónica como la estructura secundaria y terciaria fruto de su secuencia de 189 aminoácidos, definen a ApoD como miembro de la familia de las Lipocalinas [4, 12]. En esos 189 aminoácidos, ApoD posee un péptido señal (secuencia peptídica de secreción), que se pierde tras ser incorporada al lumen del retículo endoplásmico, resultando una proteína madura soluble de 169 aminoácidos que puede ser secretada al medio extracelular [13].

El peso molecular de ApoD varía entre 19 y 32 kDa en función del grado de glicosilación de sus dos asparaginas (Asn). Al menos una de las dos cadenas glicosiladas termina con un ácido siálico. Esta glicosilación variable es dependiente del tejido donde se exprese [14, 15].

La ApoD humana contiene cinco cisteínas (Cys), de las cuales cuatro forman dos puentes disulfuro intramoleculares mientras que la quinta permanece libre. Esta cisteína libre, también presente en $\alpha$ 1-microglobulina, está localizada en un bucle flexible de la estructura haciéndola especialmente accesible [16]. El grupo tiol de la cisteína posee la capacidad de reducir y atrapar (a pH menores de 7,5) radicales orgánicos. Esta cisteína, además, le permitiría establecer enlaces por puentes disulfuro con otras moléculas, como por ejemplo: el resto de apolipoproteínas presentes en las HDL [14]. Sin embargo, en el ratón, este residuo no está conservado. En el lugar de la cisteína se encuentra una treonina, que posee un grupo hidroxilo en vez de tiol, que le permitiría unirse a moléculas con grupos fosfato o con cadenas de oligosacáridos a través de enlaces de hidrógeno [13].

Por último, ApoD posee tres metioninas (Met), conservadas en el ratón pero no en los homólogos de Drosophila melanogaster (ver sección 1.5), también poseedoras de un átomo de azufre, al igual que las cisteínas. El entorno estructural de una de ellas, la Met93 localizada a la entrada del bolsillo, le confiere la capacidad de reducir lípidos peroxidados, oxidándose a su vez a MetSO [17].

\section{ESTRUCTURA TERCIARIA}

La estructura terciaria de ApoD en forma de barril- $\beta$ es una característica común a todas las Lipocalinas. Está formada por ocho láminas $\beta$ antiparalelas conectadas por siete bucles y

\footnotetext{
${ }^{3}$ Endoneuro: una de las tres capas de los nervios periféricos formada por finos fascículos de fibras de colágeno dispuestas longitudinalmente que junto con algunos fibroblastos rodean a cada fibra nerviosa. $11 . \quad$ Dubovy, P., Schwann cells and endoneurial extracellular matrix molecules as potential cues for sorting of regenerated axons: a review. Anat Sci Int, 2004. 79(4): p. 198-208.
} 
estabilizadas por una $\alpha$-hélice en la región C-terminal y los dos puentes disulfuro establecidos entre cuatro de las cinco cisteínas ya mencionadas. Estos elementos generan una cavidad estructural en forma de cáliz que delimita, debido a la naturaleza apolar de los aminoácidos de su interior, una región hidrofóbica que podría albergar pequeños ligandos (Fig.1) [13]. Esta estructura altamente conservada y tan característica ha dirigido las hipótesis sobre la función de las Lipocalinas, y por tanto de ApoD, hacia el transporte de lípidos [6].

Sin embargo, la característica que define a ApoD como una lipocalina, es decir, su estructura, es también la que le confiere una identidad especial. La región de los bucles presenta ciertas diferencias, especialmente a la entrada del bolsillo. Por un lado, los bucles están orientados hacia el exterior de la estructura, haciendo la entrada más amplia. Por otro lado, tres de los cuatro bucles situados a la entrada del bolsillo poseen cadenas hidrofóbicas. Estas peculiaridades generan en la estructura de $A p o D$ una región o parche de un alto carácter hidrofóbico inusual para una proteína soluble. Este parche hidrofóbico podría insertarse en la región lipídica de las HDL antes de que la cisteína libre pudiera establecer un puente disulfuro con alguna molécula vecina [13]. Destacable es, además, el hecho de que la metionina con actividad reductora (Met93) se encuentre inmersa en este entorno hidrofóbico, justamente a la entrada del barril [18].

Unas mutaciones en la secuencia que afectarían a la estructura de $A p o D$, detectadas en variantes alélicas presentes en algunas poblaciones africanas, son la causa de varias enfermedades cardiovasculares. Ninguna de ellas afecta al interior del bolsillo y, en principio, tampoco a su capacidad de unión a ligandos. Por el contrario, sí afectarían al parche hidrofóbico de la boca del barril, por lo que podrían estar modificando su acoplamiento a las HDL. Estas mutaciones también modificarían la cadena que contiene la cisteína libre y una de las cisteínas que genera los puentes disulfuros intramoleculares. Esta alteración estructural podría impedir las posibles interacciones intramoleculares de la cisteína libre o suscitar la generación de puentes disulfuro intermoleculares no fisiológicos que implicarían un plegamiento anómalo y una pérdida de función. Por último, algunas de estas mutaciones también alteran la región C-terminal que envuelve parte del barril [19, 20].

Por otra parte, mutaciones experimentales realizadas sobre los aminoácidos del bolsillo de los homólogos de ApoD en Drosophila melanogaster mostraron varios fenotipos similares a los observados ante la falta de la proteína como la regulación de la longevidad, la respuesta al estrés, respuestas comportamentales como la escalada o el cortejo y el almacenamiento de triglicéridos; otros mecanismos como la homeostasis de glucosa permanecieron inalterados [21] .

Existen otros polimorfismos de nucleótidos únicos (single nucleotide polymorphism) asociados a la enfermedad de Alzheimer o esquizofrenia que afectarían al péptido señal [13]. 

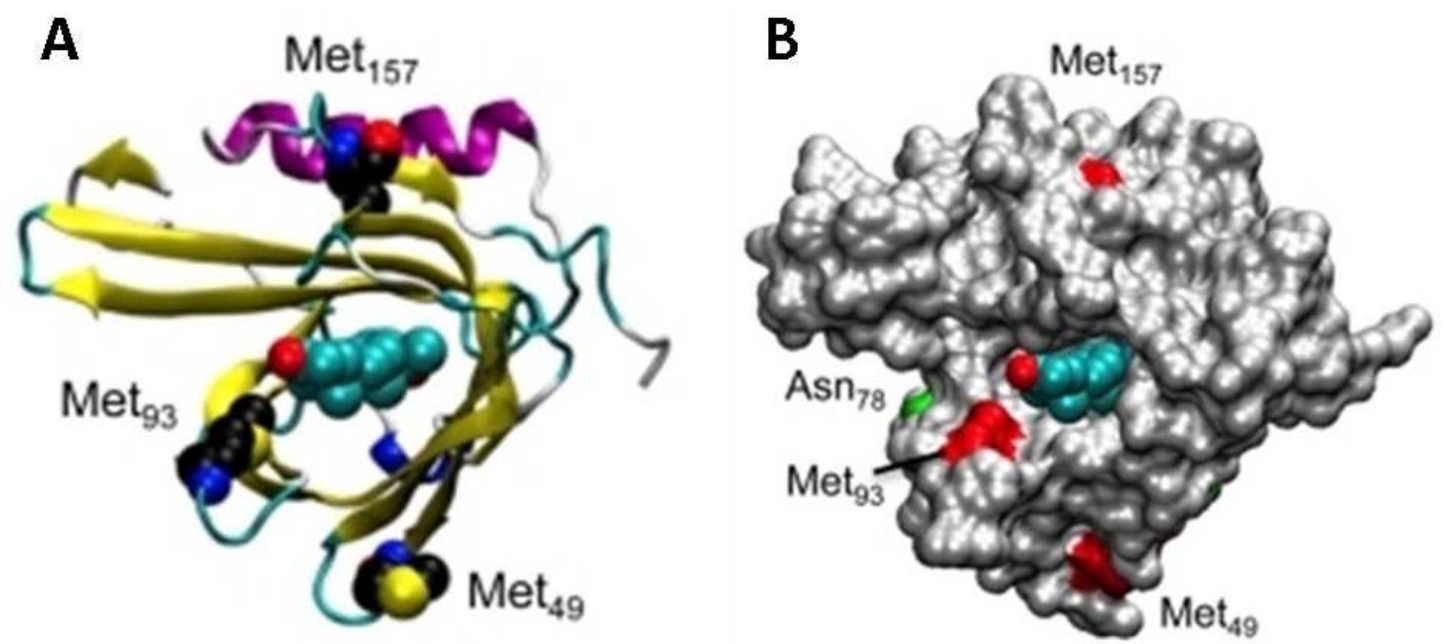

Figura 1. Estructura terciaria de ApoD. (A) Visión ortogonal de ApoD unida a progesterona. Las metioninas están representadas en rojo y los barriles $\beta$ en amarillo. En turquesa se representa un posible ligando. (B) Misma estructura representada como superficie accesible al solvente [17].

\subsection{LIGANDOS}

El bolsillo hidrofóbico de la estructura de ApoD tiene una abertura de entre 10 y $15 \AA$ de ancho y una profundidad de $15 \AA$ [13]. Varias moléculas hidrofóbicas muestran alta afinidad in vitro por este bolsillo. La progesterona fue el primer ligando atribuido a ApoD [22, 23]. Sin embargo, el ácido araquidónico (AA) es uno de los ligandos estudiados in vitro que ha mostrado mayor afinidad [24]. El bolsillo permanece prácticamente inalterado al albergar en su interior tanto a la progesterona como al ácido araquidónico, mostrando puntos de unión comunes a ambos ligandos [13]. ApoD también muestra afinidad in vitro por el retinol; aunque sería un ligando no específico dado que dicha afinidad es común a la mayoría de las Lipocalinas. A pesar de que el colesterol y la bilirrubina se han considerado durante años posibles candidatos fisiológicos dada la relación entre ApoD y LCAT y la $\alpha 1$-microgloulina ${ }^{4}[2,5,10,25]$, varios estudios in vitro han descartado ambas opciones $[21,24,26]$. Recientemente se ha comparado in vitro la capacidad de unión que presentan ApoD y algunos de sus homólogos en otras especies frente a diferentes ligandos, encontrándose uniones de alta afinidad con el cannabinoide anandamida ${ }^{5}$ o la esfingomielina y confirmando la unión a ácido retinoico, más específica que la del retinol [21], en contraposición a los estudios que defendían una mayor afinidad de ApoD por el retinol que por el ácido retinoico [28]. Los últimos estudios in vitro realizados en el laboratorio han ampliado la lista de ligandos al encontrar unión a ácido docosahexaenoico (DHA) y la lisofosfatidilcolina con ácido palmítico (16:0), ácido esteárico (18:0) o ácido oleico (18:1) (López Arias y Ganfornina, resultados no publicados).

\footnotetext{
${ }^{4}$ Bilirrubina: es un producto de la degradación de la hemoglobina que, hasta ser conjugada con el ácido glucurónico para formar parte de la bilis,se mantiene unido a la albúmina. $\alpha 1$-microglobulina se une al grupo hemo, grupo prostético (componente no aminoacídico) que forma parte de la hemoglobina. Algunas globulinas y lipoproteínas también unen albúmina.

${ }^{5}$ Anandamida: endocanabinoide neuromodulador implicado en procesos de memoria y metabolismo lipídico que se sintetiza transfiriendo ácido araquidónico de una fosfatidilcolina a la amina libre de una fosfatdil etanolamina gracias a una enzima aciltransferasa y posterior acción de enzimas con actividad fosfolipasa (PLA2, PLC) (27. 849-71.). Blankman, J.L. and B.F. Cravatt, Chemical probes of endocannabinoid metabolism. Pharmacol Rev. 65(2): p.
} 
El único ligando unido a ApoD en condiciones fisiológicas encontrado hasta el momento, además de la progesterona, es el odorante E-3-metil-2-ácido hexenoico presente en la piel de la axila humana (Fig.2) [29].

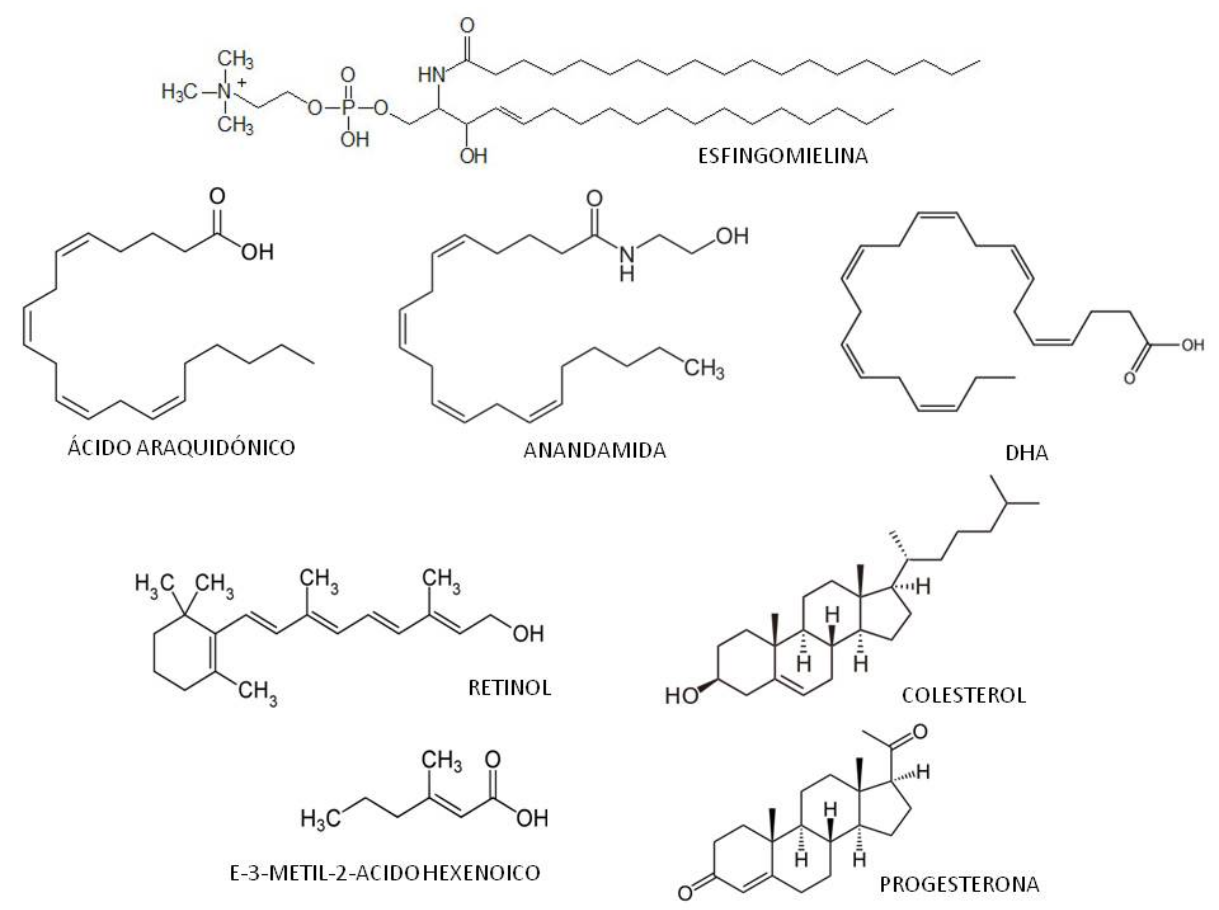

Figura.2. Algunos posibles ligandos de ApoD.

\subsection{EXPRESIÓN}

\section{PROMOTOR}

Tanto la región del promotor como el exón 1 no codificante de ApoD poseen una gran variedad de secuencias de regulación en respuesta a: estrés(STRE, stress response element), a hormonas tiroideas (TRE, thyroid-hormone response element) y esteroideas (PRE, progesteroneresponsive element; ERE, estrogen-responsive elements; RORA1, steroid hormone nuclearreceptor [retinoic acid] alpha1; GRE, glucocorticoid-responsive element), esteroles (SDR, sterol-dependent repressor) o a $\mathrm{NFkB}^{6}$ (NFKB, nuclear factor kappa $B$ ) [31]. Dos isoformas de la apolipoproteína E (ApoE) humana, ApoE3 y ApoE4, relacionadas con el desarrollo de la enfermedad de Alzheimer se unen al promotor de ApoD estableciendo una correlación inversa entre la expresión de ApoD y ApoE [32]. p73 y p63, dos miembros de la familia p53 responsable de la regulación de genes involucrados en el desarrollo y homeostasis, activan la

\footnotetext{
${ }^{6} \mathbf{N F k B e s}$ un complejo proteico que controla la transcripción del DNA (regulador transcripcional) localizado preferentemente en el cerebro. Es activado por factores de crecimiento (BDNF, NGF) utilizando el glutamato como neurotransmisor. Está implicado en la modulación de la plasticidad, función sináptica (comunicación sinapsisnúcleo), así como el crecimiento de las dendritas y de las espinas dendríticas y en la respuesta al estrés, ROS, citoquinas, LDL oxidadas, etc. (30. Salles, A., A. Romano, and R. Freudenthal, Synaptic NF-kappa B pathway in neuronal plasticity and memory.J Physiol Paris.)
} 
transcripción de ApoD [33]. Este complejo y variado sistema de regulación refleja una compleja expresión de ApoD íntimamente relacionada con el estrés (inflamación, daño, muerte celular) o el metabolismo del colesterol entre otros procesos.

\section{DISTRIBUCIÓN TISULAR}

En humanos, ApoD presenta una amplia y variada distribución de su expresión en el organismo. Se ha detectado RNA mensajero en las glándulas adrenales y riñones. También en bazo, páncreas, pulmones, placenta, ovarios y testículos (reflejando su relación con los esteroides), cerebro, nervios periféricos y líquido cefalorraquídeo [4]. Por el contrario, está pobremente expresado en hígado e intestino, a pesar de ser los mayores centros productores de otras apolipoproteínas [15]. Como ya se ha comentado, ApoD está unido a las HDL que circulan por el plasma sanguíneo, por lo que la proteína secretada se distribuye ampliamente por todo el organismo.

Muchos estudios sobre ApoD se han centrado en el sistema nervioso, ya que es una de las regiones donde su expresión parece estar evolutivamente más conservada. En el cerebro de mono, ApoD se expresa en el córtex, hipotálamo y cerebelo. En el cerebro de ratón postnatal se ha encontrado expresión en la médula espinal, cerebro y cerebelo [15, 34, 35]. Un patrón de expresión similar se ha encontrado en el embrión de pollo. ApoD también se expresa durante el desarrollo de las plumas de pollo [35]. Sus homólogos de insectos (mosca, saltamontes) se expresan en neuronas y glía $[36,37]$. ApoD también se expresa en el sistema nervioso periférico (SNP) de rata y ratón.

\section{TIPO CELULAR}

A nivel celular, ApoD se expresa en los fibroblastos próximos a vasos sanguíneos [5]. En el SNC los centros de expresión de ApoD son las células gliales, concretamente los astrocitos y oligodendrocitos $[35,38]$. En el ratón se expresa también en los pericitos que rodean los capilares del cerebro y la médula espinal. Se ha encontrado expresión de ApoD en neuronas durante el desarrollo del SNC tras el cual permanece exclusivamente la expresión en glía. Un tipo celular especial son las células de Purkinje que no muestran expresión de mRNA pero si contienen ApoD en su interior lo que indica un mecanismo de endocitosis paracrino [35].

Los primeros estudios sobre la expresión de ApoD en el SNP de la rata defendían la producción de ApoD en los fibroblastos del endoneuro [39, 40]. Sin embargo, posteriormente se demostró su síntesis mayoritaria en las células de Schwann [41]. Estudios recientes en el SNP de ratón muestran a ApoD únicamente expresada, de forma intermitente o transitoria, por células de Schwann mielinizantes y no mielinizantes sugiriendo una regulación espaciotemporal dinámica dependiente del estado funcional de las células productoras [42].

\section{TEMPORALIDAD Y REGULACIÓN POR DAÑO O DEGENERACIÓN}

La síntesis de ApoD por parte de las células gliales ocurre desde el desarrollo embrionario hasta el envejecimiento $[35,43]$. En el nervio ciático de ratón la expresión de ApoD aumenta 
durante el desarrollo postnatal principalmente en el endoneuro [44]. Como ya se ha comentado, las células de Schwann expresan ApoD de manera intermitente en base a su estado funcional. La expresión de ApoD se altera con la vejez. De hecho, ApoD es uno de los genes que más consistentemente aumentan su expresión en diferentes especies durante el envejecimiento no patológico [45]. El envejecimiento se caracteriza por un aumento del estrés oxidativo y los procesos de inflamación [46].

Además de ante el envejecimiento, la expresión de ApoD aumenta ante situaciones patológicas del sistema nervioso como muchas enfermedades neurodegenerativas, estando regulada por la vía de JNK (c-Jun N-terminal kinases) [47, 48]

Muchas neuropatologías como el Parkinson [49], la esquizofrenia [50], la esclerosis múltiple [51], meningoencefalitis [52] o la enfermedad de Niemann-Pick (en ratón) [53] comparten elevadas concentraciones de ApoD.

En pacientes con Alzheimer (AD), ApoD presenta elevados niveles de expresión tanto en el líquido cefalorraquídeo como en el hipocampo. Se han encontrado asociaciones genéticas entre pacientes con Alzheimer y polimorfismos de ApoD en poblaciones de Finlandia, América y norte de China $[52,54,55]$. En los pacientes de esta enfermedad, la expresión de ApoD parece no estar influida por la presencia del alelo E4 de ApoE [52]. Las dos apolipoproteínas aumentan con la edad y en situaciones neurodegenerativas. Ante la falta de ApoE, la concentración de ApoD aumenta en el cerebro [56]. La falta de ApoD, sin embargo, no provoca aumento alguno de $A p o E$ ante una situación de daño en el sistema nervioso periférico de ratón [57]. ApoD se localiza en las placas $A \beta$ compactas [58]. A $325-35$ induce la expresión de ApoD en células hipocampales en respuesta a estrés [59]. La enfermedad de Alzheimer se caracteriza por la degeneración de neuronas hipocampales y corticales. El péptido $\beta$-amiloide, principal causante de la enfermedad, se genera como un producto del corte de la Proteína transmembrana Precursora del Amiloide (APP) por acción de enzimas secretasas (proteasas integrales de membrana). El colesterol es un importante factor en la regulación de la producción de este péptido. Altos niveles de colesterol aumentan la generación y deposición de estos péptidos. Estudios recientes indican que el procesamiento de APP ocurre preferentemente en las balsas lipídicas [60]. Otro tipo de patologías que también conllevan daños en el sistema nervioso como las enfermedades infecciosas ola excitotoxicidad presentan la misma alteración en la expresión de ApoD [54].

Todas estas patologías neurodegenerativas presentan como característica común un importante aumento del estrés oxidativo.

ApoD se sobre-expresa en el hipocampo de modelos murinos de Alzheimer [61].

En un modelo de ictus en rata, las células gliales sobre-expresan ApoD en el área periinfartada. Varios días después de la lesión, se detecta proteína $A p o D$ en las neuronas piramidales de la zona del infarto. Por lo tanto, las neuronas podrían captar y acumular la ApoD expresada por las células gliales [62]. 
Las enfermedades cardiovasculares y metabólicas, muchas de ellas asociadas a la edad, también han sido relacionadas con ApoD dada su conexión con las HDL [63]. Varios polimorfismos de ApoD están relacionados con la resistencia a la insulina, la hiperinsulinemia, obesidad, y diabetes mellitus tipo 2 [64].

Por último, la relación entre ApoD y el cáncer se ha determinado prácticamente desde su descubrimiento [5] estableciéndose una correlación entre el aumento de la concentración de ApoD y la disminución del crecimiento del tumor, por lo que se le asume una potencial capacidad antiproliferativa. ApoD induce apoptosis en una línea celular de carcinoma de colon y una reducción de su proliferación [65].

\subsection{HOMÓLOGOS DE ApoD. LA FAMILIA DE LAS LIPOCALINAS.}

ApoD forma parte de una gran familia de pequeñas proteínas globulares con una estructura altamente conservada, las Lipocalinas. Evolutivamente las proteínas más cercanas a ApoD serían las Lipocalinas de insectos [12].

El hecho de que todas las lipocalinas compartan, como motivo central de su estructura, un dominio con conformación de barril- $\beta$ muy conservado hace pensar en un posible mecanismo de acción común, aunque, como se ha comentado anteriormente, ApoD de vertebrados presenta ciertas diferencias con el resto de miembros de su familia. A pesar de ello, el estudio de cada lipocalina podría arrojar luz al entendimiento de las demás (Fig.3).

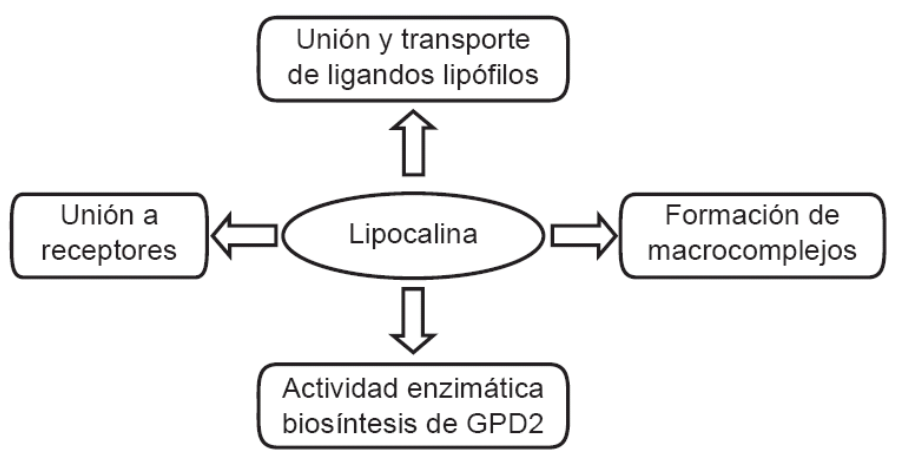

Figura 3. Posibles funciones de las Lipocalinas: unión y transporte de ligandos lipófilos, unión a receptores, formación de macrocomplejos y actividad enzimática (biosíntesis de GPD $^{7}$ [glicerol-3-fosfato deshidrogenasa2]) [66].

\footnotetext{
${ }^{7}$ GPD2 (glicerol-3-fosfato deshidrogenasa) enzima localizada en la cara interna de la membrana mitocondrial y cataliza la oxidación de glicerol-3-fosfato a dihidroxiacetona-fosfato.
} 
Algunas de las Lipocalinas más estudiadas son:

- $\boldsymbol{\alpha}_{1}$-microglobulina $\left(\boldsymbol{\alpha}_{1} \mathbf{M}\right)$ : es uno de los tres miembros originales de la familia de las Lipocalinas (junto con retinol binding protein y 6-lactoglobulina). Se ha encontrado en mamíferos, pájaros, anfibios y peces, distribuida a través del plasma a todos los órganos. Posee una cisteína libre localizada en un lazo flexible a la entrada del bolsillo que le confiere propiedades reductasa y deshidrogenasa. Presenta también tres residuos de lisina alrededor de la entrada del bolsillo con posibilidad de unión y degradación del grupo hemo y la quinurenina. También es capaz de unir retinol. $\alpha_{1} \mathrm{M}$ está implicada en la defensa contra la oxidación por hemo, quinurenina y especies reactivas de oxígeno (ROS) y en la regulación de la respuesta inmune.

- Apolipoproteína M (ApoM): es una lipocalina expresada por el hígado y los riñones y secretada al plasma sanguíneo formando parte de las HDL. Presenta como característica inusual el hecho de que la proteína madura mantiene el péptido señal, que actúa como anclaje hidrofóbico al unirse a un fosfolípido de las lipoproteínas. ApoM de ratón no está glicosilada y tiene capacidad de unión a retinol y ácido retinoico. Sin embargo, no muestra afinidad por otros potenciales ligandos como el colesterol y prostaglandinas. ApoM humana posee tres cisteínas y contiene en su estructura un parche hidrofóbico involucrado en interacciones intermoleculares. Se ha propuesto que ApoM podría unir fosfolípidos oxidados incrementando el efecto antioxidante de las HDL contra la oxidación de las LDL. ApoM también podría actuar como chaperona de la esfingomielina 1 fosfato (S1P), un lípido bioactivo con efectos en angiogénesis, tráfico de linfocitos, migración de células endoteliales e inflamación a través de la activación de cinco receptores diferentes acoplados a proteínas G. El complejo ApoM-S1P es capaz de activar el receptor-S1P-1. ApoM también es capaz de promover la movilización del colesterol celular al plasma y aumentar la secreción de insulina [67-70]

- Componente de complemento C8y es una lipocalina que se expresa en hígado y riñón y se encuentra en el plasma unido a $\mathrm{C} 8 \alpha$ por un enlace disulfuro través de su cisteína libre. El complejo $\mathrm{C} 8 \alpha-\mathrm{C} 8 \gamma$ junto con $\mathrm{C} 8 \beta$ (unión no covalente) forma el complejo activo C8, penúltimo miembro del complejo de ataque a la membrana $(\mathrm{MAC})^{8}$. Al menos tres de sus cuatro bucles a la entrada del bolsillo están también involucrados en su unión aC8 $\alpha$ mientras que un área hidrofóbica le permite insertarse en la membrana. Además posee dos tirosinas que actúan como compuertas que controlan la entrada de ligandos a su bolsillo hidrofóbico, cuyo bloqueo no altera la influencia de C $8 \gamma$ sobre la actividad de C8 [71].

- Prostaglandina D sintetasa es el primer miembro de la familia de las Lipocalinas reconocido como una enzima. Presenta una doble función ya que actúa como enzima en la síntesis de la proteína prostaglandina D2 (PGD2) (neuromodulador de acciones centrales como la regulación del ciclo sueño-vigilia, modulador nociceptivo y mediador alergénico) y

\footnotetext{
${ }^{8}$ El complejo de ataque a membrana (MAC) es un complejo multiproteico formado por cuatro proteínas del complemento que se une a la superficie exterior de la membrana plasmática formando un canal que le permite el paso libre de moléculas a ambos lados de la membrana provocando la muerte celular.
} 
como una proteína transportadora extracelular de pequeñas moléculas lipofílicas. Una cisteína libre de su estructura juega un papel importante en su actividad catalítica. Es una proteína altamente glicosilada con dos sitios de $\mathrm{N}$-glicosilación que se localiza principalmente en el sistema nervioso central y en los órganos genitales de varios mamíferos y en el corazón humano. En el cerebro se localiza en el retículo endoplásmico rugoso y en la membrana nuclear externa de los oligodendrocitos acoplada a la ciclooxigenasa para producir PGD2 que se secreta al líquido cefalorraquídeo donde es una proteína mayoritaria. Se sobre-expresa en los oligodendrocitos de ratón ante las enfermedades por depósito lisosomal. Se ha determinado la unión de esta lipocalina a los gangliósidos $\mathrm{GM} 1$ y GM2, lípidos que se acumulan en las neuronas en estas patologías. También es capaz de unir biliverdina, bilirrubina, ácido retinoico y retinal [72].

- $\boldsymbol{\alpha}_{1}$-glicoproteína ácida (AGP) es una de las proteínas del plasma humano más ácidas debido a sus cinco sitios de $\mathrm{N}$-glicosilación. Los glicanos cubren la mayoría de la superficie de la proteína. Presenta variantes en dicha glicosilación ante situaciones como procesos inflamatorios crónicos. Esas variaciones en la glicosilación influyen en las propiedades inmunomoduladoras y los efectos anti-inflamatorios que presenta esta lipocalina. AGP ejerce efectos beneficiosos durante el crecimiento del nervio periférico tras un daño. También puede unir y transportar ciertas drogas terapéuticas y componentes endógenos e influir en sus concentraciones en plasma. En humanos la isoforma AGP-1 contiene cuatro cisteínas que forman dos enlaces disulfuro intermoleculares mientras que la variante AGP2 contiene cinco cisteínas, aunque se desconoce la función de la cisteína libre. AGP1 se considera una molécula señalizadora implicada en el mantenimiento de la homeostasis y remodelación de los tejidos, capaz de inhibir la activación de neutrófilos y la actividad del complemento promoviendo la secreción de IL1RA por macrófagos murinos y de modular la producción de citoquinas inflamatorias de monocitos humanos [73].

Como se ha comentado, las lipocalinas filogenéticamente más cercanas a ApoD son la lipocalina de saltamontes Lazarillo y dos lipocalinas de Drosophila melanogaster: Lazarillo Neural y Lazarillo Glial (Fig.4). 


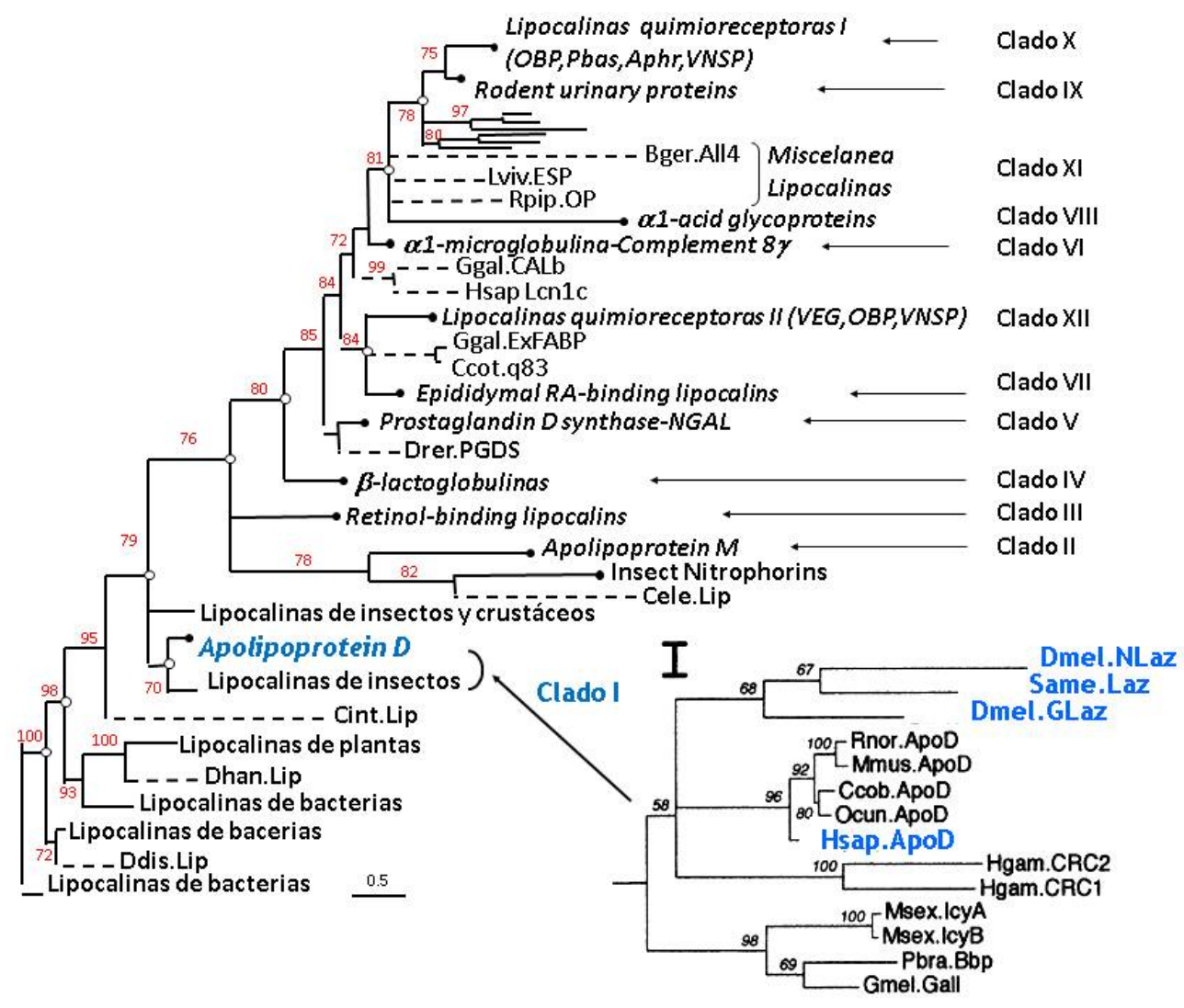

Figura 4. Árbol filogenético de la familia de las Lipocalinas. En el clado I se agrupan, cerca de ApoD, las Lipocalinas relacionadas con Lazarillo: Lazarillo de saltamontes y Lazarillo Neural y Lazarillo Glial de Drosophila melanogaster [12, 74, 75]. 


\subsubsection{LAZARILLO (Laz) Y OTRAS LIPOCALINAS CON SISTEMAS DE ANCLAJE A MEMBRANAS}

Lazarillo (Laz) es una proteína de saltamontes de 170 residuos altamente glicosilada. Presenta la estructura en barril $\beta$ propia de las Lipocalinas, con cuatro cisteínas que generan dos puentes disulfuro internos. Carece de la quinta cisteína (que permitiría a ApoD unirse a otras moléculas), sin embargo, posee una característica especial: un motivo glicosilfosfatidilinositol (GPI) que lo ancla a la membrana plasmática. Se expresa en las neuronas del sistema nervioso del saltamontes aunque también se expresa en los tubos de Malpighio y en el ganglio subesofágico ${ }^{9}$. Laz está implicada en el mecanismo de crecimiento y la guía de axones [36]. Como buena lipocalina, in vitro une ácido retinoico y también esfingomielina [21] pero no se le conoce ningún ligando específico biológico.

Lazarillo podría no ser la única lipocalina GPI. En el genoma de Drosophila melanogaster, han sido detectados 8 genes correspondientes a lipocalinas que aún no han sido estudiados en profundidad. Uno de estos genes, CG5399, muestra en su secuencia (de alta similitud con Laz) una potencial cola GPI. Karl, otra de las lipocalinas de Drosophila posee una secuencia Nterminal extremadamente larga [74]. A su vez, existe una lipocalina en plantas, AtTIL (Arabidopsis thaliana Temperature-induced lipocalin) que podría contener una secuencia similar de unión a membrana $[77,78]$. ApoM es una nueva apolipoproteína presente en las HDL que mantiene el péptido señal en su forma madura sirviéndole de anclaje hidrofóbico al establecer uniones con los fosfolípidos de las monocapas de las lipoproteínas [79].

\subsubsection{LAZARILLO GLIAL (GLaz)}

Lazarillo Glial (GLaz) es una proteína de 192 aminoácidos y un único punto de glicosilación. Se expresa en la glía longitudinal de la cuerda nerviosa ventral del sistema nervioso central y en ciertos precursores gliales durante la embriogénesis. No se ha descrito expresión alguna en larva pero sí en el sistema nervioso de la pupa y el adulto. También está presente en el intestino y las glándulas salivares y en hemocitos adultos $[37,75]$.

GLaz se sobre-expresa ante diferentes tipos de estrés generados por hiperoxia, $P Q$, dieta rica en azúcares o altas temperaturas $[37,75,80,81]$.

\footnotetext{
${ }^{9}$ Ganglio subesofágico: parte de sistema nervioso central de insectos que se extiende a ambos lados del esófago y que inerva las mandíbulas, maxilas, labio y conducto salival. Hay neuronas receptoras gustativas que tienen como diana diferentes áreas de esta estructura. 76. Colomb, J., et al., Architecture of the primary taste center of Drosophila melanogaster larvae.J Comp Neurol, 2007. 502(5): p. 834-47.
} 


\subsubsection{LAZARILLO NEURAL (NLaz)}

Lazarillo Neural (NLaz) es una proteína de 199 aminoácidos con 4 sitios potenciales de glicosilación. Su región C-terminal es más larga de lo habitual en comparación con otras lipocalinas. NLaz se expresa en neuroblastos y neuronas además de en el cuerpo graso y el intestino [37]. Su expresión se relaciona con el ritmo circadiano, está regulada por la vía de $\mathrm{JNK}^{10}$ e interviene en el mecanismo de respuesta ante el estrés [83, 84]. NLaz al igual que ApoD y Laz, une in vitro ácido retinoico y esfingomielina. También presenta especificidad por la feromona 7 (Z)-Trioseno [21].

La expresión de NLaz disminuye ante la falta de la proteína Lola, un factor de transcripción relacionado con el crecimiento axónico, y aumenta en ausencia tanto de Gp93 (proteína implicada en el metabolismo), como del receptor hormonal Hr39 o del factor de transcripción 3 (que presenta sobrecarga en el cuerpo graso) [85-87]. La transcripción de NLaz está regulada por JNK y reprime la actividad de la vía de la insulina participando en el sistema de control de la homeostasis metabólica [83].

\subsection{MODELOS DE PÉRDIDA Y GANANCIA DE FUNCIÓN}

Los diferentes estudios realizados en ratón, rata, Drosophila melanogaster y líneas celulares han aportado gran cantidad de información sobre la posible función de ApoD.

\section{PÉRDIDA DE FUNCIÓN}

Los ratones nulos para $A p o D$ de la cepa $\mathrm{C} 57 \mathrm{BL} / 6 \mathrm{~J}$ generados mediante recombinación homóloga sustituyendo el alelo silvestre por uno nulo debido a la inserción del gen de la fosfotransferasa de neomicina (Neo) en el exón 6 del gen ApoD, muestran un aumento de los lípidos peroxidados en el cerebro, una menor resistencia a Paraquat ${ }^{11}(P Q)$, y un mayor fracaso en pruebas comportamentales; presentan disminución en la actividad locomotora y exploratoria y déficit de memoria [89]. La falta de ApoD genera un estrés oxidativo basal que provoca un aumento de la expresión de genes relacionados con la respuesta el estrés oxidativo (GFAP, HO-1 y SOD2) y una expresión anómala de los mismos en respuesta a la oxidación inducida por PQ [48]. También muestran alteraciones en varios receptores de neurotransmisores, en concreto receptores de somatostatina que disminuyen su transcripción en el córtex y el hipocampo y aumentan en el estriado y la amígdala [90] o receptores de glutamato que disminuyen su expresión en el hipocampo [91]. Por otro lado, la composición

\footnotetext{
${ }^{10}$ Las proteínas c-Jun $\mathbf{N}$-terminal (JNKs) son quinasas activadas por mitógenos (MAPK) que se unen y fosforilan a la proteína c-Jun. Responden a estímulos de estrés y están implicadas tanto en procesos de apoptosis,neurodegeneración, diferenciación y proliferación celular o procesos inflamatorios. (82.

Oltmanns, U., et al., Role of c-jun N-terminal kinase in the induced release of GM-CSF, RANTES and IL-8 from human airway smooth muscle cells. Br J Pharmacol, 2003. 139(6): p. 1228-34.

${ }^{11}$ Paraquat es el nombre comercial del Dicloruro de 1,1'-dimetil-4,4'-bipiridilo usado inicialmente como herbicida y actualmente utilizado en investigación como generador de ROS y como inductor de Parkinson en modelos experimentales (88. $\quad$ Berry, C., C. La Vecchia, and P. Nicotera, Paraquat and Parkinson's disease.Cell Death Differ, 2010. 17(7): p. 1115-25.).
} 
de ácidos grasos en el cerebro de estos ratones sin ApoD está alterada. En concreto, presentan un aumento de ácido palmítico (16:00) y de ácido esteárico (18:00) y también de ácidos grasos poliinsaturados como el ácido linoléico (18:2), ácido eicosadienoico (20:2) y DHA (22:6) [50]. La falta de ApoD está asociada a una disminución de la actividad de la lipoproteinlipasa (LPL), a un aumento de triglicéridos y a hiperinsulinemia [92].

Un modelo de daño en el nervio periférico de ratón revela que la falta de $A p o D$ aumenta la duración y magnitud de la respuesta inflamatoria retrasando la regeneración. Asimismo, la ausencia de ApoD altera el grosor de la banda de mielina disminuyendo la velocidad de conducción eléctrica de las neuronas [57]. La falta de ApoD también modifica la señalización entre células de Schwann y los macrófagos, el activador de fagocitosis Galectina-3 y los niveles de lisofosfatidilcolina y ácido araquidónico tras el daño indicando que ApoD favorece la iniciación de la fagocitosis y promueve la degradación de mielina (García-Mateo, et al., datos no publicados)

El tratamiento con clozapina en ratones sin ApoD produce cambios en los lípidos de membrana relacionados con el metabolismo del ácido araquidónico [50].

La falta de GLaz en Drosophila melanogaster produce un aumento en la cantidad de triglicéridos, una disminución en la longevidad y una menor resistencia al ayuno y al estrés oxidativo provocado por $\mathrm{H}_{2} \mathrm{O}_{2}$ o PQ. En concreto, el mutante nulo, ante el tratamiento con $\mathrm{PQ}$, presenta altos niveles de peroxidación lipídica y un incremento de las células apoptóticas además de defectos en el comportamiento [75].

La pérdida de función de NLaz en Drosophila melanogaster provoca una disminución de la cantidad de triglicéridos, glucosa y glicógeno. A su vez, provoca una disminución en la resistencia al ayuno y al estrés oxidativo y una reducción de la longevidad.

La sobreexpresión de NLaz tiene el efecto contrario, incrementa la resistencia al ayuno, al estrés oxidativo y alarga su supervivencia [37, 83, 93].

\section{GANANCIA DE FUNCIÓN}

La sobreexpresión de ApoD humana (hApoD) tanto en Drosophila como en ratón induce una mayor resistencia al estrés oxidativo, un aumento de la longevidad, una disminución de lípidos peroxidados y resistencia al tratamiento con PQ o a la infección con coronavirus OC43. Esto indicaría una capacidad protectora conservada [57, 81, 94].

La sobreexpresión de ApoD en el hígado de ratón reduce la concentración de triglicéridos en plasma. La sobreexpresión de $A p o D$ en el sistema nervioso provoca resistencia a la insulina [95].

Recientemente se ha identificado a ApoD como el mayor cardioprotector en un modelo de infarto de miocardio de ratón. La sobreexpresión de ApoD reduce la tasa de infarto de miocardio y protege a los cardiomiocitos de la hipoxia y el estrés relacionado con la reperfusión [96]. 
La sobreexpresión del homólogo de ApoD expresado por neuronas en Drosophila melanogaster, NLaz, aumenta la concentración corporal de glucosa, y su pérdida un aumento de grasas neutras (triglicéridos), glucosa y glucógeno [83, 93].

La sobreexpresión del homólogo GLaz en Drosophila produce aumento de la longevidad y mayor resistencia al ayuno y la hiperoxia [75].

La sobreexpresión de GLaz en un modelo de ataxia de Friedreich en Drosophila melanogaster (que supone una disfunción de la cadena respiratoria mitocondrial y por consiguiente estrés oxidativo y degeneración) consigue rebajar el nivel de lípidos peroxidados y recuperar los valores de longevidad [97].

\section{MANIPULACIÓN DE APOD EN LÍNEAS CELULARES}

Los estudios en líneas celulares demuestran que $A p o D$ es necesaria para la protección contra el daño oxidativo, influyendo en el perfil transcripcional de la respuesta temprana al estrés. ApoD es secretada por los astrocitos tratados con PQ y modula su reactividad (efecto autocrino) a la vez que mejora (in vivo) la viabilidad de las neuronas (efecto paracrino). Este efecto podría ejercerlo a través de la vía de ERK ${ }^{12}$. Su mecanismo de acción protector estaría conservado en otras especies ya que ApoD humana también promueve la supervivencia de los astrocitos de ratón. Además, se ha observado una internalización de ApoD humana en cultivos celulares que no la expresan como la línea celular humana procedente de cáncer cérvicouterino HeLa $[47,48,65]$.

Varios estudios celulares también relacionan ApoD con los lípidos y las membranas. La expresión de ApoD se altera ante el tratamiento con esteroides y con ácido retinoico $[99,100]$. El estudio en células humanas embrionarias de riñón (HEK293) transfectadas con ApoD relaciona la función de $A p o D$ con la incorporación de ácido araquidónico a las membranas o la inhibición de su liberación y por tanto su reducción en estado libre. ApoD atenúa la adhesión celular entre células endoteliales y murales reduciendo los puntos de contacto [101].

IN VITRO

Por último, estudios in vitro han demostrado que ApoD es capaz de participar en reacciones redox, como la reducción de HpETEs (acido hidroperoxieicosatetraenoico) a sus correspondientes HETEs (acido hidroieicosatetraenoico) a través de su metionina Met93 [17, $18,102]$.

\footnotetext{
${ }^{12}$ La vía de las MAP quinasas o vía MAPK/ERK (Mitogen-Activated Protein Kinases) es una ruta de transducción de señales que se sitúa por debajo de los receptores tirosín-quinasay receptores citoquina. La señal se transporta hasta la activación de Ras, una proteína $\mathrm{G}$ monomérica, que estimula a tres proteínas quinasas que actúan de forma secuencial activando la serín-treonín-quinasa MAP (también denominada «ERK») que se transloca al núcleo regulando la actividad de varios factores de transcripción y modulando la expresión de distintos genes (98.Sabio, G. and R.J. Davis, TNF and MAP kinase signalling pathways.Semin Immunol.).
} 
En resumen, ApoD es una proteína sintetizada y secretada fundamentalmente por astrocitos y oligodendrocitos en el SNC y células de Schwann en el SNP y posiblemente endocitada por otros tipos celulares. Posee una estructura en forma de bolsillo con capacidad para unir pequeños ligandos y una región hidrofóbica anómala para una proteína extracelular soluble que podría permitirle interaccionar con las regiones lipídicas de las HDL. Presenta una compleja regulación sensible al estrés oxidativo y la neurodegeneración. Ejerce una función protectora frente al estrés oxidativo tanto en las células que la producen como a las de su entorno y su mecanismo de acción podría estar relacionado con lípidos o moléculas relacionadas con lípidos como el ácido araquidónico, esteroides y sus procesos de oxidación.

Los múltiples efectos de la función de ApoD evidencian su pleiotropía. Sin embargo, el mecanismo a través del cual se producen estos efectos aún no se ha esclarecido totalmente. Tantos variados e importantes efectos ante tan diversas situaciones y condiciones para una pequeña proteína de estructura sencilla deben tener un punto de intersección, un punto que esté presente en todas las situaciones pero que a la vez pueda ser diferente y característico de cada una de ellas y cuya modulación pueda ejercer una amplia influencia celular. Encontrar ese punto y su relación con la proteína y con ello avanzar un paso más hacia la comprensión del mecanismo de acción y función de ApoD, ha sido el motor que ha impulsado la realización de esta 


\section{LAS MEMBRANAS BIOLÓGICAS}

Las membranas biológicas son barreras de permeabilidad selectiva que permiten una comunicación controlada entre los ambientes que delimitan. Están formadas por lípidos de diferentes clases entre los que se embeben, heterogéneamente distribuidas, ciertas proteínas. Los lípidos, debido a sus propiedades físicas, tienden a la auto-agregación en medios acuosos. Las leyes de la termodinámica les ordenan siguiendo el carácter anfipático de su estructura generando una doble capa enfrentada en la que la parte apolar queda aislada entre dos mantos de cabezas polares en contacto con los medios acuosos. Esta estructura se conoce como bicapa lipídica. Para proteger sus extremos, la bicapa, de unos $30 \AA$ de grosor, tiende a cerrarse sobre sí misma formando esferas que aíslan compartimentos acuosos en su interior, delimitando, de esta manera, tanto los diferentes compartimentos intracelulares como a la propia célula en su conjunto. Las membranas dan forma y estabilidad mecánica a la célula. Crean, dentro de ella, ambientes de condiciones específicas necesarias para las diversas reacciones químicas que tienen lugar y controlan el paso de sustancias dirigiendo, por consiguiente, la comunicación entre compartimentos y la respuesta específica a los estímulos externos. Las membranas generan la polaridad celular y mantienen una constante interacción con otras estructuras mientras controlan el continuo recambio de sus componentes [103-108].

\subsection{MODELO DE MOSAICO FLUIDO}

Desde el siglo XIX es conocida la existencia de un recubrimiento celular, pero no fue hasta 1935 cuando Danielli y Davson propusieron por primera vez un modelo para explicar la estructura de las biomembranas. Estos dos investigadores defendían una estructura en la que una bicapa lipídica (estructura básica defendida desde 1925 por Gorter y Grendel) se extendía entre dos capas de proteínas globulares. Esta teoría fue ampliamente criticada, hasta que en 1972, ante la evolución de la microscopía y los estudios químico-físicos moleculares, se propuso, aunando todos los resultados obtenidos hasta ese momento, un modelo que explicaba la estructura y propiedades de la membrana plasmática: el modelo de mosaico fluido de S. J. Singer y G. Nicholson. Este modelo presentaba como novedad el hecho de que las proteínas no solo podían estar unidas a ambas caras de la membrana, sino que podían estar embebidas en ella como teselas dentro de un mosaico romano. Al contrario que en los estáticos mosaicos, Singer y Nicholson describen un mosaico fluido, donde tanto los lípidos como las proteínas están en un constante y estocástico movimiento. Este movimiento aleatorio tiene dos componentes: rotacional, sobre su propio eje, y lateral, en el plano de la membrana. Como consecuencia de estos dos únicos movimientos (no consideraban el movimiento de un lado a otro de la membrana) defendían una estructura altamente asimétrica tanto en lípidos como en proteínas que explicaba la diferente entrada y salida de partículas $[103,109]$. 
A

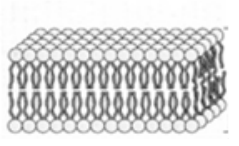

B

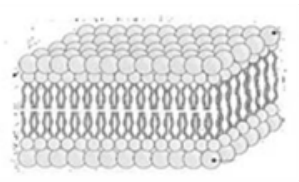

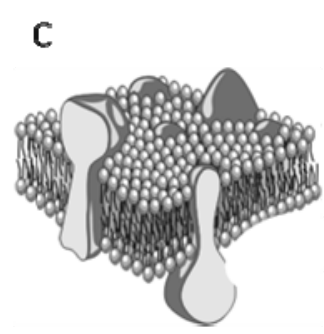

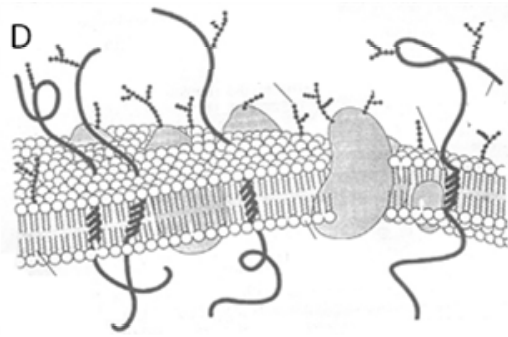

Figura 5. Evolución de los modelos de la estructura de las biomembranas. (A) Gorter y Grendel (1925). (B) DanielliDavson (1935). (C) Singer-Nicholson (1972). (D) Modelo actual. (Modificado de [109-112]

\subsubsection{MODIFICACIONES AL MODELO}

Sin embargo, y a pesar de ser un modelo que ha resistido los envites del tiempo con bastante buena fortuna, el desarrollo exponencial de nuevas técnicas $y$, por consiguiente, el interés y fascinación creciente hacia campos relacionados con él como la lipidómica, han permitido ampliarlo y completarlo (Fig.5) [113-115].

\section{FLUIDEZ}

Actualmente se acepta que la cantidad de proteínas asociadas a la membrana es mucho mayor de lo que se había descrito inicialmente (algunas de las cuales poseen, además, abultados dominios extra-membrana) aumentando, por tanto, las probabilidades de interacción entre ellas, ejerciendo mayores perturbaciones sobre los lípidos, y generando irregularidades en el grosor de la bicapa (también debidas a diferentes estructuras de los lípidos). Este complejo entramado de interacciones determina una difusión de las proteínas y lípidos de membrana mucho más restringida de lo que defendieron en su momento Singer y Nicholson; idea que subrayó en 2005 D.M. Engelman: es un modelo más mosaico que fluido [103, 116].

\section{UNIÓN A PROTEÍNAS}

Por otro lado se ha difuminado la catalogación clásica de las proteínas en función de su unión a la membrana o su solubilidad en el citosol, ante el descubrimiento de proteínas que pueden unirse y separarse de la bicapa según las circunstancias. Además, esta interacción puede tener un carácter reversible, como en el caso de algunas proteínas transportadoras de lípidos (proteínas transportadoras de fosfatidilinositol), o irreversible. Asimismo, entre las proteínas de unión reversible, pueden distinguirse las de unión fuerte pero sin modificación covalente de los lípidos (como ocurre con las fosfolipasas y otras enzimas del metabolismo lipídico) y las que implican una modificación covalente [106, 117].

\section{CURVATURA}

El estudio de la geometría y propiedades mecánicas de los diferentes lípidos y proteínas que forman las membranas, también ha redirigido la concepción aplanada de la bicapa hacia una estructura con cierta curvatura. Esta curvatura es dinámica, requiere de la asimetría de las dos capas de la membrana y de los medios que las rodean, y es dependiente de la geometría de los 
componentes lipídicos (cuanto menos cilíndricos -es decir, más cónicos- mayor curvatura) y de la composición proteica (como la presencia de ciertas proteínas que provocan una curvatura en la membrana: clatrina, dinamina, o el dominio BAR [Bin/amfifisina/Rvs]). La curvatura es esencial para procesos en los que se requiere un cambio en la forma de la célula tales como el crecimiento, la división, el desplazamiento celular, la exocitosis y endocitosis, etc. [105, 107, $118,119]$.

\section{ASIMETRÍA. MOVIMIENTO "FLIP-FLOP”}

Otra de las ampliaciones al modelo es la confirmación de la existencia, bajo ciertas condiciones, de una migración de los componentes de una a otra cara de la bicapa (movimiento "flip-flop"). Sin embargo, esta migración es reducida y altamente controlada ya que la célula necesita mantener la asimetría a ambos lados de su membrana. Las modificaciones en la asimetría se asocian con una activación celular (adhesión, apoptosis, fagocitosis, generación de vesículas...) o con una situación patológica (ver sección 4.4.1.2). Como se ha mencionado anteriormente, la asimetría también es necesaria para generar la curvatura intrínseca de la membrana. La velocidad de este movimiento "flip-flop" es, respecto a los otros dos movimientos ya mencionados, lento y dependiente de la naturaleza, la carga, y la polaridad de la cabeza del lípido; de horas a días para fosfatidilcolina, días para glucoesfingolípidos complejos, y segundos para la ceramida, el diacilglicerol y los esteroles. Sin embargo, pueden mantenerse específicamente en una cara si son atrapados en ciertos dominios, como le ocurre al colesterol que se enriquece en la cara externa gracias a su afinidad por los esfingolípidos, que a su vez, dada la voluminosidad de su cabeza polar, tienden a colocarse en la cara externa. Lípidos cargados negativamente, como ácidos grasos, fosfoglicéridos y ácido fosfatídico, pueden migrar de cara a cara rápidamente si se neutraliza su carga a bajo $\mathrm{pH}$ o pueden acumularse en un lado según un gradiente de $\mathrm{pH}$. La existencia de un gran número de proteínas transportadoras de lípidos, flipasas (dependientes de ATP), flopasas, y escramblasas, confirma la importancia funcional de la asimetría lipídica.

La asimetría de las proteínas integrales de membrana, por el contrario, se controla desde la propia síntesis de las cadenas polipetídicas que se insertan en porciones de membrana con una determinada topología. Este control tan prematuro se debe a que el paso de proteínas globulares de una capa a otra de la membrana supondría un enorme gasto energético [120, 121].

\section{FASES DE LA BICAPA}

Por último, los estudios sobre procesos celulares en los que las membranas juegan un importante papel, como la fusión o fisión (interacciones membrana-membrana), han revelado la capacidad de las membranas para adquirir una estructura diferente a una bicapa. De hecho, el estudio físico-químico de las disoluciones acuosas de lípidos determina nuevas fases estables (fases mesomórficas ${ }^{13}$ ) con relevancia funcional, caracterizadas por la disposición espacial de cada lípido y sus grados de libertad de movimiento. La principal fase que adoptan

\footnotetext{
${ }^{13}$ Fase mesomórfica: Estado de la materia en donde las partículas anisométricas (partículas no superponibles ni superponibles por reflexión especular) están ordenadas en una o dos direcciones pero dispuestas al azar en las otras direcciones (diccionario de química física J M Costa. Ediciones Díaz de Santos, 2005).
} 
las membranas lipídicas puras es la fase lamelar (L): dos capas lipídicas con sus partes apolares en contacto y aisladas del medio acuoso; la adoptan la mayoría de los fosfolípidos y glicolípidos (ver sección 4). Sin embargo, ciertos lípidos pueden generar otras estructuras: micelar, hexagonal invertida o cubo invertido. Los gangliósidos y lisofosfolípidos, debido a su geometría cónica, pueden adoptar una fase micelar (M), es decir, esferas de lípidos con los grupos polares hacia fuera y un centro formado por las cadenas apolares. La fosfatidiletanolamina, en ciertas condiciones, adquiere una conformación hexagonal invertida $\left(H_{\|}\right)$generando unos tubos lipídicos que forman un entrecruzado hexagonal. Por último, se habla de la fase de cubo invertido $\left(Q_{\| 1}\right)$ cuando se forma un entramado cúbico. Esta capacidad de los lípidos para organizarse en diferentes estructuras se denomina polimorfismo lipídico.

Así mismo, la fase lamelar puede verse modificada por la temperatura y las características de los lípidos que la forman adquiriendo dos subfases o estados: un estado de gel (sólido) $\left(L_{\beta}\right)$, propio de lípidos saturados a bajas temperaturas, y un estado fluido (también llamado líquido cristalino o desordenado) $\left(L_{\alpha} \circ L_{d}\right)$ en la que los lípidos tienen movimiento rotacional y traslacional (desorden de las cadenas acilo). Por otro lado, las fosfatidilcolinas saturadas adoptan un estado lamelar ondulado $\left(\mathrm{P}_{\beta}\right)$ en el que estos lípidos adquieren cierta inclinación. Por último, se ha descubierto la existencia de una fase líquida ordenada $\left(L_{0}\right)$ en la que está restringido el movimiento rotacional de las cadenas carbonadas pero no la difusión lateral. Esta fase es consecuencia de las propiedades fisicoquímicas de algunos fosfolípidos saturados como la esfingomielina (ver sección 3.6.1.2) y su interacción con el colesterol. La fase ordenada posee mayor grosor que el resto de la membrana y un ralentizado movimiento lateral fruto de la alta estabilidad de las interacciones que la mantienen. Ciertas proteínas presentan una mayor afinidad por esta zona y un mayor tiempo de residencia, condicionando su configuración, favoreciendo su interacción con otras proteínas o lípidos y modulando su función. Por consiguiente, la bicapa presenta heterogeneidades de consecuencias no sólo estructurales sino especialmente funcionales. Estas heterogeneidades han sido nombradas de varias maneras. De forma general se denominan dominios (ver sección 2.4) (Fig.6) [105, 106, 108].

Todas estas nuevas ideas han transformado la visión de los lípidos de meros soportes estructurales a sutiles ${ }^{14}$, eficaces y muy específicos sistemas de regulación celular. A su vez, las propiedades que poseen las membranas debidas a su composición lipídica condicionan la funcionalidad de las proteínas que interaccionan con ella.

\footnotetext{
${ }^{14}$ En su segunda acepción según la Real Academia Española: agudo, perspicaz, ingenioso.
} 
A

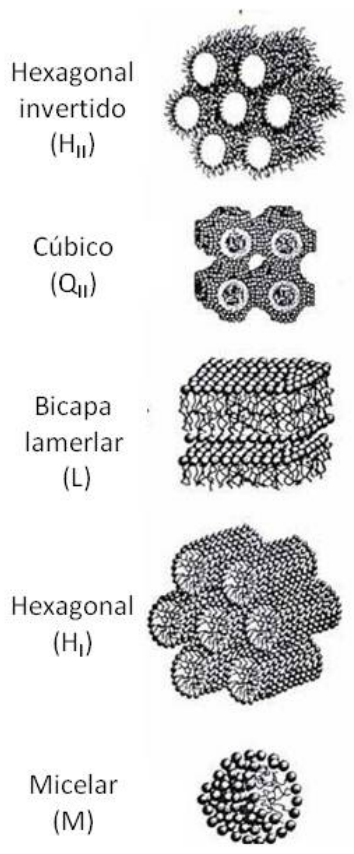

B

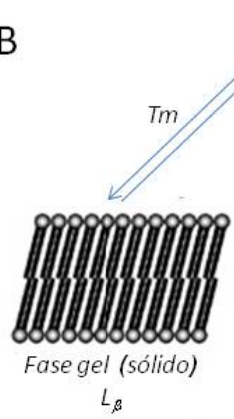

III)

Fase ondulada

$P_{\beta}$

Tm

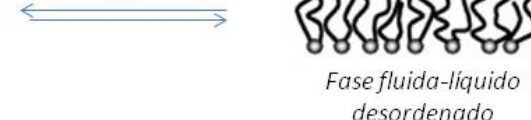
desordenado $L_{a}$

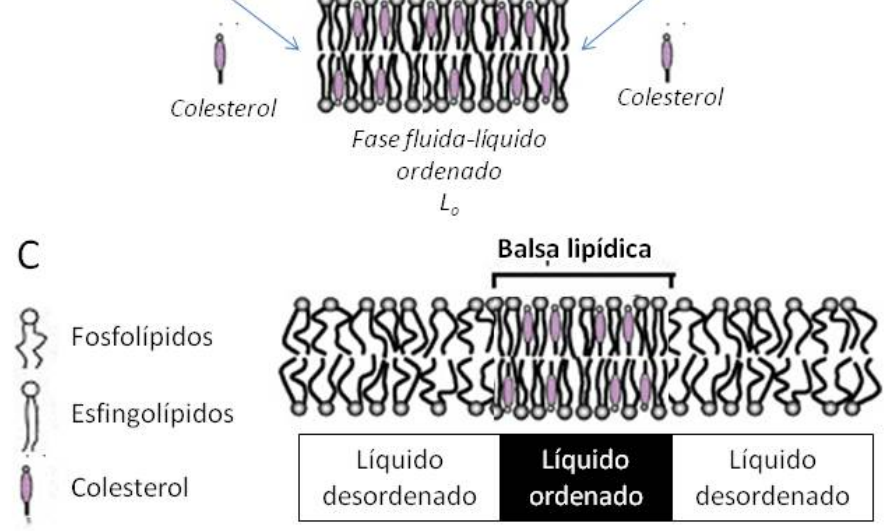

Figura 6. Estructuras lipídicas. (A) Fases de las disoluciones lipídicas. (B) Estados de la fase lamelar. (C) Balsa lipídica (Modificado de [108, 122, 123]).

\subsection{PROTEÍNAS DE MEMBRANA}

Las proteínas de membrana son un conjunto heterogéneo de moléculas que pueden unirse ${ }^{15} \mathrm{o}$ incrustarse en la matriz lipídica según sus propiedades físico-químicas. Sobre ellas recae una gran parte de la función de las membranas. Pueden desarrollar funciones conectoras, receptoras, transportadoras o enzimáticas. Asimismo, pueden clasificarse, en base a su forma de unión a la membrana, en proteínas intrínsecas o integrales de membrana y proteínas periféricas o extrínsecas.

\section{PROTEÍNAS INTEGRALES}

Las proteínas integrales de membrana contienen regiones incrustadas en la bicapa. Para su separación de la membrana se hace necesaria la ruptura de la estructura lipídica. Las proteínas integrales pueden dividirse en proteínas transmembrana y proteínas ancladas a lípidos. Las proteínas transmembrana cruzan la membrana una o varias veces (unipaso o multipaso) y poseen, por tanto, 3 dominios: citosólico, transmembrana y extracelular (o intraluminal en el caso de membranas de organelas). Las proteínas ancladas a lípidos pueden encontrarse a ambos lados de la membrana. Los anclajes lipídicos del lado citosólico (restos palmitilo, miristilo, farnesilo y geranilgeranilo) definen las llamadas proteínas preniladas (p. ej. Ras, Rab,

\footnotetext{
${ }^{15}$ Se habla de la posibilidad de unirse y no del hecho en sí de estar unidas ya que no solo pueden ser consideradas proteínas de membranas las que están permanentemente unidas sino aquellas que, en algún momento y en determinadas circunstancias, se unen a la membrana (ver modificaciones al modelo mosaico).
} 
flotilina) [124-126]. Los anclajes del lado extracelular suponen la unión covalente a un resto fosfatidilinositol dando lugar a las proteínas GPI. Estas últimas, como ya se ha comentado, pueden separarse de la membrana por acción de algunas fosfolipasas (PLC) (Fig.7) [117, 127, 128].

\section{PROTEÍNAS PERIFÉRICAS}

Las proteínas periféricas son solubles en agua pero están débilmente unidas a la membrana por cualquiera de sus lados. Su unión se produce a través de enlaces de hidrógeno y fuerzas electrostáticas entre algunas de sus regiones y las cabezas polares de los lípidos constitutivos de la bicapa o de proteínas transmembrana. Existen motivos específicos para la unión a ciertos lípidos. Los motivos PH (Pleckstrin Homology domain) permiten la unión a los fosfoinosítidos $\left(\mathrm{PIP}_{2} \circ \mathrm{PIP}_{3}\right)$ y los motivos $\mathrm{C} 2$, presentes en enzimas como la proteína quinasa $\mathrm{C}$, que fosforila proteínas activando o desactivando su función, o las fosfolipasas, que hidrolizan los enlaces éster de los fosfolípidos. Muchas proteínas periféricas internas median entre el citoesqueleto y la membrana confiriendo polaridad a la célula [129]. Las proteínas periféricas proporcionan actividad enzimática, sitios de anclaje para proteínas o moléculas señalizadoras, generan curvatura en las membranas provocando la generación de vesículas, etc. [130-132].

Como se ha comentado anteriormente, la membrana presenta diferentes fases que dependen de su composición lipídica. La estructura peptídica helicoidal más simple introducida en la membrana provoca la formación de fases en la bicapa. Las proteínas muestran preferencia por ciertas fases de la membrana. Esta preferencia está basada en la longitud de las cadenas, su grado de saturación o el grupo de la cabeza de los lípidos que la forman. Una proteína que se ancle a la membrana por una $\alpha$-hélicelo hará preferentemente en una zona en fase líquida (L). Ante las dos sub-fases, $L_{o}$ y $L_{d}$, una gran parte de los péptidos unidos a la membrana se situarán en la fase $L_{d}$. Sin embargo, en los últimos años están apareciendo un creciente conjunto de péptidos, como la familia de las caveolinas o las proteínas ancladas por GPI, que muestran una afinidad preferente por la fase $L_{o}$. Asimismo, los motivos proteicos de unión a colesterol presentan alta afinidad por las regiones ricas en colesterol. Sin embargo, aún no está claro si la afinidad se da sobre un dominio de membrana preexistente o si es la propia proteína la que induce la formación de una fase concreta. La influencia de las proteínas en la membrana podría repercutir en el comportamiento de la membrana en procesos como la formación de poros, el mantenimiento de la curvatura, la vesiculación y la tubulación mientras que la influencia de los lípidos sobre las proteínas de membrana podría repercutir en su localización, su conformación, sus interacciones y su función [133-137]. 
A
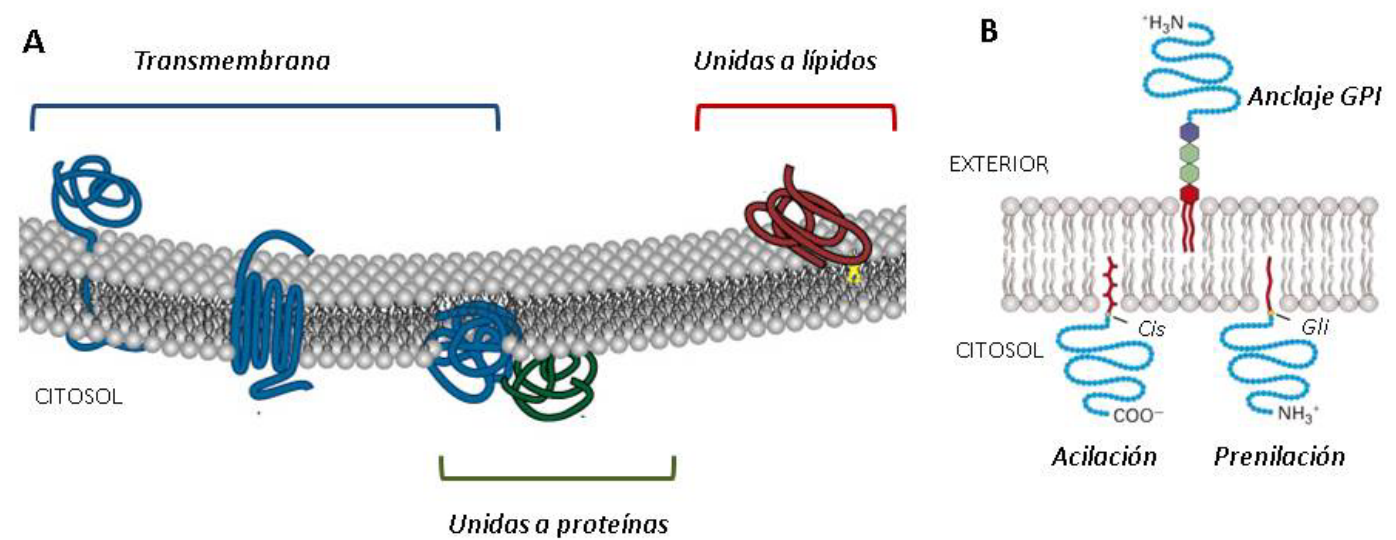

Figura 7. (A) Proteínas integrales de membrana. (B) Proteínas ancladas a lípidos (modificado de [138, 139][138, 139])

\subsection{LÍPIDOS DE MEMBRANA}

Los lípidos son moléculas orgánicas compuestas principalmente de carbono e hidrógeno y, en menor medida, oxígeno, fósforo, nitrógeno y azufre. Como ya se ha mencionado, se caracterizan principalmente por poseer una parte hidrofóbica y otra hidrofílica que les confiere un comportamiento anfipático. La región hidrofóbica está formada por cadenas alifáticas (carbonos e hidrógenos) saturadas o insaturadas. Estas partes apolares, en solución acuosa, tienden a agregarse expulsando las moléculas de agua y generando un espeso empaquetamiento estabilizado por interacciones de Van der Walls. Por el contrario, la región hidrofílica o polar está compuesta por grupos funcionales cargados eléctricamente que constituyen una superficie compacta en contacto con el medio acuoso [140].

Su composición química y estructura les confieren unas propiedades físico-químicas responsables, a su vez, del comportamiento y propiedades de las membranas que conforman:

Carácter anfipático responsable de su insolubilidad en agua y por tanto de la estabilidad de las bicapas.

Punto de fusión proporcional a la longitud de la cadena e inversamente proporcional al número de insaturaciones que confiere a las membranas más insaturadas una menor energía de fusión.

Auto-oxidación de los ácidos grasos insaturados que genera aldehídos en el lugar de los dobles enlaces covalentes [140-143].

\subsubsection{CLASIFICACIÓN}

\section{ÁCIDOS GRASOS}

Un ácido graso es una molécula de naturaleza lipídica formada por una cadena hidrocarbonada lineal de número par de átomos de carbono en cuyo extremo hay un grupo carboxilo de carácter ácido $(\mathrm{R}-\mathrm{COOH})^{16}$. Se clasifican según el número de carbonos

\footnotetext{
${ }^{16}$ La nomenclatura oficial de los ácidos grasos consiste en el número de átomos de carbono seguido por dos puntos y el número de dobles enlaces (entre paréntesis puede ir la localización del doble enlace a partir del grupo
} 
(de cadena larga o corta), el número de insaturaciones (saturados o insaturados) y la posición y configuración de dichas insaturaciones (cis o trans). Los dobles enlaces o insaturaciones aportan rigidez a la estructura impidiendo la rotación sobre si mismos. Los dobles enlaces cis son biológicamente más comunes; se generan por desaturación en el retículo endoplasmático y provocan un codo en la geometría de la molécula que dificulta su empaquetamiento con otras cadenas hidrocarbonadas. Por el contrario, los dobles enlaces trans son rectilíneos aunque igualmente rígidos. Asimismo, a nivel biológico, los ácidos grasos pueden clasificarse en esenciales, si el organismo no los puede sintetizar y deben obtenerse por la dieta, y no esenciales, si pueden ser sintetizados. El cuerpo humano es capaz de sintetizar casi todos los ácidos grasos necesarios a partir del ácido palmítico (16:0), mediante su oxidación y elongación. Sin embargo, necesita incluir en su dieta alácido linoleico (18:2(6)) y ácido linolénico (18:3(3)) como precursores de muchos otros: la serie $\omega-6$ y la serie $\omega-3$ respectivamente [144].

\begin{tabular}{|l|l|l|l|}
\hline \multicolumn{4}{|l|}{ TABLA 1.A.Ácidos grasos saturados } \\
\hline Nombre & Nombre IUPAC & Estructura & Número lipídico \\
\hline Ácido cáprico & Ácido decanoico & $\mathrm{CH}_{3}\left(\mathrm{CH}_{2}\right)_{8} \mathrm{COOH}$ & $\mathrm{C} 10: 0$ \\
\hline Ácido láurico & Ácido dodecanoico & $\mathrm{CH}_{3}\left(\mathrm{CH}_{2}\right)_{10} \mathrm{COOH}$ & $\mathrm{C} 12: 0$ \\
\hline Ácido mirístico & Ácido tetradecanoico & $\mathrm{CH}_{3}\left(\mathrm{CH}_{2}\right)_{12} \mathrm{COOH}$ & $\mathrm{C} 14: 0$ \\
\hline Ácido palmítico & Ácido hexadecanoico & $\mathrm{CH}_{3}\left(\mathrm{CH}_{2}\right)_{14} \mathrm{COOH}$ & $\mathrm{C} 16: 0$ \\
\hline Ácido esteárico & Ácido octadecanoico & $\mathrm{CH}_{3}\left(\mathrm{CH}_{2}\right)_{16} \mathrm{COOH}$ & $\mathrm{C} 18: 0$ \\
\hline Ácido nonadecílico & Ácido nonadecanoico & $\mathrm{CH}_{3}\left(\mathrm{CH}_{2}\right)_{17} \mathrm{COOH}$ & $\mathrm{C} 19: 0$ \\
\hline Ácido araquídico & Ácido eicosanoico & $\mathrm{CH}_{3}\left(\mathrm{CH}_{2}\right)_{18} \mathrm{COOH}$ & $\mathrm{C} 20: 0$ \\
\hline Ácido lignocérico & Ácido tetracosanoico & $\mathrm{CH}_{3}\left(\mathrm{CH}_{2}\right)_{22} \mathrm{COOH}$ & $\mathrm{C} 24: 0$ \\
\hline
\end{tabular}

TABLA 1.A. Ejemplos de ácidos grasos saturados. Nomenclatura tradicional, nomenclatura oficial (IUPAC: International Union of Pure and Applied Chemistry), estructura química y número lipídico (C no de carbonos : $\mathrm{n}$ ㅇ de insaturaciones).

carboxilo) (144. Fahy, E., et al., A comprehensive classification system for lipids.J Lipid Res, 2005. 46(5): p. 83961.) 


\begin{tabular}{|c|c|c|c|c|}
\hline \multicolumn{5}{|c|}{ TABLA 1.B.Ácidos grasos insaturados } \\
\hline Nombre trivial & Estructura química & Configuración & $C: D$ & $n-x$ \\
\hline Ácido miristoleico & $\mathrm{CH}_{3}\left(\mathrm{CH}_{2}\right)_{3} \mathrm{CH}=\mathrm{CH}\left(\mathrm{CH}_{2}\right)_{7} \mathrm{COOH}$ & Cis & $14: 1$ & $n-5$ \\
\hline Ácido palmitoleico & $\mathrm{CH}_{3}\left(\mathrm{CH}_{2}\right)_{5} \mathrm{CH}=\mathrm{CH}\left(\mathrm{CH}_{2}\right)_{7} \mathrm{COOH}$ & Cis & $16: 1$ & $n-7$ \\
\hline Ácido sapiénico & $\mathrm{CH}_{3}\left(\mathrm{CH}_{2}\right)_{8} \mathrm{CH}=\mathrm{CH}\left(\mathrm{CH}_{2}\right)_{4} \mathrm{COOH}$ & Cis & $16: 1$ & $n-10$ \\
\hline Ácido oleico & $\mathrm{CH}_{3}\left(\mathrm{CH}_{2}\right)_{7} \mathrm{CH}=\mathrm{CH}\left(\mathrm{CH}_{2}\right)_{7} \mathrm{COOH}$ & Cis & $18: 1$ & $n-9$ \\
\hline Ácido eláidico & $\mathrm{CH}_{3}\left(\mathrm{CH}_{2}\right)_{7} \mathrm{CH}=\mathrm{CH}\left(\mathrm{CH}_{2}\right)_{7} \mathrm{COOH}$ & Trans & $18: 1$ & $n-9$ \\
\hline Ácido vaccénico & $\mathrm{CH}_{3}\left(\mathrm{CH}_{2}\right)_{5} \mathrm{CH}=\mathrm{CH}\left(\mathrm{CH}_{2}\right)_{9} \mathrm{COOH}$ & Trans & $18: 1$ & $n-7$ \\
\hline Ácido linoleico & $\mathrm{CH}_{3}\left(\mathrm{CH}_{2}\right)_{4} \mathrm{CH}=\mathrm{CHCH}{ }_{2} \mathrm{CH}=\mathrm{CH}\left(\mathrm{CH}_{2}\right)_{7} \mathrm{COOH}$ & Cis & $18: 2$ & $n-6$ \\
\hline Ácido linoeláidico & $\mathrm{CH}_{3}\left(\mathrm{CH}_{2}\right)_{4} \mathrm{CH}=\mathrm{CHCH}{ }_{2} \mathrm{CH}=\mathrm{CH}\left(\mathrm{CH}_{2}\right)_{7} \mathrm{COOH}$ & Trans & $18: 2$ & $n-6$ \\
\hline Ácido $\alpha$-Linolénico & $\mathrm{CH}_{3} \mathrm{CH}_{2} \mathrm{CH}=\mathrm{CHCH}_{2} \mathrm{CH}=\mathrm{CHCH}_{2} \mathrm{CH}=\mathrm{CH}\left(\mathrm{CH}_{2}\right)_{7} \mathrm{COOH}$ & Cis & $18: 3$ & $n-3$ \\
\hline $\begin{array}{l}\text { Ácido } \\
\text { araquidónico }^{17}\end{array}$ & $\begin{array}{l}\mathrm{CH}_{3}\left(\mathrm{CH}_{2}\right)_{4} \mathrm{CH}=\mathrm{CHCH}_{2} \mathrm{CH}=\mathrm{CHCH}_{2} \mathrm{CH}=\mathrm{CHCH}_{2} \mathrm{CH}=\mathrm{CH} \\
\left(\mathrm{CH}_{2}\right)_{3} \mathrm{COOH}\end{array}$ & Cis & $20: 4$ & $n-6$ \\
\hline $\begin{array}{l}\text { Ácido } \\
\text { eicosapentenoico }\end{array}$ & $\begin{array}{l}\mathrm{CH}_{3} \mathrm{CH}_{2} \mathrm{CH}=\mathrm{CHCH}_{2} \mathrm{CH}=\mathrm{CHCH}_{2} \mathrm{CH}=\mathrm{CHCH}_{2} \mathrm{CH}=\mathrm{CHCH} \\
{ }_{2} \mathrm{CH}=\mathrm{CH}\left(\mathrm{CH}_{2}\right)_{3} \mathrm{COOH}\end{array}$ & Cis & $20: 5$ & $n-3$ \\
\hline Ácido erúcico & $\mathrm{CH}_{3}\left(\mathrm{CH}_{2}\right)_{7} \mathrm{CH}=\mathrm{CH}\left(\mathrm{CH}_{2}\right)_{11} \mathrm{COOH}$ & Cis & $22: 1$ & $n-9$ \\
\hline $\begin{array}{l}\text { Ácido } \\
\text { docosahexaenoico }\end{array}$ & $\begin{array}{l}\mathrm{CH}_{3} \mathrm{CH}_{2} \mathrm{CH}=\mathrm{CHCH}_{2} \mathrm{CH}=\mathrm{CHCH}_{2} \mathrm{CH}=\mathrm{CHCH}_{2} \mathrm{CH}=\mathrm{CHCH} \\
{ }_{2} \mathrm{CH}=\mathrm{CHCH}_{2} \mathrm{CH}=\mathrm{CH}\left(\mathrm{CH}_{2}\right)_{2} \mathrm{COOH}\end{array}$ & Cis & $22: 6$ & $n-3$ \\
\hline
\end{tabular}

TABLA 1.B. Ejemplos de ácidos grasos insaturados. Nomenclatura tradicional, estructura química, configuración de los dobles enlaces, número lipídico ( $\mathrm{C}$ no de carbonos : $\mathrm{n}$ de insaturaciones), designación según la posición delos dobles enlaces respecto al carbono $\omega$ (el extremo $\mathrm{CH}_{3}-$ ).

Según posean en su estructura ácidos grasos o no, los lípidos pueden clasificarse en dos grandes grupos: lípidos saponificables y lípidos insaponificables.

\section{LÍPIDOS SAPONIFICABLES}

Los lípidos saponificables están compuestos por un alcohol (R-OH (básico)) unido a uno o varios ácidos grasos ( $R^{\prime}-\mathrm{COOH}$ (ácido)) mediante un enlace éster ( $\left.R^{\prime}-\mathrm{COOR}\right)$, solo hidrolizable en medio básico (saponificación alcalina). A su vez, pueden dividirse en simples (si sólo poseen átomos de carbono, oxígeno e hidrógeno) y complejos (si además

\footnotetext{
${ }^{17}$ El ácido araquidónico es un segundo mensajero que forma parte de varias rutas de señalización. Se genera a partir de fosfolípidos de la membrana por acción de la fosfolipasa A2 (PLA2) (unida a la membrana y activada por proteínas $\mathrm{G}$ ) o por acción de la DAGlipasa sobre el DAG. Puede actuar como segundo mensajero por sí mismo o convertirse en otros mensajeros (eicosanoides). Por otro lado pueden actuar sobre rutas del interior de la célula que lo ha producido o traspasar la membrana y activar receptores de la superficie celular tanto de su propia célula como de otras vecinas (mensajero retrógrado). El 30\% de los lípidos que forman las balsas lipídicas contienen AA [145. Pike, L.J., et al., Lipid rafts are enriched in arachidonic acid and plasmenylethanolamine and their composition is independent of caveolin-1 expression: a quantitative electrospray ionization/mass spectrometric analysis.Biochemistry, 2002. 41(6): p. 2075-88.].
} 
de carbono, hidrógeno y oxígeno, contienen nitrógeno, fósforo, azufre o incluso un glúcido) (Fig.8).

Los lípidos saponificables simples se clasifican según el peso molecular de su alcohol en acilglicéridos (bajo peso molecular) y céridos (alto peso molecular). Los acilglicéridos son ésteres de ácidos grasos con glicerol. Dado que el glicerol posee tres grupos hidroxilo $(-\mathrm{OH})$ pueden ser monoacilglicéridos, diacilglicéridos o triacilglicéridos (triglicéridos) según reaccionen con uno, dos o tres ácidos grasos. Los triglicéridos constituyen la principal reserva energética del organismo y actúan como aislantes térmicos y fuentes de calor metabólico [146].

Los lípidos saponificables complejos según posean un grupo fosfato (que proporciona gran polaridad), una esfingosina o ambos se clasifican en fosfolípidos, esfingolípidos o fosfoesfingolípidos.

* Los fosfolípidos que contengan glicerol (además de grupo fosfato) se denominan fosfoglicéridos, y según el alcohol unido al grupo fosfato se clasifican en:

- Fosfatidilcolina (PC): es el fosfolípido mayoritario de las membranas celulares. Tiene preferencia por la cara externa de la membrana. Se sintetiza a partir del diacilglicerol y es fuente de ácido araquidónico y colina (precursor de acetilcolina: neurotransmisor involucrado en la memoria) También es fuente de ácido fosfatídico (por acción de la fosfolipasa D) implicado en la formación de vesículas transportadoras [147].

- Fosfatidiletanolamina (PE): posee fundamentalmente ácido palmítico, ácido esteárico o ácido oléico unidos a un ácido graso poliinsaturado de cadena larga, como el AA. Es, junto con la fosfatidilcolina, uno de los fosfolípidos más frecuentes en las bicapas lipídicas celulares.

- Fosfatidilserina (PS): es el principal fosfolípido aniónico de los tejidos neurales. Se sintetiza a partir de PC o PE gracias a la acción de la fosfatidilserinasintasa-1 y -2 localizadas en el RE. La PS del cerebro posee un alto contenido en ácido docosahexaenoico. Normalmente una flipasa la mantiene en la cara citosólica de las membranas celulares. Sin embargo, durante la apoptosis, pasa a la parte exterior de la membrana como una señal superficial de muerte celular para que la célula sea degradada por macrófagos. Es uno de los componentes mayoritarios de la mielina [148].

- Fosfatidilinositol(PI): al igual que la fosfatidilcolina, es fuente de ácido araquidónico y participa en la transducción de señales de procesos como el crecimiento celular, el transporte de glucosa o la exocitosis. Se nombran según la posición de los grupos fosfato. Su fosforilación en la cara interna de la membrana genera fosfatidilinositol 3-P (Ptdlns3P) que regula procesos de distribución de proteínas y de señalización celular [149, 150].

- Fosfatidilglicerol (glicerol) (PG): es el precursor de la cardiolipina, lípido característico de la membrana interna mitocondrial de las células cardiacas 
que se une y regula de varias enzimas implicadas en la fosforilación oxidativa [151].

* Los esfingolípidos derivan de la esfingosina, que se une a un ácido graso mediante un enlace amida formando la ceramida (unidad estructural). Se encuentran fundamentalmente en el tejido nervioso, especialmente en los organismos más complejos. Desempeñan un papel importante en la señalización intra- y extracelular, en muchos casos a través de la formación de dominios de membrana. A este grupo pertenecen los glucoesfingolípidos. Los diferentes glicoesfingolípidos se forman como combinación de unas pocas unidades conectadas en diferentes combinaciones. Esto permite la generación de una gran variedad de productos sin la necesidad de un gran número de enzimas diferentes (esfingomielinasas, SM sintasas, glicosiltransferasas). En la superficie de las membranas, los esfingolípidos establecen interacciones entre proteínas de la misma célula, de células vecinas (glicosinapsis) o de la matriz celular. Participan en procesos de fagocitosis, inhibición de apoptosis, activación de mTOR (mammalian target of Rapamycin), activación de fosfolipasa A, o síntesis de eicosanoides entre otras funciones [152].

- En los glucoesfingolípidos (GSLS) (o glucolípidos) el grupo hidroxilo de la ceramida se une, mediante un enlace glucosídico, a un monosacárido ${ }^{18} \mathrm{o}$ aun oligosacárido (glucosa, galactosa, manosa, fructosa, Nacetilgalactosamina, ácido siálico...). La cadena glucídica puede contener entre uno y quince monómeros de monosacárido. En las membranas, esta parte glucídica se orienta hacia el exterior (la curvatura de la membrana favorece la presencia de grupos voluminosos en la cara externa) formando parte del glicocálix, donde interviene en procesos intercelulares.

A su vez, se dividen en cerebrósidos, gangliósidos, y globósidos.

- Los cerebrósidos tienen un único azúcar unido a la ceramida. Si el azúcar es glucosa se denominan glucocerebrósidos, si es galactosa se denominan galactocerebrósidos(característicos de las membranas del tejido nervioso). La galactosilceramida es el principal glucoesfingolípido en el cerebro ( $23 \%$ de los lípidos de la mielina). Forma balsas lipídicas en el ER y juega un papel importante en la diferenciación de oligodendrocitos. Si la galactosa está esterificada con sulfato se denominan sulfátidos. Varias proteínas como la esfingosina quinasa 2 se unen a sulfátidos regulando funciones intracelulares (Alfred H. Merrill, Jr. 2011). Los sulfátidos están involucrados en la

\footnotetext{
${ }^{18}$ Los monosacáridos son los glúcidos más sencillos: $\left(\mathrm{CH}_{2} \mathrm{O}\right)_{n} n \geq 3$. Son azúcares reductores y no se hidrolizan (no se descomponen en compuestos más simples). Su cadena carbonada no está ramificada y todos los átomos de carbono menos uno contienen un grupo alcohol (-OH). El átomo de carbono restante tiene unido un grupo carbonilo $(\mathrm{C}=\mathrm{O})$. Se dividen en aldosas (grupo carbonilo en el extremo, es decir, un aldehído (-CHO)) y cetosas (grupo carbonilo en otra posición, es decir, una cetona (-CO-)
} 
unión axón-glía en los nodos de Ranvier a través de su interacción con la glicoproteína asociada a la mielina (MAG) (Dupree JL, 1999) [153]

- Los gangliósidos son los glucoesfingolípidos más complejos. Poseen grandes cabezas polares cargadas negativamente formadas por, al menos, una molécula de ácido siálico. El ácido siálico regula interacciones célula-célula, modula la actividad de las glicoproteínas y otras proteínas de la superficie celular y actúa como receptor de proteínas unidoras de gangliósidos, patógenos y toxinas. Los gangliósidos se concentran en las terminaciones nerviosas de las células ganglionares (de ahí su nombre). Representan un $6 \%$ de los lípidos de la sustancia gris del cerebro humano. Por la voluminosidad de su cabeza, se orientan hacia la parte externa de la membrana actuando como receptores de membrana o generando sitios de unión célula-célula (gliosinapsis). Están implicados en las interacciones axónmielina, en la estabilidad y regeneración axonal y en la excitabilidad de las células nerviosas. Los gangliósidos forman parte de algunos dominios de membrana (ver sección 2.4.1) [154]. La secuenciación del genoma de Drosophila ha revelado secuencias similares a los genes implicados en la biosíntesis de sialoglicanos como la sialiltransferasa (DsiaT) que se expresa únicamente en un conjunto de neuronas diferenciadas del SNC involucradas en la unión neuromuscular y en el transporte de calcio, hechos que podrían indicar la función ancestral del ácido siálico específica del sistema nervioso [155].

- Los globósidos tienen, unidos a la ceramida, oligosacáridos neutros (no tienen carga a pH 7 ni grupos amino libres). Están implicados en procesos de reconocimiento en la superficie de membranas como la infección viral y en la iniciación y el mantenimiento del crecimiento de neuritas [156].

Una mención especial merece la unidad estructural de los esfingolípidos, la ceramida, por la importancia biológica que posee por sí misma. Es un lípido altamente hidrofóbico formado por dos ácidos grasos de longitud variable (2-28) y una esfingosina. Actúa como una molécula señalizadora de la vía de la esfingomielina implicada en la activación de proteínas quinasas, fosfatasas (SAPK, KSR (inhibidor de Ras), JNK, PKC, PP1 y PP2A). Modula muchos procesos celulares como la apoptosis, la proliferación, la diferenciación, y la detención de crecimiento. La ceramida se produce a través de dos vías: la síntesis de novo en el ER o la vía de la SMasa. Existe un equilibrio entre la ceramida y la esfingosina-1-fosfato de gran importancia para el control de la muerte y la supervivencia de la célula. La ceramida es el punto de decisión en la respuesta apoptótica. Cuando surge como resultado de la acción de la esfingomielinasa (SMasa) sobre la esfingomielina, actúa como segundo mensajero induciendo apoptosis. Si la ceramida es degradada por 
ceramidasas se obtiene esfingosina cuya fosforilación es necesaria para la proliferación y la mitosis celular [157].

* Los fosfoesfingolípidos o esfingomielinas son lípidos saponificables complejos que poseen un grupo fosfato y una esfingosina. Las esfingomielinas forman parte de las membranas plasmáticas, y de manera especial de las membranas del tejido adiposo y de la mielina que recubre los axones de las neuronas. Aunque comparten con la fosfatidilcolina la misma cabeza hidrofílica (fosforilcolina) y dos largas cadenas hidrocarbonadas, son químicamente muy diferentes ya que no derivan del glicerol. La esfingomielina se une a la cadena acilo por una amida, mientras que la fosfatidilcolina lo hace mediante un enlace éster haciendo a la primera más polar. Además la esfingomielina posee tanto grupos donadores como aceptores de enlaces de hidrógeno mientras que la fosfatidilcolina contiene únicamente grupos aceptores. Por último, la cadena acilo esterificada de las fosfatidilcolinas contiene de uno a seis dobles enlaces en configuración cis, mientras que las esfingomielinas biológicas tienen las dos cadenas saturadas y de diferente longitud (20-24 carbonos la unida por amida). Esta asimetría les proporciona una geometría que afecta a la curvatura de la membrana y la posibilidad de interdigitación entre las capas de la membrana. Todas estas características hacen a las uniones entre esfingomielinas más abundantes y estables, y resistentes a detergentes como el Triton X-100 (ver sección 2.4.3.). Esta estabilidad y su afinidad por el colesterol en la membrana hace a la esfingomielina un componente esencial de los dominios de membrana (balsas lipídicas) y, por consiguiente, un elemento regulador de los sistemas de señalización implicado en funciones como la migración celular, apoptosis, autofagia y supervivencia celular [158-161].

\section{LÍPIDOS INSAPONIFICABLES}

Los lípidos insaponificables no presentan ácidos grasos unidos a alcoholes y por tanto no se pueden hidrolizar por saponificación. Son los terpenos, esteroides y eicosanoides. Los esteroides derivan del esterano. Su estructura es rígida y plana. Un grupo hidroxilo en el carbono 3 define a los esteroles, de los cuales el más importante es el colesterol $\left(\mathrm{C}_{27} \mathrm{H}_{22} \mathrm{OH}\right)$. Los esteroles son, junto con los fosfolípidos y los esfingolípidos, componentes esenciales de las membranas, si bien la casi exclusividad del colesterol como único esterol de membrana contrasta con la variedad de lípidos de las otras familias. El colesterol no puede formar estructuras lamelares por sí mismo pero puede rellenar los espacios entre cadenas acilo gracias a su geometría plana. El grupo hidroxilo le permite formar enlaces de hidrógeno con otros lípidos. Se sintetiza en el retículo endoplásmico, pasa al Golgi donde se combina con esfingolípidos formando complejos que son transportados a la membrana plasmática. El colesterol de la membrana también es controlado por las lipoproteínas que lo aportan o retiran en función de la concentración requerida [162]. La interacción del colesterol con los fosfolípidos y los esfingolípidos de la membrana modifica su comportamiento (ver sección 2.4). El colesterol también puede afectar a las funciones de las proteínas, bien por interacción directa (caveolina) o bien a través de los cambios que provoca en las membranas. El colesterol es un componente esencial de los dominios de 
membrana y por tanto, de alguna manera, un regulador de toda la señalización que dichos dominios controlan. Por otro lado, el colesterol es el precursor de la síntesis de las hormonas esteroideas que modulan la transcripción de genes en el núcleo [158, 163].

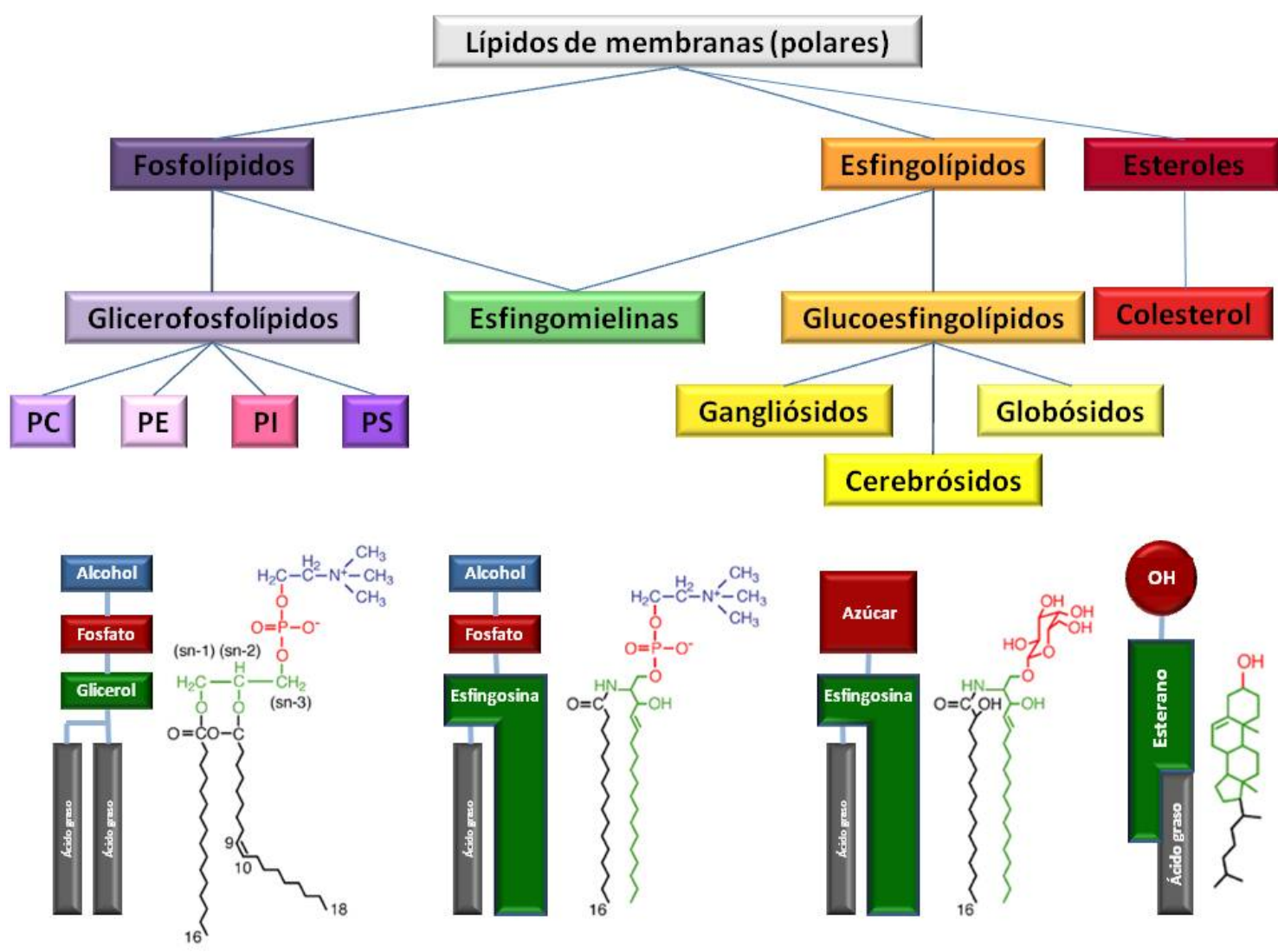

Figura 8. Esquema de los lípidos de membrana (Inspirado en[164][164])

\subsubsection{LÍPIDOS DE MEMBRANA EN DROSOPHILA}

Drosophila expresa la mayoría de las principales enzimas necesarias para la biosíntesis y procesamiento de los esfingolípidos incluyendo las involucradas en la síntesis y degradación de esfingosina y ceramida. La longitud de la base esfingoide de los esfingolípidos de Drosophila es mucho más corta (12 en lugar de los 16 de mamíferos) lo que les permite permanecer en fase líquida a la temperatura corporal de la mosca (25ㅇ) . A pesar de contener bajas concentraciones de esfingomielina (fosfocolina-ceramida), Drosophila expresa esfingomielinasintasas (SMSs) responsables de la síntesis de fosfoetanolamina-ceramidas (PEceramida) principal esfingolípido de la membrana de Drosophila [165]. Otra enzima que actúa sobre los esfingolípidos y presenta ortólogo en Drosophila es la proteína de transferencia de ceramida que transporta ceramida desde el retículo endoplásmico, donde se sintetiza, hasta el aparato de Golgi, donde se procesa, para dar glicoesfingolípidos y cuya mutación genera fenotipos de aumento de sensibilidad al estrés oxidativo y envejecimiento prematuro. Esto es debido a variaciones en la fluidez de la membrana provocadas por las propiedades gelificantes de la ceramida [166]. Los niveles de expresión de ceramidas y monohexosilceramidas aumentan drásticamente al final de la etapa embrionaria y en la fase de pupa temprana. Una 
de las primeras enzimas del metabolismo de esfingolípidos descritas en Drosophila, es la serina palmitoil transferasa (SPT) responsable de la etapa limitante de la biosíntesis de novo de los esfingolípidos. El bloqueo de la síntesis de esfingolípidos ha demostrado su implicación en la homeostasis energética, fototransducción, desarrollo del cerebro y comportamiento. Aún no se ha conseguido demostrar la relación que presentan los mamíferos entre la vía de los esfingolípidos y la de la insulina pero sí que se han encontrado cambios transcripcionales en genes del metabolismo de los esfingolípidos (como la esfingomielinasa ácida) tras una dieta alta en glucosa [165].

Los glicoesfingolípidos en Drosophila son ligeramente diferentes a los mamíferos (Man ${ }^{\beta 1}$ $4 \mathrm{GI}^{\beta 1}$-Cer [manósido] en vez de $\mathrm{Gal}^{\beta 1}-4 \mathrm{GI} \mathrm{c}^{\beta 1}$-Cer [galactósido]). Sin embargo, las moscas transgénicas para la enzima galactosiltransferasa humana que genera galactoesfingolípidos propios de mamíferos muestran un comportamiento normal. Existen 12 especies de glicoesfingolípidos que, al contrario que en mamíferos, no están sializadas aunque sí pueden ser muy largos llegando a contener hasta 10 residuos en una cadena lineal (GlcNAc, GalNAc, galactosa o ácido glucurónico terminal). Están implicados en procesos como la polaridad y la adhesión, relacionados con el receptor del factor de crecimiento epidérmico (EGF-R). Mutaciones en enzimas que catalizan la formación de glicoesfingolípidos complejos muestran deficiencias en la inervación neuromuscular y defectos de coordinación. Las concentraciones de glicoesfingolípidos se alteran drásticamente durante los cambios de estadios (embriónlarva-pupa-mosca adulta) [167].

Las moscas son auxótrofas para los esteroles, es decir, no sintetizan esteroles por sí mismas sino que extraen ergoesterol de la levadura. Las membranas de las moscas contienen menor proporción de esterol que las de mamíferos (18\% frente a $30 \%$ respectivamente). Sin embargo, células de Drosophila en cultivo pueden sobrevivir y dividirse después de la eliminación de esterol. Se ha propuesto que las fosfatidiletanolaminas puedan ejercer parte de las funciones que el colesterol realiza en las membranas de mamíferos [165].

Se han encontrado microdominios ricos en esfingolípidos y esteroles que contienen proteínas asociadas a las balsas propias de mamíferos (flotilinas, moléculas de adhesión celular [Fas/l y neuroglian]) en las membranas de varios tejidos de Drosophila [168-173]. Estos dominios de membrana presentan los mismos comportamientos que los dominios de mamíferos ante el tratamiento con detergentes o con compuestos que provocan la eliminación de esteroles como la metil- $\beta$-ciclodextrina $[165,174]$.

\subsubsection{FUNCIÓN DE LOS LÍPIDOS}

Los lípidos tienen fundamentalmente tres funciones biológicas:

-Actuar como almacenes de energía y como reservas de los componentes de las membranas gracias a su estado relativamente reducido.

-Constituir los componentes básicos de las biomembranas (carácter anfipático) convirtiéndose en las señas de identidad de cada tipo de membrana en cada una de sus circunstancias. 
- Y por último, actuar como segundos mensajeros (lípidos bioactivos) muchos de ellos degradándose, ante ciertas circunstancias, en varias moléculas, apolares y polares, capaces de difundir por la membrana o por el citosol respectivamente [175].

\section{LOS LÍPIDOS COMO UNIDADES ESTRUCTURALES DE LAS MEMBRANAS}

Los lípidos saponificables complejos, es decir, los fosfolípidos (fosfoglicéridos) y los esfingolípidos (esfingomielinas y glucoesfingolípidos) son también llamados lípidos de membrana ya que, junto con el colesterol, son los componentes principales de las membranas biológicas.

Aunque es posible formar con un único componente una membrana que actúe como una barrera física, las células invierten gran esfuerzo en la combinación de una gran variedad de grupos funcionales y de cadenas alifáticas que resultan en más de 1000 especies lipídicas diferentes presentes en cualquiera de las membranas de las células eucariotas [140, 176, 177]. Es más, la composición lipídica de las membranas es específica y característica de cada tipo celular, tejido, especie o tipo de membrana. Esto hace pensar en una gran especificidad y funcionalidad donde cada tipo de lípido podría tener un papel esencial en las funciones de las membranas. De hecho existe una correlación entre la complejidad funcional celular y su diversidad lipídica [178].

Los lípidos predominantes en las membranas eucariotas son los glicerofosfolípidos que, como se ha comentado con anterioridad, contienen diacilglicerol (DAG) y ácidos grasos insaturados de diferente longitud. El glicerofosfolípido más común es la PC que posee: una geometría cilíndrica que genera espontáneamente una bicapa plana, e insaturaciones en sus cadenas hidrocarbonadas que la hacen fluida a temperatura ambiente. Por el contrario, la PE presenta una geometría cónica que al insertarse entre las moléculas de fosfatidilcolina provoca cierta curvatura (ver sección 2.1.1.). Los otros glicerofosfolípidos como PS, PI, y ácido fosfatídico (PA), de función menos estructural, ayudan a acoplar proteínas de membrana y modular su actividad (Fig.9) [179].

La otra clase de lípidos que conforman la estructura de las membranas son los esfingolípidos, que poseen ceramida (Cer) como parte hidrofóbica y cadenas saturadas (o trans insaturadas). Su geometría también es cilíndrica pero, al no tener insaturaciones, consiguen un mejor empaquetamiento generando una estructura en estado de gel sólido. Los más comunes son la esfingomielina (SM) y los glucoesfingolípidos de entre los cuales cabe destacar los gangliósidos [157].

Por último, los esteroles, fundamentalmente el colesterol, se intercalan preferentemente entre los esfingolípidos. Se piensa que evolutivamente el colesterol entró a formar parte de las membranas mucho más tarde que el resto de componentes coincidiendo con un aumento en la cantidad de oxígeno propia de las células eucariotas, ya que uno de los pasos de su síntesis es dependiente de oxígeno [180]. El hecho de que para la síntesis de esta molécula, que en ciertas condiciones puede resultar tóxica, se necesiten unas 30 enzimas diferentes y se requiera un gran gasto energético indica una especial importancia biológica y por ello está 
altamente regulado [181]. En las membranas, su grupo hidroxilo polar se orienta hacia el medio acuoso, cerca de los grupos de las cabezas polares de los otros lípidos, y el anillo inmoviliza las cadenas hidrocarbonadas. El colesterol ejerce un efecto dual en función de la composición de la sección de membrana en donde se haya incrustado. En la fase líquido cristalina favorece el empaquetamiento entre cadenas hidrocarbonadas al restringir el movimiento de las cabezas polares. Por el contrario rompe las interacciones de las cadenas hidrocarbonadas al insertarse en zonas de la membrana en fase gel. De tal manera que, a concentraciones determinadas, mantiene la fluidez de la membrana en situaciones de un alto orden (fase líquido ordenada) formando dominios ordenados pero fluidos dentro de fases desordenadas (fases liquido desordenadas) (Fig.6) [182].

Se piensa que tanto los esfingolípidos como los esteroles, exclusivos de células eucariotas, podrían estar detrás de los procesos de tráfico de membranas, también inherentes a los eucariontes.

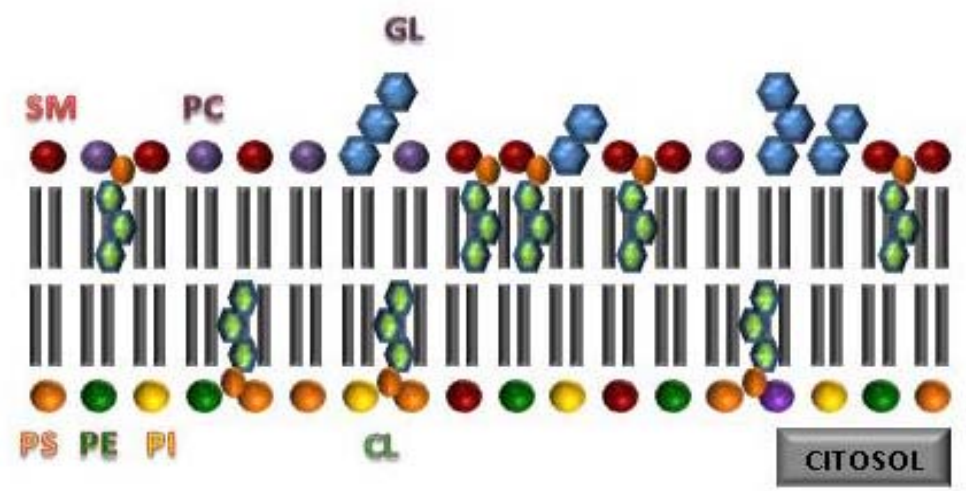

Figura 9. Esquema de la distribución de los lípidos de membrana en la bicapa lipídica. (Basado en [183])

\section{LOS LÍPIDOS COMO SEGUNDOS MENSAJEROS}

Existe una gran variedad de lípidos mediadores en la señalización y reconocimiento celular (procesos tanto intra- como intercelulares). Se liberan en respuesta a estímulos concretos y actúan a través de interacciones lípido-proteína específicas.

Ciertas situaciones inducen la hidrólisis de glicerolípidos y esfingolípidos, dando lugar a una serie de lisofosfolípidos, con función transmisora de información. La hidrólisis de los glicerolípidos por acción de las fosfolipasas (PLA) genera lisofosfatidilcolina (LPC), ácido lisofosfatídico (LPA), ácido fosfatídico o DAG. Los mensajeros hidrofóbicos permanecerán en la membrana mientras que los hidrofílicos se liberarán al citosol. Por ejemplo, la hidrólisis de fosfatidilinositol 4,5 bisfosfato $\left(\mathrm{PIP}_{2}\right)$ por la enzima unida a la membrana fosfolipasa $\mathrm{C}$ produce inositoltrifosfato $\left(\mathrm{IP}_{3}\right)$ que se libera al citosol donde estimula la liberación de $\mathrm{Ca}^{2+}$ del $\mathrm{RE}$ y diacilglicerol que permanece en la membrana desde donde activa a la proteínas quinasa $C$ (PKC) al facilitar su translocación del citosol a la membrana plasmática. Las diferentes fosfolipasas pueden eliminar uno (PLA1 y PLA2) o los dos ácidos grasos (PLB); o eliminar la cabeza polar con el fosfato (PLC); o el alcohol (PLD) [184-189]. El LPA inhibe la diferenciación a neuronas en favor de los oligodendrocitos [163]. El AA o el DHA liberados de los fosfolípidos de 
membrana por la PLA2 son importantes segundos mensajeros implicados en la neurotransmisión [190, 191].

A su vez, la hidrólisis de los esfingolípidos por esfingomielinasas resulta en esfingosilfosforilcolina (SPC), esfingosina (Sph), esfingosina-1-fosfato (S1P), ceramida-1-fosfato (C1P), y Cer, las cuales permanecen en la membrana ayudando a ciertas proteínas citosólicas a interaccionar con ella. Cuando aumenta la cantidad de ceramida, desplaza el colesterol ya que también tiende a interaccionar con lípidos saturados de cabeza grande, provocando la esterificación del colesterol [192].

Los derivados fosforilados de fosfatidilinosítidos también son importantes señales y componentes de membrana mediadores en la interacción entre la bicapa y algunas proteínas solubles (Fig.10) [193].

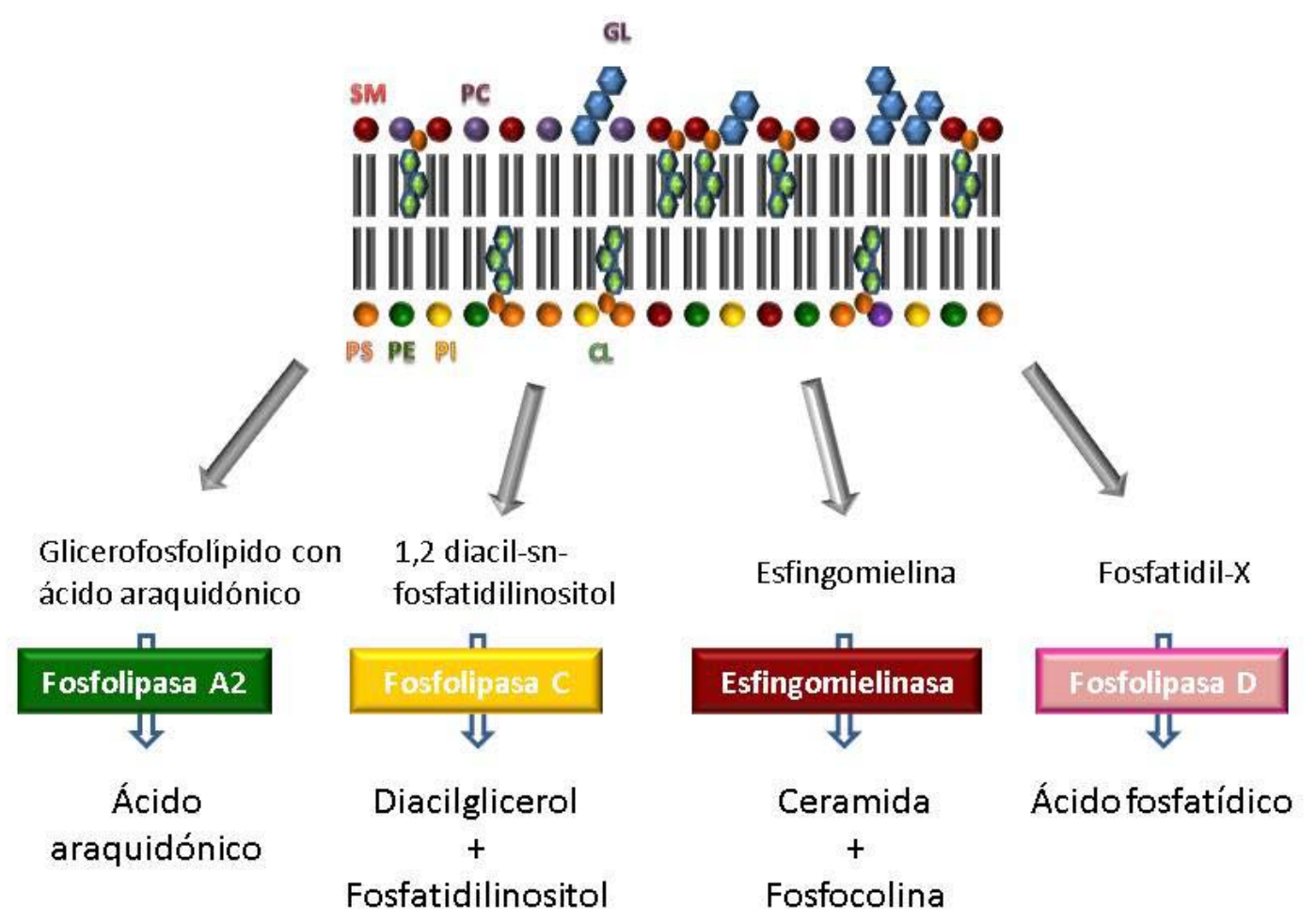

Figura 10. Los lípidos como segundos mensajeros (Inspirado en [194]).

\subsection{DOMINIOS DE MEMBRANA}

Como se ha comentado anteriormente, los lípidos han sido considerados durante años, meros componentes estructurales de membranas cuya única función era la de atrapar proteínas en la bicapa ("icebergs" flotando en un mar de lípidos). En los años posteriores a la aparición del modelo de mosaico fluido, muchos estudios sobre el tráfico de membranas sugerían la existencia de subdominios [195, 196]. Pero no fue hasta 1997 cuando Simons e Ikonen propusieron el modelo de balsas lipídicas ("Lipid Rafts Model") basado en la unión preferencial de ciertos esfingolípidos y colesterol [197]. Desde entonces, el concepto de balsa lipídica ha 
estado rodeado de polémica. Su pequeño tamaño, su naturaleza fuertemente dinámica y la falta de técnicas que permitan su observación directa en células vivas han dividido a la comunidad científica [198]. El continuo debate tanto sobre su existencia como sobre su naturaleza y funciones ha redefinido y renombrado estas estructuras en numerosas ocasiones. Balsas lipídicas, dominios de membrana (MD), microdominios, membranas resistentes a detergente (DRM), dominios ricos en glicolípidos insolubles en detergentes (DIGs), membranas enriquecidas en glicolípidos (GEMs), o complejos de baja densidad insolubles en detergente tipo Triton (LDTI) son algunos de los nombres que han recibido.

Originariamente, Simons and Ikonen definen las balsas lipídicas como estructuras dinámicas enriquecidas en colesterol y esfingolípidos en las que proteínas específicas interaccionan con la membrana. Estos autores otorgan a estas estructuras un importante papel en diferentes procesos celulares como el tráfico vesicular o la transmisión de señales [197, 199, 200].

Los experimentos y resultados obtenidos en los años sucesivos han completado y afinado esta definición.

\subsubsection{TIPOS DE DOMINIOS LIPÍDICOS}

En 2001 tuvo lugar en España la EURESCO Conference sobre "Microdominios, Balsas lipídicas y Caveolas" donde se expuso la existencia de diferentes clases de dominios específicos de tejido/célula. No solo se afirmó la existencia de dominios diferentes para cada tipo celular sino también diferentes tipos de dominio dentro de una misma célula [201, 202]. Aunque mayoritariamente se localizan en la membrana plasmática, también existen dominios en las membranas de otros subcompartimentos como el aparato de Golgi, o el núcleo [203]. Cada dominio estará definido por su composición lipídica y sus proteínas estructurales, lo que determinará su morfología y/o su función. 
La clasificación más amplia de los tipos de dominio implica dividirlos en dos grandes grupos: las balsas lipídicas (sin caveolina) y las caveolas. Cada tipo estaría implicado en la señalización de procesos diferentes. Por ejemplo, las balsas lipídicas están relacionadas con el receptor EGF, mientras que las caveolas controlarían el receptor de la insulina. Sin embargo, cuando ambas están en un mismo tipo celular, si se elimina uno de los dos tipos de balsas las proteínas específicas del tipo eliminado se reorganizan e integran en la balsa restante.

\section{Dominios ricos en caveolina}

Cuando las caveolinas se integran en una balsa lipídica, el dominio adquiere curvatura y se invagina formando las caveolas. Las caveolas tienen una composición lipídica muy específica, con alto contenido en esfingomielina, colesterol y GM1 [204, 205]. La expresión de caveolina está controlada por los niveles de colesterol, al que se une fuertemente con una estequiometría 1:1 [206, 207]. Las caveolinas participan en el tráfico vesicular y en procesos de transducción actuando como proteínas "andamio" que organizan y concentran moléculas señalizadoras como Src-quinasas, eNOS o proteínas G [208, 209]. La función de las caveolas más estudiada es su papel como plataforma para la acción de eNOS y la síntesis de NO como reguladores de la dilatación vascular. La unión de eNOS a las caveolinas inhibe su actividad. SOD1 también aparece mayoritariamente en los dominios de membrana ricos en caveolina a través de su dominio de unión a heparina (HBD) generando $\mathrm{H}_{2} \mathrm{O}_{2}$ extracelular que afecta tanto funciones celulares como la comunicación intercelular [210]. También desempeñan un papel importante en el transporte transmembrana (endocitosis o exocitosis). La endocitosis caveolar participa en la regulación de la composición lipídica de la membrana, en la señalización redox y en la vía inflamatoria asociada a ella dependiente de IL1ß [210]. La incorporación de las caveolinas a las balsas ocurre en el aparato de Golgi (donde también existen microdominios). Por lo tanto, las balsas serían los precursores de las caveolas al facilitar la inserción dependiente de colesterol de las caveolinas en las membranas. A pesar de que no existen caveolas en las neuronas, la eliminación genética de la caveolina sí que afecta a la proliferación de los progenitores neurales, lo que indica un papel de la proteína con independencia de la formación de caveolas o bien la existencia de caveolas en el SNC antes de la diferenciación neuronal [211].

\section{Dominios ricos en flotilina (non-caveolar)}

El otro importante tipo de dominio es el que contiene flotilina. Flotilina-1 y -2(FLot 1 FLot2), son dos proteínas unidas a la membrana por palmitoilación y miristoilación. Se encontraron durante la búsqueda de nuevos marcadores de dominios [212, 213]. Flotilina aparece en los axones, conos de crecimiento y filopodios de las neuronas [213]. También se encuentra en las membranas de los astrocitos y oligodendrocitos, fuera de las caveolas, y junto a las proteínas GPI y Thy-1 [170]. Por lo tanto, la flotilina sería un componente específico de un tipo de balsas de neuronas, células gliales y linfocitos T. Como ya se ha comentado, las balsas lipídicas 
controlan la señalización de los factores neurotróficos en el sistema nervioso, es decir, la actividad de muchos receptores de factores de crecimiento están regulados por estos dominios. Estos receptores se clasifican según sus diferentes comportamientos frente a las balsas: receptores componentes intrínsecos y constantes de las balsas, receptores con poca afinidad por las balsas que entran en ellos al unirse a un ligando, receptores que se inactivan con su salida de la balsa o receptores no afines a balsas pero que generan mensajeros que si lo son [214].

Las caveolas y las balsas lipídicas controlan diferentes vías de señalización incluso en el mismo tipo de células. Se cree que la formación de caveolas es constitutiva y presente incluso en condiciones de reposo mientras que las balsas lipídicas se forman en respuesta a diferentes estímulos, entre ellos, la liberación de ROS. Las balsas lipídicas podrían actuar como amplificadores de señales asegurando una transducción eficaz [210].

\section{Otras proteínas de las balsas}

Hasta el momento han sido detectadas 241 proteínas propias de las balsas lipídicas. Un número significativo de estas proteínas tienen funciones señalizadoras (quinasas y fosfatasas o subunidades G) confiriendo a las balsas un importante papel en la coordinación de la señalización [215]. Muchas de las proteínas de las balsas presentan modificaciones postranscripcionales que aumentan su afinidad por los esfingolípidos (GPI, palmitoilación, miristoilación). La mayoría de estas modificaciones son irreversibles, sin embargo, la Spalmitoilación (tioacilación), vía uniones tioester entre ácidos grasos saturados y residuos de cisteína, puede revertirse [216-218].

Las proteínas GPI son una de las familias de proteínas más importante en el campo de los dominios de membranas. Muchas de estas proteínas tienen función señalizadora que depende de su presencia en las balsas. Thy-1 y la proteína priónica (PrPc) son dos proteínas GPI presentes en las balsas de las membranas de neuronas $[219,220]$. Thy-1 es un versátil modulador de la señalización implicado procesos como el crecimiento de neuritas, apoptosis, adhesión celular, o regeneración axonal [221]. La proteína priónica PrPc está implicada en numerosas vías de señalización. Puede adquirir una conformación patológica $\left(\operatorname{PrP}^{\mathrm{Sc}}\right)$ causante de las enfermedades neurodegenerativas priónicas. La unión GPI y su localización en los dominios de membrana por su interacción a través de su dominio N-terminal con HSPGs (heparan sulfato proteoglicanos, glicoproteínas unidas a la membrana que actúan como moduladores de la señalización intercelular) juegan un papel importante en su patológica conversión conformacional, su neurotoxicidad y su propagación célula-célula [222, 223].

Se han descubierto otras proteínas también características de las balsas. En los eritrocitos humanos, la estomatina se encuentra en balsas diferentes a las de flotilina colocalizando con proteínas del citoesqueleto como espectrina y actina [224]. MAL/BENE es una proteína que se encuentra exclusivamente en las balsas de las células epiteliales lo que indica que podría mediar en el transporte apical. Cuando se produce la oxidación del colesterol de la membrana plasmática tanto BENE como caveolin-1 se van a los mismos compartimentos internos [225]. Por otro lado, la superfamilia de las dinaminas comparte la misma función moduladora de 
membrana y tubulación pero en diferentes compartimentos celulares. Son el primer nexo encontrado entre la maquinaria de endocitosis y las proteínas unidas a actina [226]. La sinapsis neuronal es un ejemplo de balsa rica en colesterol y en la proteína sinaptofisina pero con baja concentración de esfingolípidos [227].

Por lo tanto, las proteínas de membrana podrían clasificarse en función de su localización respecto a las balsas en: (1) Proteínas presentes en las balsas: como proteínas GPI, algunas proteínas transmembranas, las proteínas Hedgehog, proteínas doble-acetiladas como proteínas Src tirosina quinasas (nonreceptor tirosine kinase $\mathrm{Src}$ ), subunidades $\mathrm{G} \alpha$ de proteínas $\mathrm{G}$ y transportadores iónicos como el canal Kv2.1, canales de $\mathrm{Na}^{+}, \mathrm{Ca}^{2+}$ y Cl${ }^{-}, \mathrm{Kir} 2.1, \mathrm{HCN} 4$ o TRP [228]. (2) Proteínas presentes fuera de las balsas. (3) Proteínas que entran y salen de las balsas. Estas últimas presentan baja afinidad por las balsas, sin embargo, bajo ciertas condiciones forman complejos con otras proteínas que son transferidos a las balsas desde donde activan vías de señalización [210].

\section{CLASIFICACIÓN POR SUS LÍPIDOS CONSTITUYENTES}

Algunos tipos de dominios pueden definirse en función de su composición lipídica.

\section{Dominios ricos en ceramida}

Las ceramidas poseen propiedades químico-físicas equivalentes a las esfingomielinas, que les permiten interaccionar entre ellas de manera estable formando dominios. La ceramida se genera en las membranas biológicas por hidrólisis de esfingomielina catalizada por SMasa o de novo por acción de la ceramida sintasa. Ambos procesos están involucrados en la señalización celular. La esfingomielinasa ácida (ASMasa) es la principal enzima responsable de la formación de estos dominios. Pertenece a la familia de la PLC. Se libera al espacio extracelular hidrolizando de manera autocrina o paracrina la esfingomielina de la superficie celular. Puede incorporarse a las balsas lipídicas y generar plataformas enriquecidas en ceramida con función señalizadora redox. Cataliza la hidrólisis del enlace fosfodiester de la esfingomielina produciendo ceramida y fosfato de colina. Se encuentra en vesículas secretoras (lisosomas) que se fusionan con la membrana en respuesta a ciertos estímulos. La liberación de ROS es un prerrequisito para su activación. Un posible mecanismo sugiere que los ROS modificarían o eliminarían la cisteína libre C-terminal de la ASMase provocando su activación o inhibición (modelo similar al "interruptor de cisteína" propuesto para las metaloproteasas). La alteración funcional de los lisosomas bloquea la formación de dominios ricos en ceramida [210, 229]. 
El colesterol en estas balsas realiza las mismas funciones que en las balsas clásicas de esfingomielina, espaciando las cadenas hidrocarbonadas de las ceramidas mientras estabiliza la balsa en su conjunto. De hecho, la ASMase hidroliza esfingomielina liberando colina sin afectar la cadena unida a la ceramida por lo que su unión a colesterol se mantiene. La eliminación de colesterol conduce a una disociación de las proteínas de las balsas suprimiendo su funcionalidad [210].

\section{Dominios ricos en glucoesfingolípidos}

Los dominios enriquecidos en glucoesfingolípidos (GSL) se denominan GEMs (GSL-enriched microdomains) o glicosinapsis. Son importantes en procesos de adhesión celular y respuesta inmunológica [230]. También afectan a la diferenciación del SNC y modulan el receptor de factor de crecimiento y el receptor de la insulina. El globósido Gb5, gangliósido más simple, y su derivado GM1 son característicos de este tipo de dominios. Como ya se comentó, los gangliósidos son abundantes en muchos compartimentos subcelulares y regulan la activación de las proteínas presentes en las balsas de sus membranas. Existen dominios ricos en GM1en la membrana nuclear, donde se asocia con el intercambiador $\mathrm{Na}^{+} / \mathrm{Ca}^{2+}$ potenciando su capacidad para introducir $\mathrm{Ca}^{2+}$ en el núcleo (Tabla 2) [163]. Se han encontrado balsas lipídicas en membranas intracelulares del retículo endoplásmico, aparato de Golgi, endosomas, lisosomas e incluso, aunque de manera más controvertida, en mitocondrias. Los esfingolípidos y esteroles aumentan a lo largo de la ruta biosintética. En el aparato de Golgi desempeñan una importante función en la clasificación de moléculas. Las proteínas GPI se asocian a las membranas resistentes a detergente durante su paso por el aparato de Golgi. También existen proteínas GPI unidas a los dominios del ER: desequilibrios en los dominios de ER afectan al plegamiento de la proteína priónica causante de las enfermedades neurodegenerativas priónicas. Las balsas lipídicas en los endosomas y los lisosomas juegan papeles importantes en la formación, internalización y reciclaje endosomal. Las balsas aumentan en los lisosomas en los pacientes con enfermedades lisosomales. En las mitocondrias, ciertas señales de muerte activan movimientos intracelulares de componentes de las balsas lipídicas tales como gangliósidos que podrían determinar la supervivencia o muerte celular [210, 231-233]. 


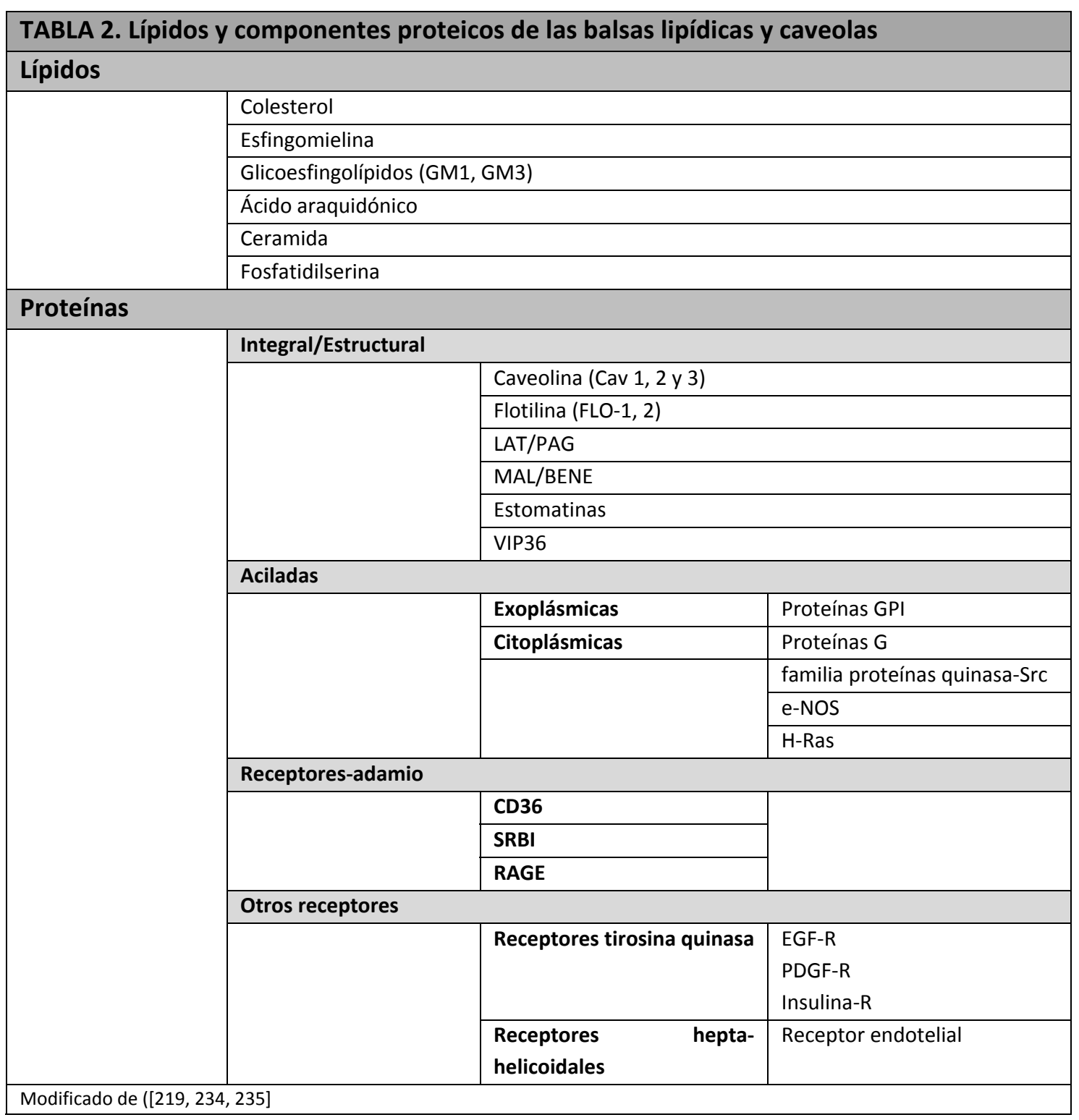

TABLA 2. Lípidos y proteínas componentes de las balsas lipídicas y caveolas

\subsubsection{LA POLÉMICA}

En los años posteriores a la presentación de las balsas, aparecieron dos corrientes enfrentadas sobre el papel de los lípidos en la formación de estos dominios [210]. Una de las corrientes defiende que los dominios se forman a partir de las interacciones proteína-proteína [236]. Las proteínas serían atrapadas por microdominios interconectados generados por interacciones proteína-proteína y probablemente estabilizados por proteínas andamio. La corriente contraria defiende la importancia de las interacciones lípido-lípido como germen de los subdominios, dentro de los cuales podrían acomodarse las proteínas a través de interacciones 
con los lípidos [237]. Finalmente aparece una corriente basada en "The Induced-Fit Model of Raft Heterogeneity" que acepta que la asociación de proteínas en las balsas puede afectar a su contenido lipídico y viceversa $[238,239]$. Es por esto que, en el simposio de Keystone "Lipid rafts and cell function"de 2006, las balsas lipídicas se rebautizaron como balsas de membrana ${ }^{19}$ (evitando así el protagonismo de los lípidos) [240]. Las balsas de membrana se definieron como: pequeños dominios, altamente dinámicos, ricos en esteroles y esfingolípidos que compartimentan los procesos celulares. Esta revisada definición también considera y agrupa las heterogeneidades de membrana que no corresponden con las características de las balsas como un tipo de dominio no-raft. Estas heterogeneidades poseen diferente composición, origen y funciones, como por ejemplo los microdominios del ER formados por fosfolípidos insaturados y colesterol. Una proteína unida a este tipo de dominio no-raft es la fosfolipasa A2 (PLA2) que, modulada por fosfolípidos de dominios no-raft, convierte el ácido araquidónico (poliinsaturado) en lípidos mediadores de inflamación (eicosanoides) [241].

Por último, se debe señalar que las balsas de membrana (raft) y los dominios no-raft podrían estar de alguna manera interconectados. Así, la formación de uno de ellos podría deberse a la exclusión de material (p. ej. colesterol) por parte del otro y, por lo tanto, el estudio y entendimiento de los dominios no-rafts podrían arrojar información sobre los dominios "rafts".

Con la aceptación de estos nuevos dominios se hace necesaria una estratificación de la información colocando por encima a los microdominios como definición general y a las balsas lipídicas o balsas de membrana como un tipo de microdominio. Contreras y sus colaboradores definen los microdominios como compartimentos de membrana de diferente composición que modulan las funciones enzimáticas de las proteínas de membrana. $Y$ a las balsas como los microdominios dependientes de esterol y esfingomielina que forman una red de interacciones lípido-lípido, lípido-proteína y proteína-proteína implicados en la compartimentalización de procesos en las membranas biológicas [242].

En esos años, y por si no era suficiente el caos provocado por la gran cantidad de nueva información y el cambiante debate sobre su denominación, la sección científica más crítica cuestiona la existencia de los dominios en su totalidad, considerándolos artefactos de las técnicas utilizadas, debido a la imposibilidad de estudiarlos en células vivas, o a la obtención de diferentes resultados según la técnica utilizada. Es por esto que en los últimos años se ha luchado por aportar, con las técnicas disponibles, el máximo número de evidencias de su existencia a la espera de una confirmación directa con las técnicas en desarrollo [243-245].

\subsubsection{TÉCNICAS DE ANÁLISIS.EVIDENCIAS DE SU EXISTENCIA}

En 1998 se observaron por primera vez, gracias a la microscopia electrónica, microdominios ricos en proteínas GPI. Desde entonces las proteínas GPI se han relacionado ampliamente con las balsas. Su estudio ha aportado mucha información sobre ellas [246, 247].

\footnotetext{
${ }^{19}$ Sin embargo, actualmente se utiliza indistintamente la denominación de balsas lipídicas, balsas de membrana o dominios de membrana según el criterio o interés del autor.
} 
Una de las primeras técnicas, ampliamente utilizada y a la vez controvertida, en el estudio de las balsas es el aislamiento de dominios de membrana con detergentes no iónicos. Esta técnica se aplicó en los años 70 al aislarse por primera vez unas regiones de membrana ricas en colesterol, esfingomielina y gangliósidos. La técnica se basa en la alta estabilidad de las interacciones que se forman entre el colesterol, la esfingomielina y los glucoesfingolípidos de la cara externa de las membranas, junto con las que se dan entre el colesterol y los fosfolípidos saturados de la cara interna. Como se comentó en secciones anteriores, la posibilidad de formar enlaces de hidrógeno y el carácter insaturado, longitud y asimetría de las cadenas de esfingomielina permiten la formación de fases líquido-ordenadas (ver Fig.6) y una interdigitación entre las cadenas de ambas capas que las conecta y estabiliza aun más. En consecuencia, esta región se hace resistente a su disolución por ciertos detergentes no iónicos y le confiere una característica flotabilidad ante gradientes de densidad (Fig.11) [248].

El escepticismo ante esta técnica se debe a que la resistencia a la disolución es dependiente del tipo de detergente y de la temperatura, obteniéndose diferentes resultados según las características del detergente y la temperatura utilizadas en la extracción [249]. En algunas ocasiones se han obtenido mezclas de resultados propios de regiones solubles e insolubles a detergentes. Esta variabilidad de resultados podría deberse a la disolución específica de diferentes tipos de balsas, o mezclas de ellas por parte de cada detergente y a la necesidad de condiciones muy específicas y controladas para que la extracción sea correcta. Otra teoría sugiere que las balsas no están estrictamente definidas en sus bordes [250], sino que existe cierto gradiente no tan resistente al detergente, de tal manera que las proteínas que se encuentran en esta zona no serán igualmente extraídas. Por otro lado, se ha acusado al propio detergente de ser el generador de dominios artefactuales no existentes en la realidad biológica. La confirmación de los resultados obtenidos por esta técnica con los obtenidos por otras (extracción de regiones insolubles en modelos de membranas sintéticas de lípidos puros, o el estudio de proteínas GPI) y la repetitividad obtenida bajo condiciones estrictas de concentración de detergente y temperatura [239, 251-253] han hecho que la extracción con detergentes sea una técnica actualmente aceptada y ampliamente utilizada, aunque siempre con la precaución de denominar a los dominios en función de las condiciones de su aislamiento, es decir, membranas resistentes a detergentes o DRM [254].

La extracción con detergentes ha permitido el análisis de los lípidos y proteínas asociados a las balsas. Sin embargo, no permite conocer ni el tamaño, ni la localización, ni la cantidad de dominios [255].

El detergente tradicionalmente utilizado es el Triton X-100 a 4으, aunque en los últimos años se ha ampliado la lista de detergentes capaces de extraer balsas lipídicas (Triton X-114, CHAPS, Lubrol WX, Brij96, and Brij98) [256, 257]. La diferente solubilidad de las membranas ha subclasificado a los dominios en base al detergente que permite su extracción. En la mayoría de los casos la extracción se hace a $4 \stackrel{\circ}{ } \mathrm{C}$, excepto en el caso del Brij98, que debido a su alto 
punto de turbidez ${ }^{20}$ se puede utilizar a 370 C. Esto confirma la existencia de dominios a la temperatura a la que se encuentran realmente las membranas en la célula [249].

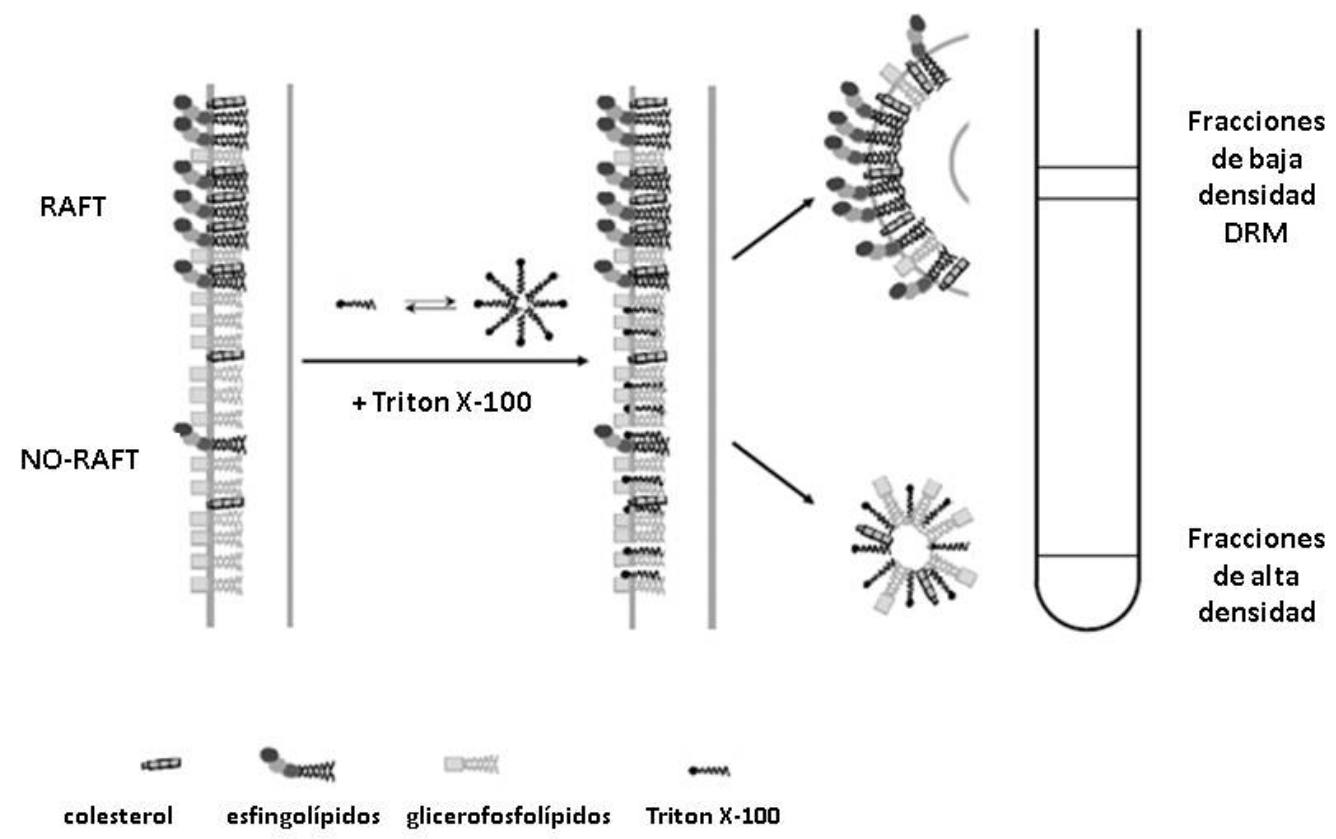

Figura 11.Dominios de membrana resistentes a la disolución por detergente.

Esquema de la preparación de dominios de membranas resistentes a detergente. El detergerte en agua, a una determinada concentración (concentración micelar crítica), forma pequeñas micelas. Los monómeros de detergente en solución penetran en las regiones de la membrana de fase fluida y las disuelven formando pequeñas micelas mixtas ricas en detergente y proteínas, dejando inalterada la bicapa de las regiones menos fluidas ricas en esfingolípidos y colesterol. Esta diferente composición permite separar ambas secciones según su densidad por centrifugación en gradiente [258].

Desde un punto de vista constructivo, la diferencia en los resultados obtenidos con los diferentes detergentes podría ser una gran fuente de información además de una herramienta de mayor especificidad para el aislamiento y estudio de los diferentes dominios de membrana. S. Schuck y sus cols. analizaron la composición lipídica de los dominios aislados con los diferentes detergentes [259]. Este estudio reveló que los dominios insolubles en Triton X-100 están enriquecidos en esfingolípidos y colesterol respecto a la cantidad de glicerofosfolípidos (coincidiendo con la definición tradicional de balsa). Por el contrario, los dominios extraídos por Brij 98 tienen un enriquecimiento menor en estos componentes, mientras que los extraídos con Lubrol son de composición similar al resto de la membrana. Sin embargo, otro estudio similar independiente muestra un enriquecimiento en fosfatidilcolina insaturada de los dominios extraídos con este último detergente por lo que el Lubrol podría estar aislando algún tipo de dominio no-raft [260].

\footnotetext{
${ }^{20}$ El punto de turbidez(cloud point) es la temperatura a la cual una solución de detergente cerca de su concentración micelar crítica se separa en dos fases cuando sus cabezas polares excluyen las moléculas de agua que lo mantienen en disolución.
} 
Existen otros métodos de extracción de dominios en los que se sustituye el detergente como agente solubilizador por sonicación o cambios de $\mathrm{pH}$, a los que también son resistentes algunos tipos de dominios [219, 261]. Sin embargo, estas técnicas alternativas no son adecuadas para todos los tipos de tejidos. La sonicación, por ejemplo, no está recomendada para aislar dominios en el cerebro por la gran cantidad de fracciones de membrana de baja densidad como la mielina o las vesículas sinápticas [262].

Otra técnica utilizada para la confirmación de la existencia de las balsas y su función, es el estudio de la respuesta celular que provoca la ruptura de las balsas al utilizar diferentes compuestos como: metil- $\beta$-ciclodextrina $(\mathrm{M} \beta \mathrm{CD}$ ), filipina III, colesterol oxidasa (CHOX) y mevastatina. La alta afinidad de unión de $M \beta C D$ al colesterol induce la salida del lípido de la membrana plasmática destruyendo la estructura de las balsas [263, 264]. La filipina III forma complejos con colesterol en las membranas, con similares consecuencias [264]. A su vez, la mevastatina es una reductasa que interfiere en la síntesis de colesterol [264, 265]. La ruptura de las balsas lipídicas con estos reactivos tiene efectos pro- y anti-apoptóticos (según los factores pro- o anti-apoptóticos presentes en las balsas) indicando que una función de control de la homeostasis celular es importante y exclusivamente debida a la estabilidad y ruptura de las balsas, independientemente del tratamiento utilizado para ello [265-268].

Por otro lado, ante la imposibilidad de visualizar directamente los dominios en las membranas de las células vivas dado su reducido tamaño y dinamismo, se ha recurrido a técnicas alternativas que aportan información parcial sobre las balsas. Para estudiar las interacciones lípido-lípido en las balsas se han utilizando simulaciones de dinámica molecular [269-275] y membranas artificiales, formadas por un número controlado de especies lipídicas [158, 276, 277]. Gracias a estos estudios se ha confirmado y caracterizado la existencia de interacciones específicas entre varias clases de lípidos y especies moleculares, que apoyan la teoría de regiones de membrana de específica composición y fase. En estos modelos de membrana, la esfingomielina y el colesterol son componentes críticos para la formación de fases líquidas ordenadas (Lo). Sin embargo, estos estudios resultan demasiado simplistas para zanjar definitivamente el debate sobre la existencia biológica de las balsas, al no considerar el resto de especies lipídicas ni las proteínas presentes en las membranas.

Varias son también las técnicas y métodos utilizados para el estudio de las interacciones lípidoproteína de las balsas como la cristalografía de rayos $\mathrm{X}$, cristalización electrónica, espectroscopía NMR, microscopía de fuerza atómica (AFM) espectroscopía de IR (Fourier Transform-Infrared spectroscopy), resonancia de spin electrónico (ESR), escáner calorimétrico diferencial, simuladores de dinámica moleculares, o transferencia de energía de resonancia de Förster (FRET) [278-281]. Con estas técnicas se ha caracterizado la estructura de las proteínas, su entorno lipídico, las configuraciones de las cadenas acilo, el número de uniones a lípidos (tiempo de residencia), la fuerza de las interacciones, su dinamismo, etc.

En los últimos años se ha utilizado el marcaje de lípidos con especies fluorescentes (como la toxina colérica que se une al gangliósido GM1), fotoactivables (microscopía de localización por fotoactivación fluorescente (FPALM)) o radiactivas junto a las más avanzadas técnicas en microscopía(microscopía de doble fotón) para estimar el tamaño de los dominios (de 50 a 200 
nm de diámetro), la cantidad de proteínas que puede contener (entre 10 y 30 proteínas) [282] el porcentaje en el que se encuentran frente a la totalidad de la membrana [283] o las regiones más enriquecidas en balsas lipídicas (tales como la membrana de los filopodios de los macrófagos, los puntos de adhesión celular o de contacto célula-célula).

El desarrollo de nuevas tecnologías tanto en microscopía como en espectroscopía ${ }^{21}$ está aportando cada vez más resultados que permiten confirmar la existencia de las balsas en células vivas [284]. En los últimos años se han desarrollado técnicas para el análisis cualitativo y cuantitativo de lípidos $[176,285]$ como la espectrometría de masas cuyos resultados resultan esenciales para la completa caracterización y entendimiento de estas controvertidas estructuras (Fig. 12).

Sin embargo, el mayor obstáculo continúa siendo la falta de herramientas (biológicas y moleculares) que confirmen las interacciones a nivel específico de especies moleculares lipídicas. Tampoco existen métodos equivalentes a la generación de mutantes nulos, o a la introducción de mutaciones para manipular las especies lipídicas de forma individual en células vivas. Extrapolando la velocidad de crecimiento de este campo de la biología en los últimos años, es lógico pensar en una pronta aparición de estas técnicas y por consiguiente la aparición de un nuevo y muy amplio campo de estudio.

\footnotetext{
${ }^{21}$ scanning probe microscopy (SPM), atomic force microscopy, single-particle tracking (SPT), fluorescence correlation spectroscopy (FCS), fluorescence resonance energy transfer (FRET), and fluorescence photoactivation localization microscopy (FPALM)
} 


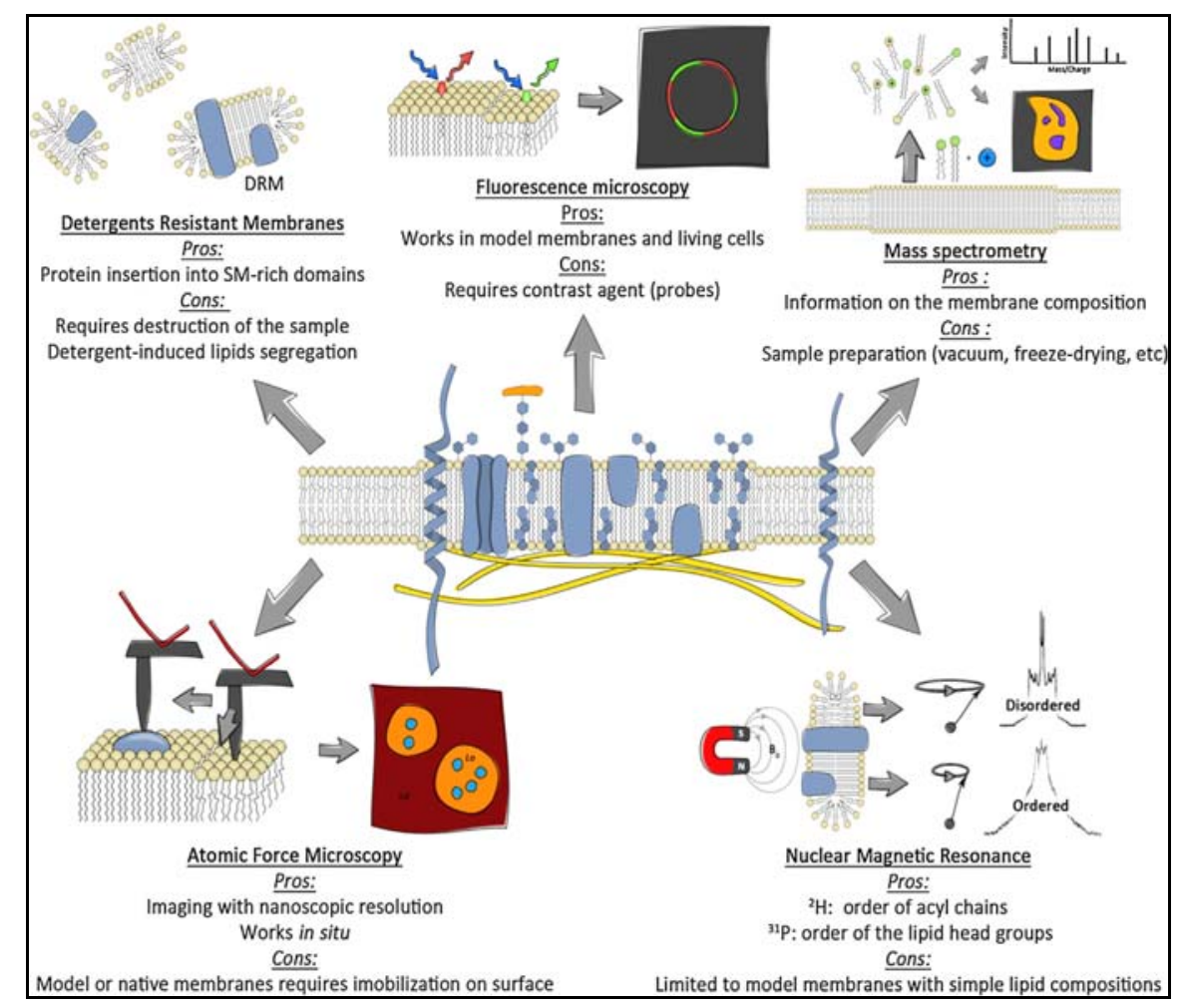

Figura 12. Ventajas e inconvenientes de los métodos más comunes para la caracterización de las balsas lipídicas: membranas resistentes a detergente, microscopía de fluorescencia, espectrometría de masas, microscopía de fuerza atómica y resonancia magnética nuclear [286].

\subsubsection{FUNCIÓN}

Se han sugerido múltiples funciones de los dominios de membrana, especialmente la generación y mantenimiento de la polaridad, el tráfico de membranas y la transmisión de señales $[287,288]$.

\section{POLARIDAD CELULAR}

En lo que respecta al control de la polaridad de las membranas, los dominios mantienen un orden y un transporte de lípidos y proteínas hacia y por las membranas. Esta polaridad es muy importante en las neuronas, las células epiteliales y los neutrófilos. En las neuronas generan diferentes áreas donde se agrupan, por un lado, las proteínas encargadas de la exocitosis de neurotransmisores y por otro, los receptores. Además controlan la plasticidad sináptica al estabilizar los puntos de contacto entre las neuronas y sus dianas. Igualmente controlan la polaridad de las células epiteliales dirigiendo las diferentes trayectorias de los productos que salen del Golgi [289]. En los neutrófilos, controlan su polarización durante la migración. En ellos, la región delantera de la membrana (insoluble en Triton X100) es una gran balsa lipídica que contiene CD44, a través del cual se une a la F-actina del citoesqueleto estimulando la polimerización necesaria para la extensión de lamelas [290]. 


\section{TRÁFICO DE MEMBRANAS}

En cuanto al tráfico de membranas, muchos agentes patogénicos como bacterias y virus utilizan las balsas para su internalización en la célula. Esto sugiere un papel importante en las vías de endocitosis [291]. También intervienen en el procesado y clasificación de endosomas [292] y en la fusión vesicular.

\section{TRANSMISIÓN DE SEÑALES}

Son muchas las vías de transmisión de señales en las que las balsas lipídicas están involucradas y muchos los procesos que modulan.

En general, las balsas agrupan y/o separan diferentes proteínas señalizadoras o componentes de la maquinaria de activación de muchos procesos, favoreciendo o impidiendo su interacción, coordinando su organización espacio-temporal, generando complejos activos ("signalosomas") y, por tanto, controlando la activación o inactivación de la vía que ponen en marcha [293].

Son importantes para la señalización de factores de crecimiento, la adhesión celular, la guía de axones, el tráfico de vesículas o la función neuronal en general. Su presencia tanto en neuronas como en glía es crítica para el normal funcionamiento del cerebro, uno de los órganos con mayor componente lipídico [294-296]. Controlan el proceso de apoptosis, la activación de muchas quinasas, como SRC, JNK... [297], y forman plataformas de señalización redox que favorecen la unión de las subunidades NADPH oxidasa y su activación [210]. Conectan a las células con el metabolismo de las lipoproteínas, promueven una fusión eficiente entre membranas [298] y conectan la membrana al citoesqueleto. Modifican la conformación de algunas proteínas controlando así su función. Controlan la neurotransmisión (al contener receptores y transportadores de neurotransmisores) y la posterior señalización a través de receptores acoplados a proteínas G [299]. También intervienen en la señalización en células hematopoiéticas, especialmente en linfocitos y mastocitos, y regulan la proteólisis intramembranal de proteínas transmembrana (precursor $\beta$ amiloide ErbB4, Delta1, Jagged2, cáncer colorectal, p75 neurotrofin receptor) [300, 301].

Una teoría emergente sugiere que la formación o estabilización de las balsas ocurre en respuesta a una estimulación; las balsas actuarían entonces como un gran receptor. Las balsas en condiciones basales (células no estimuladas), si existieran, serían muy pequeñas (nanoescala). La aparición, en respuesta a un estímulo, de receptores de superficie y otras moléculas con gran afinidad a las balsas incrementarían el tamaño y la estabilidad de estas balsas o incluso las generarían [302]. Según esta teoría, la membrana en situación basal poseería una composición muy cercana a la necesaria para que se diera una separación de fases, pero sin llegar a producirse hasta la aparición de algún estímulo. Esta situación límite otorgaría a la membrana una alta sensibilidad y velocidad de respuesta dado que pequeñas variaciones (en proteínas o lípidos) conllevarían grandes efectos en la organización de dominios [254].

Sea como fuere, la participación de las balsas lipídicas en tan variados e importantes procesos requiere de una estricta regulación, una alta especificidad y una gran sensibilidad, convirtiéndoles en uno de los más apasionantes procesos de la homeostasis celular. 


\section{LA AUTOFAGIA}

\subsection{DEFINICIÓN. TIPOS}

La autofagia es un proceso altamente regulado por el entorno celular, que controla el reciclado de proteínas y organelas a través de su degradación en el lisosoma, manteniendo así la homeostasis celular [303]. Junto al proteasoma son los dos grandes sistemas de degradación macromolecular. El proteasoma es responsable de la degradación de proteínas marcadas con ubiquitina tanto en el citosol como en el núcleo. Sin embargo su capacidad degradativa es limitada debido a sus características estructurales. La autofagia, por el contrario, permite la degradación de grandes componentes celulares incluyendo organelas completas. El material deteriorado, sobrante o potencialmente reciclable se aísla en vesículas de doble membrana (autofagosomas) de unos 300 a $900 \mathrm{~nm}$ de diámetro que se fusionan con los lisosomas (autofagolisosoma) donde será degradado y reciclado. La autofagia ocurre en todas las células eucariotas y forma parte de sus procesos naturales como un sistema de control. Sin embargo, también se activa en respuesta a ciertas situaciones de estrés. La autofagia participa en el metabolismo energético, contribuye a la degradación de las proteínas de larga vida y al reciclado de organelas [304]. Esto le convierte en un sistema de supervivencia en caso de falta de nutrientes. También participa en la regulación del crecimiento y desarrollo embrionario, por lo que los desajustes en su funcionamiento y regulación tendrían consecuencias perjudiciales como la muerte celular, crecimiento desmesurado (cáncer), envejecimiento prematuro, etc. La autofagia ha sido objeto de estudio desde 1960, siendo los trabajos con levaduras los que han aportado mayor cantidad de información molecular sobre el proceso. A partir de su implicación en el desarrollo embrionario ha pasado de ser un mero proceso degradativo a convertirse en un campo de gran interés y evolución. Drosophila melanogaster también ha resultado ser una eficiente herramienta en el estudio de la autofagia dada la alta conservación de los genes involucrados [305]. Inicialmente los estudios se centraron en los primeros estadios de la autofagia desentrañando los mecanismos moleculares implicados en la formación del autofagosoma. Sin embargo, actualmente son los pasos finales y en concreto el papel de los lisosomas, como última estación del proceso autofágico, los que focalizan la atención científica [306]. La autofagia se ve alterada en muchas enfermedades neurodegenerativas y en el envejecimiento además de jugar un importante papel en la muerte celular programada siendo, en muchos casos, esencial para una eficiente apoptosis [307].

Según la vía de llegada del material a degradar al lisosoma se han definido varios tipos de autofagia (Fig.13).

En la microautofagia la membrana del lisosoma rodea al material citoplasmático formando pequeñas invaginaciones que se internalizaran en el lumen del lisosoma, donde será degradado [308].

En la autofagia mediada por chaperonas (CMA: Chaperone Mediated Autofagy) las proteínas citosólicas a digerir entran en el lisosoma a través de un transportador de membrana, LAMP2, tras ser reconocidas y desplegadas por un complejo de chaperonas citosólicas que reconocen el motivo KFERQ. Este tipo de autofagia es altamente selectiva [309]. 
En la macroautofagia el material citoplasmático a degradar se envuelve con una doble membrana formándose un compartimento denominado autofagosoma. Posteriormente se fusionará con un lisosoma donde el material será degradado, junto con la membrana interna del autofagosoma. El autofagosoma también podría fusionarse con un endosoma, cargado de material extracelular, formándose un anfisoma que igualmente terminará fusionándose con el lisosoma. La formación del autofagosoma se induce por la conjugación de la fosfoinositol 3-quinasa (PI3K) y el gen beclina-1. La macroautofagia en respuesta a un daño puede inducirse por varias vías. Sin embargo, el paso común es la conjugación covalente de Atg8 (LC3-I) a una fosfatidiletanolamina que lo anclará a la membrana en formación. La macroautofagia (o simplemente autofagia) está implicada en la degradación de sustratos tanto de forma selectiva como no selectiva [304, 310, 311].

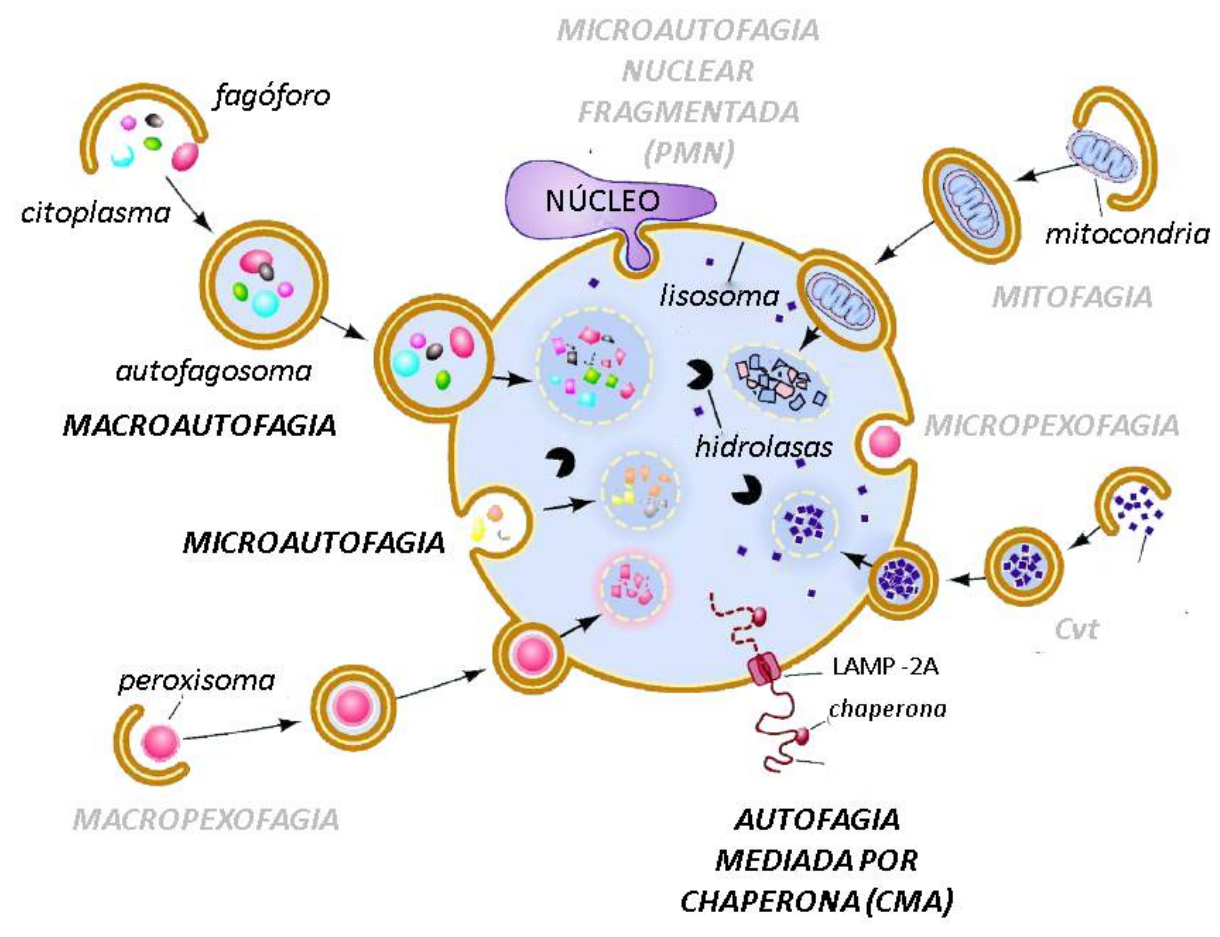

Figura 13. Tipos de autofagia. Diferentes tipos de autofagia y otros procesos de degradación [312].

Este último tipo de autofagia ha sido objeto de estudio en este trabajo.

\subsection{MACROAUTOFAGIA}

La macroautofagia es un complejo proceso altamente regulado en el que intervienen una gran variedad de participantes (más de 30 proteínas), entre ellos, la familia de las autofaginas (Atg 1-16). Estas proteínas forman diferentes complejos que controlaran las etapas de la macroautofagia: Inducción, nucleación, elongación de membrana, reconocimiento de carga y fusión con el lisosoma (Fig. 14). 


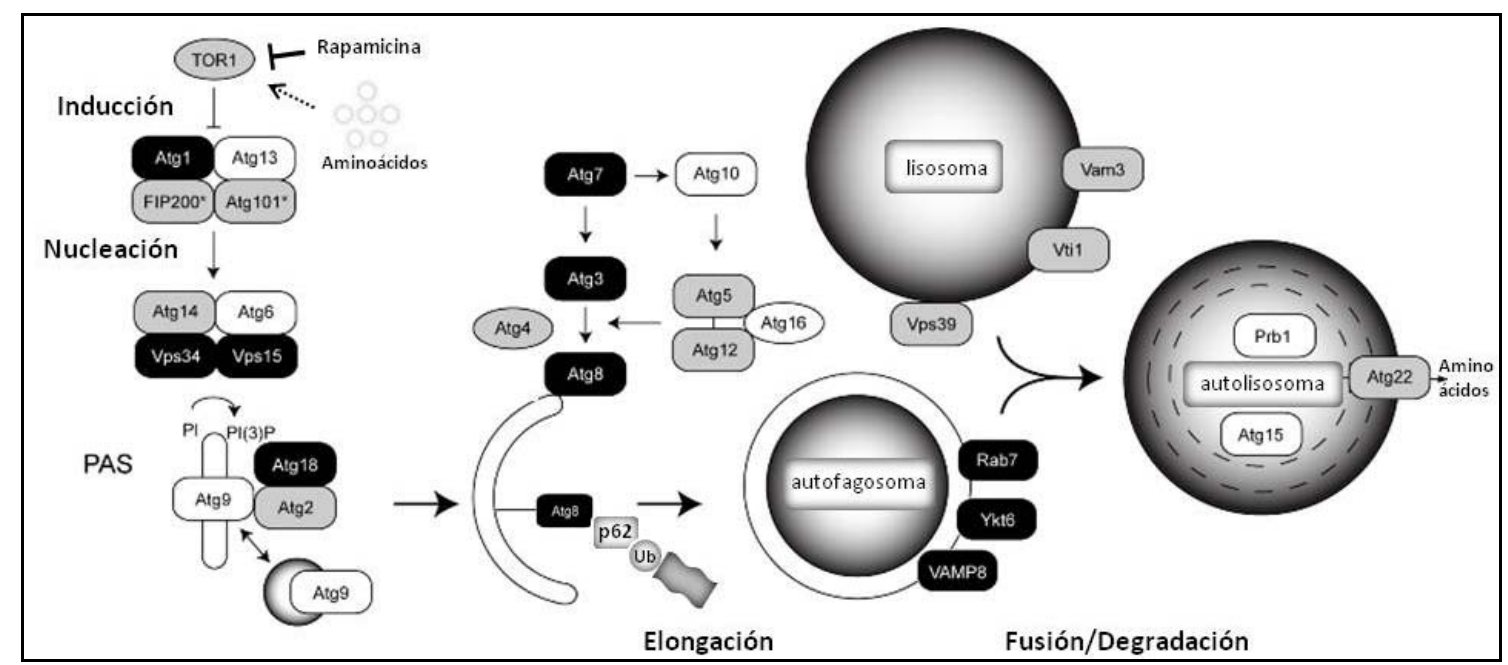

Figura14. Proceso de la macroautofagia. (Modificado de [313])

\subsubsection{PROCESO}

La macroautofagia comienza con la liberación de beclina-1 (Atg6) del complejo que forma con Beclina-2. Posteriormente Beclina-1 se unirá a un grupo de proteínas (complejo PI3kIII) para formar una estructura pre-autofagosómica (PAS) que se dirigirá hacia el lugar de formación de la membrana (nucleación) [314-316].

El origen de la membrana que secuestra los sustratos a degradar es uno de los puntos controvertidos del proceso de autofagia que aún debe ser estudiado en profundidad [317]. Una posibilidad sería su formación de novo. Otra posibilidad es que fuera una modificación de una estructura preexistente procedente de la membrana plasmática [318], del ER o del Golgi [319]. O incluso que fuera una región de la membrana mitocondrial en condiciones de ayuno [320] o una sección del RER libre de ribosomas [321]. Esta variabilidad podría indicar un origen dependiente del estado de la célula, de las condiciones que inicien la autofagia e incluso del tipo celular.

La formación de la membrana autofágica y su elongación requieren dos eventos en paralelo:

a) La conjugación de Atg5 y Atg12, (similar a la conjugación entre ubiquitinas) que involucra ligasas para la activación y conjugación enzimática de sustratos [322, 323]. El complejo Atg5-Atg12 es crítico para el otro evento necesario.

b) La lipidación de la proteína citosólica Atg8 (LC3-I, Microtubule-assoiated protein 1A/1Blight chain 3)con una PE para formar Atg8-PE (LC3-II) [322, 324, 325]. Esta conjugación covalente con un lípido permite a Atg8 unirse a la membrana del futuro autofagosoma regulando su crecimiento y tamaño [326]. La lipidación de Atg8 es un proceso dependiente de la curvatura de la membrana [327]. Atg8 permanecerá unido al autofagosoma hasta su degradación, por lo que se utiliza como el marcador por excelencia de activación de la autofagia [328].

Se formará, entonces, una cisterna membranosa llamada fagóforo, al que se unirá el material a degradar (marcado con ubiquitina) reclutado y dirigido por la proteína p62 a través de su unión a Atg8-PE. Este fagóforo crecerá en longitud hasta cerrarse por sus extremos generando el 
autofagosoma. El proceso de sellado dependerá de otras proteínas Atg, de proteínas SNARE y Rab. p62 será atrapado dentro del autofagosoma donde se degradará. Es por ello que la monitorización de los niveles de esta proteína permite estudiar el desarrollo de los pasos finales del proceso de degradación [329].

Inicialmente se pensó en la autofagia como un mecanismo de degradación poco o nada específico. Sin embargo, los constantes avances en este campo indican un alto grado de selectividad. Se considera la existencia de una autofagia no selectiva activada en situación de hambruna que ayudaría a la célula a sobrevivir temporalmente proporcionando energía por la degradación de parte del citosol. Por el contrario, la autofagia selectiva (o específica de sustrato) sería el mayor sistema de control de calidad de la célula. La autofagia específica de sustrato es un importante mecanismo de eliminación de agregados proteicos y organelas dañadas, productos de muchas enfermedades. Está mediada por el marcaje con ubiquitina del sustrato a degradar. El material marcado será reconocido por adaptadores proteicos que contienen un dominio de reconocimiento y unión a Atg8que lo dirigirán hacia el autofagosoma. p62 (también llamado Sequestosome1, SQSTM1), NBR1, NDP52, Nix, optineurin y Stbd1 son los seis receptores encontrados en mamíferos hasta el momento de los cuales únicamente se ha encontrado homólogo en Drosophila para p62 [305]. p62 se une a la proteína Atg8 que se encuentra en el autofagosoma en formación conectando el sustrato específico a degradar con la vía de la autofagia [330]. La acumulación de proteínas ubiquitinadas por deficiencias del proteasoma provoca la agregación de proteínas aberrantes junto a proteínas de unión a ubiquitinas como p62. Esta acumulación de p62 promueve un incremento de la síntesis de dicha proteínas a través de la modulación de factores de transcripción como NRF2. p62 se degrada mediante la autofagia selectiva. El bloqueo del flujo de la autofagia conlleva una acumulación de p62. La inhibición de la autofagia también causa la acumulación de proteínas ubiquitinadas. Por tanto, se considera a p62 como un nexo entre la proteólisis mediada por proteasoma y la autofagia [331]. Los niveles de p62 retroalimentan inversamente la autofagia. Bajas cantidades de p62 incrementan la autofagia, lo que reduciría aún más la expresión de p62 manteniendo una activación constante (autofagia basal) [332]. Altas concentraciones de p62 reducen la autofagia, lo que provoca un incremento de su expresión [333]. A su vez, tanto la disminución como la acumulación de p62 dificultan la degradación de sustratos por el proteasoma. Niveles elevados de p62 bloquean el proteasoma redirigiendo la carga hacia los lisosomas. De la misma manera, grandes acúmulos de proteínas defectuosas también podrían impedir la correcta actividad del proteasoma. Por lo tanto, p62 promueve la autofagia selectiva de proteínas, agregados proteicos, organelas y bacterias (Fig. 15) [334-336]. Las células con autofagia deficiente presentan inclusiones que son positivas para ubiquitina y p62 [337, 338]. Este tipo de autofagia juega un importante papel en las enfermedades neurodegenerativas, cáncer y otras patologías asociadas a la edad [336, 339344]. 


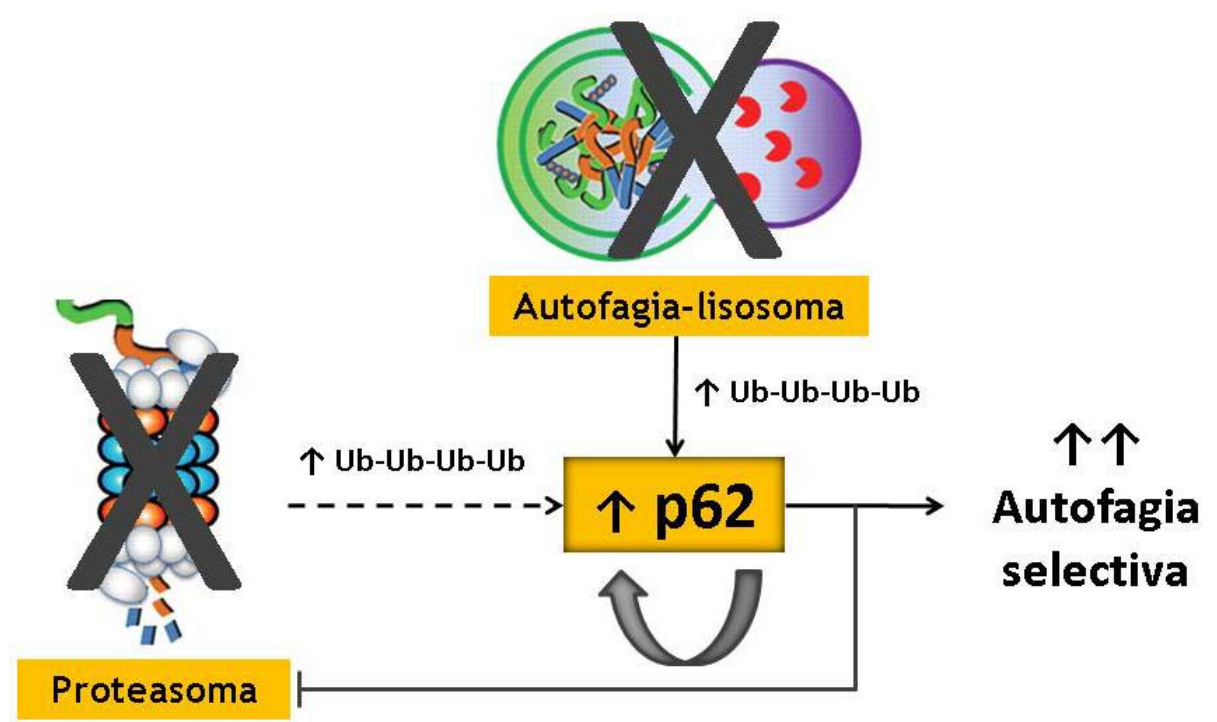

\begin{abstract}
Figura 15. Relación entre la proteólisis mediada por el proteasoma y la autofagia a través de la proteína $\mathbf{p} 62$.

El bloqueo del proteasoma provoca la acumulación de conjugados ubiquitinados que retienen la proteína p62. El aumento de los niveles de p62 activa la síntesis de nuevo p62. P62 conduce los agregados proteicos ubiquitinados a los autofagosomas incrementando la autofagia selectiva. De la misma manera la inhibición o el bloqueo de la autofagia provocan la acumulación de p62, sustrato de dicho proceso. La acumulación de p62 puede favorecer su unión a proteínas ubiquitinadas cuyo destino habría sido la degradación en el proteasoma por lo que defectos en la autofagia generan indirectamente situaciones homólogas al bloqueo del proteasoma (Modificado de [331]).
\end{abstract}

Una vez formado, el autofagosoma será dirigido a través de los microtúbulos hasta un lisosoma con el que se fusionará. Este proceso está controlado por elementos del citoesqueleto, por proteínas de membrana del lisosoma y del autofagosoma y por la composición lipídica de sus membranas [345].

El encuentro entre las enzimas hidrolíticas con el material del autofagosoma derivará en la degradación de este último y su posterior reciclaje. Esta última parte del proceso aún no está caracterizada en profundidad.

\title{
3.2.2. REGULACIÓN
}

La macroautofagia está regulada por la serina/treonina quinasa mTOR (target of rapamycin) que a su vez regula la actividad de proteínas fosfatasas que actúan sobre activadores transcripcionales que modulan la autofagia. La falta de alimentos o el tratamiento con rapamicina (antibiótico macrólido antifúngico e inmunosupresor) inhiben la vía de TOR que activa unas quinasas que favorecen la afinidad deAtg13 por Atg1 poniendo en marcha el proceso autofágico [346]. Por el contrario, la activación de TOR ante el exceso de nutrientes (aminoácidos, insulina) mantiene hiperfosforilada a Atg13 debilitando su unión a Atg1, inhibiendo con ello la autofagia. La quinasa c-Jun $N$-terminal (JNK) es otro regulador de autofagia que regula la fosforilación de Beclina-2 liberando Beclina-1 ante la falta de nutrientes o el estrés oxidativo [347-349]. La proteína quinasa A (PKA) también puede inhibir la autofagia 
a través de la fosforilación de Atg1 y Atg13 [350]. Algunas hormonas específicas también consiguen modular la actividad autofágica celular [351]. El tamaño y la cantidad de autofagosomas formados están controlados, al menos en parte, por los genes Atg8 y Atg9 respectivamente. Atg8 podría estar sensando el tamaño del material a degradar y controlando la curvatura de la membrana a través de sus interacciones con p62 y PE. Atg9 (única Atg transmembrana) se localiza en el extremo del fagóforo controlando el transporte de membrana y su cierre [352].

\subsection{LOS LISOSOMAS}

Los lisosomas constituyen un elemento clave y fundamental del proceso autofágico dado que se encuentran en el último paso de mecanismo y son el vehículo de las enzimas responsables de la degradación. Es por esto que merecen un apartado dentro de este capítulo.

Los lisosomas son vesículas rodeadas por una membrana simple, y situadas en el citoplasma, que contienen enzimas que degradan los materiales que entran en el lisosoma. Su descubrimiento, junto al de otros orgánulos celulares, le otorgó al biólogo belga Christian de Duve el Premio Nobel de Fisiología y Medicina en 1974 [353]. Los lisosomas son estructuras comunes a todas las células animales (salvo glóbulos rojos), si bien su contenido, sus enzimas y su tamaño (entre 0,1-1,2 $\mu \mathrm{m}$ ) varían entre tipos celulares y entre lisosomas de una misma célula. Se han identificado más de 40 enzimas lisosomales con actividad hidrolítica a pH ácido. La membrana lisosomal mantiene a estas destructivas enzimas separadas del resto de la célula además de generar y controlar las condiciones óptimas para su máxima efectividad. Una proteína transmembrana, la bomba de protones vacuolar [V-ATPasa], transporta protones del citosol al interior del lisosoma hasta establecer un $\mathrm{pH}$ de 4,8 [354]. A este $\mathrm{pH}$, las enzimas lisosomales pueden degradar proteínas, lípidos, y otras moléculas provenientes de la autofagia o directamente del citosol transportadas al interior del lisosoma por proteínas transmembranas, y digerir bacterias y otras macromoléculas que entran en la célula por fagocitosis $u$ otros procesos de endocitosis. Las proteínas de la membrana del lisosoma están altamente glicosiladas haciéndolas resistentes a la degradación. Los residuos resultantes de la hidrólisis lisosomal se liberan al citosol, por difusión directa a través de la membrana o por medio de proteínas transportadoras, permitiendo el reciclaje de material orgánico y la continua renovación de los orgánulos celulares $[355,356]$. El material que ya no puede continuar degradándose ni tampoco volver al citosol forma los denominados cuerpos residuales; si no son exocitados, se van acumulando en los lisosomas convirtiéndose en marcadores de envejecimiento celular. Un ejemplo de estos cuerpos residuales son los acúmulos de lipofuscina: agregados fluorescentes de proteínas, lípidos y metales oxidados [357].

Recientemente se han definido tres tipos (o tres estados) de lisosomas: Los lisosomas convencionales que mantienen la clásica función digestiva intracelular; un tipo de lisosoma que se fusiona con la membrana plasmática y secreta su contenido al medio extracelular; $y$ un tercer tipo de lisosomas que ejercería ambas funciones, fusionándose con la membrana plasmática y reparando sus áreas dañadas. El estudio de los lisosomas ha ampliado su definición pasando de ser únicamente vesículas digestivas a parte importante de la 
homeostasis celular dada su implicación en múltiples procesos como la secreción, la reparación de membranas, la señalización celular o el metabolismo energético [210, 358-361]

\subsubsection{FORMACIÓN}

Los lisosomas pueden originarse a través de la biogénesis de novo o de la reformación autofágica de lisosomas. La biogénesis de novo requiere de la conjunción de componentes de la vía endosomal, de la autofágica y de hidrolasas sintetizadas en el retículo endoplásmico. La reformación autofágica recicla lisosomas ya existentes a través de la vía de mTOR activada por inducción de la autofagia en situaciones de ayuno [362]. El factor de transcripción TFEB (Transcription factor EB) activado en situaciones de ayuno, es un elemento regulador fundamental común a la autofagia y a la formación de lisosomas [363-365].

La formación de novo del lisosoma comienza con la salida, desde el aparato de Golgi, de una vesícula cargada de enzimas hidrolíticas a la espera de fusionarse con otras vesículas y degradar su carga. Esta vesícula se denomina lisosoma primario. La fusión de los lisosomas primarios con otras vesículas genera el lisosoma secundario en donde confluyen los sustratos a degradar y las enzimas capaces de ello [366].

Según el origen de la vesícula con la que se fusionan los lisosomas se denominarán:

- Fagolisosomas: fruto de la fusión de un lisosoma primario con una vesícula procedente de la fagocitosis (fagosoma) cargada de material extracelular de gran tamaño.

- Endosomas tardíos: resultado de la maduración de endosomas tempranos (descenso del $\mathrm{pH}$ a 5,5 ) y su posterior unión al lisosoma. Contienen macromoléculas que entran en la célula a través de un receptor (endocitosis mediada por receptor) o de forma inespecífica.

- Autofagolisosomas: producto de la fusión de un lisosoma primario con una vesícula autofágica (autofagosoma) cargada con material citoplasmático que requiere ser reciclado.

Por lo tanto, la maduración del lisosoma es el punto de intersección entre la vía de secreción, donde se procesan las proteínas lisosomales, y la vía endocítica y autofágica, por la cual se internaliza, se señaliza y se recicla material extra e intracelular (Fig.16). 


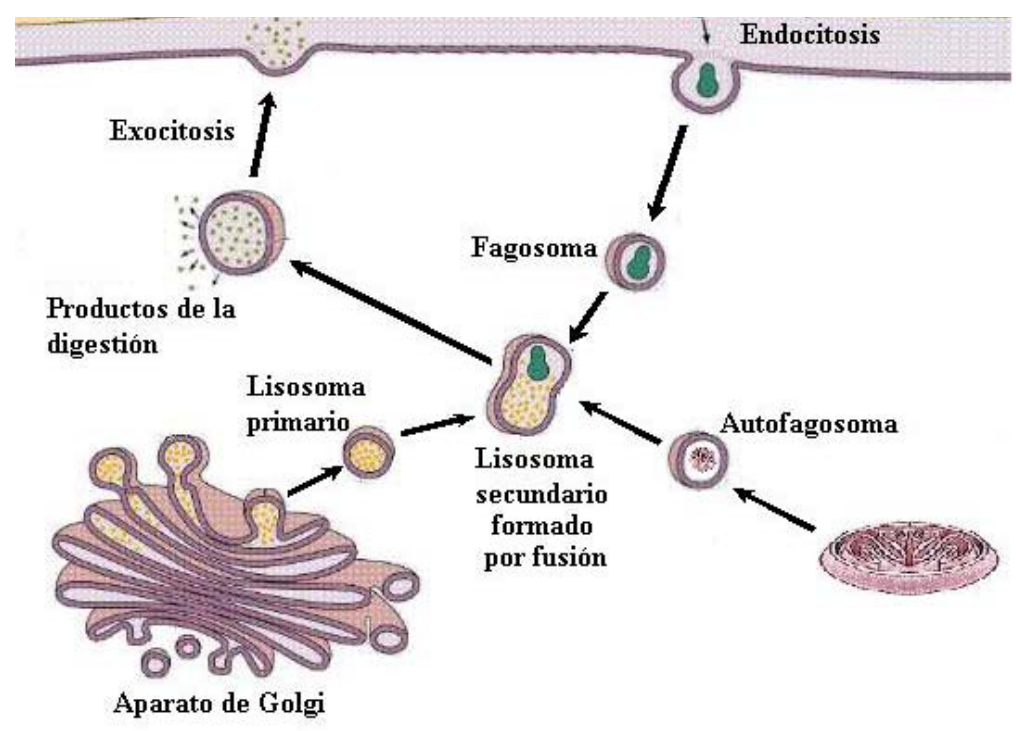

Figura 16. Esquema de la convergencia de los procesos de endocitosis y exocitosis en la formación de lisosomas secundarios. (Modificado de [367]).

\subsubsection{FUNCIÓN}

Los lisosomas están implicados en gran variedad de procesos celulares, muchos de los cuales están relacionados con la digestión de materiales. Son elementos clave en el reciclado de componentes celulares por autofagia ya que son los responsables del correcto desenlace del proceso autofágico. Asimismo, son centros de obtención de materiales esenciales bien por digestión intracelular de material ingerido por endocitosis (como la extracción de colesterol de las LDL) o bien por fagocitosis [368]. Resultan una herramienta esencial en la reparación de membrana dañada y en la eliminación de mielina y detritus intra- y extracelulares generados en situación de daño. Son responsables de la liberación de la hormona tiroidea por degradación de la tiroglobulina de los endosomas. Por último, participan en muchos otros procesos en los que es necesaria la acción de sus enzimas hidrolíticas, como la remodelación del tejido óseo o la fecundación del espermatozoide [306, 369-372]. 
Las enzimas lisosomales son secretadas al retículo endoplásmico rugoso donde se glicosilan, haciéndose resistentes al ambiente que encontrarán dentro del lisosoma. Una vez glicosiladas alcanzan el aparato de Golgi en donde serán marcadas con un residuo de manosa-6-fosfato (Man-6-P) que definirá su destino lisosomal. En el trans Golgi estos residuos son reconocidos, capturados por los receptores de membrana M-6-P y transportados al lisosoma mediante vesículas cubiertas con clatrina ${ }^{22}$ [373]. Tras la fusión de estas vesículas con la membrana lisosomal, el pH ácido del interior del lisosoma rompe la unión de las enzimas con sus receptores. La enzima libre estará preparada para realizar su actividad hidrolítica mientras que el receptor volverá al Golgi donde se reutilizará. De esta manera los lisosomas se llenan de lipasas que hidrolizan lípidos a ácidos grasos, glucosidasas que digieren carbohidratos, proteasas que degradan proteínas dando aminoácidos libres o nucleasas que actúan sobre los ácidos nucléicos [374].

Uno de los tipos de enzimas lisosomales más importantes son las fosfolipasas, gracias a las cuales los lisosomas juegan un papel crucial en el metabolismo lipídico. La fosfolipasa $A$ (actividad a pH ácido, independiente de $\mathrm{Ca}^{2+}$ ) actúa sobre gran variedad de sustratos fosfolipídicos. Para realizar su función necesita generar interacciones electrostáticas con los lípidos cargados negativamente presentes en la membrana lisosomal o endosomal $[375,376]$. La fosfolipasa $\mathrm{C}$ se une a la membrana por sus dominios de unión a lípidos $\mathrm{PH}$ y $\mathrm{C} 2$ desde donde hidroliza fosfatidilinositolbifosfato $\left(\mathrm{PIP}_{2}\right)$ generando $\mathrm{IP}_{3}$ y $\mathrm{DAG}$. La fosfolipasa $\mathrm{D}$ actúa específicamente sobre la fosfatidilcolina. En respuesta a ciertos estímulos se traslada a la membrana plasmática. La fosfolipasa D1 regula el flujo de la autofagia a través de cambios en los fosfolípidos [187, 377]. Las fosfolipasas también están involucradas en la degradación de proteínas lipidadas; en concreto, algunas fosfolipasas C y D hidrolizan específicamente la unión que ancla a las proteínas GPI con la membrana. Las proteínas ancladas a GPI se encuentran en dominios de membrana ricos en colesterol y esfingomielinas (Ver sección 2.4.1)a través de los cuales pueden endocitarse, ser recicladas y regresar a la membrana mediante la vía endosomal de reciclaje perinuclear ${ }^{23}$ (ERC), o transportadas a endosomas tardíos [378]. Las fosfolipasas que liberan de su anclaje a estas proteínas también se han encontrado en los dominios de membrana [379]. Esto sugiere que el reciclado de las proteínas GPI tiene lugar, al menos en

\footnotetext{
${ }^{22}$ La clatrina es una proteína con una estructura en forma de trisquelión que genera una vesícula en la membrana. La clatrina favorece la curvatura hacia dentro de la membrana capturando los receptores unidos a la proteína a endocitar. La clatrina se une a la membrana a través de las adaptinas. Estas se unen, por una parte, a los trisqueliones y, por otra, a las colas de los receptores generando selectividad en el proceso. Existen diferentes tipos de adaptinas, según el tipo de receptor. Las moléculas de clatrina y adaptina se unen espontáneamente pero para separarse necesitan ATP y $\mathrm{Ca}^{+}$. Las vesículas pierden la cubierta de clatrina y se unen a un endosoma temprano. El $\mathrm{pH}$ acido causa la liberación de la partícula del receptor.

${ }^{23} \mathrm{El}$ endosoma de reciclaje perinuclear (ERC), es un orgánulo que participa en el reciclaje de material endocitado de vuelta a la superficie celular. Está involucrado en el reciclaje de lípidos y proteínas en células no polarizadas. Es un compartimento de morfología túbulo-vesicular ligeramente ácido $(\mathrm{pH}$ 6.4-6.5) que suele encontrarse en torno al núcleo (Horgan et al., 2007) conectando las rutas endocíticas y exocíticas y permitiendo el reciclaje de la membrana plasmática.
} 
gran parte, en los lisosomas [380]. Otras dos enzimas lisosomales, la tioesterasa palmitoilada (PPT1) y la prenilcisteinaliasa (PCL) están especializadas en la hidrólisis de proteínas de membrana palmitoiladas y preniladas (también unidas a dominios de membrana) [381]. Esta especificidad frente a proteínas altamente relacionadas con los dominios de membrana señala a los lisosomas como posibles puntos de destino de estas estructuras membranales y de las proteínas que contienen.

De entre las proteasas presentes en el lisosoma, cabe destacar las catepsinas. Pueden cortar las proteínas por un residuo de cisteína, serina o aspartil y están implicadas en varias vías de muerte celular y daño de la membrana lisosomal [374, 382, 383]. Un incremento de ROS puede provocar la permeabilización de la membrana, la salida de catepsina $D$ al citosol e inducir apoptosis [384].

Otras proteínas como las GTPasas (Rab 8 o Rab 9), implicadas en el trafico de membranas, también forman parte de las proteínas lisosomales [374, 385].

\section{OTRAS PROTEÍNAS}

Además de las enzimas hidrolíticas, y las bombas que mantienen el pH, los lisosomas contienen otras proteínas, la mayoría glicosiladas, unidas a la membrana y muchas de ellas relacionadas con el transporte de lípidos [386]. Estas proteínas alcanzan la membrana del lisosoma por endocitosis de la superficie celular o a través de vesículas de clatrina procedentes de trans Golgi [387]. NPC1 (Niemann-Pick disease type (1) es una glicoproteína integral de membrana ligada a la homeostasis de los gangliósidos. NPC2 juega un papel esencial en el flujo de colesterol [388]. Ambas están involucradas en la enfermedad de Niemann-Pick tipo C. La proteína endosomal MLN64 (Metastatic Lymph Node 64, también llamada StarD3) y ORP1L (Oxysterol binding protein-Related Protein-1) son dos proteínas de la cara citosólica de los endosomas tardíos también involucradas en el transporte de esteroles [389]. La Pdro (Proteína asociada a DRMs y endosomas) ha sido descubierta recientemente en la superficie de endosomas tardíos y lisosomas e influye en la captación de LDL exógena y en el contenido de colesterol libre celular [390]. LAMP-1 y LAMP-2 (lysosomal-associated membrane protein 1 -2) son las mayores glicoproteínas integrales de membrana de los endosomas tardíos y lisosomas. Su ausencia también provoca la acumulación de colesterol libre [391].

\subsubsection{LA MEMBRANA LISOSOMAL}

La cara interna de la membrana de los lisosomas está intensamente glicosilada protegiéndola de los enzimas que encierra. Contiene enzimas hidrolíticas, proteínas que controlan el pH interno y proteínas que transportan los productos iniciales o finales de la digestión dentro o fuera del lisosoma. La membrana limitante del lisosoma (y también del endosoma tardío), a pesar de contener poco colesterol, presenta microdominios resistentes a detergente (ver sección 2.4.3). La falta de colesterol modifica las propiedades del lisosoma y disminuye la resistencia de su membrana [392]. A lo largo de la vía de endocitosis, se incrementa la 
concentración del lípido bis-monoacilglicerofosfato (BMP/LBPA) ${ }^{24}$ y de ceramida, que a su vez desplaza al colesterol [393] hasta llegar a la máxima concentración de ceramida cuando se alcanza el pH óptimo de la esfingomielinasa ácida (pH 5.5). La concentración de colesterol será, por tanto, inversamente proporcional a la cantidad de ceramida [394]. Este control específico de la composición lipídica permite una regulación precisa de la degradación lisosomal.

Los lisosomas pueden tener varias membranas intra-lisosomales ricas en colesterol y BMP/LBPA. Los cuerpos multivesiculares (MVBs) son un tipo de endosoma tardío que contiene múltiples vesículas en su lumen. La acumulación de membranas internas comienza en el endosoma temprano. La membrana limitante se invagina hacia el lumen del endosoma y seguidamente se separa [395]. Es necesaria la presencia de PI3P y otros complejos proteicos que se unen a los dominios de membrana resistentes a detergente para liberar las vesículas, ya que catalizan la escisión de los cuellos de las invaginaciones. Por lo tanto las balsas lipídicas juegan un papel importante en el proceso de invaginación. La existencia de diferentes membranas internas indica diferentes funciones dentro del endosoma/lisosoma [377].

Cuando los MVBs se fusionan con la membrana plasmática se liberan al medio extracelular pequeñas vesículas (40-100nm de diámetro) denominadas exosomas. Sus membranas también poseen dominios de colesterol, esfingolípidos, ceramida y glicerofosfolípidos con cadenas largas saturadas. La ceramida podría promover la génesis de exosomas a través de la formación de microdominios ya que, debido a su geometría cónica, induce espontáneamente una curvatura negativa en la bicapa $[396,397]$.

\section{IMPORTANCIA DE LOS LÍPIDOS EN LAS FUNCIONES LISOSOMALES}

Las modificaciones en la composición lipídica de la membrana de los lisosomas afectan a gran número de procesos.

Las membranas de los lisosomas pueden fundirse con las membranas de diferentes compartimentos celulares como los endosomas tardíos, autofagosomas, fagosomas o con la propia membrana plasmática. El mecanismo de fusión depende de ciertas proteínas (SNAPs, SNAREs (presentes en balsas lipídicas), Rab7, sinaptotagmina VII o calmodulina y lípidos reguladores (ergosterol, diacilglicerol, ácido fosfatídico, fosfatidiletanolamina y fosfoinosítidos (PI(3)P y PI(4,5)P2) [398]. Los lisosomas se fusionan con la membrana plasmática proporcionando membrana extra para su reparación. Para ello es necesaria la eliminación de la membrana lesionada por endocitosis dependiente de dinamina (GTPasa), la cual promueve la ruptura del citoesqueleto de actina. Durante la fusión con la membrana se libera

\footnotetext{
${ }^{24}$ Bis-monoacilglicerofosfato (BMP/LBPA)es un isómero estructural de fosfatidilglicerol, un fosfolípido con dos grupos glicerol, cada uno con una cadena acilo. Se sintetiza a partir de fosfatidilglicerol por acción de la fosfolipasa A2. Posee una configuración especial que le hace bastante resistente ala degradación. Sus precursores llegan a los lisosomas por transporte vesicular, por aproximación de membranas o por proteínas transportadoras de lípidos. (Hullin-Matsuda F, 2009). Recientemente se ha localizado en la membrana interna de los endosomas tardíos donde forma dominios lipídicos especializados. Parece estar implicado en el control de la distribución celular de proteínas y lípidos, fundamentalmente el colesterol. También jugaría un papel importante en la vía de degradación lisosomal. Una peculiaridad es que está naturalmente enriquecido en ácido docosahexaenoico o lo incorpora preferencialmente adquiriendo propiedades biofísicas y funcionales.
} 
esfingomielinasa ácida lisosomal al exterior de la célula. Esto indica que la formación de ceramida es necesaria para la internalización de la membrana dañada $[377,399,400]$.

En la macroautofagia, el contenido lipídico tanto en el autofagosoma como en el lisosoma también modula la fusión vesicular. Cambios en el contenido de colesterol, la acumulación de lípidos en el lisosoma, o los cambios en el metabolismo lipídico y el contenido lipídico intracelular modifican la fusión entre autofagosoma y lisosoma teniendo un profundo efecto sobre la macroautofagia [401].

Es posible que el colesterol participe directamente en la fusión o que indirectamente cambie las propiedades físicas de la membrana. El colesterol es importante en los lisosomas y endosomas ya que controla su movilidad y posición dentro de la célula. Los endosomas tardíos cargados de colesterol se vuelven inmóviles afectando, por tanto, a sus posibilidades de fusión con un lisosoma. Además, la eliminación de colesterol estimula la macroautofagia [377]. La destrucción de los microdominios de membrana lisosomales activa la CMA [392]. La CMA permite al lisosoma degradar proteínas específicas unidas a chaperonas. LAMP2 las introduce en el lisosoma. Cuando la CMA es baja, LAMP2 se dirige a los dominios de membrana donde se produce su proteólisis por catepsina A. De esta manera un aumento de colesterol podría inhibir la activación de CMA al favorecer la formación de microdominios y por tanto la degradación de LAMP2. Los cambios en la composición lipídica de las membranas lisosomales con el envejecimiento también podrían ser la causa de defectos en CMA por disfunción de LAMP2 [377].

\subsection{PAPEL DE LA AUTOFAGIA EN LA HOMEOSTASIS CELULAR Y ANTE EL ESTRES}

\section{PAPEL DE LA AUTOFAGIA EN LA HOMEOSTASIS CELULAR}

En ausencia de estrés, la célula mantiene una autofagia basal permanente que le permite eliminar estructuras defectuosas o dañadas. La correcta síntesis y el adecuado procesamiento de proteínas siguen procedimientos complejos que requieren de la actuación perfectamente diseñada y organizada de múltiples factores. De hecho, una de cada tres proteínas sintetizadas tiene algún defecto y debe ser eliminada. Esta demanda de autofagia basal depende del tipo de tejido, siendo especialmente necesaria en las células que no se dividen como las neuronas. Junto a la autofagia, el proteasoma también controla el material celular, si bien este último degrada fundamentalmente moléculas de vida corta y tamaño medio, mientras que la autofagia se encarga de las de vida larga y gran tamaño pudiendo llegar a degradar orgánulos enteros como mitocondrias (mitofagia), peroxisomas (macropexofagia) o RE (Fig.13) [402]. La inhibición de esta autofagia basal produciría la muerte celular [350, 403].

\section{PAPEL DE LA AUTOFAGIA ANTE EL ESTRÉS}

La autofagia se estimula en una gran variedad de situaciones de estrés como la falta de alimento, la falta de factores de crecimiento, infecciones, estrés de retículo, estrés oxidativo o hipoxia [322, 404, 405]. En una situación de estrés, la autofagia luchará por la supervivencia celular. Al degradar el contenido intracelular, disminuye el número de elementos que 
consumen energía a la vez que produce moléculas esenciales para la célula, proporcionándole las herramientas necesarias para responder ante el estrés. Sin embargo, si la autofagia se prolonga demasiado podría dañar la célula de forma irreversible.

Muchas enfermedades neurodegenerativas presentan alteraciones en los procesos de autofagia [406]. La degradación de proteínas mutadas, características de muchas enfermedades neurodegenerativas, depende de la autofagia. En concreto, las proteínas poliglutaminadas causantes de enfermedades como el Huntington o algunas Ataxias Espinocerebelosas y las formas de $\alpha$-sinucleina que causan el Parkinson son degradadas por macroautofagia. La autofagia mediada por chaperonas también participa en su eliminación, pero las formas mutadas y sus agregados, de tamaño considerable, bloquean fácilmente el receptor lisosomal inhibiéndola. La autofagia, dirigida por la proteína p62, eliminaría los agregados de proteínas y cuerpos de inclusión de una manera directa. La enfermedad de Alzheimer también presenta alteraciones de la autofagia por acumulación de autofagosomas que no maduran a autolisosomas debido a defectos en la fusión con los lisosomas que implicaría alteraciones del flujo autofágico [407, 408]. Ante el estrés causado por una infección, la autofagia no solo es el mecanismo para degradar microorganismos, sino que supone una fuente de material antigénico para el sistema inmune. Por lo tanto, autofagia también podría jugar un papel importante en las enfermedades autoinmunes [409].

Durante el envejecimiento celular se produce la acumulación de material dañado o inservible especialmente dañino en células diferenciadas como las neuronas. La actividad autofágica disminuye con la edad y con ella la eficacia en la eliminación de material deteriorado, por lo que es un mecanismo clave en el proceso de envejecimiento [410].

La autofagia también es un eficaz sistema de protección contra el estrés oxidativo, más eficaz incluso, que los antioxidantes. Los antioxidantes que actúan sobre los radicales libres no pueden revertir los daños que estos han provocado en las proteínas y los orgánulos, y por lo tanto tampoco controlar los efectos que este material en mal estado pueden provocar. Además, las especies antioxidantes son bastante específicas, por lo que sólo serán eficaces cuando coincidan con su sustrato. Incluso, la eliminación de ciertas especies reactivas con importantes funciones señalizadoras podría ser contraproducente. Por el contrario, la autofagia es capaz de retirar no sólo parte de las moléculas oxidantes sino también el material dañado y los sustratos propensos a ser oxidados, convirtiéndose en una eficaz respuesta celular ante la oxidación. Por lo tanto, la autofagia y sus posibles moduladores podrían emerger como dianas terapéuticas muy prometedoras contra los efectos oxidativos de muchas patologías [405].

La macroautofagia también juega un papel importante en el metabolismo lipídico y sus alteraciones. El aumento de las reservas de triglicéridos, en ciertas condiciones, se debe a una disminución de la lipolisis de las reservas de lípidos y no a un incremento de su síntesis o una reducción de su secreción a través de las lipoproteínas (VDL). Este hecho se corresponde con una disminución de la cantidad de lípidos que llegan a los lisosomas. En condiciones de activación de la autofagia (rapamicina), los lípidos colocalizan con marcadores autofagosómicos (LC3) y lisosómicos (LAMP), es decir, sufren autofagia. Dietas extremas (por ejemplo alta en grasas) no solo muestran defectos en la degradación de las reservas lipídicas 
por autofagia sino que también alteran la degradación de otros sustratos. Esto indica que el defecto recae sobre el proceso de la autofagia y no sobre las reservas de lípidos. En estas situaciones las etapas iniciales de la autofagia no están alteradas. El defecto se encuentra en el paso de fusión del autofagosoma con el lisosoma. Es decir, la composición lipídica de la membrana es un factor decisivo en la fusión autofagosoma-lisosoma. En concreto el colesterol tiene una importante función en la estructura y propiedades de la membrana influyendo, en este caso, en procesos como la fusión. La macrolipofagia (autofagia de lípidos) también ejerce el mismo control sobre las reservas lipídicas en las neuronas. La regulación de la autofagia a través de la dieta también podría ser una interesante diana terapéutica [377, 411]. 


\section{EL ESTRÉS OXIDATIVO. SUS EFECTOS SOBRE EL SISTEMA NERVIOSO}

El estrés oxidativo en los sistemas biológicos es un desequilibrio entre la producción de especies reactivas de oxígeno y los mecanismos encargados de eliminarlos o reparar los daños que generan. Los ROS (especies reactivas de oxígeno) ${ }^{25}$ y las especies reactivas de nitrógeno (RNS) (radicales libres y peróxidos) son productos del metabolismo aeróbico altamente destructivos. Estas especiesson pequeñas moléculas muy reactivas debido a la presencia de electrones desapareados en su capa de valencia que les confieren un alto poder oxidante.De manera basal, se encuentran en concentraciones cuyos daños pueden ser reparados constantemente. Mantener un entorno reductor supone para las células un constante aporte energético. Un desbalance en el estado redox resulta tóxico para la célula al producirse daños tanto en las proteínas como en los lípidos y los ácidos nucleicos que podrían llegar a provocar la muerte celular por apoptosis, si el daño es moderado, o por necrosis, si es elevado. La mayoría de los efectos que el estrés oxidativo ejerce sobre los lípidos, proteínas y ácidos nucleicos resultan en cambios estructurales que conllevan a su disfunción o pérdida de actividad [412]. La fuente de oxígeno reactivo más importante en condiciones normales es la mitocondria a través de la respiración oxidativa. La respiración celular es un conjunto de reacciones que degradan compuestos orgánicos (hidratos de carbono (glucosa), ácidos grasos, aminoácidos o cuerpos cetónicos) por oxidación utilizándolos como combustible para la obtención de energía (ATP, nucleótido trifosfato). La respiración permite liberar hasta 2,870kJ a partir de la oxidación completa de $1 \mathrm{~mol}$ de glucosa, mientras que el metabolismo anaeróbico consigue tan sólo 197kJ. Sin embargo, la alta eficiencia del metabolismo aeróbico implica la utilización del oxígeno como aceptor final de electrones gracias a su alto potencial redox.

$$
\mathrm{C}_{6} \mathrm{H}_{12} \mathrm{O}_{6}+6 \mathrm{O}_{2}+6 \mathrm{CO}_{2} 12 \mathrm{H}_{2} \mathrm{O}+6 \mathrm{CO}_{2}=38 \mathrm{ATP}
$$

A pesar de su toxicidad a altas concentraciones, los ROS y RNS a niveles fisiológicos tienen funciones señalizadoras (señalización redox) que contribuyen a la homeostasis celular por lo que es necesaria una intensa regulación. Pueden actuar como segundos mensajeros de manera autocrina, paracrina o intracelular implicándose en muchos procesos señalizadores [210]. Algunos ROS y RNS, incluyendo óxido nítrico, pero fundamentalmente el peróxido de hidrógeno (el menos reactivo), cruzan las membranas y activan procesos fisiológicos vitales como la inflamación a través de la activación de NFkB y AP1 $[413,414]$, la vascularización, biogénesis mitocondrial [415-417], o la plasticidad sináptica [418-421]. Es por esto que actualmente se les considera "espadas de doble filo" esenciales para el buen funcionamiento celular [422].

25

Especies reactivas e oxígeno (ROS). Radicales:anión superóxido $\left(\mathrm{O}^{2-{ }^{-}}\right)$, radical hidroxilo $\left(\mathrm{OH}^{-}\right)$y radical peroxilo $\left(\mathrm{RO}_{2}\right)$, alcoxilo $(\mathrm{RO})$, hidroperoxilo $\left(\mathrm{HO}_{2}\right)$.No radicales: oxígeno singlete $\left(\Delta \mathrm{gO}_{2}\right)$, peróxido de hidrógeno $\left(\mathrm{H}_{2} \mathrm{O}_{2}\right)$ RNS: óxido nítrico (NO), dióxido de nitrógeno $\left(\mathrm{NO}_{2}\right)$, trióxido de dinitrógeno $\left(\mathrm{N}_{2} \mathrm{O}_{3}\right)$ y peroxinitrito $\left(\mathrm{ONOO}^{\circ}\right)$. 
Para protegerse de los efectos de la oxidación, las células despliegan una variedad de mecanismos defensivos que incluyen el recambio lipídico, la degradación de proteínas y la reparación de DNA además de la producción de una amplia batería de moléculas antioxidantes. Los antioxidantes celulares controlan los niveles de estas especies tóxicas y mantienen el equilibrio redox. Los más importantes son las enzimas superóxido dismutasa (SOD), catalasa, glutatión peroxidasa y tioredoxinas y los antioxidantes no encimáticos: glutatión (GSH), tocoferol (vitamina E), ácido ascórbico (vitamina C), bilirrubina y la coenzima Q10. Existen otras proteínas con actividad redox aunque no como función principal.SOD intercepta el $\mathrm{O}_{2}{ }^{-}$evitando su posible reacción con $\mathrm{NO}$ e impidiendo la generación del ONOO', uno de los oxidantes más potentes. Las catalasas catalizan la conversión del peróxido de hidrógeno en agua y oxígeno, usando hierro o manganeso como cofactor. La glutatión peroxidasa cataliza la ruptura del peróxido de hidrógeno y de hidroperóxidos orgánicos. La proporción del estado oxidado frente al reducido del glutatión es un indicador del estado redox celular [423, 424] (Fig. 17)

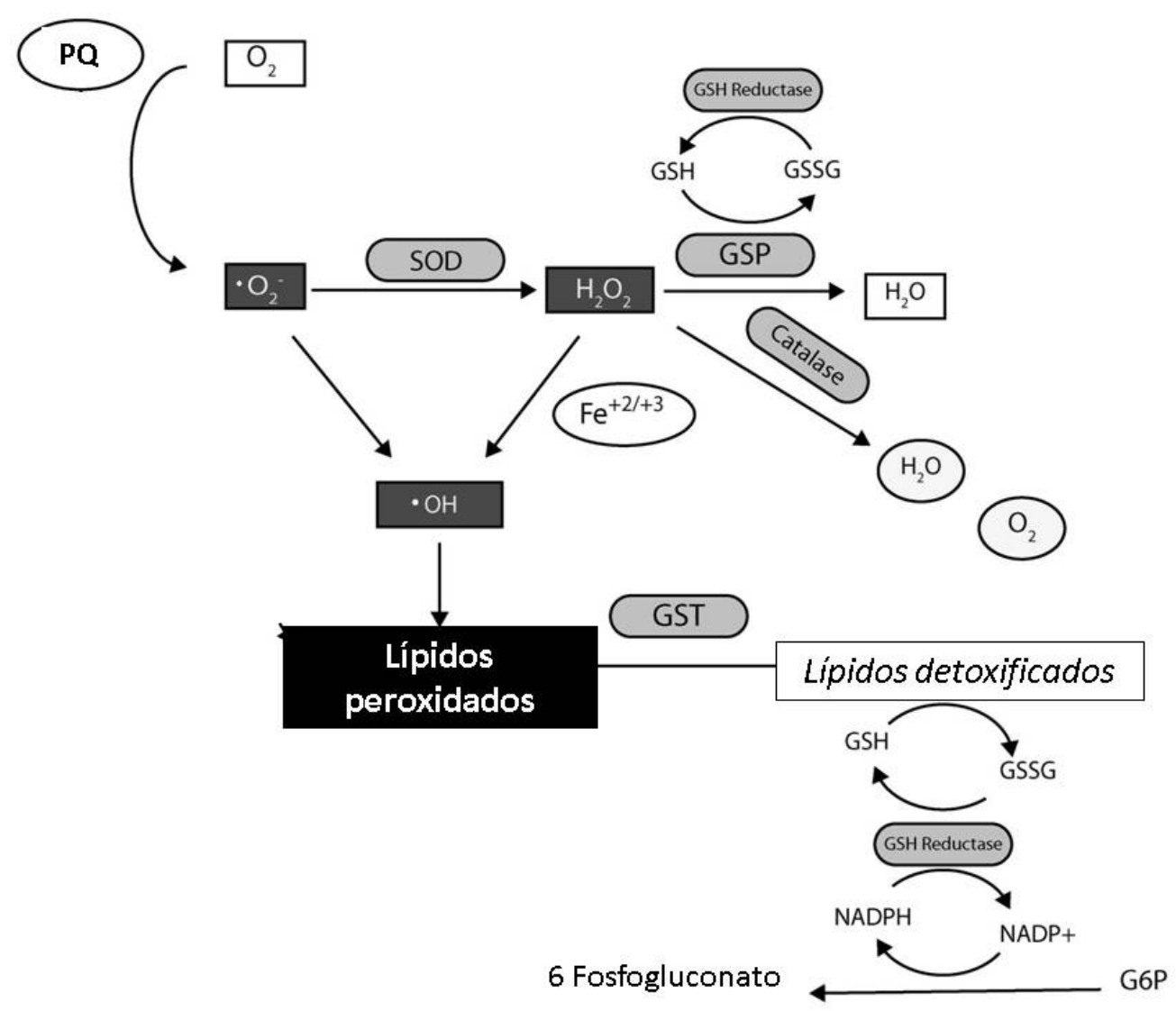

Figura 17. Defensa antioxidante contra la oxidación por superóxido. La glutatión-S-transferasa (GST) elimina los lípidos peroxidados mientras el glutatión reducido (GSH) se oxida a (GSSG). La superóxido dismutasa (SOD) cataliza el paso de superóxido a peróxido de hidrógeno que es eliminado por la glutatión peroxidasa (GSP) y la catalasa. (Modificado de [425]) 


\section{OXIDACIÓN DE LÍPIDOS}

El cerebro es un órgano altamente sensible al estrés oxidativo debido a su elevada tasa metabólica y a sus altos niveles de hierro y cobre (que aumentan con el envejecimiento) [426]. Las interacciones de estos metales con el peróxido de hidrógeno, producto de numerosos procesos cerebrales, generan radicales hidroxilo extremadamente reactivos [427, 428]. EI cerebro es un importante generador tanto de peróxido de hidrógeno como de ROS asociados al $\mathrm{Ca}^{2+}$. Además, la activación e inhibición neuronal implica la producción de glutamato que aumenta los niveles de $\operatorname{ROS}[429,430]$. A pesar de la protección que la barrera hematoencefálica ofrece al cerebro, algunos agentes oxidantes pueden atravesarla y generar radicales en él [431]. Sin embargo, la respuesta del cerebro no es uniforme. Existen poblaciones selectivas de neuronas especialmente vulnerables. Esta diferente vulnerabilidad hace a ciertas regiones del cerebro ser las primeras en mostrar degeneración tanto en el envejecimiento como en las enfermedades neurodegenerativas [432]. La región hipocampal CA1 y las células de los granos del cerebro son particularmente vulnerables al estrés oxidativo [433-436] lo que explicaría, entre otras cosas, su alta fragilidad ante condiciones como la isquemia, estadios tempranos de la enfermedad de Alzheimer o el envejecimiento [437-439].

Por otro lado, el metabolismo lipídico es particularmente importante en el cerebro, ya que es el órgano que contiene la mayor concentración de lípidos, con excepción del tejido adiposo. Los lípidos son moduladores importantes de la fisiología del cerebro pero son también objetivo de los ROS. Las membranas neuronales contienen gran cantidad de fosfolípidos formando ésteres con ácidos grasos poliinsaturados muy sensibles al ataque de ROS como el AA (20:4), el ácido eicosapentaenoico (EPA) (20:5) o el DHA (22:6), que favorecerían, en caso de oxidación, reacciones en cadena que generarían radicales de lípidos y un extenso daño en la membrana. Los radicales, especialmente hidroxilo, alcoxilo y peroxilo, pueden atraer un átomo de $\mathrm{H}$ del grupo metileno de un ácido graso poliinsaturado generando radicales libres de carbono. La reacción inicial del radical hidroxilo con ácidos grasos produce un radical lipídico que, tras reaccionar con el oxígeno, genera un radical peroxilo que puede reaccionar con ácidos grasos para producir hidroperóxidos lipídicos (Fig.18). Comienza entonces una reacción en cadena que provocará alteraciones significativas en la estructura de las membranas, modificando su fluidez, su permeabilidad y el transporte y por tanto, los procesos metabólicos relacionados con dicha membrana. Los peróxidos de ácidos grasos dan lugar a aldehídos entre los que el 4hidroxi-2-nonenal (4HNE) se considera uno de los más tóxicos, causante de grandes daños y activador de la apoptosis [440]. 4HNE puede ser generado a partir del AA o del ácido linoleico pudiendo estar asociado a las membranas. Sin embargo, HNE también puede desintegrar la membrana y viajar entre los componentes celulares [440, 441]. HNE puede interactuar y desactivar el proteasoma favoreciendo la acumulación de proteínas oxidadas. Por lo tanto, las reacciones en cadena de la peroxidación de lípidos podrían dañar los sistemas de degradación y causar un aumento excesivo de proteínas alteradas [442]. 


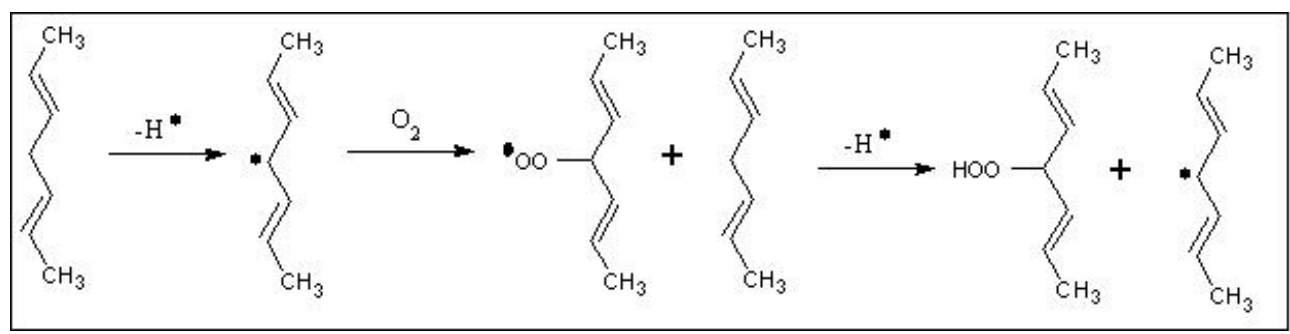

Figura 18. Reacción en cadena de la peroxidación lipídica. Los ROS arrancan un H generando un radical que reacciona con el $\mathrm{O} 2$ generando un radical peroxilo que reacciona con otro ácido graso [443].

El estrés oxidativo está estrechamente relacionado con una gran variedad de enfermedades neurodegenerativas, incluyendo los trastornos asociados a la edad [444-446]. Este estrés puede ser debido al aumento de los niveles de ROS o a deficiencias en los sistemas de reparación. Los cambios provocados por la oxidación en los lípidos, proteínas y ADN son considerados marcadores de daño oxidativo. Estos marcadores incrementan con el envejecimiento y en muchos casos son causantes de la progresión de enfermedades [447-449]. En concreto, la peroxidación lipídica es una fuente de daño presente en muchas enfermedades neurodegenerativas, incluyendo $A D$ y otros tipos de demencia, enfermedad de Parkinson, accidente cerebrovascular, enfermedad de Huntington, Enfermedades de Niemann-Pick, etc. [450]. Los niveles de peroxidación lipídica en varios órganos, incluido el cerebro, aumentan con el envejecimiento [451].

Los antioxidantes lipídicos, especialmente las vitaminas solubles en lípidos, el glutatión o las glutatión $\mathrm{S}$ transferasas conforman el mecanismo natural de la célula para contrarrestar la oxidación, incluyendo la eliminación de HNE. La albúmina y las apolipoproteínas capturan HNE, desintoxicando el medio celular. La enzima fosfolipasa $\mathrm{A} 2$ independiente de $\mathrm{Ca}^{2+}$ repara la oxidación de la cardiolipina, lípido aniónico componente de la membrana mitocondrial y de las lipoproteínas [452, 453]. Sin embargo, la mayoría de las enzimas de la familia de la fosfolipasa A2 son generadoras de estrés oxidativo y peroxidación de lípidos durante la síntesis de prostaglandinas a partir AA [450]. La inhibición de la secreción de la fosfolipasa A2 podría ser una herramienta para disminuir la inflamación asociada a la peroxidación lipídica [454]. Desde otro punto de vista, la peroxidación lipídica catalizada por la fosfolipasa A2 es una reacción enzimática, es decir, regulada, y por tanto, podría tener funciones fisiológicas [455]. Los cambios en la membrana fruto de la peroxidación lipídica podrían afectar a la señalización celular de los sistemas de degradación importantes en la remodelación de las bicapas. Los ROS generados en las neuronas de hipocampo durante el envejecimiento provocan una reducción en el contenido de colesterol de sus membranas que a su vez activa las vías que promueven la supervivencia celular [456].

Se ha descrito que la conformación de ciertos glicerofosfolípidos dentro de la membrana podría cambiar con la oxidación, desenterrándose de la membrana el resto de ácido graso oxidado, sobresaliendo hacia el medio acuoso y haciéndose accesible a receptores presentes en la superficie de otras células proporcionando con ello información sobre su estado de oxidación. De esta manera, durante el envejecimiento u otros procesos que conlleven peroxidación lipídica, las porciones hidrofóbicas de ciertos ácidos grasos se orientarán hacia el exterior de la bicapa llenando la membrana de "bigotes" accesibles al reconocimiento de 
receptores. En concreto, se ha estudiado que el receptor de macrófagos CD36 reconoce estos "bigotes" de la superficie de células senescentes señalizando la posibilidad de fagocitosis (Fig.19) [457].

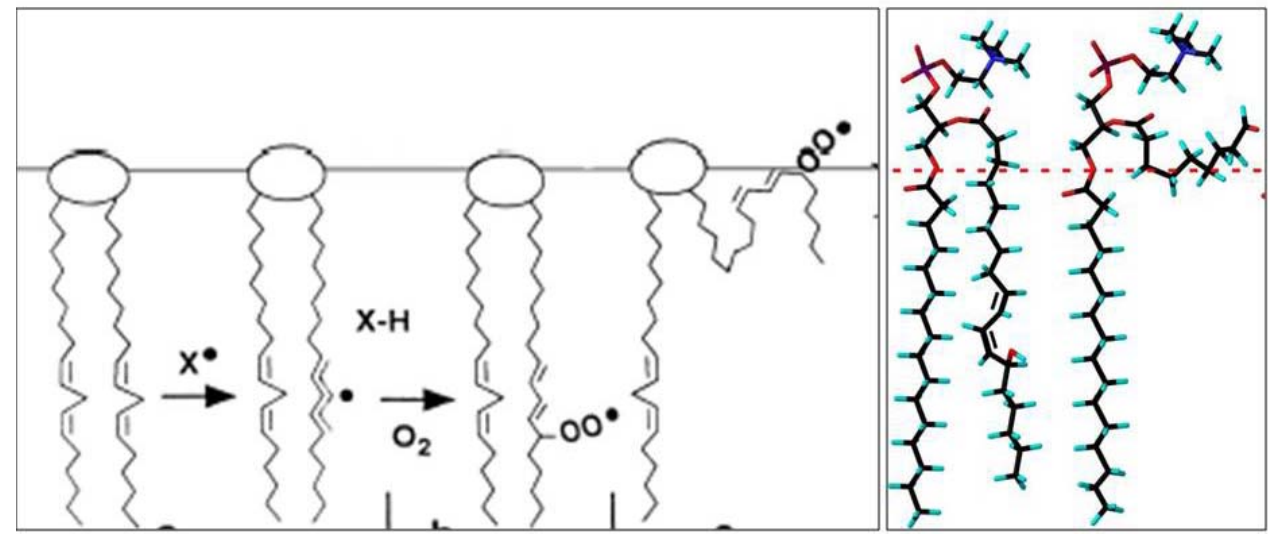

Figura 19. Modelo de bigotes lipídicos. Tras la oxidación, la cadena oxidada emerge de la membrana sobresaliendo como un "bigote" accesible al reconocimiento por un receptor $[457,458]$

\section{OXIDACIÓN DE PROTEÍNAS}

Las modificaciones que el estrés oxidativo provoca en las proteínas tienen importantes consecuencias en la homeostasis celular. La oxidación por ROS de los aminoácidos de las proteínas podría tener un papel regulador en la homeostasis proteica que explicaría el relativamente alto grado de cambios conformacionales asociados a $\operatorname{ROS}[459,460]$.

Aunque todos los aminoácidos pueden ser atacados por los ROS, la metionina y la cisteína son los más propensos a la oxidación por la presencia de azufre en su composición. Los residuos de cisteína se convierten en disulfuros por oxidación aunque pueden reducirse de nuevo bajo ciertas condiciones. Los residuos de metionina son altamente hidrofóbicos. En las proteínas de membrana esta metionina se encuentran interaccionando con la bicapa protegida de la oxidación. Cuando se oxida, la metionina se transforma en metionina sulfóxido (MetSO) de carácter más hidrofílico, cambio que puede afectar a la estructura total de la proteína. Este cambio puede ser revertido por las metioninasulfóxidoreductasas (MrsA, MrsB) [461]. La oxidación reversible de la metionina señala que esta modificación podría desempeñar un papel en la regulación celular. La oxidación de las metioninas afecta a la función de proteínas como IkB que se hace resistente a su eliminación favoreciendo la inhibición de NFkB [462]. Durante el envejecimiento se acumulan los residuos de metionina oxidada debido a una disminución en la actividad de las metioninasulfóxidoreductasas [463] por lo que la manipulación en la expresión de las metioninasulfóxidoreductasas afectaría significativamente a la sensibilidad al estrés oxidativo convirtiéndose en una buena diana terapéutica [464, 465]. Además de las metioninas y las cisteínas, otros aminoácidos también sufren los efectos del estrés oxidativo. La tirosina, precursor de neurotransmisores (dopamina, epinefrina y la norepinefrina), se nitra fácilmente produciéndose nitrotirosina que se utiliza como un marcador de estrés [466]. El 
triptófano, aminoácido aromático, también es propenso a la oxidación. La oxidación directa de residuos de lisina, arginina, prolina y treonina también se usan como un marcador de estrés oxidativo [467].

Los niveles elevados de proteínas oxidadas también correlacionan con enfermedades asociadas a la edad y al progreso de enfermedades [468]. La oxidación inactiva las enzimas afectando a gran variedad de procesos bioquímicos mientras que la acumulación de proteínas inservibles oxidadas pone en peligro las funciones celulares y la viabilidad [469]. Sin embargo, la oxidación de las proteínas aumenta su hidrofobicidad [470], "etiqueta" reconocible para el sistema del proteasoma, favoreciendo su degradación (Fig.20) [471, 472]. Durante el envejecimiento aparecen defectos en los sistemas de degradación que aumentarían la vida media de las proteínas y también la posibilidad de sufrir daño oxidativo y un deterioro de su función $[473,474]$. La actividad del proteasoma es diferente en los diversos tipos de células del cerebro, siendo menor en las neuronas que en la glía y también menor en el núcleo que en el citoplasma. Esto explica la diferente acumulación de proteínas mal plegadas en diferentes tipos de células y orgánulos [475]. La función del sistema de proteasoma es importante, no sólo para la degradación de las proteínas dañadas, sino también para la memoria y la remodelación después de una lesión cerebral traumática [476-478].

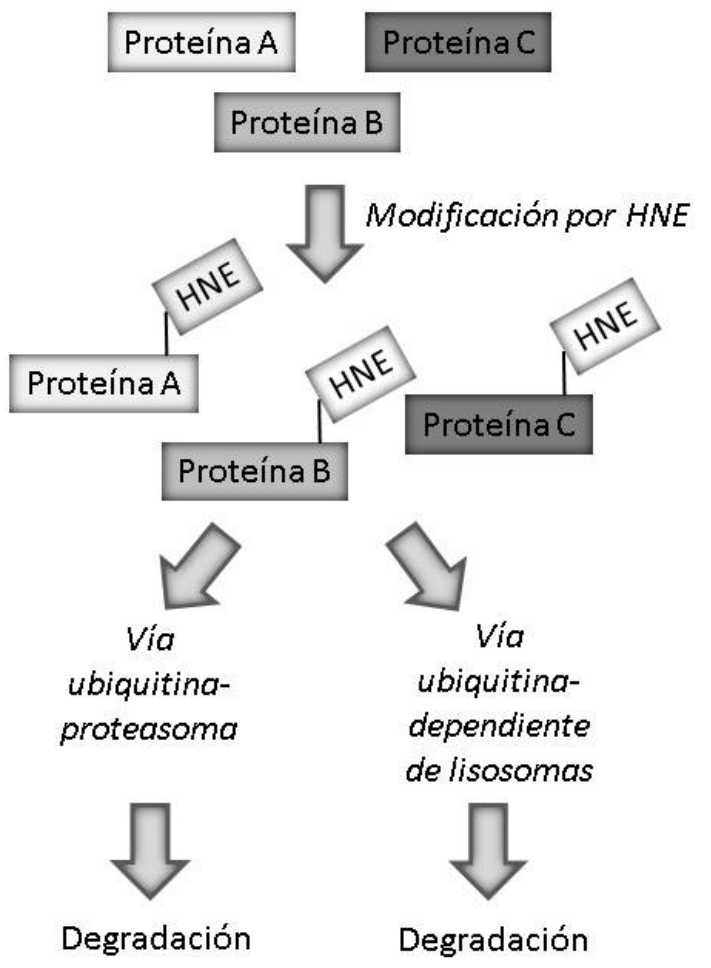

Figura 20. Mecanismos responsables de la eliminación de proteínas modificadas por los productos de peroxidación lipídica: la vía ubiquitina-proteasoma y la vía ubiquitinadependiente de lisosomas. (Modificado de [479][479]) 
Por otro lado, durante el envejecimiento disminuye la oxidación de histonas haciendo la cromatina más compacta. Esta compactación conlleva una menor actividad transcripcional y reparadora del ADN [480]

La acetilación de residuos de lisina previene la ubiquitinación y posterior degradación. Durante el envejecimiento aumenta significativamente la acetilación de lisinas en el cerebelo y en el hipocampo lo que imposibilita la ubiquitinación aumentando así la vida útil de las proteínas y con ello las probabilidades de ser oxidadas [481]. Los tratamientos que pudieran contrarrestar el deterioro de los sistemas de degradación como consecuencia de las enfermedades neurodegenerativas y el envejecimiento podrían ser herramientas importantes para paliar sus efectos.

\section{OXIDACIÓN DE ÁCIDOS NUCLÉICOS}

Los aumentos de ROS asociados a la edad también provocan daños oxidativos en el DNA [482]. La guanina es la base más sensible a la oxidación. Las regiones de ADN ricas en guanina sugieren que un cierto nivel de oxidación de guanina podría ser necesario para las funciones fisiológicas normales. Sin embargo, la acumulación de daño en el ADN (presencia de 8-oxoG) en el cerebro es un factor importante en el envejecimiento y las enfermedades neurodegenerativas $[483,484]$. Las neuronas son especialmente sensibles al daño oxidativo sobre su ADN [412] y su capacidad de reparación difiere en las distintas regiones del cerebro según la naturaleza de sus neuronas [485]. Por otra parte, el fracaso en la reparación del ADN mitocondrial acelera el proceso de envejecimiento y la neurodegeneración.

Los daños provocados por los ROS en el ADN se acumulan con la edad contribuyendo al envejecimiento y enfermedades neurodegenerativas. La inducción de sistemas de reparación del ADN también podría ser una herramienta terapéutica para retrasar el envejecimiento y las enfermedades neurodegenerativas. En concreto, las sirtuinas se han presentado como importantes candidatos potentes moduladores de la reparación del ADN [446, 486].

\section{ESTRÉS OXIDATIVO EXPERIMENTAL}

Para el estudio de los mecanismos involucrados en la oxidación se utilizan fármacos y compuestos que inducen la formación de ROS. El paraquat es uno de los compuestos más ampliamente utilizados (1,2- dimetil 4-4- bipiridinio). PQ es un herbicida no selectivo generador de ROS. Los efectos derivados de la exposición a PQ se equiparan a los observados en la enfermedad de Parkinson y se atribuyen a la pérdida selectiva de neuronas dopaminérgicas [487]. El mecanismo de toxicidad del PQ [488] estaría controlado por SOD (Fig.21). Las barreras de protección del sistema nervioso hacen necesario un estudio del efecto de los tratamientos tanto los oxidantes como los antioxidantes en las diferentes regiones del cerebro especialmente cuando se suministran fuera del sistema nervioso [489]. El hipocampo es un área clave para el estudio del estrés oxidativo. Las neuronas que lo forman están densamente empaquetadas en una sola capa dividida en varias regiones (CA1-CA4). A pesar de que tanto CA1 como CA3 poseen neuronas piramidales, responden de manera diferente al estrés oxidativo siendo CA1 mucho más sensible [433]. Algunos agentes productores de superóxido, como el PQ, son capaces de destruir selectivamente las neuronas de la región CA1 $[433,490]$. 
El sulfato ferroso (FeSO4), un generador de radicales hidroxilo o el peróxido de hidrógeno también producen el mismo efecto [491] coincidiendo con la vulnerabilidad que presentan estas neuronas frente a otras condiciones adversas como la hipoxia, isquemia o neurodegeneración $[492,493]$. El PQ también causa la muerte de las neuronas en la capa de células granulares del cerebelo, pero no en la corteza cerebral (capas IV - VI) [436].

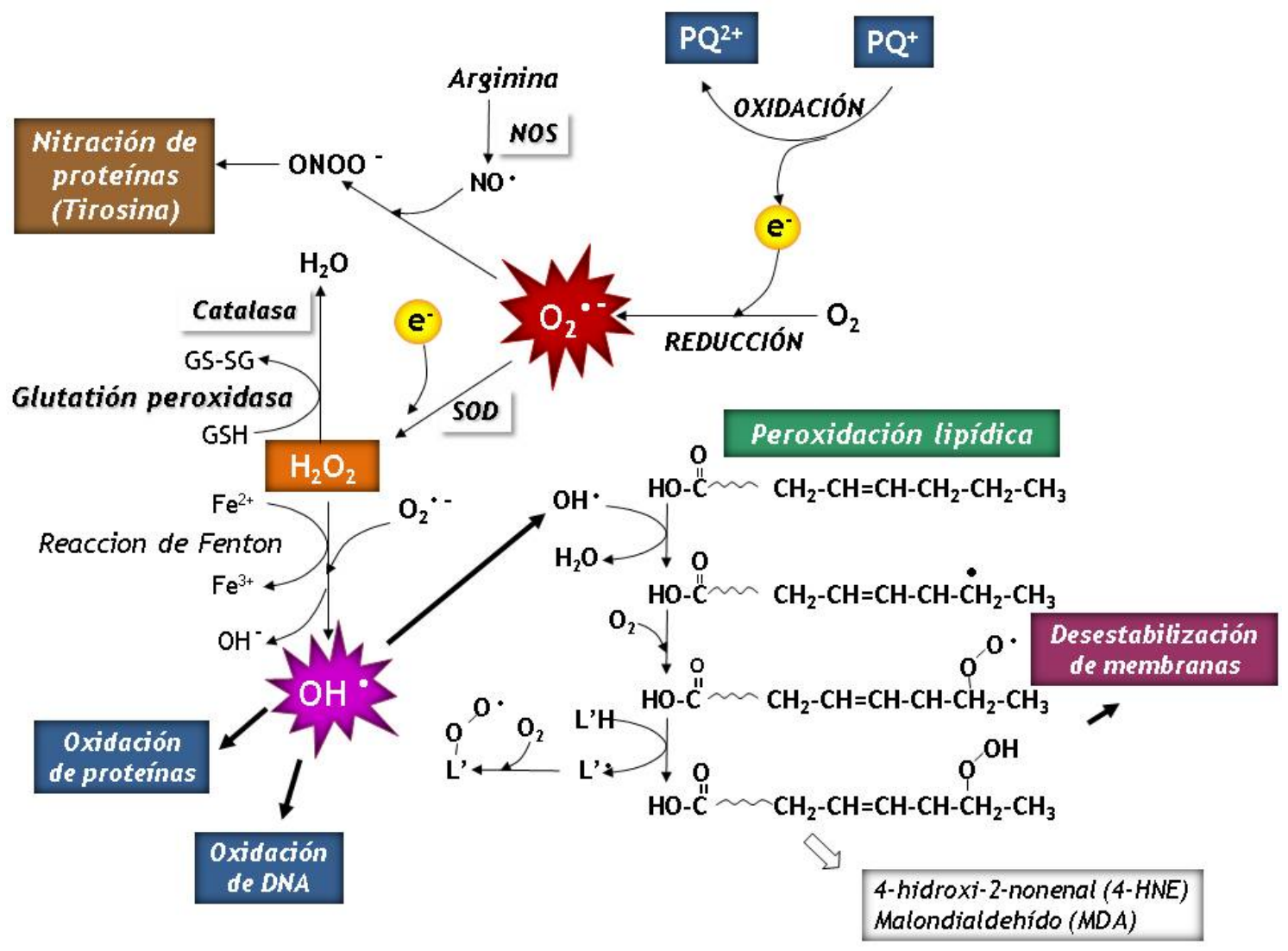

Figura 21. Esquema de actuación del paraquat. El paraquat se oxida provocando la reducción del $\mathrm{O}_{2}$ a anión superóxido. Este anión puede provocar la nitración de proteínas a través de la oxidación del óxido nítrico (NO·) (radical generado por las óxido nítrico sintasas (NOS) a partir del aminoácido arginina). La superóxidodismutasa (SOD) posee la capacidad de transformar el anión superóxido en peróxido de hidrógeno que a su vez puede transformarse en $\mathrm{H}_{2} \mathrm{O}$ por acción de la catalasa o en anión hidroxilo, a través de la reacción de Fenton. El anión hidroxilo produce la oxidación de las proteínas, los lípidos y del ADN. 


\section{LAS PROTEINOPATÍAS}

Proteinopatía es un término utilizado para determinar los trastornos neurodegenerativos debidos a la acumulación de ciertas proteínas en el interior de las neuronas. En situación normal estas proteínas presentan una estructura monomérica mientras que en situación patológica experimentan un cambio conformacional que les confiere una actividad tóxica o la pérdida de la función normal y que conduce a la formación de pequeños oligómeros que se agregan en estructuras de orden superior. Dos de las proteinopatías más abundantes son la enfermedad de Alzheimer y la enfermedad de Parkinson seguidas de muchas otras como la demencia de cuerpos de Lewy, las enfermedades priónicas, tauopatías, esclerosis lateral amiotrófica, degeneración lobular fronto-temporal o enfermedades por poliglutaminas. Cada una de estas enfermedades está asociada a una proteína diferente (tau, $\alpha$-sinucleína, huntingtina, superóxido dismutasa 1 , ataxina 1 ) lo que refleja una gran heterogeneidad entre estas enfermedades. Algunas proteinopatías se caracterizan por un solo tipo de agregado proteico mientras que otras presentan dos agregados de proteínas diferentes. Las proteínas mal plegadas exponen las cadenas laterales de aminoácidos hidrofóbicos en sus superficies que normalmente están enterrados en el interior de la estructura nativa por lo que se vuelven propensos a la auto-asociación además de actuar como núcleos de reclutamiento de otros monómeros. Los agregados de proteínas pueden adquirir características amiloides [494]. El término amiloide fue introducido por Rudolph Virchow, en 1854, para describir una anormalidad macroscópica del tejido que mostraba reacción positiva a la tinción con yodo (técnica utilizada para la detección de almidón) [495], surgiendo así el nombre de amiloide: "como almidón". Hoy en día, el término amiloide se utiliza para describir precipitados de $A ß$ amiloide, es decir, placas de Alzheimer. Sin embargo, existe controversia entre si son los agregados los que provocan graves déficits de aprendizaje y de memoria y la pérdida de neuronas o si las placas representan un depósito seguro para las proteínas tóxicas solubles [496].

Los priones son agentes proteicos infecciosos que causan enfermedades neurológicas hereditarias, esporádicos e infecciosas como la enfermedad de Creutzfeldt-Jakob en humanos o la encefalopatía espongiforme bovina en el ganado debido a un cambio conformacional de la proteína priónica PrPc a PrPSc causante de la enfermedad [497]. La enfermedad priónica presenta la peculiaridad de que la proteína priónica alterada es altamente contagiosa y puede propagar la tendencia a la autoagregación. Actualmente se contempla la posibilidad de que esta misma propagación pudiera darse en las proteínas mal plegadas causantes de la enfermedad de Alzheimer y enfermedad de Parkinson ya que los agregados de proteínas, pueden pasar del área afectada a áreas no afectadas del cerebro. Estas observaciones indican que los mecanismos no autónomos celulares son importantes para la patogénesis de las enfermedades neurodegenerativas (Meyer-Luehmann et al., 2008) y PD [498-500].

Todas estas patologías parecen tener un importante componente genético ya que muchos de los trastornos están estrechamente vinculados a mutaciones [501]. El factor de riesgo más común, sin embargo es la edad avanzada [502] y, a veces la lesión cerebral traumática [503]. 
En todos los casos, las proteínas se agregan debido a una disminución de la eficacia de los sistemas encargados de su eliminación.

\subsection{LAS ENFERMEDADES POR POLIGLUTAMINAS}

Las enfermedades por poliglutaminas son trastornos genéticos dominantes de aparición tardía que causan neurodegeneración debido a la repetición anómala del aminoácido glutamina (CAG) en la región codificante de genes específicos que provoca el mal plegamiento de la proteína y la acumulación de agregados intracelulares. La estructura de la cromatina y la regulación epigenética están involucradas en la patología de estas enfermedades [504]. La longitud de la expansión de poliglutamina correlaciona con la toxicidad y con la temprana aparición de la enfermedad. El sistema de ubiquitina-proteasoma y la autofagia son las dos principales rutas responsables de la eliminación de proteínas mal plegadas, por lo que son el foco de atención en los estudios terapéuticos [505].

Una de las características más importantes de las enfermedades por poliglutaminas es que, a pesar de la expresión ubicua de la proteína, en cada una de estas enfermedad degeneran diferentes poblaciones específicas de neuronas por lo que se consideran enfermedades de célula-autónoma. Sin embargo, la toxicidad en las células no neuronales vecinas contribuye al daño neuronal. Otro aspecto controvertido en el estudio de estas patologías es si la toxicidad se debe a una ganancia de función o a una nueva función adquirida tras el cambio conformacional [506]. Más de 100 proteínas celulares humanas contienen repeticiones de poliglutaminas, sin embargo, muy pocas se asocian a enfermedades [507].

La enfermedad de Huntington (HD) es una enfermedad neurodegenerativa causada por una expansión de poliglutamina en la proteína huntingtina. HD implica síntomas psiquiátricos, déficit cognitivo y de memoria y síntomas motores. Diferentes regiones del cerebro, incluyendo la corteza y el cuerpo estriado están afectados en HD además de un déficit de la neurogénesis adulta en el hipocampo [508].

Las ataxias cerebelosas autosómicas dominantes (ADCAs) representan un grupo heterogéneo de enfermedades neurodegenerativas con ataxia progresiva y degeneración cerebelosa. La clasificación de este grupo de enfermedades se basa en los defectos genéticos, dividiéndose en ataxias espinocerebelosas (SCA) con un desarrollo progresivo de la enfermedad, y las ataxias episódicas (EA) con episodios aislados de ataxia. Se conocen 31 tipos de SCAs [509].

La expansión por repetición de CAG y pérdida de CAT en la región codificante del gen ataxina-1 se asocia a ataxia espinocerebelosa tipo1 (SCA1). Se ha delimitado el rango de repeticiones a partir de las cuales se desencadenan los fenotipos patológicos resultando normal la repetición de 6-39 unidades de glutamina y patológica una expansión de 31-81 CAG. Los agregados proteicos pueden perjudicar el transporte axonal, alterar los factores de transcripción y bloquear los sistemas de control de calidad de proteínas. Los mecanismos encargados del control de calidad de las proteínas, el proteasoma y la autofagia, se ven afectados en estas enfermedades por ser los responsables de la eliminación de las proteínas mutantes. Por consiguiente, se han convertido en los principales candidatos sobre los que focalizar los tratamientos terapéuticos. En concreto, la autofagia podría jugar un papel fundamental en estas situaciones ya que es la vía de eliminación de los agregados de tamaño considerable que 
tienden a formar las proteínas poli-Q. Por lo tanto, la autofagia sería la maniobra de defensa natural de la célula frente a la expresión de estas proteínas mutantes [510]. La inducción de la autofagia tiene efectos protectores en modelos de enfermedades por poliglutaminas [511]. Sin embargo, el incremento de los niveles de autofagia no siempre tiene efectos beneficiosos. En un modelo de neurodegeneración provocada por la extensión patológica de poliglutaminas en la proteína atrofina, la inducción de la autofagia no resultó ser suficiente para rescatar el fenotipo ya que es igualmente necesario que los pasos finales del proceso se resuelvan adecuadamente [512].

\section{CRECIMIENTO AXÓNICO}

El crecimiento de los axones durante el desarrollo neuronal, así como su regeneración después de una lesión del sistema nervioso adulto está controlado por señales específicas extracelulares unidas a las membranas celulares o presentes en la matriz extracelular. Actualmente no se conocen de forma exacta los mecanismos moleculares a través de los cuales estas señales extracelulares se integran en el axón en crecimiento pero se acepta que la mayoría de las cascadas de señalización activadas por estas señales convergen en el citoesqueleto a través de relaciones entre los factores extracelulares y elementos intrínsecos a la neurona como receptores de membrana y proteínas asociadas al citoesqueleto. Los dos componentes principales del citoesqueleto del cono de crecimiento, los filamentos de actina y los microtúbulos, juegan un papel importante en este proceso [513].

La mayoría de las proteínas del citoesqueleto necesarias para la elongación axonal se sintetizan en el cuerpo de la célula, aunque también existe cierta síntesis local tanto durante el crecimiento como en la regeneración de los axones. Después de su síntesis, las proteínas del citoesqueleto deben ser transportadas al sitio de crecimiento axónico. Existe una correlación entre la tasa de regeneración axonal y el transporte de proteínas [514-516].

Durante la elongación axonal, se pueden distinguir 3 fases. En la fase inicial los lamelipodios y filopodios se extienden a partir de la punta del axón formando el cono de crecimiento. Esta fase se rige principalmente por la actina, que a su vez, está regulada por GTPasas de la familia Rho y por los microtúbulos (MTs). Seguidamente se produce la invasión de los MTs y ciertos orgánulos en el cono de crecimiento. Durante la fase final de consolidación, se detiene la formación de abultamientos de actina mientras que los microtúbulos se asocian a ella. La elongación axonal está modulada por factores extracelulares que provocan la activación de diversas cascadas de señalización intracelular controlando el avance del cono de crecimiento $[513,517,518]$.

En muchos casos el objetivo del axón requiere recorrer una larga distancia. Durante el recorrido los conos de crecimiento 'toman decisiones' sobre la dirección de la trayectoria guiados por células ubicadas a lo largo de su camino por lo que los conos de crecimiento viajan de "estación en estación sin conocer el destino final". Las células gliales son parte responsable de la información presente en estas estaciones mostrando patrones de reconocimiento de superficie $\mathrm{o}$ generando gradientes moleculares extracelulares al secretar moléculas importantes para la orientación del axón como las netrinas (quimio-atrayente) o Slits (quimiorepelente). Otros axones (fasciculación: unión a otros axones de la misma ruta) y algunas neuronas también participan en la regulación del ambiente necesario para un crecimiento 
correcto. La generación de un sistema nervioso funcional no sólo requiere que los conos de crecimiento alcancen sus objetivos sino que las redes neuronales deben ser funcionales. Tan pronto como se consolidan, los axones son envueltos por las células gliales para proporcionar el aislamiento y la homeostasis necesaria para la función neuronal por lo que durante la orientación del axón, las células gliales también deben estar muy controladas [519].

\subsection{EL CONO DE CRECIMIENTO}

El cono de crecimiento es una estructura extremadamente móvil y dinámica que explora el medio ambiente. Para guiar un axón hacia el objetivo apropiado, el cono de crecimiento sensa las señales extracelulares, transmite la señal y proporciona movilidad. El avance del cono de crecimiento está mediado por la polimerización y depolimerización del citoesqueleto y sus interacciones específicas. El citoesqueleto axonal se compone de tres grandes polímeros filamentosos: neurofilamentos, microtúbulos y microfilamentos de actina. Los microtúbulos y filamentos de actina son los principales componentes del citoesqueleto en el cono de crecimiento. Su organización espacial y posición relativa en el cono definen diferentes zonas funcionalmente específicas [520]:

El dominio periférico: parte más distal del cono de crecimiento, es una estructura altamente dinámica y rica en actina. Este dominio tiene lamelipodios, protuberancias membranosas a partir de las cuales se extienden los filopodios. Estas estructuras en forma de dedos muy delgados contienen haces de filamentos de actina y sufren ciclos de elongación y retracción permanentes en respuesta al entorno.

La zona de transición: situada en la interfaz entre el dominio periférico (rico en actina) y el dominio central (rico en MT). La miosina es el motor molecular para contraer la red de actina limitando la penetración de MTs en el dominio periférico.

El dominio central: sitio principal de polimerización de los neurofilamentos de MTs y de localización de vesículas de transporte y organelas. Modifica su tamaño en relación al modo de crecimiento: delgado durante el modo de avance rápido y largo en situación de pausa del crecimiento.

\subsection{LOS DOMINIOS DE MEMBRANA EN EL CRECIMIENTO AXONAL}

Muchos de los componentes moleculares que regulan el citoesqueleto de actina, la movilidad celular, el tráfico vesicular y la adhesión se asocian con los dominios de membrana, incluyendo Rho GTPasas, Src quinasas y fosfoinosítidos [521].

En la migración celular se establecen complejos de adhesión focal, que contienen componentes de señalización y de anclaje del citoesqueleto, y que deben estar sometidos a una severa regulación dinámica y espacial (se elimina la adhesión de la parte trasera de las células mientras que la delantera forma nuevos sitios de adhesión). Los dominios de membrana están implicados en esta regulación $[522,523]$. En el desarrollo de las neuronas, el crecimiento axónico depende de la movilidad y la capacidad de búsqueda de caminos del cono de crecimiento. Estas habilidades también dependen del citoesqueleto, de la adhesión 
selectiva y de la captación de señales. Las moléculas de adhesión (CAMs) y otras proteínas implicadas en la adhesión del cono de crecimiento y la movilidad se asocian también con DRM $[524,525]$.

El crecimiento axónico es uno de los procesos en los que el tráfico vesicular juega un papel fundamental. La expansión de la membrana plasmática requiere de la actividad conjunta de los procesos de endocitosis y exocitosis [526, 527]. Por un lado, el suministro de membrana, a través de la vía secretora, desde el soma hasta las dendritas y los axones es fundamental para la generación de polaridad. Por otro lado, la endocitosis de moléculas señalizadoras, neurotransmisores y factores de crecimiento, es especialmente necesaria para el desarrollo axonal. Los procesos que estos factores ponen en marcha ejercerían una gran influencia sobre la proliferación, diferenciación, maduración de sinapsis y supervivencia neuronal. El transporte axónico implicaría uniones entre vesículas, proteínas transportadoras y citoesqueleto que requerirían de una regulada composición y organización lipídica. Los dominios de membrana son esenciales en los procesos de endocitosis y exocitosis y el tráfico vesicular [528].

Los axones en desarrollo son guiados a sus objetivos por una variedad de señales extracelulares que atraen o repelen a los conos de crecimiento mediante la unión a sus receptores en la superficie de la membrana plasmática activando cascadas de señalización. EI entorno lipídico es crucial en la transducción de señales implicadas en la orientación axonal ya que la composición lipídica específica de la membrana plasmática contribuye tanto a las interacciones proteína-proteína como a la señalización lipídica en respuesta a estímulos extracelulares [529]. Ciertas proteínas asociadas a la mielina pueden inhibir el crecimiento axonal a través de interacciones con gangliósidos específicos y dominios de membrana [530]. La activación de TrkB es un requisito necesario para su localización en dominios modulando la transmisión sináptica. La fosfolipasa C, PI3 quinasas, BDNF son elementos implicados en vías de señalización durante el crecimiento axónico que interaccionan con balsas lipídicas en respuesta a señales externas $[531,532]$. El giro del cono de crecimiento en respuesta a los gradientes externos también requiere de una señalización asimétrica. Los dominios de membrana están involucrados en los mecanismos que controlan la polaridad celular pudiendo controlar la presencia de receptores específicos y las respuestas a señales externas en zonas diferentes de la membrana. Los dominios de membrana actúan como plataformas de regulación espacial que conectan las señales extracelulares con sus receptores y a estos con los elementos de las vías de señalización que desencadenan hasta llegar al citoesqueleto.

Los dominios de membrana juegan un papel importante en el crecimiento y la guía axonal ya que proporcionan plataformas que controlan espacial y temporalmente la respuesta celular a las señales de guía extracelulares, los mecanismos de adhesión, la dinámica del citoesqueleto y la movilidad del cono de crecimiento. Por lo tanto estas estructuras son elementos cruciales tanto en el desarrollo normal del cerebro como en los mecanismos de reparación tras una lesión o la neurodegeneración [513, 521]. 


\section{OBJETIVOS}

El objetivo general de esta Tesis es esclarecer el mecanismo de acción de ApoD y sus homólogos (proteínas Lazarillo) a través del estudio de su función en diferentes procesos celulares: una situación de alteración de la autofagia, el proceso de crecimiento axónico y el estrés oxidativo, todos ellos procesos en los que las membranas juegan un papel muy importante. Los estudios previos sobre ApoD o sus homólogos indican que estas lipocalinas podrían alterar estos procesos y señalan a las membranas como posibles dianas sobre las que podría recaer una parte importante de los efectos de la función de ApoD bien directa o indirectamente. Por lo tanto el estudio del efecto de la sobreexpresión o la falta de estas lipocalinas en procesos biológicos relacionados con las membranas prometen ser una fructífera herramienta para la determinación y comprensión de su mecanismo de acción.

Para ello se han planteado los siguientes objetivos:

1. Estudiar la función de GLaz y NLaz en la enfermedad neurodegenerativa basada en proteínas poliglutaminadas SCA1. Concretamente:

- Estudiar el efecto protector de GLaz y NLaz en dicha condición degenerativa

- Estudiar sus efectos sobre el mecanismo de la autofagia.

2. Estudiar el efecto de la falta de NLaz y GLaz en el crecimiento axónico y la formación de sinapsis en cultivos primarios de neuronas de Drosophila.

3. Estudiar la interacción de ApoD con las membranas y su efecto sobre la composición de los dominios de membrana. 


\section{MATERIALES Y METODOS}

\section{ANIMALES EXPERIMENTALES}

\subsection{DROSOPHILA MELANOGASTER}

Todas las moscas utilizadas pertenecen a la especie Drosophila melanogaster. Fueron mantenidas en incubación a $25 \stackrel{\circ}{\circ}$, con $60 \%$ de humedad relativa y bajo un ciclo de 12 horas de luz-oscuridad. Se cuidaron y manipularon siguiendo las condiciones de laboratorio estándares descritas en [75].

\subsubsection{SISTEMA UAS-GAL4}

EL sistema Gal4>UAS $[533,534]$ originario de la levadura, es una herramienta genética que permite expresar in vivo un gen concreto en un tipo celular específico. La secuencia del activador transcripcional Gal4 se inserta detrás del promotor (o secuencias promotoras) del gen $(X)$ cuyo patrón de expresión se pretende reproducir. Por otro lado, se inserta la secuencia UAS en la posición $5^{\prime}$ del gen de la proteína a expresar. Al activarse el promotor en la célula de interés, se expresará el activador transcripcional Gal4 que, a su vez, activará la transcripción del gen $(X)$ al unirse a la secuencia UAS localizada en su posición $5^{\prime}$. Es decir, el gen $X$ será expresado por todas las células que expresen la proteína GAL4.

\subsubsection{ESTIRPES DE DROSOPHILA}

\subsubsection{GLaz y NLaz, GANANCIA Y PÉRDIDA DE FUNCIÓN}

La deficiencia para GLaz se generó por deleción de 22 genes alrededor del locus GLaz,GLaz $\Delta 2$,descartando así la posibilidad de mutaciones deletéreas en otras partes del genoma que pudieran contribuir al fenotipo observado [75]. El mutante nulo para NLaz se consiguió mediante una mutación puntual que genera un codón de parada (NLaz $\left.{ }^{\mathrm{NW5}}\right)[83,535]$. Ambos mutantes nulos se generaron en un fondo $\mathrm{w}^{1118}$. Para obtener un fondo homogéneo, las moscas se cruzaron con líneas silvestres Canton-S durante cinco generaciones y posteriormente fueron seleccionadas por PCR [75].

Para la sobreexpresión de GLaz se utilizó la construcción(GLaz:GLaz-GFP) que contiene 1,9kb de la región del promotor y el gen GLaz completo junto a la secuencia codificante de GFP produciendo así una proteína fusionada GLaz-GFP expresada bajo el control de la secuencia reguladora nativa de GLaz [75]. Se utilizaron dos inserciones independientes de este constructo, una de ellas localizada en el primer cromosoma, GLaz:GLaz-GFP[FX], y otra en el segundo, GLaz:GLaz-GFP[F2]. También se han utilizado construcciones de elementos P, EP3100 y EP2383, que contienen el sitio de unión UAS insertado en una región del genoma próxima y orientado hacia el gen GLaz controlando su expresión bajo el control del sistema UAS-GAL4. Además se utilizaron las líneas UAS:GLaz1 y UAS:GLaz2.

La expresión de NLaz se caracterizó con dos construcciones reporteras. Una con $3 \mathrm{~Kb}$ del promotor nativo de NLaz seguido de la secuencia GFP: NLaz:GFP[R2]. Y otra que combina la 
secuencia de expresión de GFP unido a la membrana (UAS:CD8-GFP) con la construcción de la misma región del promotor de NLaz bajo el sistema GAL4 (NLaz:GAL4). Por último, para sobreexpresar NLaz, se utilizaron las línea UAS:NLazC4, UAS:NLazC5 y UAS:NLaz15 (Tabla 3).

\begin{tabular}{|c|c|c|c|c|}
\hline & & & Cromosoma & \\
\hline \multicolumn{5}{|l|}{ GLaz } \\
\hline & Sobreexpresión & & & \\
\hline & & GLaz:GLaz-GFP[FX] & 1 & $\begin{array}{l}\text { Fusión GFP + Promotor } \\
\text { nativo }\end{array}$ \\
\hline & & GLaz:GLaz-GFP[F2] & II & $\begin{array}{l}\text { Fusión GFP + Promotor } \\
\text { nativo }\end{array}$ \\
\hline & & EP3100 & II & Elemento P-UAS \\
\hline & & EP2383 & II & Elemento P-UAS \\
\hline & & UAS:GLaz1 & II & Sistema UAS-GAL4 \\
\hline & & UAS:GLaz2 & II & Sistema UAS-GAL4 \\
\hline & Falta de función & & & \\
\hline & & GLaz $\Delta 2$ & II & Deleción \\
\hline \multicolumn{5}{|l|}{ NLaz } \\
\hline & Sobreexpresión & & & \\
\hline & & GFP:NLaz:GFP[R2] & II & $\begin{array}{l}\text { Expresa GFP bajo promotor } \\
\text { nativo de NLaz }\end{array}$ \\
\hline & & NLaz:GAL4 & II & $\begin{array}{l}\text { Región promotora de NLaz } \\
\text { seguida de la secuencia } \\
\text { codificante del factor de } \\
\text { transcripción GAL4 }\end{array}$ \\
\hline & & UAS:NLazC4 & II & Sistema UAS-GAL4 \\
\hline & & UAS:NLazC5 & II & Sistema UAS-GAL4 \\
\hline & & UAS:NLaz15 & III & Sistema UAS-GAL4 \\
\hline & Falta de función & & & \\
\hline & & $\mathrm{NLaz}^{\mathrm{NW5}}$ & $\|$ & Mutación puntual \\
\hline
\end{tabular}

TABLA 3. Construcciones utilizadas para la manipulación de la expresión de GLaz y NLaz.

\subsubsection{MODELO DE SCA1 EN LA RETINA}

El constructo UAS:hAtxn1 $1^{82 Q}$, que controla la expresión de la proteína Ataxina 1 humana poliglutaminada, se cruzó con la línea gmr:GAL4 (Glass Multimer Reporter) y para dirigir la expresión a los fotorreceptores del ojo [536-540] generando un modelo de neurodegeneración en los fotorreceptores [541].

Para la sobre-expresión de GLaz y NLaz se utilizaron líneas de moscas con UAS:GLaz y UAS:NLaz $[83,542]$ y para dirigir la expresión a los fotorreceptores del ojo también se cruzaron con la línea gmr:GAL4.

Este modelo degenerativo también se generó en un fondo mutante de pérdida de función para NLaz y GLaz. 
Los cruces para el estudio del efecto de GLaz ante la activación de la autofagia fueron realizados en viales con comida instantánea de moscas (Instant food Carolina Biological Supply Company) con rapamicina ( $2 \mu \mathrm{M}$ ) en DMSO (concentración final de DMSO 0,02 \%). Los cruces control fueron realizados en la misma comida con $0,02 \%$ de DMSO.

El ayuno hidratado se realizó colocando individuos de 3 días en agar al $1 \%$ en $\mathrm{H}_{2} \mathrm{O}$ durante 17 horas.

Únicamente se han utilizado moscas hembras en todos los experimentos.

\subsection{RATONES}

Todos los ratones fueron criados y estabulados en el animalario de la Universidad de Valladolid, siendo alimentados ad libitum con dieta estándar para roedores (Harlan) y agua filtrada e irradiada con luz ultravioleta, en jaulas con ventilación controlada y un ciclo de 12 horas luz/oscuridad. Los procedimientos experimentales fueron aprobados por el comité de cuidado y uso animal de la Universidad de Valladolid en conformidad con las directrices para el cuidado y uso de mamíferos en la investigación (Directiva Comisión Europea 86/609/CEE y el Real Decreto Español 1201/2005).

\subsubsection{ESTIRPES DE RATONES}

Se han utilizado ratones de la cepa C57BL/6J silvestres (WT) y mutantes nulo de función para ApoD (ApoD-KO).

Los ratones ApoD-KO se generaron mediante recombinación homóloga sustituyendo el alelo silvestre por uno nulo debido a la inserción del gen de la fosfotransferasa de neomicina (Neo) en el exón 6 del gen ApoD que imposibilita la expresión de la proteína ApoD madura. El fondo genético se homogeneizó mediante el cruce, durante 10 generaciones, con animales C57BL/6J. Posteriormente se genotiparon y caracterizaron [89].

Para evitar el efecto materno, las derivas genéticas a largo plazo y mantener un fondo genético homogéneo, las cohortes de animales experimentales se obtuvieron a partir de individuos homocigotos, obtenidos a su vez como segunda generación de cruces entre heterocigotos para cada genotipo.

\subsubsection{TRATAMIENTO CRÓNICO CON PARAQUAT (PQ)}

Ratones machos de 6 meses de edad $(\mathrm{N}=5)$ de genotipo WT y ApoD-KO fueron inyectados intraperitonealmente con $10 \mathrm{mg} / \mathrm{kg}$ de PQ (grupo experimental) o PBS (tampón fosfato salino) (grupo control) en 7 ocasiones, dos veces a la semana durante las dos primeras semanas y una vez a la semana en las 3 siguientes. Una semana después de la última inyección se extrajeron los hipocampos de los cerebros de cada uno de los individuos y se congelaron a -80 ㄷ. Este tratamiento crónico a dosis bajas de $\mathrm{PQ}$ genera un leve estrés oxidativo y una lenta acumulación de $P Q$ en el cerebro, concentrando con ello los efectos del tratamiento en el cerebro y evitando el daño sistémico propio de la exposición a altas concentraciones de PQ 
[543]. 


\section{CULTIVOS CELULARES}

\subsection{CULTIVOS PRIMARIOS DE ASTROCITOS DE RATÓN}

Para generar cultivos primarios de glía, primeramente se extrajeron las cortezas cerebrales de ratones neonatales $\left(P_{0}\right)$. Se retiraron las meninges haciendo rodar el tejido sobre un papel de filtro estéril. El tejido restante fue sumergido en Earle's Balanced Salt Solution (EBSS) con 2,4 $\mathrm{mg} / \mathrm{mL}$ de DNAsa I y $0,2 \mathrm{mg} / \mathrm{mL}$ de albúmina de suero bovino donde se disgregó con una cuchilla quirúrgica. Seguidamente se centrifugó a 200g durante 2 minutos y se incubó con 10 $\mathrm{mg} / \mathrm{mL}$ de tripsina durante $15 \mathrm{~min}$ a $37^{\circ} \mathrm{C}$ Ctras los cuales se procedió a su desactivación por adición de $10 \%$ de suero bovino fetal (FBS). Finalmente se realizó una disociación mecánica con una pipeta Pasteur, y se centrifugó a $200 \mathrm{~g}$ durante 5 minutos. Los últimos dos pasos se repitieron y las células resultantes se resuspendieron en medio Eagle-Dulbecco (DMEM) con 10

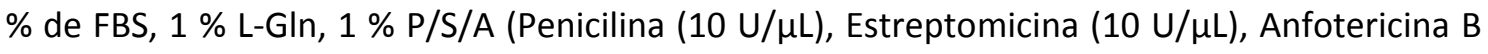
$(25 \mu \mathrm{g} / \mathrm{mL}))$. Las células se incubaron en frascos a 37 으 en $5 \%$ de $\mathrm{CO}_{2}$ con un $90-95 \%$ de humedad. El medio se reemplazó semanalmente. Tras tres pases, alrededor de $95 \%$ del cultivo estaba compuesto por astrocitos tipo1 (corroborado por marcaje con GFAP y criterios morfológicos). Los cultivos presentaron también una pequeña proporción de células microgliales (marcaje de $\mathrm{Cd} 11 \mathrm{~b}$ ). Sin embargo, no fueron detectados oligodendrocitos (marcaje de pi-GST) [544].

\subsection{LÍNEA CELULAR ASTROCITARIA HUMANA}

La línea celular de astrocitoma humano $1321 \mathrm{~N} 1$ se creció y mantuvo en DMEM con 5\% de FBS, $1 \% \mathrm{~L}-\mathrm{G}$ In y $1 \%$ de $\mathrm{P} / \mathrm{S} / \mathrm{A}$ a $37{ }^{\circ} \mathrm{C}$ en $5 \%$ de $\mathrm{CO} 2$ con $90-95 \%$ de humedad.

\subsection{CULTIVOS PRIMARIOS DE NERONAS DE DROSOPHILA. CRECIMIENTO AXÓNICO}

Para generar los cultivos primarios de Drosophila se siguió el protocolo descrito previamente por $[545,546]$. Brevemente, para la generación de triplicados experimentales de cada genotipo, se recolectaron 30 embriones en el estadio 11 (6-7 horas después de la puesta a 25으) [547]. Los embriones se sumergieron en medio de dispersión [ $30 \mathrm{~mL} \mathrm{HBSS} \mathrm{(Gibco),} 3 \mathrm{~mL}$ de solución penicilina-estreptomicina (Gibco), 0,01 g feniltiourea (Sigma), 167mLdestilada, $0,5 \mathrm{mg} / \mathrm{mL}$ Colagenasa (Worthington, Cellsystems), y $2 \mathrm{mg}$ Dispasa II (Roche)] donde se prensaron con un émbolo. Tras 3 minutos de incubación a 37으 la digestión enzimática se neutralizó con la adición demedio de cultivo Schneider (Invitrogen). Las células se centrifugaron durante 4 minutos a $1200 \mathrm{rpm}$ y seguidamente se retiró el sobrenadante. Finalmente se resuspendieron las células mecánicamente con una pipeta de $100 \mu \mathrm{l}$ en el volumen final de medio Schneider (5 ○ $6 \mu$ l por embrión). Gotas de 30 a $40 \mu \mathrm{l}$ de dicha suspensión se colocaron en cámaras especiales de cultivo generados específicamente para este fin (un portaobjetos con un orificio circular de $15 \mathrm{~mm}$ pegado sobre un portaobjetos intacto generando así un pocillo circular de fondo plano). Las cámaras se cubrieron con cubreobjetos tratados con acetona y se sellaron con vaselina quedando la gota en contacto con ambas superficies. Las cámaras se colocaron giradas sobre los cubres durante 90 minutos 
en un incubador a $26 \circ \mathrm{C}$ tras los cuales volvieron a ser giradas colocándose esta vez sobre los portaobjetos. Las células permanecieron pegadas al cubreobjetos (boca-abajo) a $26 \% \mathrm{C}$ durante 6horas para el estudio de filopodios y longitud del axón y 2 días para el estudio de la sinapsis (Fig. 22).

Para la inmunocitoquímica, las células fueron fijadas durante 30 minutos con $4 \%$ de paraformaldehído en tampón fosfato $0,05 \mathrm{M}(\mathrm{pH} 7,2)$, lavadas y permeabilizadas con $0,1 \%$ Triton X-100 en PBS (PBT) e incubadas con el anticuerpo primario durante 2 horas ( $\alpha$-Tubulina y sinapsina [3CII(antiSYNORF-1] para el estudio de sinapis y $\alpha$-Tubulina y Faloidina/TRITC (2) para el estudio de filopodios). Tras 3 lavados con PBT se incubaron con sus correspondientes anticuerpos secundarios durante una hora y media. Finalmente se lavaron y montaron con Vectashield (Vector Labs).

Se cuantificó el número de filopodios, la longitud del axón, el número de sinapsis, área de cada sinapsis y cantidad de sinapsina (suma de la intensidad de todas las sinapsis de cada neurona) para neuronas aisladas de cultivos de densidades similares $\left(1000-2500\right.$ células $/ \mathrm{mm}^{2}$ ) (30 neuronas/cultivo).

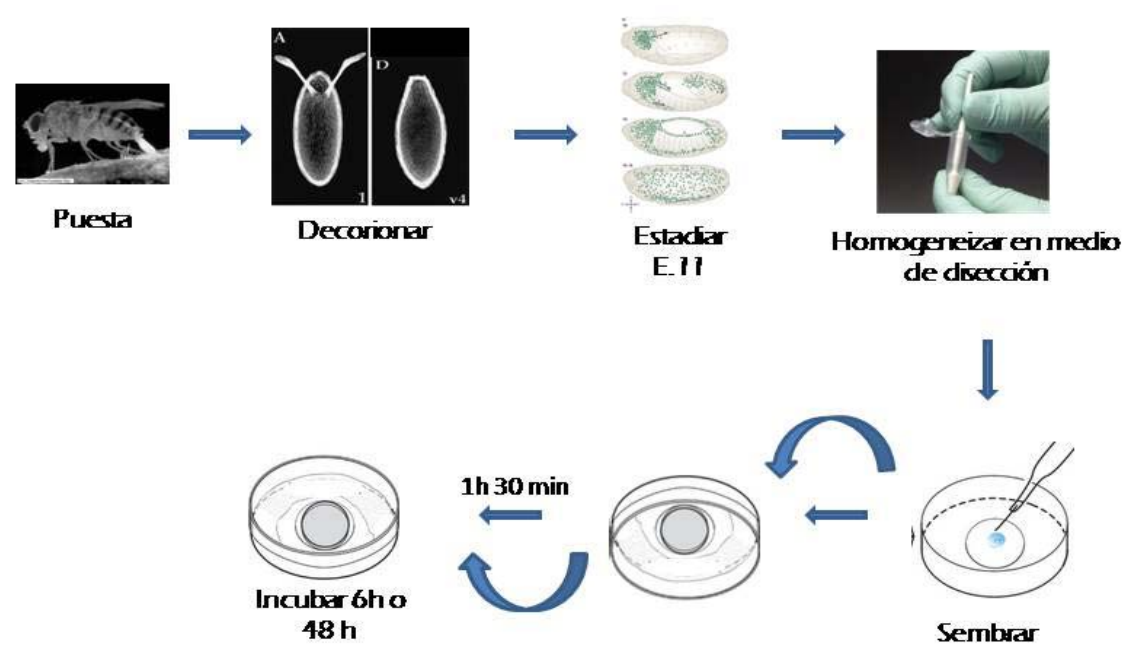

Figura 22. Esquema del proceso de generación de cultivos primarios de neuronas de Drosophila.

\section{ANÁLISIS MORFOLÓGICODE LA SUPERFICIE DEL OJO DE DROSOPHILA}

Las moscas fueron anestesiadas con $\mathrm{CO}_{2}$ e inmovilizadas con cinta adhesiva. Los ojos de mosca se fotografiaron con una cámara digital Nikon DS-L1 en un equipo estereoscópico Nikon SMZ1000 con un objetivo Plan Apo 1x WD70. Las imágenes fueron procesadas con Adobe Photoshop 6.0 usando un filtro de superficie, la máxima local se obtuvo con un software de ImageJ, y las distancias vecinas se calcularon para cada omatidio. Se estimó un índice de regularidad como la varianza de las distancias y se calculó un \% de recuperación considerando $0 \%$ el promedio degenerado y $100 \%$ el tipo de ojo silvestre control.

Para las imágenes de microscopía electrónica de barrido, las moscas fueron inmovilizadas y fotografiadas con un microscopio ESEM-FEI-Quanta 200FEG. 


\section{INMUNODETECCIÓN DE PROTEÍNAS}

\subsection{INMUNOHISTOQUÍMICA}

Para la detección inmunohistoquímica de proteínas, se fijaron cabezas de mosca con $4 \%$ paraformaldehído y se embebieron en parafina siguiendo los procedimientos estándares.

Se realizaron secciones de tejido de $4 \mu \mathrm{m}$ de grosor con un micrótomo HM 340E (Microm) y se montaron y secaron en portaobjetos tratados con polilisina (Polysine ${ }^{\text {tm }}$ ) Menzel-Gläser). Las secciones se desparafinaron en xileno y rehidrataron a través de concentraciones decrecientes de etanol en un tampón fosfato salino (PBS).

Los discos imaginales ópticos de la larva fueron diseccionados y fijados en $4 \%$ de paraformaldehído. Posteriormente el tejido fue bloqueado y permeabilizado con Triton X-100 $(0,1 \%$ en PBS $)$ y $2 \%$ de suero de cabra. Seguidamente se incubaron durante toda la noche a $4 \circ \mathrm{C}$ con los siguientes anticuerpos primarios: policlonal de conejo anti-p62 (amablemente cedido por Dr. Juhasz, Loránd University, Hungary), policlonal de conejo anti-Atxn1 (amablemente cedido por Dr. J. Botas, Baylor College of Medicine, USA), monoclonal de ratón P4D1 antiUbiquitina (Cell Signaling), policlonal de conejo anti-GFP (Santa Cruz Biotechnology, Inc), monoclonal de ratón 4C5 anti-Rhodopsina (DSHB) y monoclonal de ratón anti-MAP1B 22C10 (DSHB).

Para inmunohistoquímica con HRP se usaron anticuerpos secundarios HRP conjugados con anticuerpos de cabra anti IgG de conejo (Abcam) y anti-IgG de ratón (Dako). Para revelar estos anticuerpos secundarios con HRP las muestras se incubaron con 0,03 \% DAB (3,3'diaminobencidina tetrahidrocloruro) (Sigma-Aldrich) y $0,002 \% \mathrm{H}_{2} \mathrm{O}_{2}$ en $50 \mathrm{mM}$ Tris ( $\mathrm{pH}$ 8.0). Las secciones fueron lavadas con PBS, deshidratadas y montadas en un cubreobjetos en medio de montaje Eukitt ${ }^{\mathrm{TM}}$ (Sigma-Aldrich).

Para la inmunohistoquímica fluorescente, se usaron los anticuerpos secundarios: cabra antiratón conjugados con FITC y cabra anti-conejo conjugado con Cy3.5 (Abcam). Posteriormente fueron lavadas con PBS y montadas con Vectashield-DAPI (Vector Labs).

Para la cuantificación de muerte celular por apoptosis en las secciones de las cabezas de mosca se utilizó TUNEL FITC labeling kit (Roche) siguiendo su protocolo de uso.

Finalmente las secciones se visualizaron y fotografiaron con un equipo de microscopía fluorescente Eclipse 90i (Nikon) con una cámara digital DS-Ri1 (Nikon)

Las imágenes fueron adquiridas y procesadas con el software NIS-Elements BR 3.0 (Nikon).

\subsection{INMUNOCITOQUÍMICA}

Para la caracterización de la localización intracelular de ApoD tras su endocitosis se sembraron las células (astrocitos primarios y 1321N1) en cubreobjetos tratados con poli-L-lisina. En situación de bajo suero (0,2\% FBS), los astrocitos primarios se trataron con ApoD humana 
purificada de fluido cístico $(4 \mathrm{mM})$ durante $24 \mathrm{~h}$. Fueron fijadas con $4 \%$ de formaldehido en PBS. Tras varios lavados con PBS fueron bloqueados y permeabilizados (0,25\% Triton X-100, $1 \%$ suero de cabra en PBS). Las células fueron incubadas durante dos horas en anticuerpo antiLAMP2 (H4B4) y anti-hApoD (generado por C. López-Otín) y posteriormente en anticuerpos secundarios conjugados con Cy3 y FITC para su detección por fluorescencia. Finalmente fueron lavados con PBS y montados con Vectashield-DAPI (Vector Labs)

Las imágenes de microscopía confocal se obtuvieron con un microscopio DMI 6000B con un sistema confocal TCS SP5 $\mathrm{X}$ y un láser blanco (WLL) (Leica) controlado por el programa LAS AF (Leica).

\subsection{INMUNOBLOT}

Las proteínas de las cabezas de mosca se solubilizaron por homogeneización en un tampón de lisis y la concentración de proteína total fue evaluada por el método colorimétrico BCA ${ }^{26}$ (ácido bicinconínico) (Micro BCA ${ }^{T M}$ Protein Assay Kit (Pierce)). Las proteínas (10 ○ $20 \mu \mathrm{g}$ por calle) diluidas en un tampón de carga (63mM Tris- $\mathrm{HCl}, \mathrm{pH} 6,8,10 \%$ glicerol, 2\% SDS, 100mM DTT y azul de bromofenol) y desnaturalizadas ( 5 minutos a 70 으) fueron separadas en función de su peso molecular mediante electroforesis en gel de poliacrilamida con dodecilsulfato sódico (SDS-PAGE). La electroforesis se llevó a cabo en una disolución tampón (25mM Tris-HCl, $190 \mathrm{mM}$ de glicina, 0,1\% SDS) y a voltaje constante de 80-100 V durante 90 minutos.

Las proteínas se transfirieron a una membrana de polifluoruro de vinilideno (PVDF) (immobilonTM-P Transfer Membrane, Millipore) mediante un amperaje constante de $400 \mathrm{~mA}$ durante 90 minutos en tampón de transferencia $(25 \mathrm{mM}$ Tris- $\mathrm{HCl}, 190 \mathrm{mM}$ glicina, $20 \%$ metanol; $\mathrm{pH} 8,5$ ).

Finalizada la transferencia, los geles fueron teñidos con azul de Coomassie $[0,1 \% \mathrm{p} / \mathrm{v}$ Coomassie Brilliant Blue, $50 \% \mathrm{v} / \mathrm{v}$ metanol, $5 \% \mathrm{v} / \mathrm{v}$ ácido acético] y seguidamente desteñidos [25\% v/v etanol puro, 7,5\% v/v ácido acético en $\mathrm{dH}_{2} \mathrm{O}$ ] y digitalizados (densitómetro GS800 BioRad) para la visualización de proteínas y comprobación de la eficiencia de la transferencia. Por otro lado, las membranas, tras ser bloqueadas durante una hora a temperatura ambiente $(5 \%$ leche desnatada en polvo, 0,05\% Tween-20, 50mM Tris- $\mathrm{HCl}, 150 \mathrm{mM} \mathrm{NaCl}, \mathrm{pH} 7,5)$, fueron expuestas a los siguientes anticuerpos: policlonal de conejo anti p62 (Dr. Juhasz, Loránd University, Hungary) y monoclonal de ratón P4D1 anti-Ubiquitin (Cell Signaling). Todos ellos se incubaron durante toda la noche a 4 으. Tras varios lavados $(0,05 \%$ Tween-20, $50 \mathrm{mM}$ Tris $\mathrm{HCl}, 150 \mathrm{mM}$ $\mathrm{NaCl}, \mathrm{pH} 7,5$ ) las membranas fueron expuestas a anticuerpos secundarios (cabra anti-conejo o anti-ratón) conjugados con la peroxidasa de rabanillo (HRP) (DAKO). Se usó HRP-conjugado con anticuerpo anti- $\beta$ actina (Sigma, St Louis, MO, USA) para normalizar la intensidad de banda respecto a la cantidad de muestra cargada.

Las membranas fueron reveladas mediante una reacción quimioluminiscente con ECL (Millipore, Billerica, MA, USA), y la señal visualizada con una cámara digital (VersaDoc, BioRad).

\footnotetext{
${ }^{26}$ La cuantificación de proteínas se basa en la detección colorimétrica resultante de la reacción del ácido bicinconínico (BCA) con el Cu+ fruto, a su vez, de la reducción del catión Cu2+ por oxidación de las proteínas presentes en la muestra.
} 
La densidad óptica integrada de las bandas proteicas inmunoreactivas se midió en imágenes tomadas en el rango lineal de la cámara, evitando la saturación de la señal.

\section{RT-PCR CUANTITATIVA}

Para los estudios de expresión de mRNA las cabezas de mosca se almacenaron a $-80^{\circ} \mathrm{C}$. Posteriormente se extrajo el RNA usando QIAzol ${ }^{\mathrm{TM}}$ Lysis Reagent (Qiagen).

La concentración de RNA se midió, a partir de la absorbancia a 260nm, con un espectrofotómetro Nanodrop ND1000 (Thermo Scientific). Tras un tratamiento con DNAsa I (Fermentas) para eliminar una posible contaminación con DNA genómico, se recogieron 500ng del total de RNA purificado para realizar su retrotranscripción a DNA complementario (cDNA). Para ello se utilizó, a $4 \stackrel{-}{ } \mathrm{C}$ durante una hora, el PrimeScript ${ }^{\mathrm{TM}}$ Reagent kit (Takara Bio Inc., Otsu, Japan) junto con cebadores oligo-dT (25 pmol) y hexámeros aleatorios (50 pmol). El cDNA

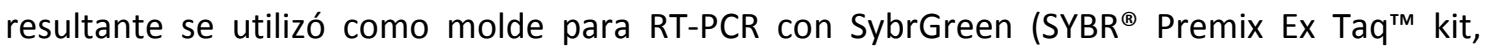
Takara). El gen Rpl18 se utilizó como referencia. Estos experimentos se realizaron por quintuplicado en un termociclador Rotor-Gene RG-3000 (Corbett Research). Las condiciones de ciclado fueron 30 segundos a 95 C y 40 ciclos de ( 5 segundos a 95, 15 segundos a 55ㅇ, 15 segundos a $72^{\circ} \mathrm{C}$ ). Se establecieron curvas de fusión (curvas de Melting) para verificar la ausencia de amplificaciones inespecíficas. Los cebadores usados para la RT-PCR se muestran en la Tabla 1. Finalmente, los niveles relativos de mRNA se calcularon con el método $\Delta \Delta C_{T}$ [548]. En este método, el ciclo de amplificación $(\mathrm{Ct})$ en el que aparece el producto del gen de interés se normaliza frente al gen de referencia: $\Delta \mathrm{C}_{\mathrm{T}} \mathrm{Ct}$ gen interés $-\mathrm{Ct}$ gen referencia. $\mathrm{El}$ nivel de expresión de cada gen $\Delta \Delta C_{T}$ en las diferentes condiciones es el resultado de: $\Delta \Delta C_{T=} \Delta C_{T}$ condición 1- $\Delta C_{T}$ condición 2. $Y$ la magnitud del cambio en la expresión de un gen se expresa como: $2^{-\Delta \Delta C t}$. Las diferencias estadísticamente significativas fueron evaluadas con Mann-Whitney U-test [549], usando $\Delta C_{T}$ de cada réplica. En función de la magnitud del cambio los valores fueron expresados como el valor medio de $2^{-\Delta \Delta C t} \pm \mathrm{SD}$ o de $\log 2^{-\Delta \Delta C t} \pm \mathrm{SD}$. El nivel de significación estadístico se fijó en $P<$ 0,05 .

\begin{tabular}{|c|c|c|}
\hline Gen & Orientación del cebador & Secuencia del cebador \\
\hline \multirow{2}{*}{ NLaz } & Forward & 5'-CGAGTACGCAGCCTATCCAT-3' \\
\hline & Reverse & 5'-CCAGGTAGTTGGCCTTCGT-3' \\
\hline \multirow{2}{*}{ GLaz } & Forward & 5'-GCGAACAATCGAAGTTTTCC-3' \\
\hline & Reverse & 5'-ACAAGATGGCGAAGTTCTCG-3' \\
\hline \multirow{2}{*}{ hATXN1 } & Forward & 5'-GTGGCCGTGATACAGTTCG-3' \\
\hline & Reverse & 5'-AGCCGTTCTTCAGGTTCTTG-3' \\
\hline \multirow{2}{*}{ GstS1 } & Forward & 5'-AAGGACAACGATGGTCACCTGGC-3' \\
\hline & Reverse & 5'-CGGTGAACTTAGACCTCGGTGACG-3' \\
\hline \multirow{2}{*}{ Vib } & Forward & 5'-GGCCAATCGCACTCCCCAGTTC-3' \\
\hline & Reverse & 5'-TAACACCTCGATGCCCTCGCC-3' \\
\hline \multirow{2}{*}{ Atg8a } & Forward & 5'-CATCGGTGATTTGGACAAGA-3' \\
\hline & Reverse & 5'-AGTCCTCCTCGTGATGTTCC-3' \\
\hline L18 & Forward & 5'-AGAACCGAGCCCAAATCC-3' \\
\hline
\end{tabular}




\begin{tabular}{|l|l|l|}
\hline & Reverse & 5'-CGACCACGATGGTAGACTCC-3' \\
\hline
\end{tabular}

TABLA 4. Secuencias de los cebadores utilizados en las RT-PCR.

\section{AISLAMIENTO DE DOMINIOS DE MEMBRANA RESISTENTES A DETERGENTE}

a) Preparación de membranas

Se homogeneizó un hipocampo de ratón en $2 \mathrm{ml}$ de TNE en un homogeneizador Potter a 245 rpm durante10 toques y en hielo, posteriormente se centrifugó en centrífuga clínica a $4^{\circ} \mathrm{C}$ a 3000 g (4000 rpm Rotanta 460R Hettich) durante 10 minutos. El sobrenadante se volvió a centrifugar otros 2 minutos a 3000G. El segundo sobrenadante se llevó a un tubo de centrífuga de sellado (Quick-Seal 13×64 mm) de $6 \mathrm{ml}$ donde se sedimentaron las membranas al someterlas a ultra-centrifugación (BECKMAN COULTER Optimal-100XP Ultracentrifugue) con un rotor $100 \mathrm{Ti}$ a $100.000 \mathrm{~g}$ durante $1 \mathrm{~h} 15 \mathrm{~min}$ a 4 으. Finalmente las membranas se resuspendieron en $200 \mu \mathrm{l}$ de TNE. La cantidad de proteína total se cuantificó por análisis de BCA (Pierce). Durante todo el proceso la muestra siempre se mantuvo a 4 으.

\section{b) Separación de dominios insolubles en detergente}

Se cogieron $300 \mu \mathrm{g}$ de proteína de las preparaciones de membrana anteriormente descritas y se llevaron a un volumen de $1 \mathrm{ml}$ con $1 \%$ Triton X-100 en TNE (Tris $\mathrm{HCl} 50 \mathrm{mM}(\mathrm{pH} 7,4), \mathrm{NaCl}$ $150 \mathrm{mM}$ y EDTA $5 \mathrm{mM}$ ). Se incubaron en detergente durante $40 \mathrm{~min}$ a $4{ }^{\circ} \mathrm{C}$ en un agitador noria. Posteriormente el mililitro se transfirió a $2,25 \mathrm{ml}$ de una disolución de sacarosa al $80 \%$ en TNE (concentración final de $45 \%$ de sacarosa). Sobre ella se generó un gradiente discontinuo al añadir muy suavemente $6 \mathrm{ml}$ de TNE-sacarosa al $35 \%$ y sobre ellos, $3 \mathrm{ml}$ TNEsacarosa al 5\%. El gradiente se ultra-centrifugó durante 19 horas a 4ำ y $102445 \mathrm{~g}$ (rotor: SW 40 1b o 3B) (aceleración y deceleración máxima). Tras las 19 horas se tomaron fracciones de 1 $\mathrm{ml}$ y se congelaron a $-80^{\circ} \mathrm{C}$ con $0,01 \%$ de butilhidroxitolueno (BHT) como antioxidante. La fracción 3 corresponde a los DRM.

\section{c) Precipitación de proteínas}

A cada fracción del gradiente $(1 \mathrm{ml})$ se le añadió TCA al $40 \%$ en $\mathrm{H}_{2} \mathrm{O}$ y se incubaron en hielo durante 20 minutos. Posteriormente se centrifugaron a $14.000 \mathrm{rpm}$ a $4 \stackrel{\circ}{ } \mathrm{C}$ durante 30 minutos. Descartado el sobrenadante, se añade etanol absoluto frío y se vuelve a centrifugar 14.000

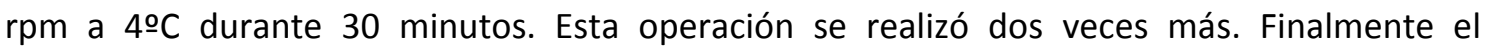
precipitado final se dejó secar y se resuspendió en un tampón de carga $(63 \mathrm{mM}$ Tris- $\mathrm{HCl}, \mathrm{pH}$ 6,8, $10 \%$ glicerol, $2 \%$ SDS, $100 \mathrm{mM}$ DTT y azul de bromofenol) se calentó durante 5 minutos a 70 ㄷ para su desnaturalización y se cargó en un gel de poliacrilamida para la detección de proteínas por inmunoblot. 


\section{ELECTROFORESIS BIDIMENSIONAL}

Las proteínas de la suma de dos fracciones de DRM extraídas en experimentos independientes fueron precipitadas con TCA.

El precipitado proteico se disolvió en un tampón de hidratación (o solución con surfactantes múltiples) conteniendo $8 \mathrm{M}$ urea, $2 \mathrm{M}$ tiourea, $4 \%$ CHAPS w/v, 0,5\% anfolitos, 50mM DTT, y azul de bromofenol. La disolución se cargó en una tira de gradiente de $\mathrm{pH}$ inmovilizado (IPG) (gradiente de $\mathrm{pH}$ lineal 3-10, $18 \mathrm{~cm}$ de longitud, GE Healthcare).

El isoelectroenfoque se llevó a cabo en un IPGphor (GE Healthcare). Tras la rehidratación activa de las tiras a 30-60 V durante 12 horas, comenzó el isoelectroenfoque a $500 \mathrm{~V}$. El voltaje se fue gradualmente incrementado hasta $8000 \mathrm{~V}$ donde se mantuvo constante durante 6 horas. Inmediatamente después, las tiras de IPG se equilibraron [550] durante 15 minutos con $1 \%$ DTT w/v en un tampón de equilibración ( $50 \mathrm{mM}$ Tris- $\mathrm{HCl}, \mathrm{pH} 8,8,6 \mathrm{M}$ urea, 30 \% glicerol v/v, 2 $\%$ SDS w/v, 0,01 \% azul de bromofenol w/v), seguido de otros 15 minutos en 2,5\% iodacetamida $\mathrm{w} / \mathrm{v}$ en el mismo tampón. La segunda dimensión se realizó mediante electroforesis en gel de poliacrilamida al $10 \%$ con dodecilsulfato sódico (SDS-PAGE). Las tiras IPG procedentes de la primera dimensión (IEF) se colocaron directamente sobre los geles (20x $18 \mathrm{~cm}$ ) y se corrieron a $40 \mathrm{~mA}$ en un aparato SE 600 Ruby (GE Healthcare). Posteriormente, las proteínas se fijaron en el gel con $50 \%$ de metanol y $10 \%$ de ácido acético durante 30 min para ser finalmente teñidas con plata.

\section{TINCIÓN CON PLATA}

La sensibilización se realizó con 30\% Etanol/ 0,2\% Tiosulfato sódico y 6,8\% Acetato sódico en agua MilliQ durante 30 minutos con agitación. Tras tres lavados con agua MilliQ de 5 minutos, se incubó en $0,25 \%$ de Nitrato de plata (fresco) durante 20 minutos con agitación. Tras otros dos lavados de 1 minuto se reveló con carbonato sódico al 2,5\% (p/v) y formaldehido al 0,04\% agitando manualmente durante 2 a 5 minutos hasta la aparición de las bandas. Finalmente se detuvo el revelado con EDTA- $\mathrm{Na}_{2} \cdot 2 \mathrm{H}_{2} \mathrm{O}$ al $1,46 \%(\mathrm{p} / \mathrm{v})$ durante 10 minutos. Tras los lavados finales los geles se conservaron en agua MilliQ y a 4 으. Se digitalizaron usando un escáner de imagen (GE Healthcare) a una resolución de 600 puntos por pulgada (dpi) y las imágenes fueron analizadas con un software Image Master, 2D Platinum 6.0 (GE Healthcare).

\section{CUANTIFICACIÓN DE COLESTEROL Y ESFINGOMIELINA}

Se midió la concentración de colesterol y esfingomielina en las diferentes fracciones extraídas del gradiente de sacarosa utilizado para la obtención de los dominios de membranas.

Para la cuantificación de colesterol se utilizó el Kit Amplex Red Cholesterol Assay kit de (Invitrogen) siguiendo las instrucciones de uso. El colesterol presente en la muestra pasa a cetona por acción de la enzima colesterol oxidasa transformando en paralelo una molécula de $\mathrm{H}_{2} \mathrm{O}$ en $\mathrm{H}_{2} \mathrm{O}_{2}$. Cada molécula de $\mathrm{H}_{2} \mathrm{O}_{2}$ reacciona con el compuesto Amplex Red (10-acetil-3,7- 
dihidroxifenoxazina) en presencia de peroxidasa de rabanillo con una estequiometria 1:1 dando como producto de reacción una molécula de resorufina altamente fluorescente $(\lambda$ excitación $=571 \mathrm{~nm}, \lambda_{\text {emisión }}=585 \mathrm{~nm}$ ). Usando placas de 96 pocillos (NUNC) se midió la fluorescencia de cada fracción $(15 \mu \mathrm{L})$ utilizando un lector de placas TECAN Genios Pro excitando a $535 \mathrm{~nm}$ y midiendo a $590 \mathrm{~nm}$ a 22,8 ㅇ C (Fig.23).
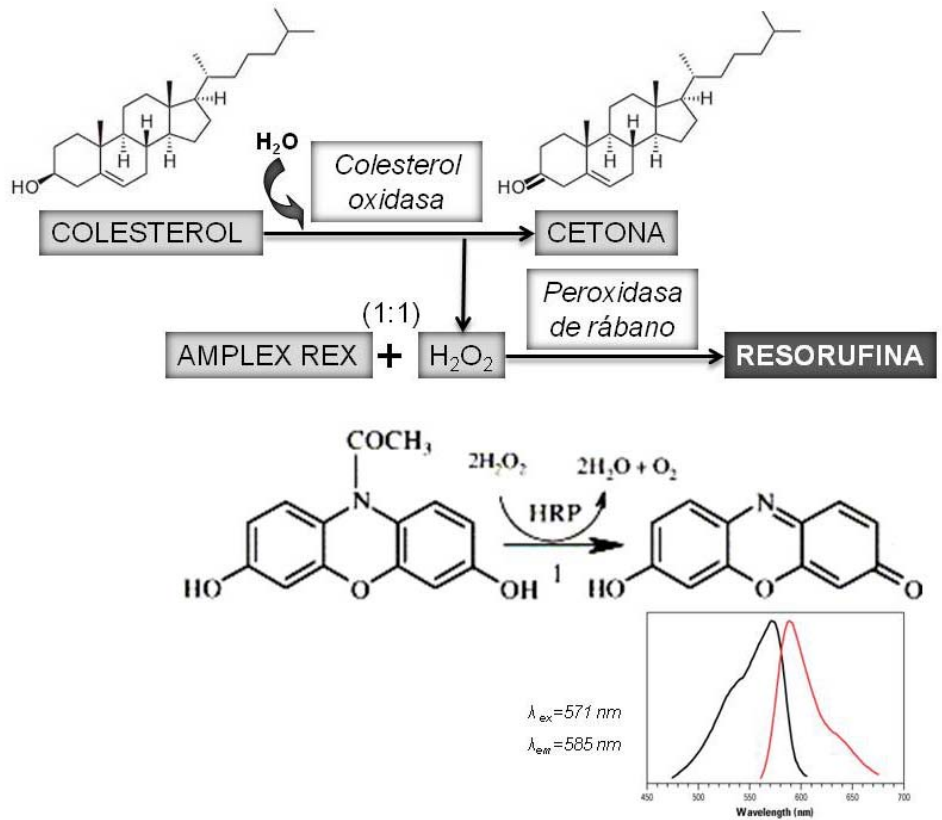

Figura 23. Ensayo fluorimétrico para la cuantificación de colesterol.

Para la cuantificación de esfingomielina se utilizó un ensayo fluorimétrico modificado de Hojjati y Jiang (2006) [551] puesto a punto por el laboratorio de la Dra. Ledesma [552] basado en la transformación de la esfingomielina presente en la muestra (secada en presencia del detergente Thesit) en colina y su posterior oxidación a betaína aldehído por acción de la enzima esfingomielinasa, la fosfatasa alcalina y la colina oxidasa produciendo $\mathrm{H}_{2} \mathrm{O}_{2}$, que a su vez se hace reaccionar con ácido homovanílico (HVA) transformándose en un dímero fluorescente $\left(\lambda_{\text {excitación }}=321 \mathrm{~nm}, \lambda_{\text {emisión }}=420 \mathrm{~nm}\right)$. Para ello se añadieron a $30 \mu \mathrm{g}$ de proteína (10 $\mu \mathrm{l}$ de cada fracción del gradiente de sacarosa) $4 \mu \mathrm{l}$ de Thesit $20 \%$ en cloroformo. La mezcla se secó con $\mathrm{N}_{2}$. Seguidamente se resuspendieron en $10 \mu \mathrm{l}$ de $\mathrm{H}_{2} \mathrm{O}_{\mathrm{ma}}$ y se incubaron en un baño a 37으 C durante10 min. Transcurrido este tiempo se añadieron $30 \mu \mathrm{l}$ de mezcla de reacción (Tris $\mathrm{HCl} \mathrm{pH} \mathrm{7,550mM,} \mathrm{MgCl}_{2}$ 0,5mM, peroxidasa de rábano $10 \mathrm{U} / \mathrm{ml}$, esfingomielinasa $\mathrm{C} 0,5 \mathrm{U} / \mathrm{ml}$, fosfatasa alcalina $10 \mathrm{U} / \mathrm{ml}$, colina oxidasa $1 \mathrm{U} / \mathrm{ml}$, HVA 1,2mM) y se incubaron en un baño a 37 ㅇ C durante una hora protegido de la luz. Finalmente se añadieron $200 \mathrm{ml}$ de carbonato /EDTA para parar la reacción (Fig. 24).

La fluorescencia se midió a 440nm utilizando un espectrofluorímetro RF-5301 PC SHIMADZU. 

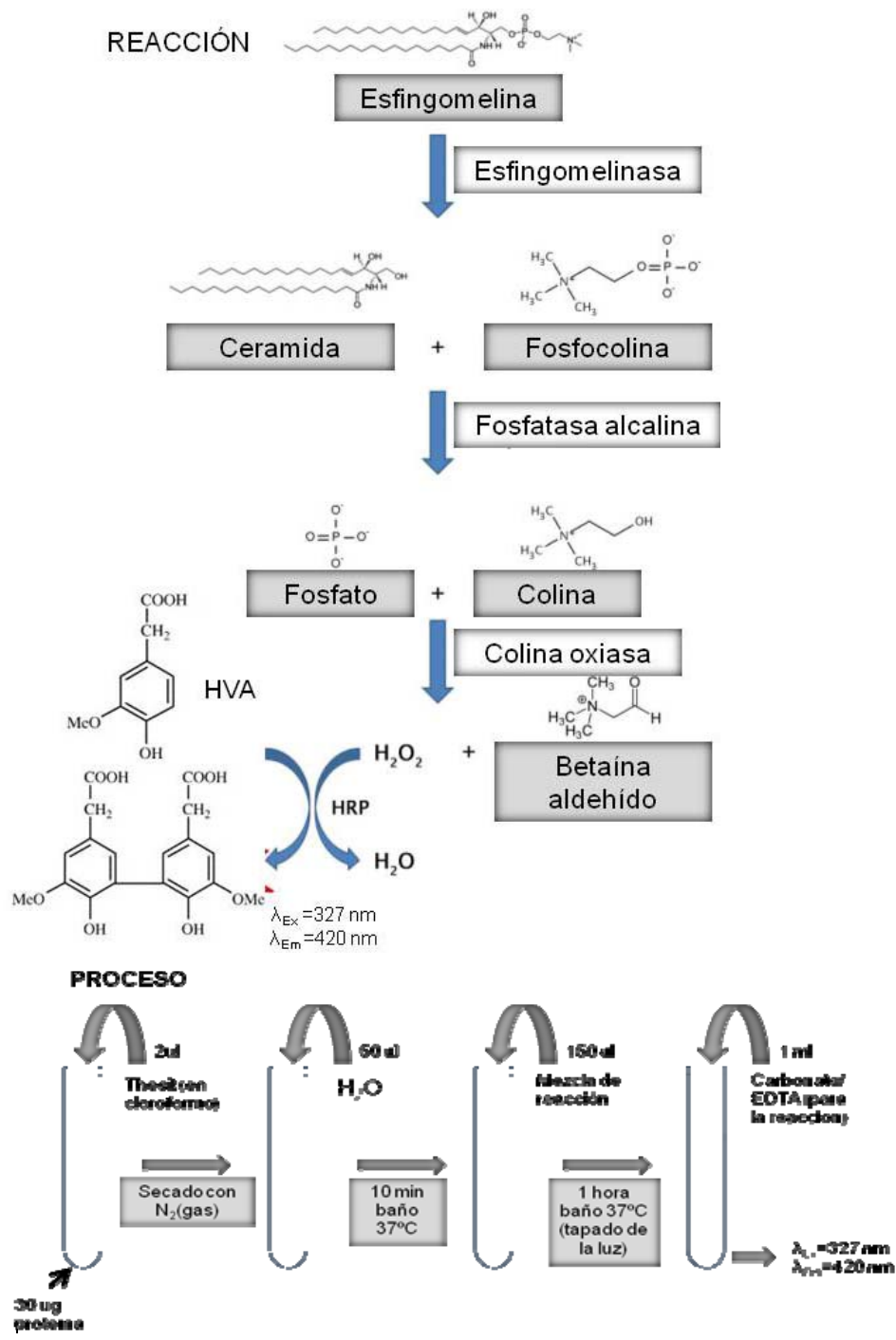

Figura 24. Esquemas de la reacción y procedimiento del ensayo fluorimétrico para la cuantificación de esfingomielina.

Para determinar las concentraciones se generaron curvas patrón para cada compuesto utilizando el rango lineal.

\section{ANÁLISIS LIPIDÓMICO}

La espectrometría de masas es una técnica de análisis cualitativo que aunque se denomina como una técnica espectroscópica, poco tiene que ver con la espectrofotometría clásica ya que no proporciona ningún parámetro relacionado con la emisión o absorción de una radiación, además de ser una técnica destructiva en contraposición al resto de técnicas espectroscópicas. Se basa en la obtención de iones a partir de moléculas orgánicas que posteriormente serán separados en función de su masa y su carga y finalmente detectados. El espectro de masas representa, por tanto, un parámetro relacionado con la presencia de los diferentes iones en función de la relación masa/carga [553]. La espectrometría de masas (MS) se ha posicionado en los últimos años como la técnica dominante en los análisis lipidómicos. Consta de tres eventos fundamentales: la ionización, la separación iónica dependiente de su masa y la 
detección del ión. La ionización normalmente va precedida de una separación en cromatografía líquida (LC) o cromatografía de gases (GC). Los principales métodos de ionización son ionización por eletrospray (ESI), ionización por impacto electrónico (EI) o desorción/ionización láser asistida por matriz (matrix assisted laser desorption/ionisation (MALDI)). La separación puede realizarse por varios tipos de analizadores de masas como triple cuadrupolo, trampa de iones, orbitrap o tiempo de vuelo (TOF), que utilizan campos eléctricos o magnéticos para afectar la trayectoria y la velocidad de las partículas en función de su carga/masa $(q / m)$. Finalmente el detector registra la carga del ión. La MS permite la determinación de especies moleculares lipídicas intactas en pequeñas cantidades de muestra que está impulsando la caracterización lipidómica de los diferentes tejidos y condiciones biológicas en múltiples especies.

Las muestras a analizar deben ser conservadas a $-80^{\circ} \mathrm{C}$ y manipuladas a $-20^{\circ} \mathrm{C}$ para evitar su degradación, fundamentalmente por oxidación de los lípidos poliinsaturados. La determinación "semi-cuantitativa" toma como referencia la cantidad de proteínas de la muestra además de la medida de estándares internos introducidos en la muestra. Actualmente la lipidómica se considera una técnica cualitativa utilizándose fundamentalmente para la determinación relativa de componentes en diferentes condiciones. La extracción de lípidos con diferentes mezclas de metanol conlleva la precipitación de las proteínas de la muestra. Las distintas mezclas de extracción se utilizan en función del tipo de lípido de interés y del método analítico que se va a utilizar siendo la más común la mezcla cloroformo/metanol (2:1). Variaciones en dicha mezcla junto a extracciones en fase sólida o separaciones cromatográficas permiten la realización de extracciones selectivas y el fraccionamiento en extractos lipídicos para un mejor análisis posterior. Las técnicas lipidómicas permiten la obtención de datos para diferentes subclases lipídicas salvo en el caso del colesterol que únicamente permiten obtener la suma de especies que contienen colesterol y colesteril ésteres y triacilgliceroles ya que muchos de ellos solapan durante la detección. La ionización puede estar dirigida hacia la formación de iones positivos (útil para el análisis de fosfolípidos, esfingolípidos y acilgliceroles) o hacia iones negativos (para fosfatidilinositoles, fosfatidilserina y ácido fosfatídico). La identificación de cada compuesto requiere de librerías basadas en patrones de fragmentación reproducibles obtenidos para sustancias de referencia(www.lipidmaps.org). Finalmente los datos crudos deben ser procesados para convertirlos en listas de moléculas lipídicas. El análisis y la interpretación de los datos consiste en tratamientos estadísticos, análisis multivariantes y aproximaciones bioinformáticas (Fig. 25) $[554,555]$.

Los lípidos de los DRM se analizaron como se describe en [556]. Se utilizó una plataforma basada en cromatografía líquida de ultra-rendimiento (UPLC)-tiempo de vuelo (TOF)espectrometría de masas (MS) para analizar los lípidos extraídos con cloroformo/metanol (glicerolípidos, colesteril ésteres, esfingolípidos, diacilglicerofosfolípidos y acil-eterglicerofosfolípidos. 


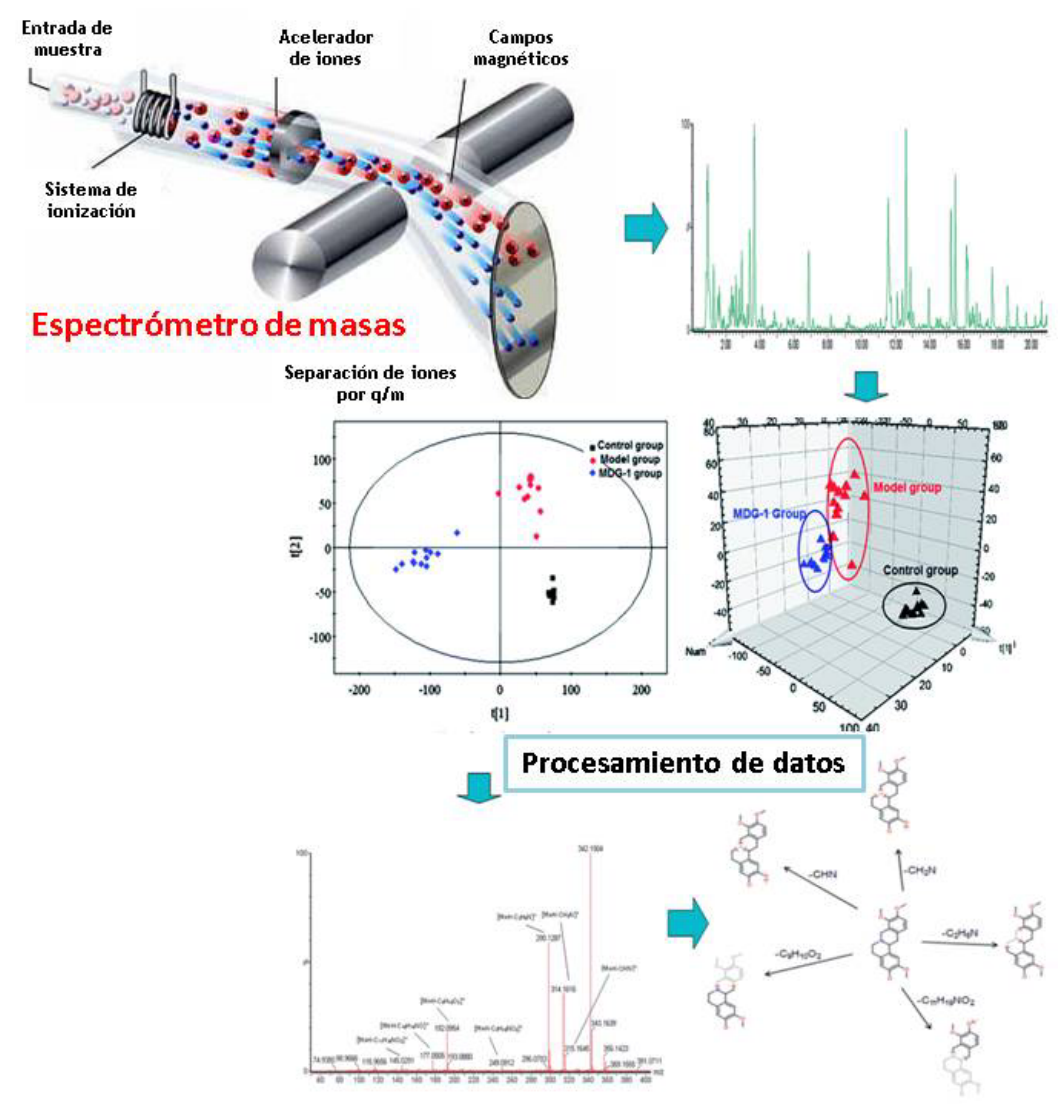

Figura 25. Proceso de análisis por espectrometría de masas (modificado de[557, 558])

\section{ESPECTROMETRÍA RAMAN}

La Espectroscopía Raman es una técnica fotónica de alta resolución que proporciona información química y estructural de compuestos orgánicos e inorgánicos, sin necesidad de destruir la muestra ni someterla a una preparación especial, permitiendo analizar materiales en cualquier estado: sólido, líquido o gaseoso. El fenómeno Raman fue descrito por el físico indio C.V. Raman en 1928, hecho por el que recibió el premio Nobel de física en 1930. Se produce al incidir un fotón sobre una molécula e interaccionar con la nube de electrones de sus enlaces, excitándola a un estado virtual.

Los enlaces entre iones y átomos que conforman las moléculas y estructuras macromoleculares están sometidos a constantes movimientos vibracionales y rotacionales (modos), que dependen de la masa de las partículas y del comportamiento dinámico de los enlaces implicados. La vibración global de la molécula está compuesta por la suma de los diferentes modos de vibración de diferentes frecuencias. Cada modo lleva asociada una energía que depende de la amplitud del movimiento y es propia de cada molécula, es decir, la energía de los modos está cuantizada y cada molécula sólo podrá acceder a unos determinados estados energéticos característicos. En condiciones normales, la mayoría de las moléculas se encuentran en el estado de menor energía o fundamental. Cuando los fotones, con energía $h v_{0}$ ( $h=$ constante de Plank) chocan con una molécula, la mayor parte la atraviesan pero una pequeña fracción se dispersa. La molécula absorbe la energía y pasa a estados 
energéticos superiores. Inmediatamente la molécula tenderá a relajarse y volver a estados de baja energía. La mayor parte de los fotones dispersados mantendrán la misma frecuencia que los fotones incidentes, lo que indica que la molécula retorna al estado inicial (dispersión Rayleigh, choque elástico). Este hecho no aporta información sobre la muestra. Sin embargo, una pequeña fracción presenta un cambio de frecuencia (choque inelástico) como resultado de un intercambio energético: la dispersión Raman, que es característica de la naturaleza química y el estado físico de la muestra e independiente de la radiación incidente. Si la molécula regresa a un estado de mayor energía que el de partida, el fotón dispersado habrá cedido parte de su energía produciéndose la dispersión Raman Stokes. Si la molécula termina en un estado energético de menor energía que el inicial significaría que el estado de partida no era el estado fundamental y que la molécula le ha transferido energía al fotón produciendo dispersión Raman anti-Stokes (Fig. 26A). Las variaciones de frecuencia propias del fenómeno de dispersión Raman, son equivalentes a variaciones de energía. Cada material presenta un conjunto de frecuencias características que se recogerán en el espectro Raman.

El espectro Raman podría considerarse un tipo de espectro de vibración y por tanto, cada uno de sus picos podría asociarse a un modo de vibración. El espectro representa la intensidad óptica dispersada en función de número de ondas normalizado $\left(\mathrm{cm}^{-1}\right)$ (número de veces que vibra una onda en una unidad de distancia; proporcional a la frecuencia e inversamente proporcional a la longitud de onda; $V=v / c=1 / \lambda$ ). Consta de una banda principal o Rayleigh $y$ dos series de bandas secundarias simétricamente situadas a ambos lados correspondientes a las bandas Raman Stokes y anti-Stokes (Fig. 26B). Sin embargo, dado que la frecuencia Raman es independiente de la frecuencia de la radiación incidente y que la banda Rayleigh es de gran intensidad (mayor proporción de choches elásticos) y no aporta información, el origen del eje suele situarse sobre la banda Rayleigh, siendo el eje de abscisas la diferencia entre la frecuencia Raman y la de la radiación incidente, normalizada respecto a la velocidad de la luz. Además, a temperatura ambiente, el $99 \%$ de las moléculas se encuentra en el estado vibracional de menor energía (ley de distribución de energías de Maxwell-Boltzman) y por tanto, la probabilidad de que ocurra dispersión Raman Stokes es mucho mayor que dispersión Raman anti-Stokes por lo que su intensidad es 100 veces superior y suele ser la única que se representa en la parte positiva del eje.

En la actualidad, la Espectroscopía Raman se utiliza para la determinación de muestras biológicas. Permite la detección de proteínas, ácidos nucleicos, lípidos [559],e hidratos de carbono. Ofrece información sobre procesos metabólicos, sobre la viabilidad celular, o su estado de diferenciación [560]. 

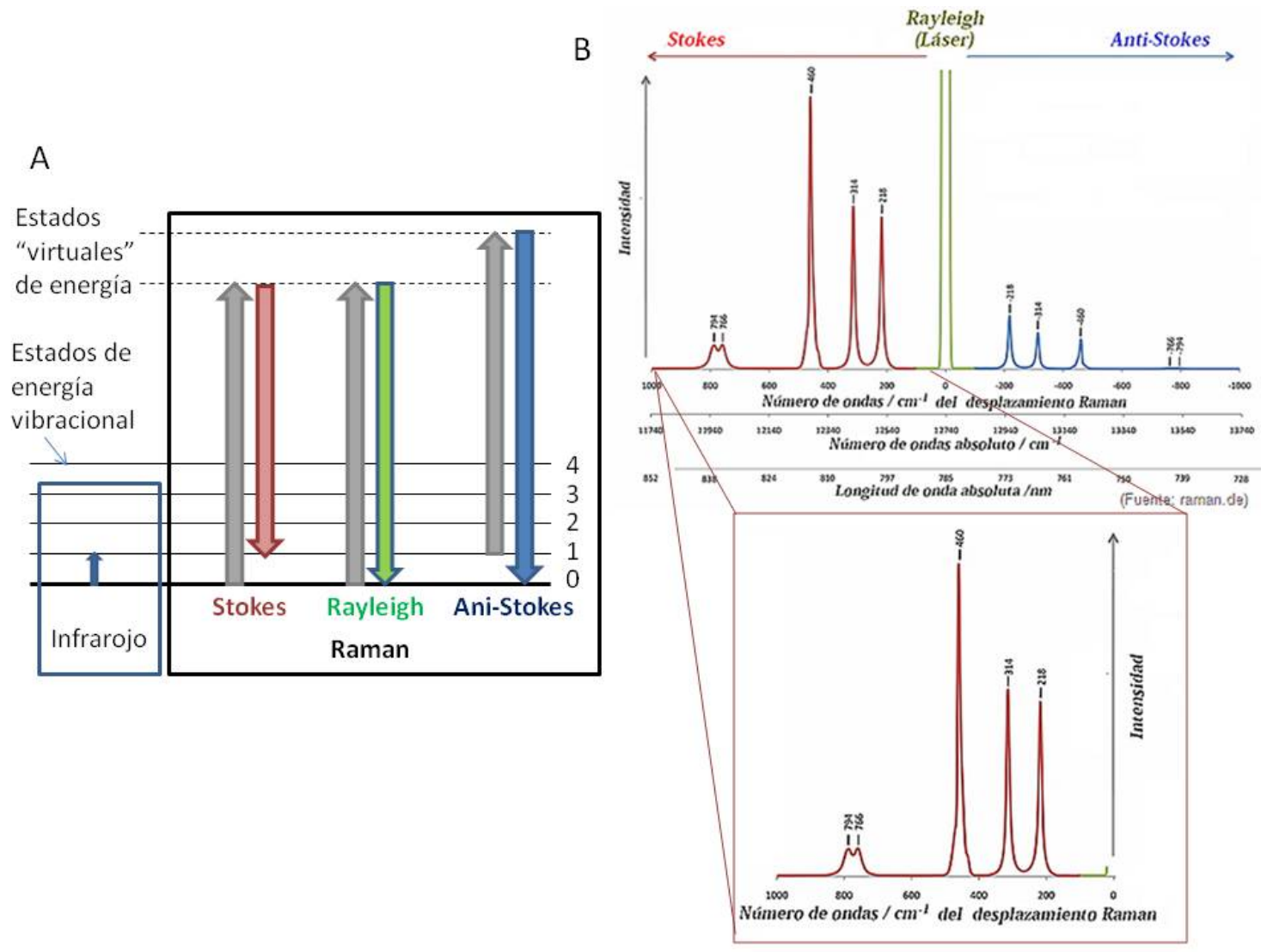

Figura 26. Espectroscopía Raman.

A. Esquema energético del fenómeno Raman. B. Espectro Raman (Modificado de [561]).

Para realizar el estudio de las balsas lipídicas por espectroscopía Raman las fracciones de DRM (fracción 3) de membranas de cerebros WT y ApoD-KO se secaron a 35C durante 24 horas en un Savant SPD121P Speed Vac. Se realizaron dos tipos de espectros: FT-Raman (transformada de Furier) que registran áreas (o"spots") de $1 \mathrm{~mm}$ de diámetro y permite un análisis promedio de la muestra y Micro-Raman que registran spots de $20 \mu \mathrm{m}$ de diámetro asociando el espectrómetro a un microscopio (50X) permitiendo así estudiar heterogeneidades dentro de la misma muestra.

\section{ANÁLISIS ESTADÍSTICO}

Los test estadísticos fueron realizados con software SigmaPlot ( $v$ 11.0). Se definió $p$ valor $<0,05$ como umbral para los cambios significativos. Las medias y medidas de dispersión se calcularon de un mínimo de triplicados experimentales. El test usado en cada experimento se especifica en la leyenda de cada figura. 


\section{RESULTADOS}

\section{CAPÍTULO 1: ESTUDIO DE LA FUNCIÓN DE ApoD EN UNA PROTEINOPATÍA: LA ATAXIA ESPINOCEREBELOSA TIPO I (SCA1)}

Los efectos neuroprotectores y la interacción con lípidos, son dos constantes de la ecuación que definiría la función de ApoD y sus homólogos [21, 57, 72, 75, 81, 83, 89, 542-544, 562-568] La sobreexpresión de ApoD observada durante el envejecimiento y en un amplio espectro de enfermedades neurodegenerativas parece ser una respuesta del SNC frente al daño, especialmente frente al estrés oxidativo $[15,43,45,569]$. Tanto el envejecimiento como las enfermedades neurodegenerativas comparten dos mecanismos responsables de sus devastadoras consecuencias incluso en los casos en los que el origen primario de la enfermedad fuera de muy diferente naturaleza [570]: el daño provocado por la generación exacerbada de ROS y el deterioro de los sistemas que controlan la calidad y el buen funcionamiento de las proteínas y organelas. La presencia de estos focos generadores de daño comunes hace posible la existencia de agentes protectores, también comunes, que actuarían sobre dichos procesos independientemente de la causa primaria que los alteró.

La protección frente al estrés oxidativo y la sobreexpresión de ApoD como respuesta común a muchas enfermedades neurodegenerativas, situarían a ApoD y sus homólogos como parte activa de la respuesta protectora general frente al primer proceso común ya mencionado: la generación anómala de ROS [97]. Sin embargo, no se ha estudiado el posible efecto de ApoD sobre el otro importante mecanismo común a los procesos de neurodegeneración: el deterioro de los sistemas de control de la funcionalidad de proteínas y organelas.

Este es, por tanto, el punto de partida de esta Tesis: el estudio de los efectos de los homólogos de ApoD, GLaz y NLaz, ante una situación patológica en la que los sistemas de control de calidad de proteínas se encuentren especialmente alterados. Para ello se seleccionó un modelo de ataxia provocado por la expresión de proteínas poliglutaminadas [541], la Ataxia Espinocerebelosa tipo I (SCA1) en donde tanto el sistema del proteasoma como la autofagia juegan un papel fundamental.

Ningún estudio ha probado el efecto de una lipocalina sobre la neurodegeneración provocada por proteínas poliglutaminadas. 


\subsection{GLaz SE SOBREEXPRESA ANTE LA EXPRESIÓN DE LA PROTEÍNA ATAXINA 1 HUMANA POLIGLUTAMINADA EN LA RETINA DE DROSOPHILA (MODELO DE SCA1)}

Hasta el momento no se han realizado estudios sobre la expresión de ApoD en los pacientes de SCA1. Por lo tanto, en primer lugar era necesario comprobar si el efecto que este tipo de neurodegeneración provoca en la expresión de GLaz se corresponde con la sobreexpresión de ApoD observada en el resto de patologías neurodegenerativas estudiadas.

La expresión de la versión patogénica de la proteína humana Ataxina 1 poliglutaminada (hATXN1 ${ }^{820}$ ) en los receptores de la retina de Drosophila (promotor gmr), usando el sistema GAL4/UAS, construye un modelo de degeneración en el ojo. Esta degeneración comienza en el estadio de pupa tardía $\left(a 2^{\circ} \mathrm{C}\right.$ ) con la aparición de las primeras inclusiones nucleares en los fotorreceptores [541].

En este modelo, las medidas por PCR cuantitativa de los niveles de mRNA en las cabezas de moscas de 5 a 6 días mostraron una expresión de GLaz tres veces mayor que los controles, lo que demostró que la sobreexpresión, como parte de la respuesta natural ante la neurodegeneración, está conservada para el homólogo de ApoD, GLaz, y que dicha respuesta es característica de la neurodegeneración provocada por poliglutaminas (Fig. 27A).

Seguidamente se procedió a la caracterización de la sobreexpresión de GLaz para determinar las células implicadas en esta respuesta a la neurodegeneración usando una proteína de fusión reportera: GLaz fusionada con GFP. El estudio de la expresión de la proteína GLaz fusionada con la proteína fluorescente GFP bajo el promotor nativo de GLaz (dos inserciones independientes: GLaz:GLaz-GFP[FX] y GLaz:GLaz-GFP[F2]) [75] mostró células GFP positivas en la retina (Fig. 27B). Estas células no colocalizaron con el marcador neuronal 22C10 (Fig. 27Bb), por lo que se identificaron como células de soporte (flechas de la Fig. 27B) y glía basal de la retina (cabezas de flecha en la Fig. 27B).

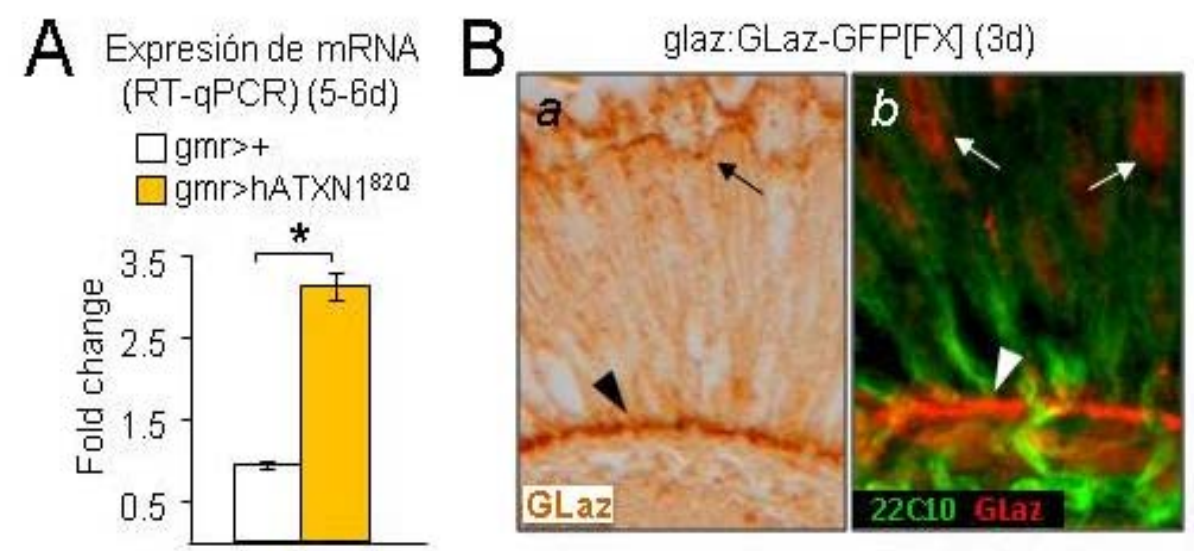

Figura 27.Expresión nativa de GLaz en un modelo de neurodegeneración SCA1 en Drosophila.

A. Niveles de transcriptos de GLaz medidos mediante RT'-PCR en cabezas de moscas de 5-6 días de edad. Diferencias estadísticas estudiadas con el test de Mann-Whitney $\mathrm{U}$. ${ }^{*} p<0,05$. B. Sobreexpresión nativa de GLaz usando el transgen reportero GLaz:GLaz-GFP[FX]. Las flechas 
señalan células de soporte de la retina positivas para GLaz y las cabezas de flecha señalan células de la glía basal positivas para GLaz.

1.2. GLaz REDUCE LA DEGENERACIÓN DE LOS FOTORRECEPTORES PROVOCADA POR ATAXINA-1 HUMANA POLIGLUTAMINADA

Una vez comprobada la influencia de este modelo de degeneración sobre la expresión de GLaz y la localización de la lipocalina en los alrededores del daño, se procedió a la comprobación de su posible efecto protector.

Para estudiar el efecto de GLaz ante la neurodegeneración basada en proteínas poliglutaminadas, primeramente se expresó GLaz en los propios fotorreceptores junto a la proteína poliQ usando el mismo controlador de ia expresión (gmr-GAL4) para ambos genes (UAS:GLaz y UAS:hATXN1 ${ }^{82 a}$ ). De esta manera se estudió la capacidad protectora de GLaz en la propia célula que la produce.

La co-expresión de GLaz junto a hATXN1 ${ }^{82 Q}$ produjo un rescate significativo de la degeneración de los receptores (Fig. 28, Fig. 29). Este efecto se repitió utilizando dos inserciones independientes de UAS:GLaz y dos inserciones EP que también controlan la expresión de GLaz.

Tanto la degeneración como el rescate de los fotorreceptores se reflejan en la morfología externa del ojo (Fig. 28A y B; Fig. 29). La regularidad de la superficie del ojo se cuantificó (Fig. 28B) por estimación de un índice de regularidad en función de la varianza de la distancia entre máximos de intensidad (Diez-Hermano et al., resultados no publicados) 

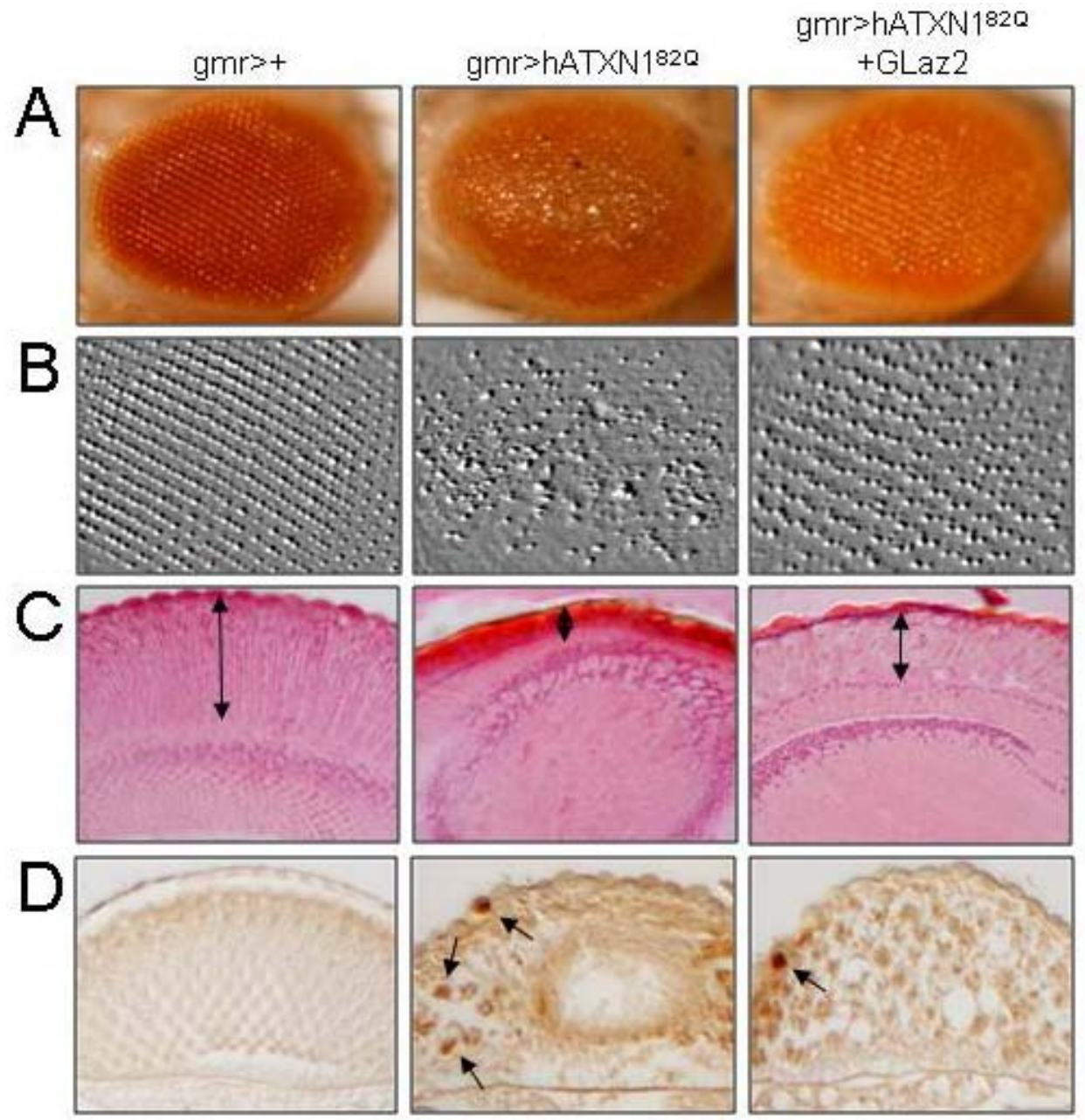

Figura 28. Rescate de GLaz en el modelo de neurodegeneración SCA1 en Drosophila.

A. Morfología del ojo de Drosophila adulta (5-6 días). Genotipo control (gmr>+), degenerado $\left(g m r>h A T X N 1^{82 Q}\right.$ ) y rescatado (gmr>hATXN1 ${ }^{82 \mathrm{Q}}+\mathrm{GLaz2}$ ). Ejemplos representativos de microscopía de luz. B. Imagen procesada con un filtro de superficie de la región central de la retina. C. Histoquímica hematoxilina/eosina de secciones de parafina. La doble flecha marca el grosor de la retina en las secciones histológicas. D. Inmunohistoquímica de Ataxina 1 en secciones de parafina. Las flechas señalan los cuerpos de inclusión de proteína poliQ.

Para estudiar la degeneración interna del ojo, se realizaron experimentos de histoquímica en secciones de parafina (Fig. 28C) que mostraron una atrofia severa de las células de la retina ante la expresión de hATXN1 $1^{82 Q}$ que remitió ante el aumento de expresión de GLaz.

Para comprobar que el rescate no fuera un efecto artefactual ante la expresión inespecífica de cualquier proteína en los fotorreceptores, se expresó una proteína control (LacZ) que no modificó el fenotipo de degeneración. (Fig. 28B, Fig.29A).

También se comprobó que la cantidad de hATXN1 ${ }^{82 a}$ producida en los fotorreceptores no se veía alterada por la expresión del transgen de GLaz (UAS:GLaz) cuantificando la señal de inmunomarcaje en los discos imaginales de los ojos en el tercer estadio larvario [571]. 

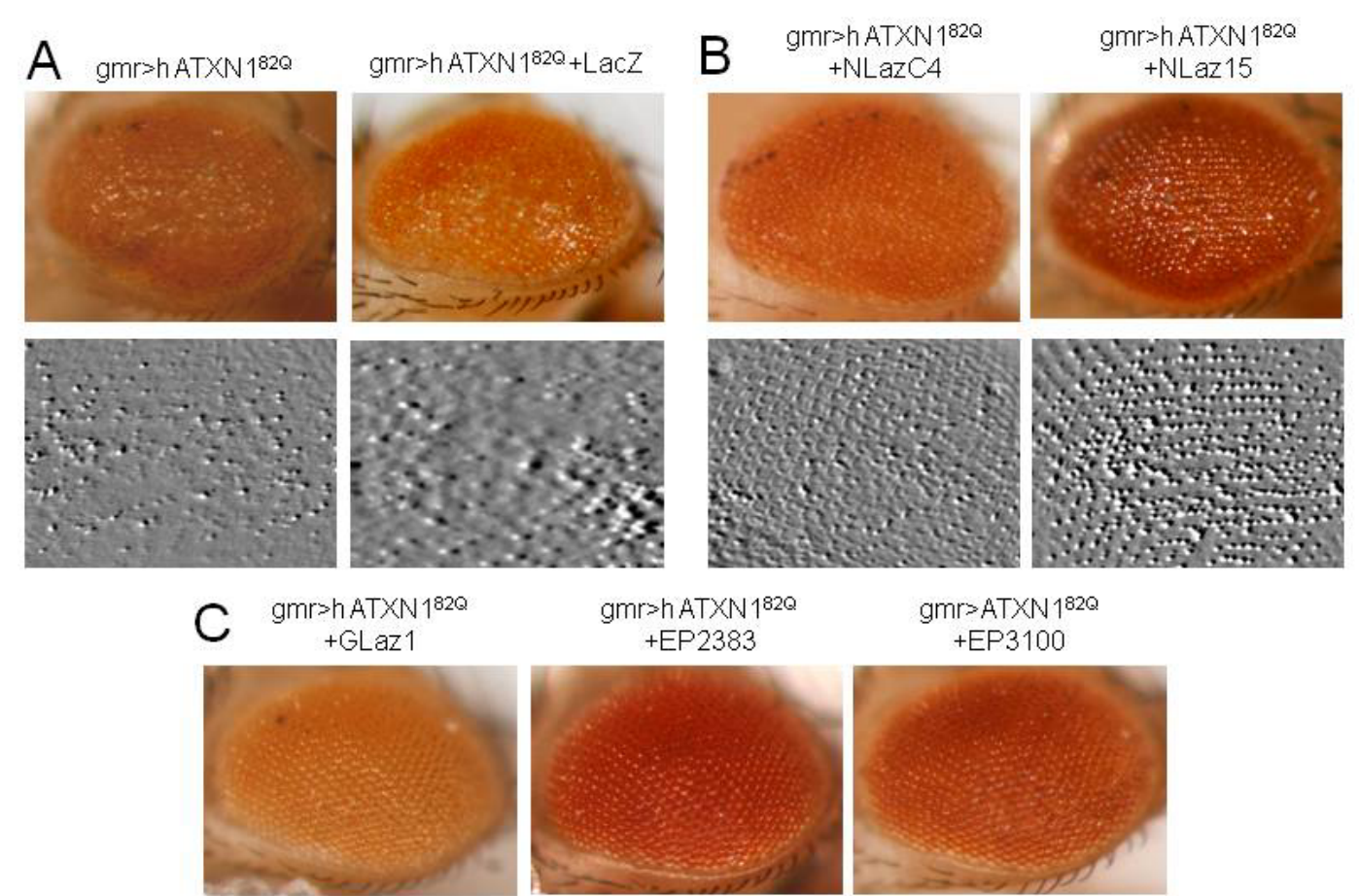

gmr>h ATXN $182 Q$ $+\mathrm{EP} 2383$

gmr>ATXN182Q

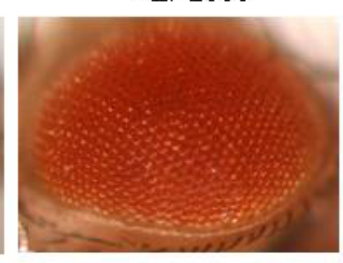
+ EP3100
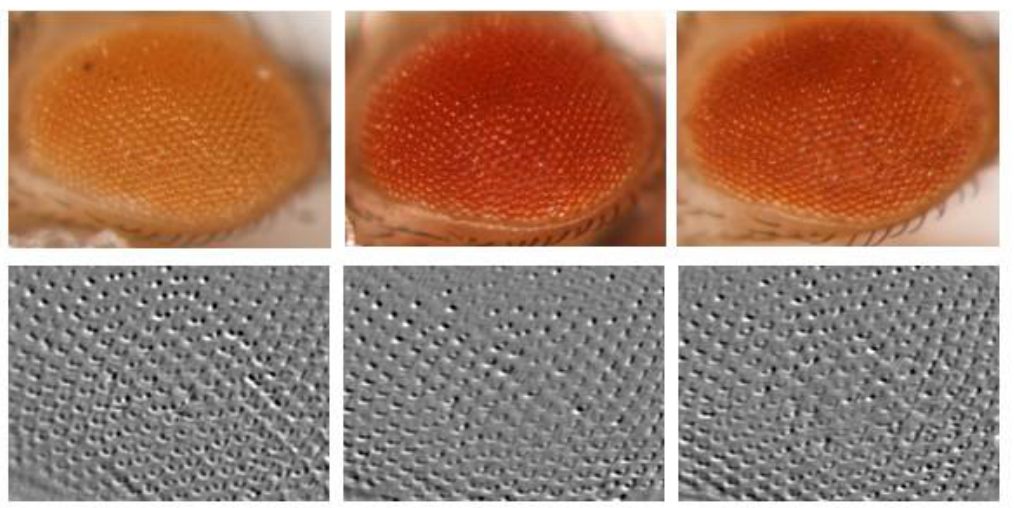

Figura 29. Efecto de diferentes formas de ganancia de función de GLaz y NLaz sobre la degeneración de los fotorreceptores causada por hATXN1 ${ }^{82 Q}$. Ejemplos representativos de ojos adultos de Drosophila de diferentes genotipos. Se muestras en todos los casos la microscopía de luz (paneles superiores) e imagen de la superficie (paneles inferiores). A. Retinas afectadas por SCA1 y falta de rescate en la sobreexpresión de LacZ. B. La ganancia de función de NLaz rescata dos líneas con transgenes diferentes. C. La ganancia de función de GLaz rescata tanto con un transgen de GLaz como con dos líneas con inserciones EP.

Por otro lado, la misma expresión de la proteína mutadahATXN $1^{82 Q}$ se realizó sobre un fondo mutante nulo para GLaz. La ausencia total de GLaz no agravó los efectos deletéreos provocados por la proteína poliglutaminada lo que indicó un alto grado de degeneración basal (Fig. 30).

El efecto observado ante la sobreexpresión de GLaz fue mínimo al agravar la degeneración realizando los experimentos a $29{ }^{\circ} \mathrm{C}$ (debido a que la expresión del sistema GAL4-UAS aumenta con la temperatura) o con una mayor expresión del genhATXN $1^{82 Q}$ en función del sitio de inserción (inserción en el cromosoma tercero) [571]. Por esto se deduce la existencia de un grado de degeneración umbral a partir del cual la función beneficiosa de GLaz no es capaz de contrarrestar el daño. 

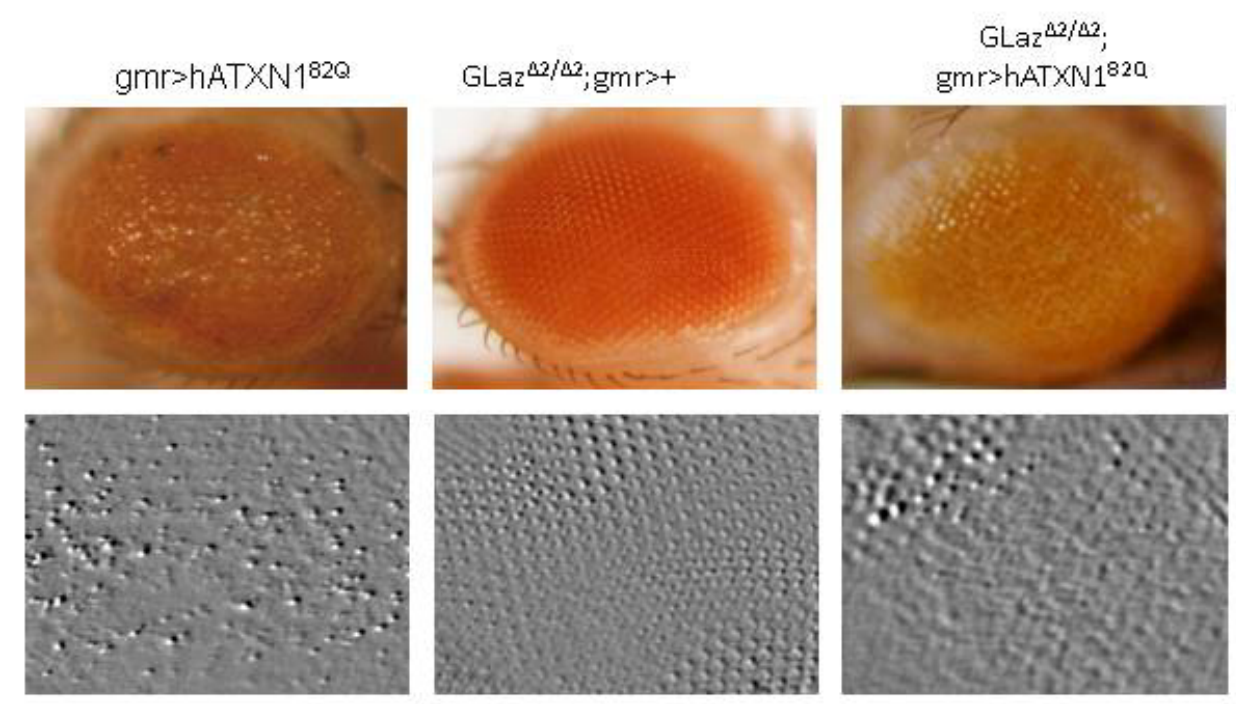

Figura 30.La pérdida de función de GLaz no rescata la degeneración de los fotorreceptores con hATXN1 ${ }^{82 Q}$.

Ejemplos representativos de ojos de Drosophila adultas. A-B. Microscopía de luz (paneles superiores) e imagen de superficie (paneles inferiores) para retinas control con pérdida de función de GLaz (A) y para retinas con expresión patogénica de hATXN1 ${ }^{82 Q}$ en fondo mutante nulo para GLaz (B).

Por último, el efecto de GLaz sobre los agregados nucleares característicos de este modelo [541] se estudió mediante la detección inmunohistoquímica de Ataxina humana en las secciones de retina (Fig. 28D). La expresión de GLaz no impidió completamente la formación de los agregados nucleares a pesar de mantener la integridad del tejido(flechas en la Fig. 28D).

Por lo tanto, se concluye que GLaz es capaz de aminorar la degeneración en un modelo de ataxia espinocerebelosa 1 al sobre-expresarse en la misma célula que sufre el daño, siempre y cuando la gravedad de la degeneración esté por debajo de su poder de rescate. Así bien, se deduce que GLaz actuaría sobre las consecuencias patológicas que la expresión y agregación de la proteína mutada provocan y no sobre la propia proteína.

\subsection{GLaZ PRODUCIDA EN SU DOMINIO DE EXPRESIÓN NATIVO RESCATA LA DEGENERACIÓN DE MANERA ESTABLE}

Teniendo en cuenta que las lipocalinas son proteínas secretadas y que los fotorreceptores no expresan GLaz, siendo las células gliales las que responden a la degeneración con un aumento de la expresión, se estudió, en segundo lugar, un posible efecto paracrino. Para ello se sobreexpresó GLaz en las células que naturalmente la producen mientras se expresaba la proteína poliglutaminada en los fotorreceptores (gmr-GAL4>UAS-hATXN1 ${ }^{820}$ ). Concretamente se estudió el efecto de una dosis doble de GLaz, expresando la proteína de fusión GLaz-GFP bajo el control de su promotor nativo (GLaz:GLaz-GFP) (dos inserciones independientes: GLaz-GFP [F2] y GLaz-GFP[FX]), sobre la degeneración provocada por la expresión de la proteína poliglutaminada en los receptores (Fig. 29C y Fig.31). 
Con su patrón de expresión espacio-temporal nativo, GLaz fue capaz de proteger a los fotorreceptores posiblemente accediendo a la ellos desde el espacio extracelular. El rescate se manifestó desde los estadios tempranos de la degeneración en la pupa ( 5 días después de la formación de la pupa) hasta las moscas adultas viejas (30 días de edad) (Fig. 31).

Estos resultados indican que el rescate no requiere de la expresión de GLaz por parte de la célula que está sufriendo el daño, sino que el efecto protector es posible cuando la fuente de la lipocalina es una célula diferente a la degenerada. Las células gliales y de soporte en la retina serían las fuentes naturales de GLaz más próximas en este caso (Fig. 28B). Este mecanismo de neuroprotección paracrino es lo suficientemente estable como para mantener la morfología natural de la retina hasta edades avanzadas (Fig. 31).

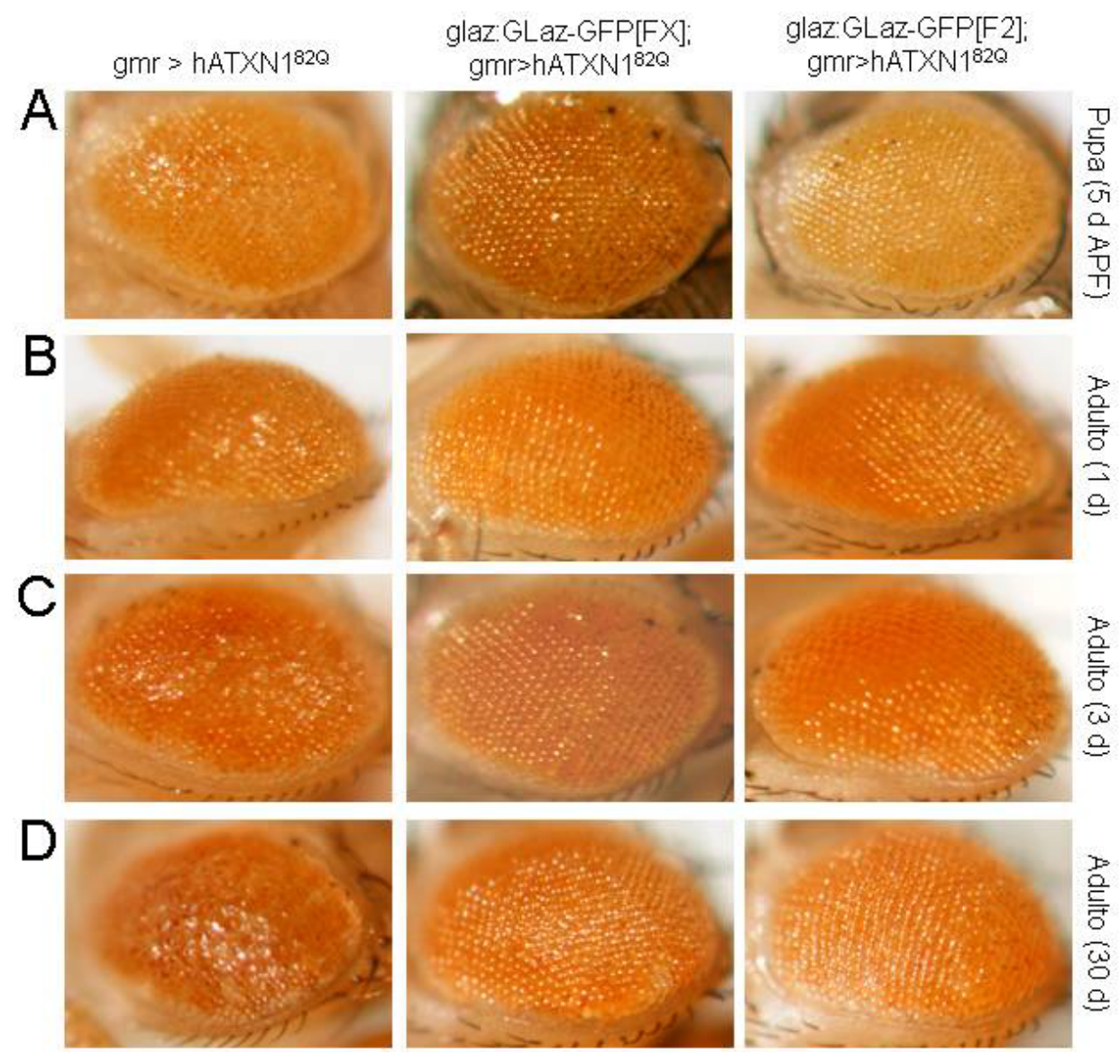

Figura 31. La expresión de GLaz con su patrón espacio-temporal nativo rescata la degeneración de los fotorreceptores dependiente de hATXN1 ${ }^{82 Q}$ a lo largo del envejecimiento. A-D. Ejemplos de ojos de Drosophila degenerados (gmr>hATXN1 ${ }^{82 \mathrm{Q}}$ ) y dos diferentes transgenes de expresión de GLaz (GLaz:GLaz-GFP[FX] y GLaz:GLaz-GFP[F2]) A. Pupas (5 días después de pupación). B. Moscas de 1 día. C. Moscas de 3 días. D. Moscas de 30 días.

La expresión de GLAZ, en moscas-SCA1 de 5-6 días de edad, se observó claramente en la zona que sufre la degeneración (Fig. 32Ca, b). Cuatro días después de la fase de pupa (APF), las regiones levemente degeneradas presentaron una señal de GLaz de diferente distribución al 
marcador de fotorreceptores 4C5 (Fig. 32Cb). Sin embargo, en retinas más degeneradas, la señal de GLaz aparece en los fotorreceptores marcados con 4C5 (Fig. 32Cd).

\section{Esto sugiere una potencial incorporación de la lipocalina extracelular a los fotorreceptores en degeneración. Esta internalización concordaría con la observada en el laboratorio en cultivos de astrocitos [543].}

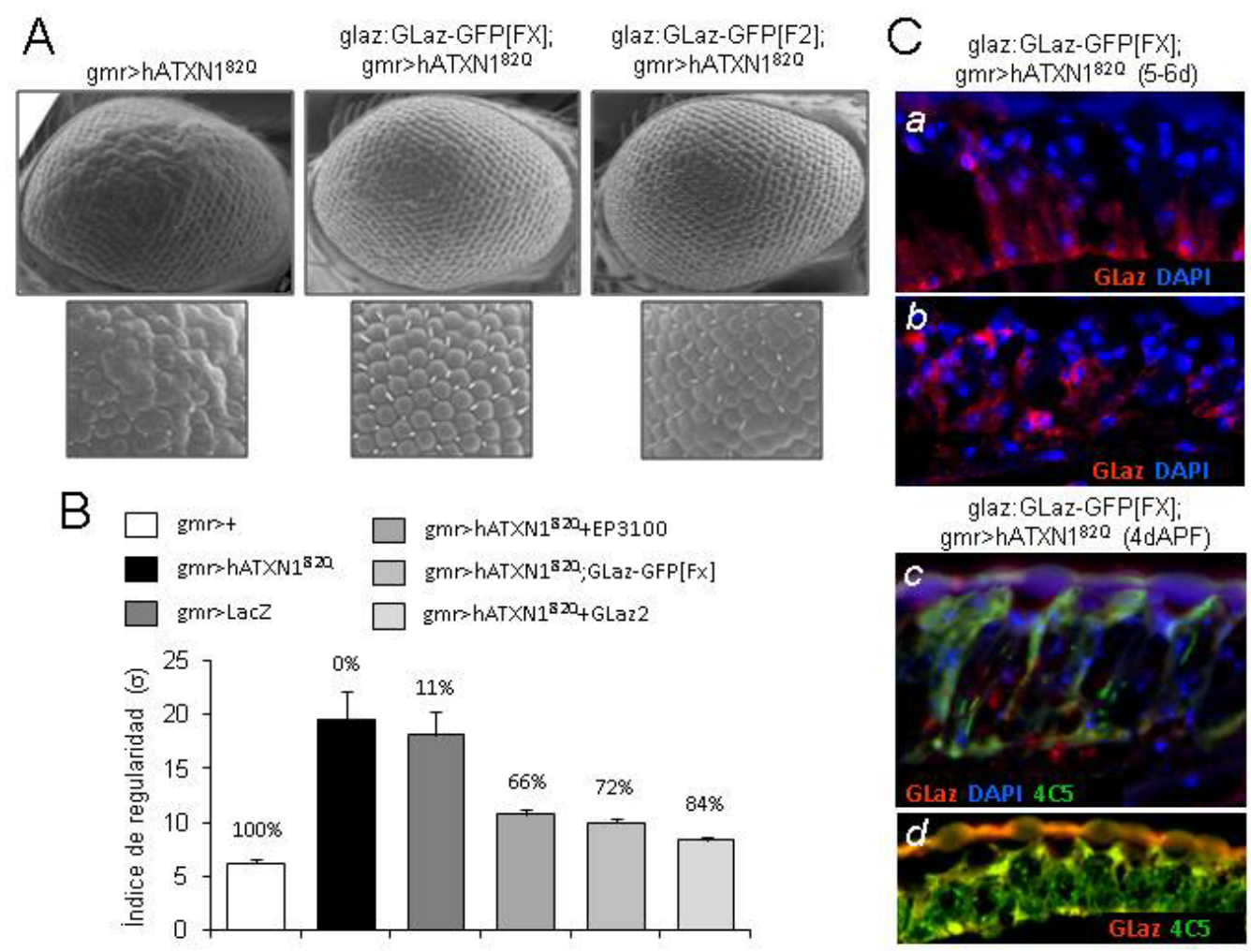

Figura 32. Rescate de la degeneración de los fotorreceptores dependiente de hATXN1 ${ }^{82 Q}$ por la sobreexpresión de GLaz con su patrón espaciotemporal nativo. A. Ejemplos representativos de microscopía electrónica de barrido e imágenes magnificadas de degeneración (gmr>hATXN1 ${ }^{82 \mathrm{a}}$ ) y dos diferentes transgenes de expresión de GLaz (GLaz:GLaz-GFP[FX] y GLaz:GLaz-GFP[F2]). B. Estimación cuantitativa de degeneración por computarización de un índice de regularidad basado en la varianza $(\sigma)$ de las distancias de máxima intensidad local. Para cada genotipo se indica el porcentaje de recuperación de degeneración. Se utilizaron más de 20 ojos por genotipo para calcular los índices de regularidad. C, a, b: la expresión de GLaz revelado por fluorescencia de GFP inmunohistoquímica de secciones de parafina de retinas de moscas que expresanhATXN182Qy el transgen de GLazGLAZ-GFP [FX]: los núcleos se muestran mediante tinción con DAPI. c, d: doble inmunohistoquímica de fluorescencia revela GLaz y el marcador de fotorreceptores rodopsina (4C5). DAPI marca los núcleos en c. 


\subsection{NLaZ TAMBIÉN SE SOBREEXPRESA ANTE LA EXPRESIÓN DE ATAXINA-1 HUMANA POLIGLUTAMINADA EN LA RETINA DE DROSOPHILA Y RESCATA LA NEURODEGENERACIÓN}

Una vez comprobados los efectos del homólogo glial de ApoD en mosca, se realizó el mismo estudio para su homólogo expresado en neuronas, NLaz [37]. La expresión transcripcional de NLaz se duplicó ante el mismo modelo de SCA1 (Fig. 33A).

La co-expresión de NLaz junto a hATXN1 ${ }^{82 Q}$ en los fotorreceptores también mostró efectos protectores (Fig. 33B; Fig. 27B). La medida del índice de regularidad morfológico de la superficie del ojo reveló una capacidad de rescate similar a la de GLaz. (Figs. 29B y 33D). Sin embargo, el rescate obtenido al sobre-expresar en los fotorreceptores las dos lipocalinas a la vez resultó comparable al obtenido por cada una por separado (Fig. 33C, D), lo que sugiere que ambas proteínas podrían actuar través de un mecanismo común.

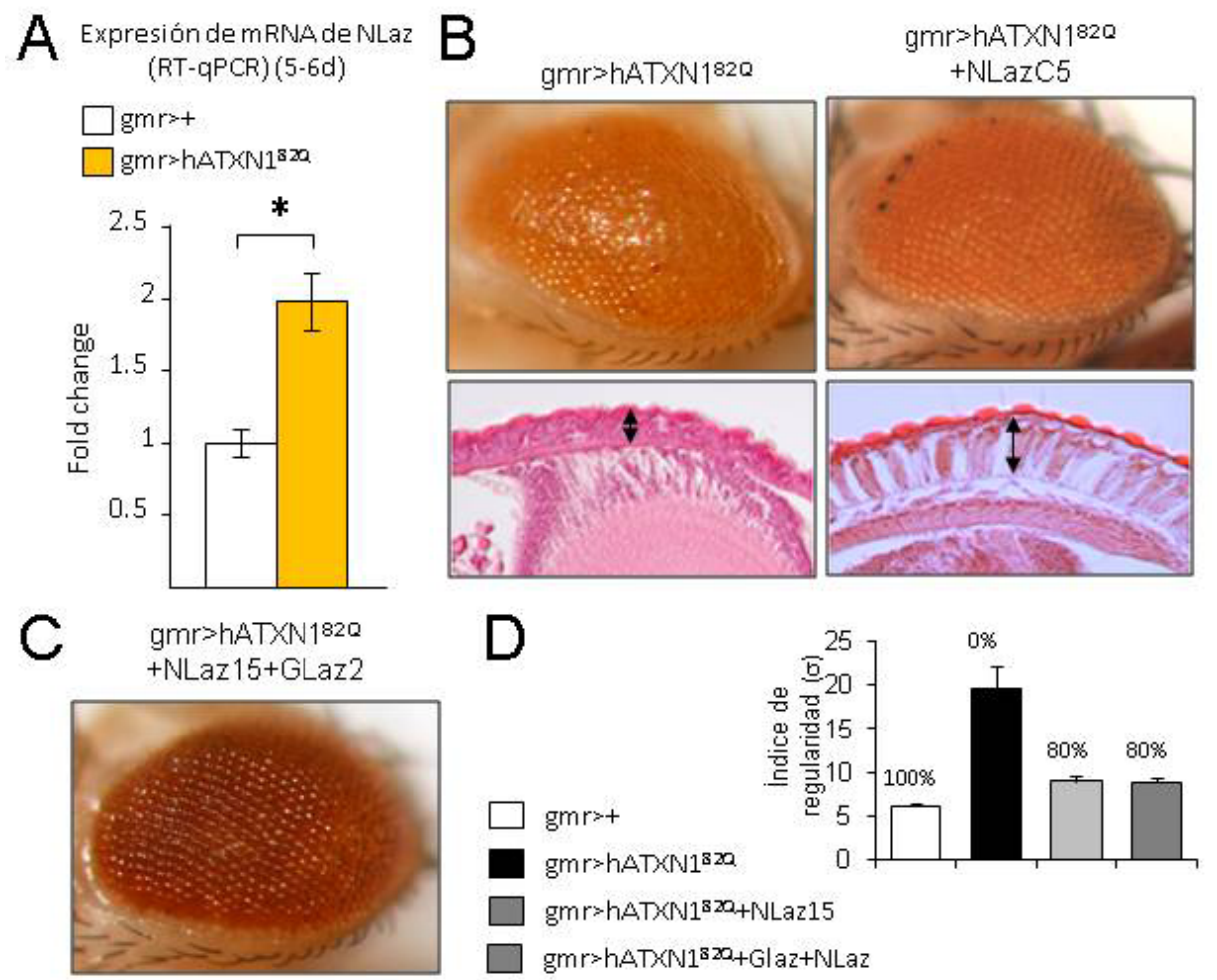

Figura 33. NLaz se sobre-expresa en respuesta a la degeneración de los fotorreceptores dependiente de hATXN1 ${ }^{82 Q}$ y su sobreexpresión con el sistema GAL4/UAS rescata el fenotipo patogénico. A. Niveles de mRNA de NLaz medidos por RT-PCR en cabezas de moscas de 5-6 días. Las diferencias estadísticas se analizaron con el test Mann-Whitney $U .{ }^{*} P<0,05$. B. Ojos de mosca representativos e histoquímica con hematoxilina/eosina de secciones de parafina mostrando el fenotipo de degeneración (gmr>hATXN1 $1^{82 a}$ ) y el rescate de NLaz (gmr>hATXN1 $\left.1^{82 \mathrm{a}}+\mathrm{NLazC5}\right)$. Las flechas marcan el grosor de la retina en las secciones histológicas. C. Rescate de la degeneración de los fotorreceptores por la co-expresión de hATXN1 ${ }^{82 Q}$ con las lipocalinas NLaz y GLaz. D. Cuantificación del rescate de la degeneración de los fotorreceptores por NLaz y la co-expresión de NLaz y GLaz. 


\subsection{LA SOBREEXPRESIÓN DE GLaZ DISMINUYE LA MUERTE POR APOPTOSIS EN PRESENCIA DE ATAXINA-1 HUMANA POLIGLUTAMINADA}

La técnica histoquímica TUNEL (Terminal deoxynucleotidyl transferase dUTP nick end labeling) utilizada en cortes de parafina de cabezas de moscas de 5-6 días reveló que la expresión de la proteína poliglutaminada hATXN1 ${ }^{82 Q}$ provoca la muerte de los fotorreceptores por apoptosis. La sobreexpresión de GLaz produjo una clara disminución del número de células apoptóticas en la retina de la mosca. (Fig. 34A). Para estimar cuantitativamente esta reducción de muerte celular se consideraron los niveles de mRNA de hATXN1 como un marcador de viabilidad, asumiendo que únicamente los fotorreceptores intactos podrán contribuir a la transcripción del mRNA a partir del transgen humano.

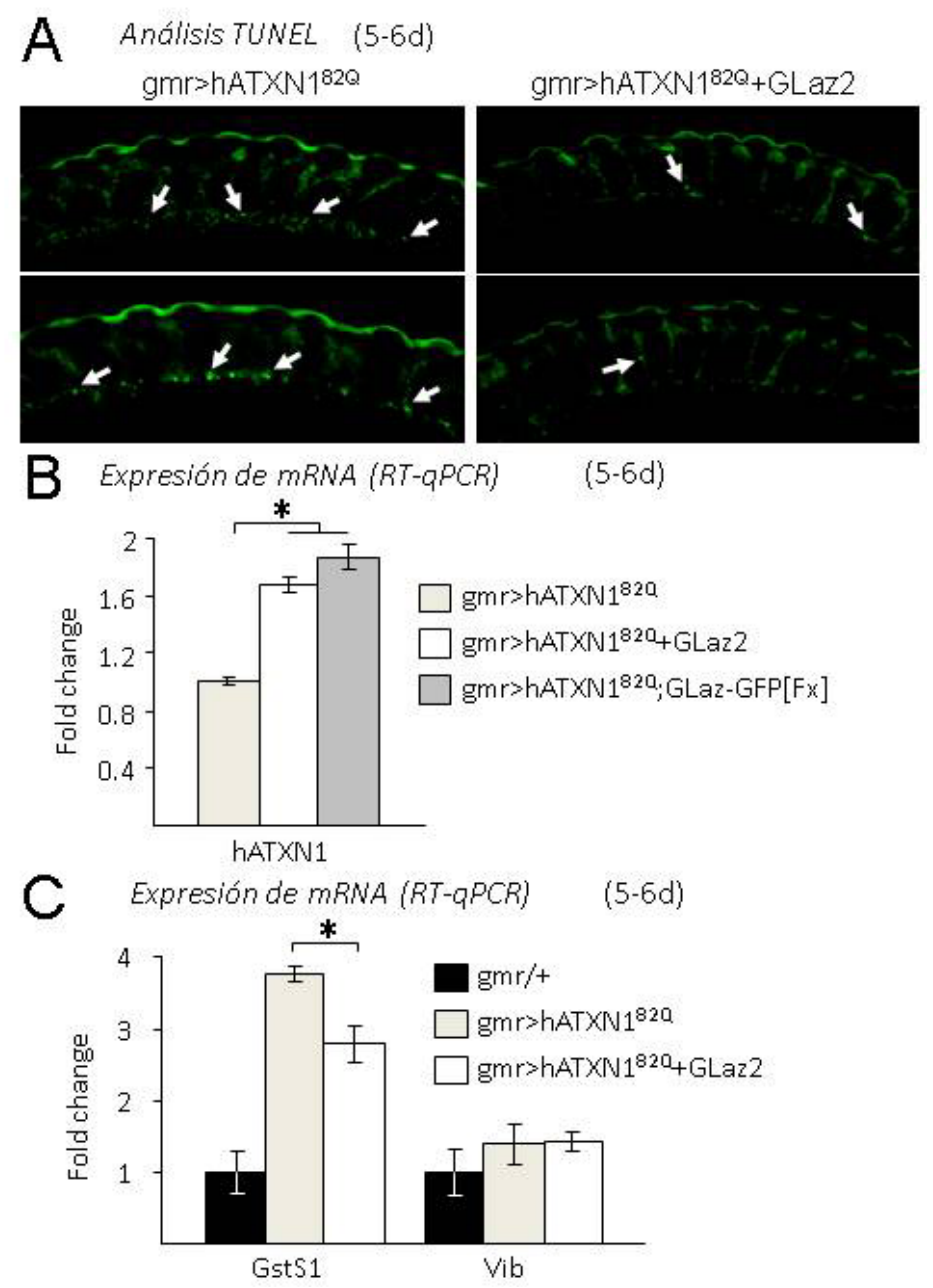

Figura 34.Efecto de la sobreexpresión de GLaz sobre la muerte celular debido a la degeneración dependiente de hATXN1 ${ }^{820}$ y sobre la expresión de modificadores deSCA1.A. Análisis TUNEL de muerte celular por apoptosis en secciones de parafina de retinas degeneradas (gmr>hATXN1 ${ }^{82 a}$ ) y rescatadas por GLaz (gmr>hATXN1 ${ }^{82 a}+\mathrm{GLaz2}$ ). Ejemplos representativos de secciones de retinas que muestran una disminución del número de núcleos apoptóticos (flechas blancas) en moscas que sobre-expresan GLaz. B. Niveles de mRNA de hATXN1 en cabezas de moscas del modelo de SCA1 y en líneas que expresan doble dosis de GLaz. C. Niveles de expresión por RT-PCR de los modificadores de la neurodegeneración de SCA1:GstS1 y Vib. Test de Mann-Whitney U* $P<0,05$. 
Los niveles de transcripción de Ataxina 1, medidos por RT-PCR, aumentan con la co-expresión de GLaz tanto en neuronas fotorreceptoras como en las células gliales vecinas (Fig. 34B) lo que indicaría un mayor número de fotorreceptores vivos en concordancia con los datos obtenidos por el ensayo de TUNEL.

\subsection{GLaZ ALTERA LA EXPRESIÓN DE UN GEN RESCATADOR DEL FENOTIPO DE SCA1 INVOLUCRADO EN LA ELIMINACIÓN DE LÍPIDOS PEROXIDADOS}

Una vez comprobada la función neuroprotectora, se procedió a la búsqueda del mecanismo sobre el cual GLaz pudiera estar actuando.

La búsqueda de indicios que se acercaran al mecanismo protector de GLaz llevó al estudio de otros genes capaces también de modificar la neurodegeneración inducida por el mismo modelo de SCA1 en Drosophila [541, 572]. Se seleccionaron aquellos que presentaran alguna relación con lípidos, con la intención de estudiar su comportamiento frente al rescate de GLaz. Estos genes fueron Glutation S transferasa S1 (GstS1), un homólogo de la prostaglandina D sintasa hematopoyética (HPGDS), y Vibrator (Vib) una proteína transportadora de fosfatidilinositol homóloga a $\alpha$-PITPN en vertebrados. Tanto la sobreexpresión de GstS1 como de Vib suprimen la neurodegeneración causada por la Ataxina 1 poliQ humana mientras que únicamente la falta de función de GstS1 acentúa el fenotipo [541, 572]. Sin embargo, no se conoce la respuesta nativa de estos genes ante la degeneración.

La transcripción de Vib se mantuvo constante tanto en el modelo de SCA1 como en la situación de rescate por sobreexpresión de GLaz (Fig. 34C). Por el contrario, GstS1 presentó una expresión cuatro veces mayor en el modelo neurodegenerativo frente a la situación control. Esta inducción se redujo significativamente ante la sobreexpresión de GLaz (Fig. 34C).

GstS1 se ha clasificado como parte del mecanismo defensivo contra el estrés oxidativo [573] y por primera vez, se ha encontrado una relación entre su regulación transcripcional y una neurodegeneración, aunque la causa directa deberá ser estudiada. Mientras que GstS1 estaría controlando la eliminación de lípidos peroxidados, GLaz controlaría el nivel de lípidos que se peroxidan [75] de tal manera que la sobreexpresión de GLaz provocaría un descenso del nivel de lípidos peroxidados que produciría, a su vez, una disminución de la transcripción del gen encargado de su eliminación, GstS1, al haber menos sustrato que eliminar.

En resumen, la expresión ectópica de la proteína humana Ataxina 1 poliglutaminada provoca una inducción en la expresión de GLaz y GstS1 que contribuyen a la eficiente eliminación de los lípidos peroxidados. Sin embargo, otros genes también relacionados con los lípidos como Vib, a pesar de modificar el fenotipo degenerativo de SCA1 ante su falta de función o su sobreexpresión experimental, no sufren alteración en su transcripción ni ante la degeneración ni ante el rescate producido por GLaz. 


\subsection{GLaZ REDUCE LA ACUMULACIÓN DE PROTEÍNAS UBIQUITINADAS DEPENDIENTE DE ATAXINA-1 HUMANA POLIGLUTAMINADA}

El estudio de los efectos de GLaz en un ambiente degenerativo provocado por la expresión de una proteína poliglutaminada tenía como objeto indagar en la existencia de un efecto de GLaz sobre la proteostasis y los sistemas de control de calidad de proteínas.

La relación de GLaz con GstS1 es un primer indicio de conexión entre los mecanismos de control de lípidos peroxidados y los involucrados en la proteostasis.Gsts1 se oxida al catalizar la conjugación de los sustratos lipofílicos con glutatión reducido. Esto provoca la liberación de JNK induciendo la autofagia [573]. Por lo tanto, el control de la oxidación de lípidos podría tener efectos sobre los procesos de la autofagia en los que estén involucradas las membranas.

Para determinar el estado de la proteostasis, se estudió del patrón de expresión de las proteínas ubiquitinadas tanto por inmunohistoquímica como por inmunoblot (Fig. 35). Este estudio mostró una proteostasis alterada, propia de la neurodegeneración por poliglutaminas, por abundante presencia de agregados proteicos ubiquitinados (Fig. 35Ab, d) en comparación con los controles (gmr sólo [resultados del laboratorio no publicados] y gmr>GLaz (sobreexpresión de GLaz en fondo silvestre) (Fig. 35Aa).

La co-expresión de GLaz con hATXN1 ${ }^{820}$ redujo considerablemente esta acumulación (Fig. 35Ac, e, f). Esta reducción es independiente del lugar de sobreexpresión de GLaz ya que tanto si GLaz es expresado por los fotorreceptores como por sus células nativas, se reproduce un descenso significativo de las proteínas ubiquitinadas, como demuestra el análisis cuantitativo por inmunoblot (Fig. 35B).

Por consiguiente, GLaz estaría favoreciendo la eliminación de las proteínas defectuosas y sus agregados y, por lo tanto, influyendo en los mecanismos encargados de esta degradación. 


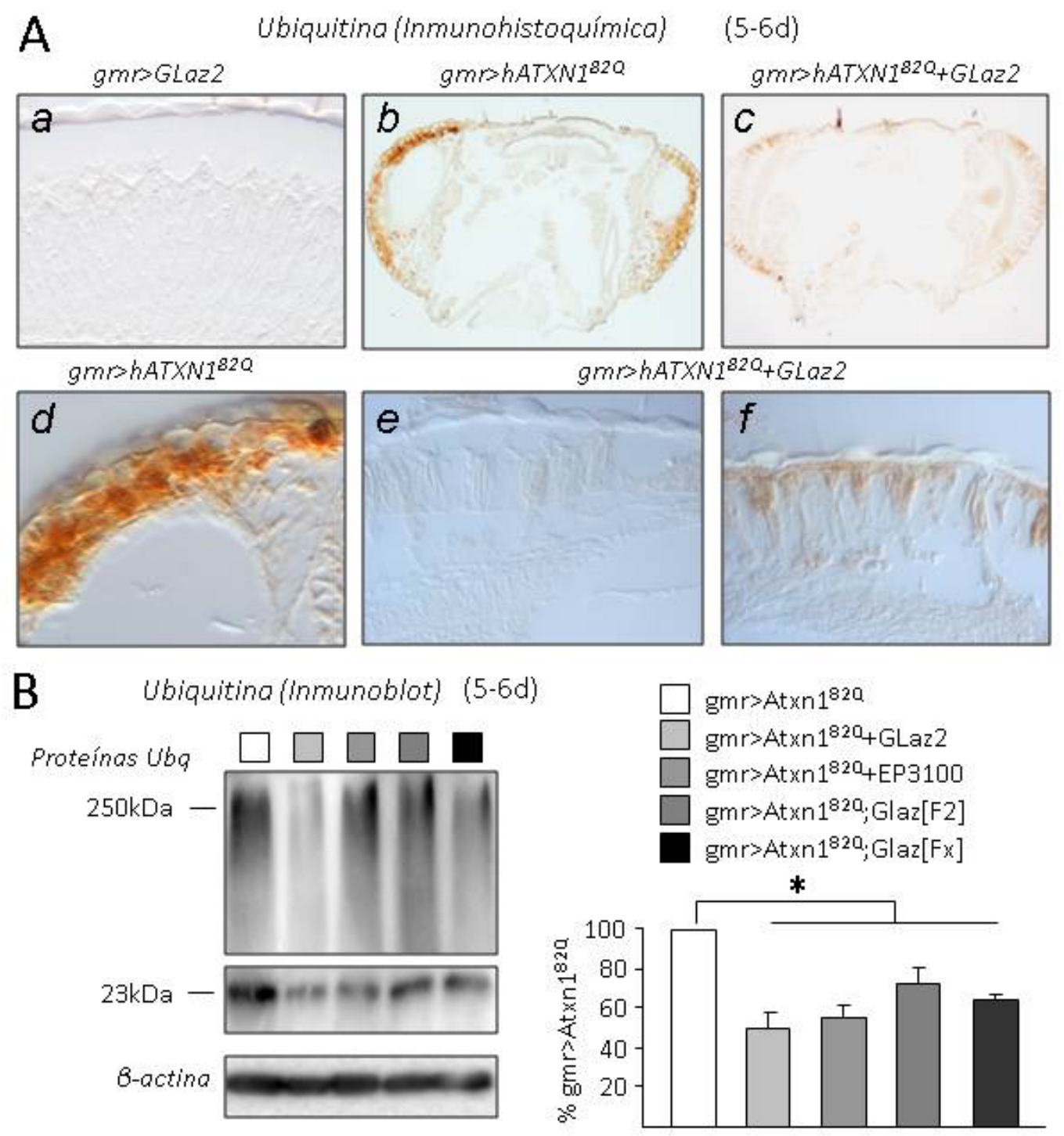

Figura 35. Descenso de proteínas ubiquitinadas acumuladas por la sobreexpresión de GLaz.A. Inmunohistoquímica con HRP para la detección de ubiquitina en secciones de parafina de retinas control, degeneradas o rescatadas por GLaz que muestra una disminución del marcaje de ubiquitinas al sobre-expresar GLaz. B. Cantidad de proteína ubiquitinada medida por inmunoblot de ubiquitina en diferentes líneas que expresan la patogénica hATXN $1{ }^{820}$ sola o en combinación con transgenes que expresan GLaz. Las diferencias estadísticas se determinan mediante el test de $t$ de Student. ${ }^{*} P<0,05$.

\subsection{GLaz REDUCE LA INDUCCIÓN DE LA AUTOFAGIA DEPENDIENTE DE ATAXINA-1 HUMANA POLIGLUTAMINADA}

Los estudios realizados en otros modelos de enfermedades poliglutaminadas [510] y la propia inducción de GstS1 observada en el modelo de SCA1 en los fotorreceptores presagiaban una alteración de la autofagia (Fig. 34C). De acuerdo con lo esperado, en el modelo de degeneración de los fotorreceptores de Drosophila, la autofagia presenta un aumento de su inducción (Fig. 36A) caracterizado por el incremento de la transcripción del gen Atg8a, un homólogo de LC3 en vertebrados [574]. Esta inducción, desencadenada por la neurodegeneración, es similar en magnitud a la inducción de Atg8a provocada por la desnutrición. Sin embargo, al aplicar las dos condiciones en el mismo individuo, es decir, 
moscas que expresan hATXN1 ${ }^{82 Q}$ sometidas a desnutrición, el aumento en la transcripción de Atg8 es aún mayor. Esto sugiere que existen diferentes mecanismos de inducción de la autofagia que actuarían de manera aditiva.

La sobreexpresión de GLaz tanto en los fotorreceptores como en las células gliales nativas produce una reducción significativa de la autofagia provocada por la ataxina-1 humana poliglutaminada (Fig. 36B).

A pesar de que este resultado está en concordancia con la reducción de la expresión de GstS1 ante la sobreexpresión de GLaz, resulta paradójico si se tiene en cuenta la reducción de proteínas poliubiquitinadas que esta misma sobreexpresión provoca, dado que es la autofagia la vía natural de eliminación de estos agregados (Fig. 35 y 36). Es decir, la sobreexpresión de GLaz reduciría tanto la acumulación de proteínas ubiquitinadas como la activación del propio proceso que las elimina.

Por otra parte, cuando la autofagia en el modelo de SCA en mosca, se estimula aún más por la ingestión de rapamicina (un inhibidor de la señalización de TOR, [575]) GLaz consigue reducir todavía más la cantidad de proteínas ubiquitinadas acumuladas (Fig. 36C).

Estos datos podrían indicar dos posibilidades:

1) GLaz no actuaría directamente sobre los procesos de inducción o de iniciación de la autofagia, sino que favorecería su resolución final.

2) La contribución GLaz en la eliminación de proteínas es independiente de la autofagia. 


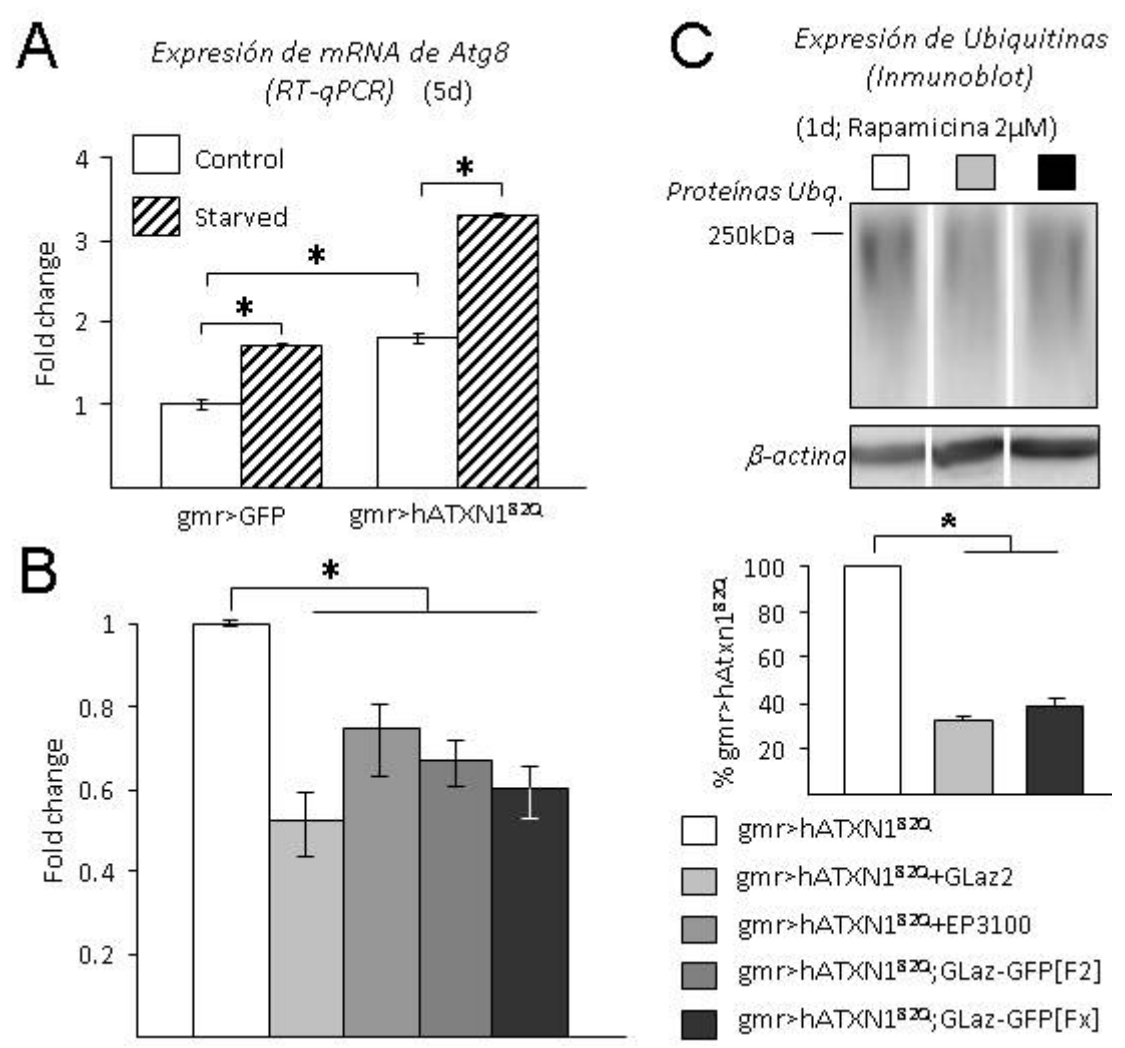

Figura 36.Descenso de la inducción de la autofagia por la sobreexpresión de GLaz.

A. La expresión patogénica de hATXN1 $1^{82 Q}$ y la hambruna incrementan la inducción de la autofagia medida por los niveles de mRNA del gen Atg8B. La expresión de Atg8 disminuye por la coexpresión de GLaz y de hATXN1 ${ }^{82 Q}$. Las diferencias estadísticas se determinaron por el test MannWhitney $U$. ${ }^{*} P<0,05$. C. Niveles de proteína ubiquitinada en cabezas de mosca medidas por inmunoblot después del tratamiento con el inductor de autofagia rapamicina. Se observa un descenso de la cantidad de ubiquitina en la retina de moscas SCA1 cuando se expresa GLaz en los fotorreceptores y en las células de soporte y células gliales. Las diferencias estadísticas se determinaron por el test de $t$ de Student. ${ }^{*} P<0,05$.

\subsection{GLaZ PREVIENE LA ACUMULACIÓN DE P62 EN LA AUTOFAGIA ESTIMULADA POR ATAXINA-1 HUMANA POLIGLUTAMINADA Y RAPAMICINA}

Para discernir entre las dos alternativas anteriores era necesario estudiar el estado de los procesos finales de la autofagia. Para ello se monitorizó la acumulación de p62, una proteína cuya actuación es decisiva en la degradación de los agregosomas (agregados de proteínas mal plegadas demasiado largas para ser degradadas por el sistema del proteasoma). P62 ancla los agregosomas a la membrana autofágica recién formada, controlando así su incorporación al autofagosoma [576]. Si la autofagia funciona correctamente, p62 también se degrada en el proceso. Por lo tanto, la acumulación de p62 puede considerarse como una señal de defecto en la resolución final de la autofagia de agregados proteicos [577, 578].

Si GLaz favoreciera la resolución de la autofagia (hipótesis 1) debería observarse una reducción en la acumulación de p62. Este efecto es lo que se observa ante la sobreexpresión de GLaz (Fig. 37A). Por otro lado, los niveles de la proteína p62 aumentan tras la inducción de la 
autofagia por rapamicina, tanto en las moscas control (Fig. 37B)como en el modelo degenerativo (Fig. 37C). La sobreexpresión de GLaz reduce los niveles de p62 en el modelo de SCA1 con o sin inducción de autofagia por rapamicina (Fig. 37A, C).

Por lo tanto, GLaz estaría promoviendo específicamente el flujo de la autofagia dependiente de p62 en oposición a la idea de que pudiera estar eliminando las proteínas agregadas por un mecanismo independiente (por ejemplo: el sistema de proteasoma).

A Expresión de p62 (inmunoblot)

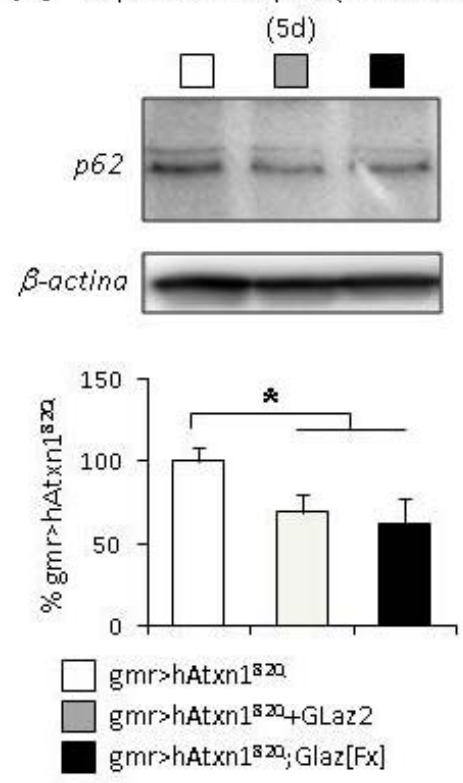

B
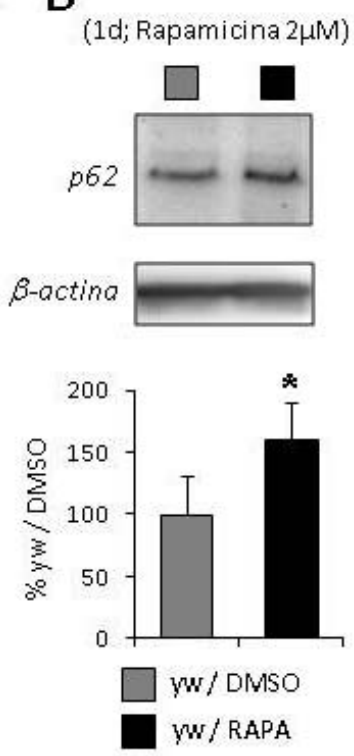

C
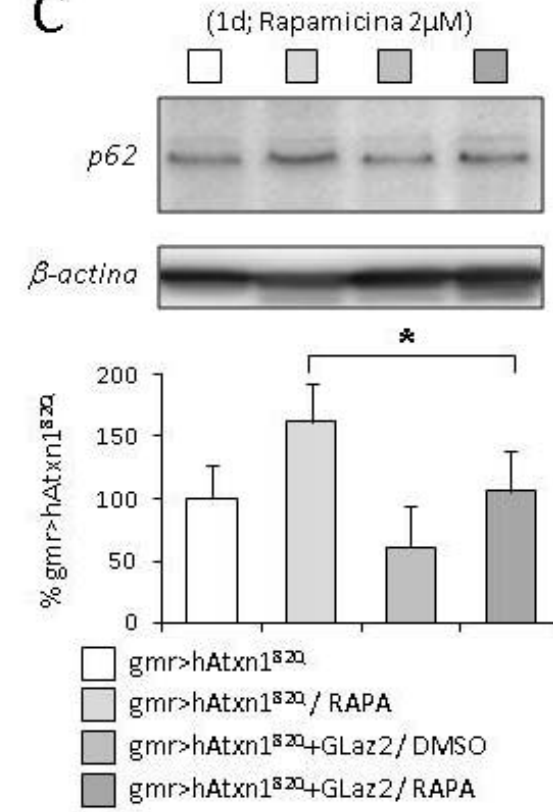

Figura 37.La sobreexpresión de GLaz disminuye la acumulación de p62 en respuesta a la degeneración por ATXN1 y la inducción de la autofagia.

A. La acumulación de p62 medida por inmunoblot disminuye en retinas afectadas por SCA1 que sobre-expresan GLaz. B. Como era de esperar, la expresión de la proteína p62 incrementa con el tratamiento de rapamicina en moscas silvestres. C. El tratamiento de moscas SCA1 con rapamicina, combinado con la sobre-expresión de GLaz reduce la acumulación de p62. Las diferencias estadísticas se determinaron por el test $t$ de Student. * $P<0,05$.

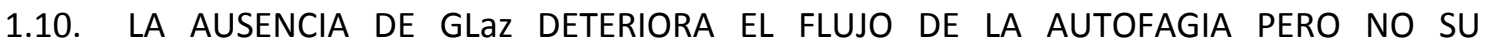 INICIACIÓN.}

Si la sobreexpresión de GLaz favorece el desarrollo de la autofagia, la falta de GLaz podría disminuir su eficiencia. Las moscas mutantes nulas para GLaz presentan niveles altos de $p 62$ respecto a sus controles (Fig. 38A, B). Este efecto está acompañado por un aumento en los niveles de transcripción de Atg8a (Fig. 38C).

Por lo tanto, la acumulación de p62 no es debida a daños en la iniciación de la autofagia sino a una resolución deficiente. 

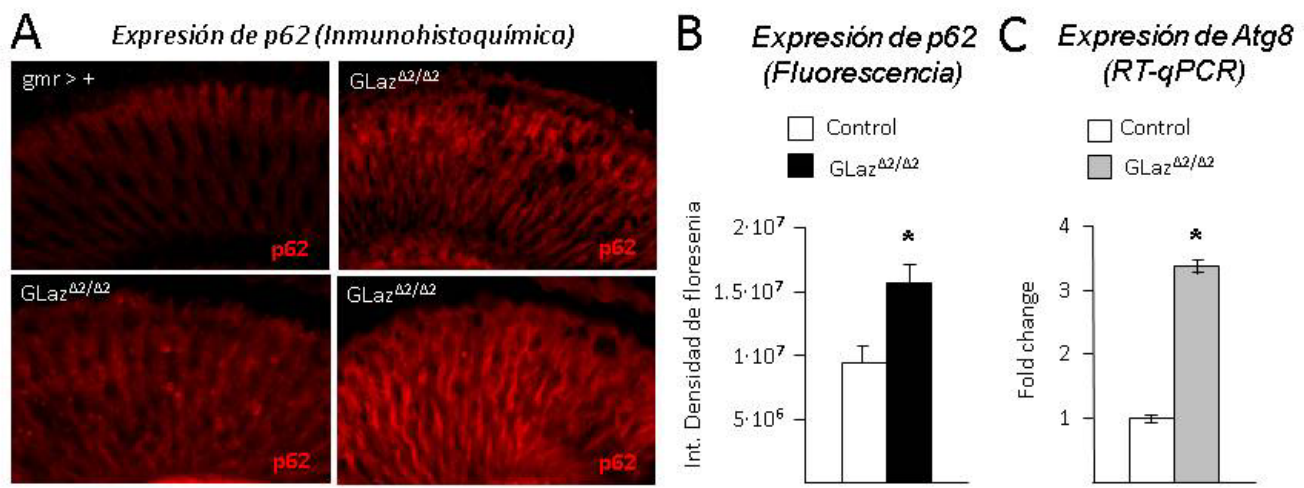

Figura 38.La pérdida de función de GLaz incrementa la expresión de p62 y Atg8.

A. La inmunofluorescencia de retinas control (gmr>+) y con falta de función de GLaz (GLaz ${ }^{\Delta 2 / \Delta 2}$ ) muestra la expresión de p62. B. Cuantificación de la inmunofluorescencia de p62. C. Niveles de mRNA de Atg8 medidos por RT-PCR en cabezas de mosca control y con falta de función. Las diferencias estadísticas en $\mathrm{B}$ y $\mathrm{C}$ se determinaron por el test de $t$ de Student. ${ }^{*} P<0,05$.

\subsection{LOCALIZACIÓN INTRACELULAR DE ApoD}

Según los resultados presentados en este capítulo, una proteína extracelular, unidora de lípidos, miembro de las Lipocalinas, podría ejercer una función sobre un proceso intracelular como la autofagia. ¿De qué manera?

Los resultados obtenidos con el modelo de SCA1 en los fotorreceptores, junto con experimentos previos [5] y resultados obtenidos en otra línea de investigación independiente del laboratorio [543]revelan una internalización de ApoD situándola dentro de estructuras vesiculares en el citoplasma y refuerzan la idea de una posible actuación de GLaz desde el interior de las células afectadas. Por un lado, GLaz aparecía en compartimentos vesiculares intercelulares de los fotorreceptores en degeneración que no la expresan lo que implicaría una internalización desde el medio extracelular. Por otro lado, las inclusiones nucleares de la proteína poliglutaminada permanecen presentes tras el rescate de GLaz sugiriendo un efecto sobre el espacio intercelular pero no sobre el núcleo.

Esta posible localización de ApoD en el interior de la célula le permitiría actuar sobre los dos mayores factores de la neurodegeneración y el envejecimiento: el daño provocado por ROS y el deterioro de la proteostasis. En concreto, para poder explicar los efectos sobre el flujo autofágico observados en el capítulo anterior, ApoD debería tener acceso a los procesos finales de la autofagia en los que existiera participación de membranas y lípidos. Por otro lado, la estrecha relación de ApoD con la protección contra el estrés oxidativo implicaría su presencia en un compartimento sensible a dicho estrés en donde la función protectora de ApoD pudiera ser especialmente necesaria y cuyo deterioro estuviera relacionado con la supervivencia y la longevidad.

Para encontrar el lugar del interior celular desde donde ApoD pudiera ejercer una función protectora tras su endocitosis se utilizaron dos tipos celulares: cultivos primarios de astrocitos de ratón y la línea celular de glioblastoma humano 1321N1. 
Los lisosomas son puntos de intersección entre la vía endocítica y autofágica, claves en la eliminación y reciclado de materiales dañados. Así mismo son fuentes de obtención de materiales esenciales a partir del reciclado de elementos adquiridos por endocitosis (como la extracción de colesterol de las LDL), tienen una estrecha relación con el metabolismo lipídico y son una herramienta clave en la reparación de membranas y la eliminación de detritus generados tras un daño. Son los compartimentos celulares donde más reacción de Fenton ocurre, cuyo producto final es el anión hidroxilo $(\mathrm{OH})$ responsable, a su vez, de la peroxidación lipídica. Además son puntos de decisión entre el inicio de programas de muerte celular o supervivencia.

Estos datos señalarían a los lisosomas como buenos candidatos para la localización de ApoD intracelular.

\subsubsection{APOD ENDOCITADO SE DIRIGE A LOS LISOSOMAS}

Para determinar la localización de ApoD tras su internalización se realizaron cultivos de células de glioblastoma humano (1321N1) que expresan ApoD. La inmunocitoquímica de hApoD mostró una distribución espacial centrada en dos regiones celulares: un punteado pericitosólico propio de un marcaje de membrana y un marcaje vesicular citosólico. El marcaje intracelular de hApoD colocalizó con vesículas marcadas con LAMP2, una proteína integral de membrana característica de los compartimentos lisosomales. (Fig. 39 A)

El mismo procedimiento se repitió en cultivos primarios de astrocitos de ratón que también expresan ApoD, para comprobar si esta colocalización era un fenómeno específico de un tipo celular o de especie, hApoD se detectó dentro de las células por inmunocitoquímica con un anticuerpo que se une específicamente a la proteína humana, y no a la de ratón, permitiendo diferenciar la proteína endocitada de la producida por la célula (Fig.39 B). 

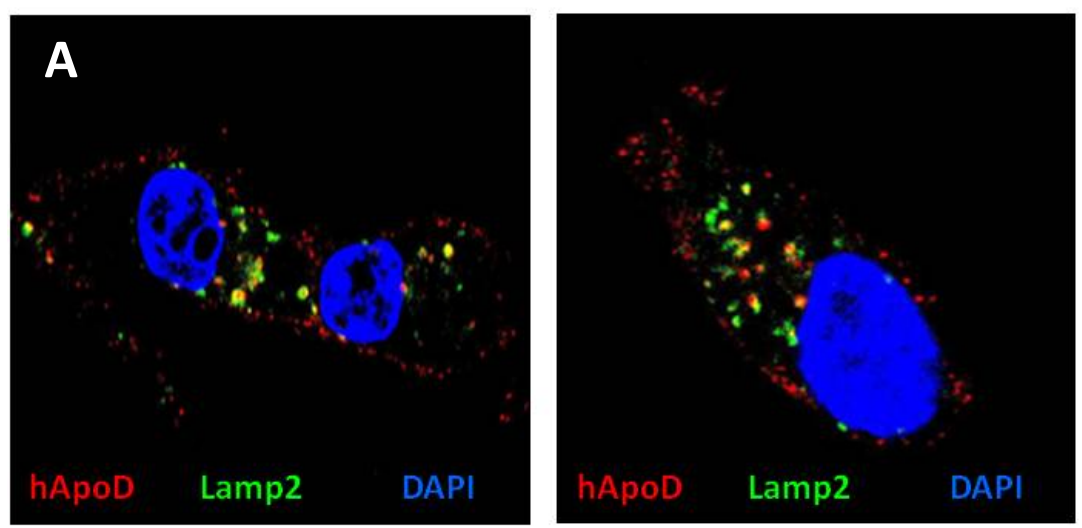

1321N1 human glioma
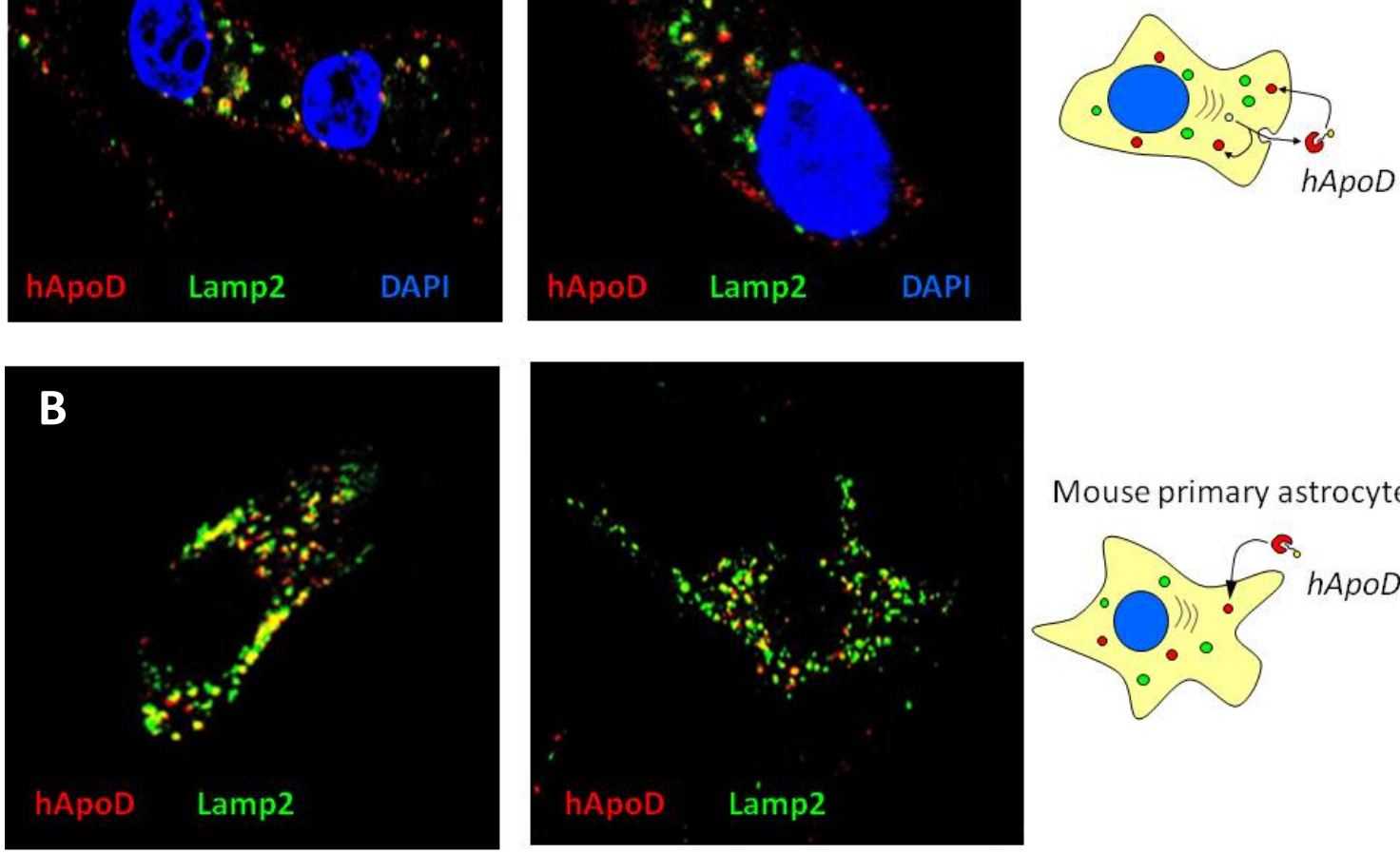

Mouse primary astrocyte

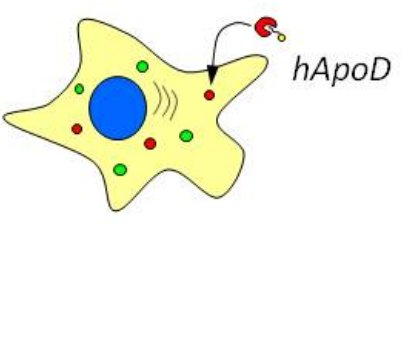

Figura 39. ApoD se endocita y acumula en los lisosomas. Ejemplos representativos de inmunocitoquímica para hApoD y LAMP2 (lisosomas) A. línea celular de astroglioma 1321N1 en respuesta a la adición de hApoD. Se observa colocalización de hApoD (rojo) citosólica con LAMP2 (verde) y marcaje pericitosólico de hApoD. B. cultivos primarios de astrocitos de ratón en respuesta a la adición de hApoD. Se observa colocalización de hApoD citosólica con LAMP2 (verde)

Experimentos preliminares realizados en una línea de astrocitoma humana, no han mostrado cambios significativos de la presencia de ApoD en los lisosomas ante el tratamiento con PQ (datos no mostrados). La presencia estable de ApoD en los lisosomas determinaría una nueva vía de actuación para una lipocalina. El hecho de que ApoD sea una proteína altamente glicosilada le permitiría permanecer activa dentro del lisosoma. ApoD podría controlar el estado de oxidación de la membrana del lisosoma favoreciendo así los procesos de fusión con el autofagosoma y por tanto fomentando la eficacia de la autofagia. De la misma manera podría mantener la integridad de los lisosomas y con ello favorecer la supervivencia celular. De hecho, la adición de la proteína en estos cultivos mejora la resistencia al estrés de los astrocitos y disminuye sus niveles de reactividad [543].

La descripción y caracterización de la endocitosis de ApoD y su tráfico vesicular permitirá obtener información importante para el conocimiento de ApoD. Actualmente es un proyecto independiente en el laboratorio que se está estudiando en profundidad (Pascua Maestro, R., Tesis). 


\section{CAPÍtULO 2. ESTUdIO DE GLAZ Y NLAZ EN EL CRECIMIENTO AXONAL Y LA SINAPTOGÉNESIS}

Tanto el efecto de ApoD sobre la eficacia de la autofagia, como su presencia en los lisosomas indican que ApoD y sus homólogos poseen un efecto modulador sobre el flujo del tráfico de membranas y posiblemente pueda influir en diferentes tipos de vesículas. Modificaciones en la composición lipídica de las membranas vesiculares afectan a un gran número de procesos. Los cambios en la concentración de ciertos lípidos alteran los procesos de fusión entre membranas [398] o modifican las propiedades fisicoquímicas de las bicapas [377]

El crecimiento axónico es uno de los procesos en los que el tráfico vesicular juega un papel fundamental. La expansión de la membrana plasmática requiere de la actividad conjunta de los procesos de endocitosis y exocitosis [526, 527]. El transporte axónico implicaría uniones entre vesículas, proteínas transportadoras y citoesqueleto que requerirían de una regulada composición y organización lipídica.

El primer fenotipo observado ante la falta de la lipocalina Lazarillo fue un defecto en el crecimiento y trayectoria de los axones durante el desarrollo del sistema nervioso de saltamontes [36]. Esta función en la guía de axones fue el origen de su nombre. Los intentos previos de extrapolar este fenotipo a sus homólogos de mosca no obtuvieron resultados satisfactorios (datos del laboratorio no publicados). Sin embargo, los resultados presentados en esta Tesis sobre la influencia de GLaz en procesos intracelulares como la autofagia, en los que podría estar actuando sobre procesos de tráfico vesicular, impulsaron la realización de un nuevo intento. Aunque podría considerarse que los cultivos primarios celulares son una simplificación exagerada de los sistemas y que los resultados no son extrapolables a los fenotipos del organismo completo, en algunas ocasiones simplificar el sistema, sobre todo en el caso del estudio del mecanismo de una proteína concreta, puede permitir eliminar aquellos otros factores que colaboran en su función y que impiden observar un fenotipo claro. Muy probablemente el efecto de $A p o D$ o de su pérdida se vea amortiguado por muchos otros factores presentes en el órgano completo y por ello los cultivos primarios podrían ser, en este caso, un buen sistema para estudiar la función de ApoD.

Para ello se utilizó una línea de Drosophila doble mutante de pérdida de función para NLaz y GLaz, evitando, así, los posibles efectos compensatorios que una de ellas pudiera ejercer ante la ausencia de la otra.

\subsection{LA FALTA DE GLaz Y NLaz PROVOCA LA DISMINUCIÓN DE LA LONGITUD DEL AXÓN PERO NO DEL NÚMERO DE FILOPODIOS EN NEURONAS DE DROSOPHILA EN CULTIVO.}

Se realizaron cultivos de neuronas de Drosophila procedentes de mutantes nulos para NLaz y GLaz. Tras 6 horas después de la siembra, se fijaron y marcaron por inmunocitoquímica con faloidina que marca los filopodios y tubulina que marca axones. Finalmente se cuantificó el número de filopodios por neurona y se midió la longitud de los axones (Fig. 40A). 
No se detectaron diferencias significativas en el número de filopodios de las neuronas de los mutantes nulos para NLaz y GLaz comparados con las neuronas provenientes del control silvestre. Sin embargo, sí se encontraron diferencias significativas en la longitud del axón de neuronas sin GLaz y NLaz frente a neuronas silvestres (Fig. 40). Esta diminución en la longitud del axón ante la falta de las dos lipocalinas va acompañada de defectos en la organización de los microtúbulos(Fig. 40A).Estos resultados demuestran por primera vez que el fenotipo generado por Lazarillo de saltamontes está conservado en sus homólogos de Drosophila.

A Cultivos de 6 horas
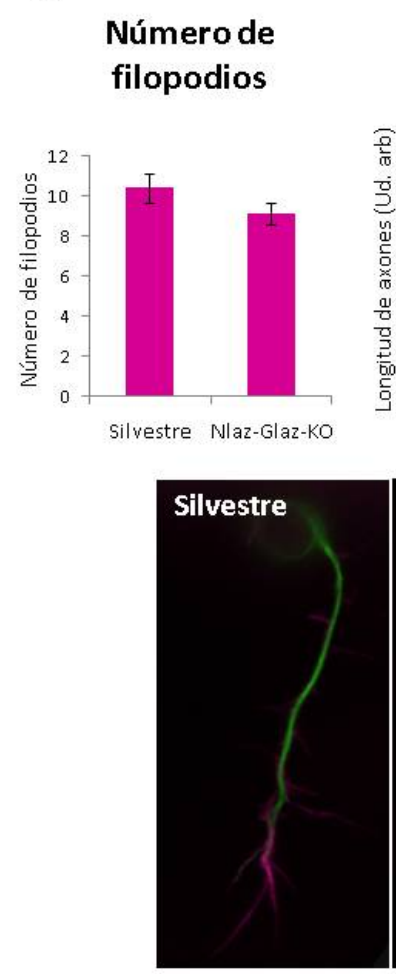

Longitud de los axones

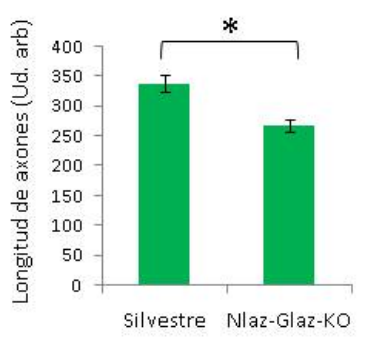

Silvestre Nlaz-Glaz-KO

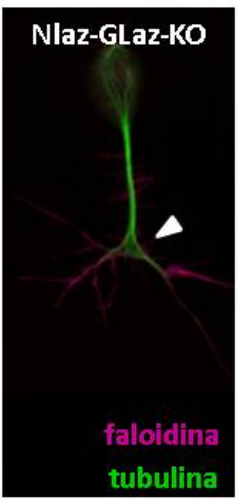

B Cultivos de 48 horas

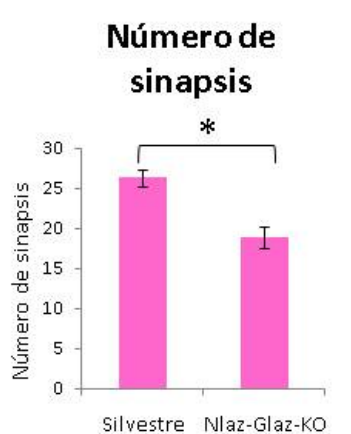

Área de las sinapsis
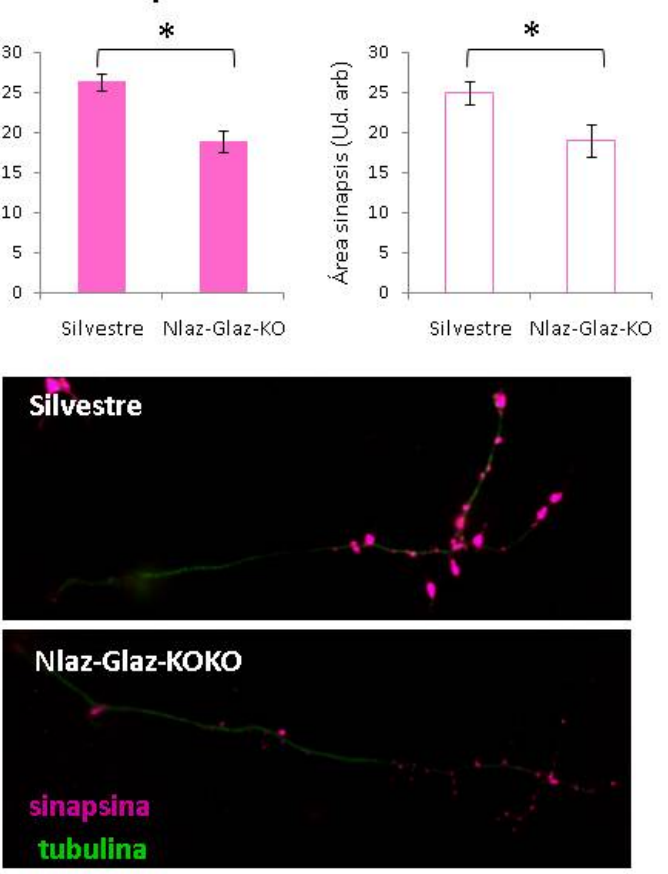

Figura 40. La falta de NLaz y GLaz afecta al crecimiento axonal y a la sinaptogénesis en cultivo. A. Número de filopodios y longitud de los axones de cultivos primarios de neuronas de 6 horas de Drosophila silvestre y NLazGLaz-KO. Neurona representativa de cada fenotipo. La punta de flecha señala la zona de desorganización de microtúbulos. B. Número de sinapsis y área de cada sinapsis de cultivos primarios de neuronas de 48 horas. Las diferencias estadísticas se determinaron por el test de Mann-Whitney * $P<0,05$.

\subsection{LA FALTA DE GLaz Y NLaz DISMINUYE EL NÚMERO DE SINAPSIS ESTABLECIDAS EN NEURONAS DE DROSOPHILA EN CULTIVO}

Para el estudio sobre la influencia de GLaz y NLaz sobre la sinapsis se realizaron cultivos de neuronas de Drosophila de la línea mutante para NLaz y GLaz y se incubaron durante dos días a 26 ㄷ tras lo cual se fijaron y marcaron con tubulina y sinapsina. Posteriormente se cuantificó el número de sinapsis por neurona. 
La falta de NLaz y GLaz provoca una disminución en el número de sinapsis y su área pero no de la cantidad de sinapsina (Fig.40). Esto podría indicar que los efectos de la falta de las dos lipocalinas no afectarían a la síntesis de las proteínas de las vesículas sinápticas en sí, sino a la generación y tamaño de las sinapsis, lo que es compatible con una posible función sobre las membranas.

Por lo tanto, se confirmó por primera vez la conservación del fenotipo que dio nombre a las lipocalinas de Drosophila homólogas a ApoD Lazarillo Glial y Lazarillo Neural. La presencia de fenotipo en el axón pero no en los filopodios concuerda con diferentes procesos de regulación del tráfico vesicular independientes para axones y dendritas [527, 579]. La disminución de sinapsis ante la falta de estas dos proteínas también sugiere la influencia de NLaz y GLaz en los procesos de tráfico de vesículas y su fusión. Estos resultados enfocan con mayor nitidez a las membranas como centro del mecanismo de acción de ApoD y sus homólogos. 


\section{CAPÍTULO 3.APOD Y LAS MEMBRANAS}

Desde los estudios iniciales de su estructura, hasta la compleja regulación que ejerce sobre el flujo de la autofagia, se ha evidenciado una estrecha relación entre ApoD (y sus homólogos) y los lípidos. Su pertenencia a una familia de proteínas con capacidad para unir ligandos hidrofóbicos (las Lipocalinas), su presencia en las macromoléculas transportadoras de lípidos, su secreción al exterior celular y sus efectos sobre la oxidación lipídica reflejan un diseño molecular destinado al manejo de lípidos y control de calidad de las membranas. Sin embargo, la falta de un receptor y los variados efectos derivados de su función observados ante una gran diversidad de condiciones han dirigido las hipótesis de su mecanismo de acción hacia el transporte lipídico y la regulación de su disponibilidad frente a las necesidades celulares, otorgando más importancia a sus ligandos en sí que a la propia lipocalina. Sin embargo, ApoD posee ciertas características que le otorgarían funciones mucho más específicas que la que compartiría con el resto de los miembros de su amplia familia de transportadores lipídicos. La lipocalina más cercana al ancestro común con ApoD, el homólogo en el saltamontes, Lazarillo, posee una peculiaridad estructural que definiría una función íntimamente ligada a las membranas y que podría, incluso, contraponerse a la función transportadora. Lazarillo posee una cola GPI que la ancla a la cara externa de la membrana plasmática. Considerando una función común ancestral, parecería más lógico pensar en una función sobre la propia membrana que una función que le alejara de ella (transporte) (ver sección 1).

Como se comentó al comienzo de esta Tesis, el objetivo general de este trabajo era un acercamiento al mecanismo molecular de ApoD y todos los resultados anteriores señalan a la membrana como centro de su mecanismo.

ApoD no posee esta cola GPI, es decir, carece de este sistema de anclaje a la membrana. Sin embargo, posee una región en su estructura anormalmente hidrofóbica para una proteína extracelular que podría interactuar con la membrana. Esta zona, es la que le permitiría adherirse a las HDL y LDL además de interaccionar mediante enlaces disulfuro con otras apolipoproteínas (mediante la cisteína libre; ver sección 1.2). El propio bolsillo hidrofóbico también podría ser un sistema de anclaje si le permitiera anclarse directamente a los lípidos de la bicapa. Curiosamente, el parche hidrofóbico de ApoD se encuentra a la entrada del bolsillo. Por otro lado, en el capítulo 1 de resultados se ha mostrado un marcaje que podría ser de membrana tras la adición de ApoD al medio extracelular de una línea de astroglioma humana de hApoD. Estos resultados han sido recientemente confirmados en el laboratorio (PascuaMaestro, resultados no publicados). La internalización de ApoD también podría implicar un contacto con la membrana. El hecho de que hasta el momento no se haya encontrado un receptor, quizás indique que podría ser capaz de incorporarse a una vía de endocitosis sin necesidad de receptor.

Las proteínas GPI son características de una región muy concreta de las membranas, los dominios de membranas. Los dominios de membrana actúan como centros de reclutamiento de proteínas que permiten la formación de signalosomas, activando cascadas de señalización o 
promoviendo la internalización de las proteínas que contienen. Las balsas lipídicas podrían ser el nexo entre la localización extracelular de ApoD, su mecanismo de acción sobre los lípidos y su localización intracelular [247].

Por lo tanto, el último capítulo de este trabajo consistió en el estudio de una posible interacción de ApoD con la membrana, en concreto con los dominios de membrana y, en caso afirmativo, las posibles consecuencias de la presencia o ausencia de ApoD en estos dominios de membrana.

\title{
3.1. ApoD SE ENCUENTRA EN LOS DOMINIOS DE MEMBRANAS RESISTENTES A DETERGENTEY ESTA ASOCIACIÓN ESTÁ CONSERVADA EN LAS MEMBRANAS DE RATÓN Y HUMANAS.
}

En primer lugar se estudió la posibilidad de que ApoD pudiera estar unida a la membrana. Para ello se realizaron preparaciones de membrana de cerebros de ratones adultos. El primer precipitado tras la centrifugación (3000 g, $10 \mathrm{~min}$ ) rico en núcleos y grandes organelas, el precipitado de membrana y el sobrenadante obtenidos tras la ultra-centrifugación (100.000 g, 1h $15 \mathrm{~min}$ ) se cargaron en un gel de electroforesis. El análisis por inmunoblot de la membrana resultante confirmó por primera vez la presencia estable de ApoD en las membranas (Fig. 41). Esta localización estaba conservada en membranas de la línea de astrocitoma humana 1321N1 (datos no mostrados).

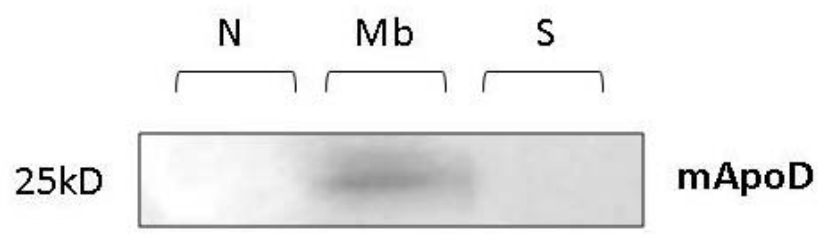

\begin{abstract}
Figura 41. ApoD se encuentra fuertemente unido a la membrana. Inmunoblot para mApoD. (N) precipitado rico en núcleos y grandes organelas tras la centrifugación a $3000 \mathrm{~g}$ durante $10 \mathrm{~min}$ de cerebro de ratón adulto (4 meses). (Mb) precipitado de membrana y (S) sobrenadante obtenidos tras una ultra-centrifugación a $100.000 \mathrm{~g}$ durante1h $15 \mathrm{~min}$.
\end{abstract}

Para determinar la presencia de ApoD en las balsas lipídicas se extrajeron las membranas de cerebros completos de ratones adultos. Tras una incubación con Triton X114 (que disuelve las membranas salvo en las regiones ricas en colesterol y esfingomielina (dominios de membrana resistentes a detergente o DRM) se sometieron a una separación por densidad en gradiente de sacarosa (Fig. 42A). Las fracciones se precipitaron y analizaron por inmunoblot. ApoD aparece en la fracción correspondiente a los DRMs (fracción 3), caracterizada por un enriquecimiento en flotilina, colesterol y esfingomielina (Fig. 42B). Esta localización está conservada en células humanas. Este experimento se reprodujo en membranas de células de glioblastoma humano donde nuevamente se obtuvo un enriquecimiento de ApoD en la fracción correspondiente a los DRMs (fracción 3) (Fig. 42C).

Por lo tanto se demostró no solo que ApoD se une a la membrana plasmática sino que además, se encuentra en las balsas lipídicas. 


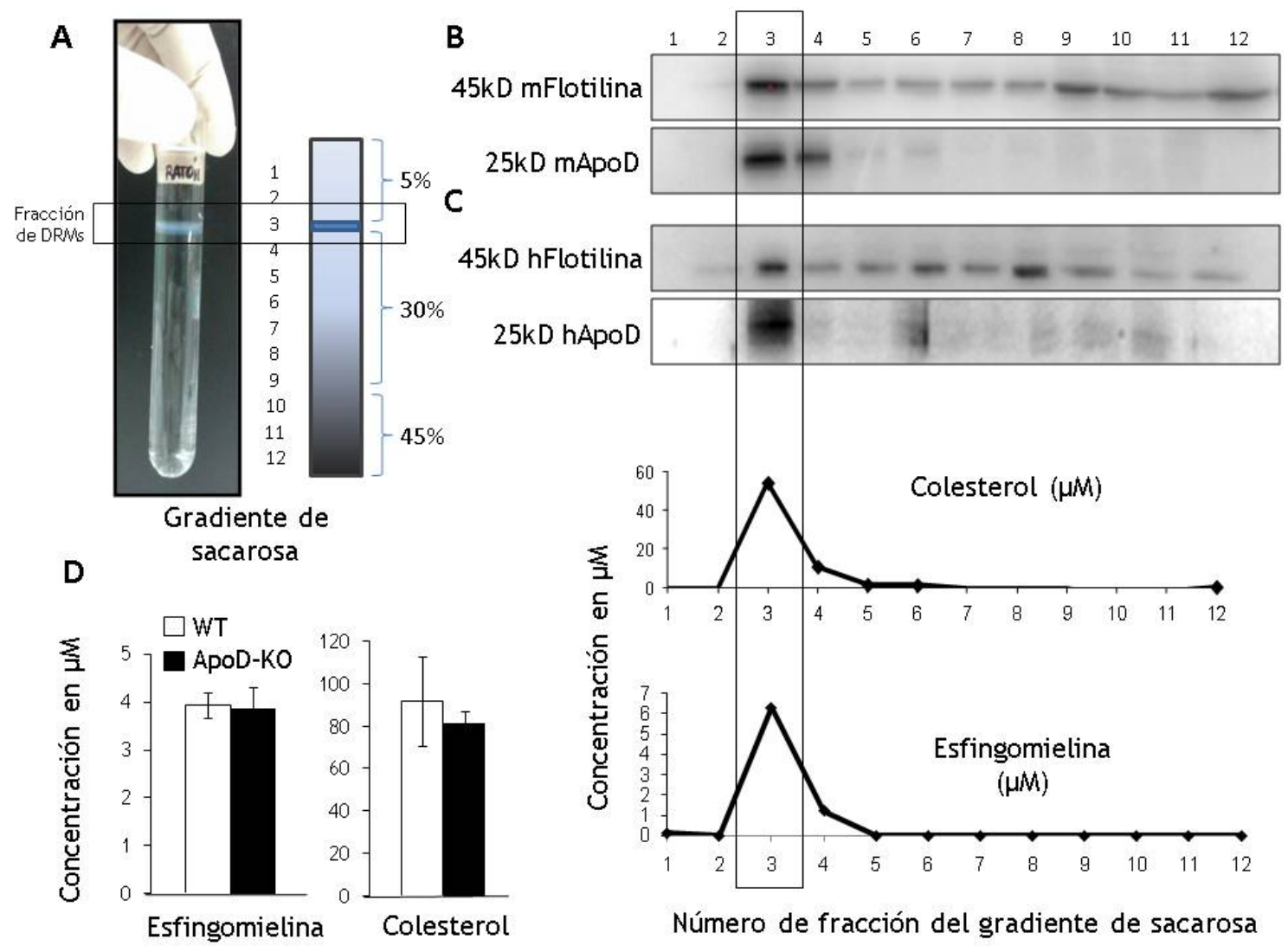

Figura 42. ApoD se encuentra en las balsas lipídicas de membranas de cerebro de ratón y de células de astroglioma humano pero no modifica su composición en colesterol y esfingomielina.

A. Fracción 3 (balsas lipídicas) del gradiente de sacarosa para la extracción de DRM. B. Inmunoblot de ApoD de ratón y Flotilina para las fracciones del gradiente de sacarosa para la extracción de DRM de membranas de cerebro de ratón WT con Triton X-114. C. Inmunoblot de hApoD y Flotilina para las fracciones del gradiente de sacarosa para la extracción de DRM de membranas de 1321N1 (glioblastoma humano) con Triton X-114. Perfil de enriquecimiento en colesterol y esfingomielina del gradiente de sacarosa. C. Concentración de esfingomielina y colesterol en los DRMs (fracción 3) de membranas de cerebros de ratón WT y ApoD-KO. Las diferencias estadísticas se determinaron por el test de $t$ de Student. ${ }^{*} P<0,05$.

\subsection{LA FALTA DE APOD NO MODIFICA LA CANTIDADDE COLESTEROL Y ESFINGOMIELINA DE LOS DOMINIOS DE MEMBRANA RESISTENTES A DETERGENTE DE CEREBROS DE RATÓN.}

Una vez determinada la presencia de ApoD no solo en membranas aisladas sino también en los dominios de membrana resistentes a detergente, el siguiente objetivo fue estudiar las variaciones derivadas de la presencia o la ausencia de ApoD en estas estructuras. Para ello se utilizaron ratones WT y ApoD-KO como fuente del material a estudiar.

En primer lugar se midió la cantidad de colesterol y esfingomielina, dos de los componentes principales de las balsas lipídicas, en los DRM (fracción 3) de membranas de cerebro de ratones WT y de ratones ApoD-KO. No se encontraron diferencias significativas para ninguno de estos dos lípidos ante la falta de ApoD (Fig.42D). 


\subsection{LA FALTA DE ApoD NO MODIFICA SUSTANCIALMENTE EL PATRÓN GLOBAL PROTEICO DE LOS DOMINIOS DE MEMBRANA RESISTENTES A DETERGENTE DE CEREBROS DE RATÓN.}

En segundo lugar se comparó el patrón proteico de las DRM de cerebros de ratones WT con el de ratones mutantes nulos para ApoD por electroforesis bidimensional. El patrón obtenido para ambos genotipos es muy similar a otros análisis proteicos de balsas lipídicas [580]. No se encontraron diferencias consistentes ante la falta de $A p o D$ en tres réplicas del experimento (La figura $\mathbf{4 3}$ muestra una de estas réplicas). Curiosamente, en todos los casos se observó un peor enfoque en los geles de ApoD-KO que podría indicar diferencias en la naturaleza de la muestra como aumento de la glicosilación o de la oxidación de proteínas.

Es importante señalar que la electroforesis bidimensional no es la mejor técnica para el análisis de proteínas hidrofóbicas, especialmente para las proteínas de membrana. Esto es debido a dos propiedades de estas proteínas. Sus puntos isoeléctricos $(\mathrm{pl}=\mathrm{pH}$ al que un polianfolito tiene carga neta 0 ) son generalmente alcalinos lo que harían necesarios gradientes de pH más amplios que supondría una disminución en la eficacia de la separación. Por otro lado, al haber sido diseñadas para ser solubles en la bicapa lipídica (sobre todo las proteínas integrales) son poco solubles en los disolventes acuosos utilizados para el enfoque isoeléctrico [581, 582]. ApoD de rata tiene un $\mathrm{pl}=4,05-4,37$ (según su grado de glicosilación) [39], hApoD del fluido cístico mamario presenta un $\mathrm{pl}=3,75$ [583]. Sin embargo, no se encontró ningún punto a 25kD que sólo estuviera presente en los geles WT y no en los ApoD-KO. Por lo tanto no se puede descartar la existencia de cambios proteicos debidos a la falta de ApoD pero, al menos, si pueden descartarse grandes cambios en un amplio grupo de proteínas con pl entre 3 y10 y de alta solubilidad en medio acuoso.
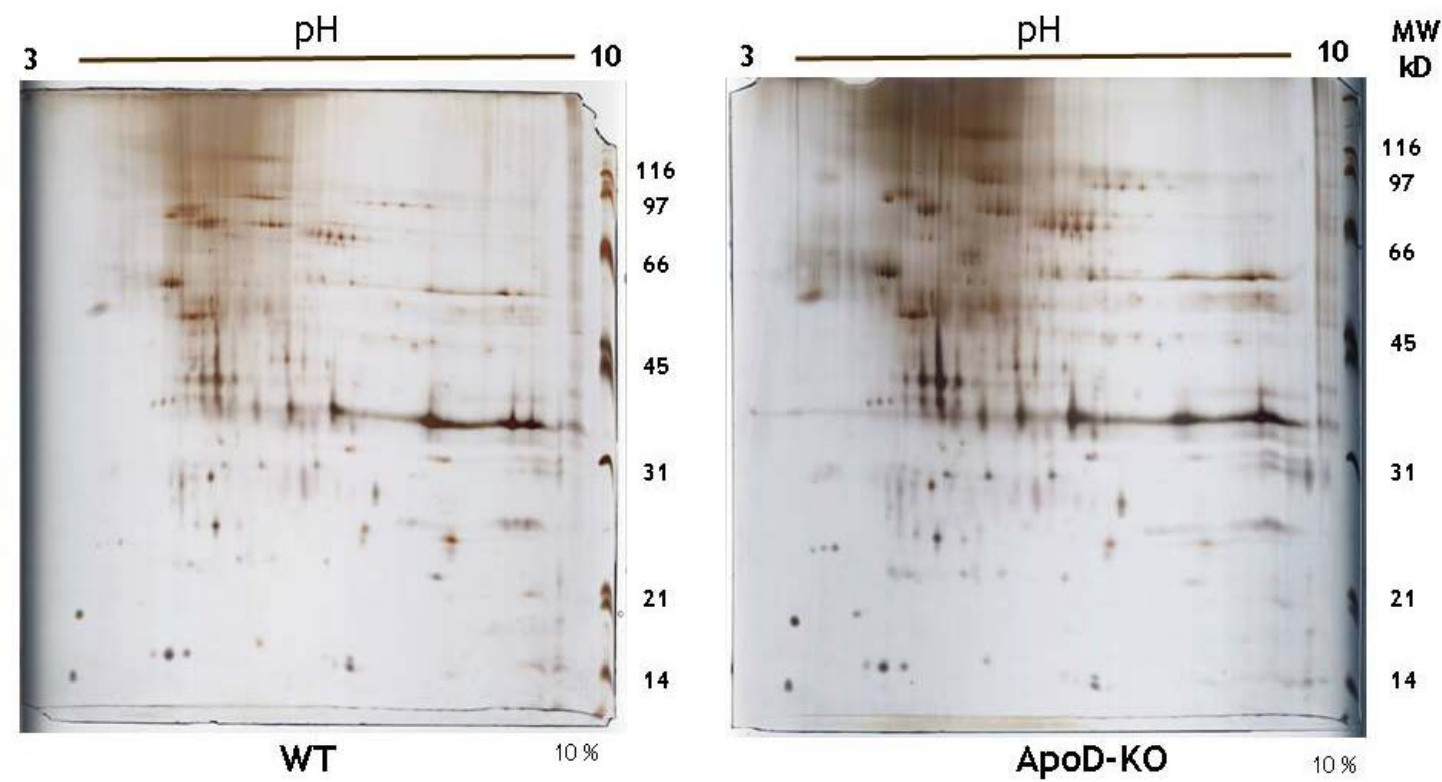

Figura 43. La falta de ApoD no modifica el patrón global proteico de los DRM de membranas de cerebro de ratón. Electroforesis bidimensional en gel de poliacrilamida al $10 \%$ (SDS-PAGE) $(20 \times 18 \mathrm{~cm})$ para DRM de 
membranas de cerebros de ratones WT y ApoD-KO. Gradiente de pH inmovilizado (IPG) de pH lineal 3-10, 18 cm (GE Healthcare). Tinción con $0,25 \%$ de nitrato de plata.

\subsection{LA FALTA DE APOD PROVOCA CAMBIOS CONFORMACIONALES EN LA ESTRUCTURA DE LOS DOMINIOS DE MEMBRANA RESISTENTES A DETERGENTE DE CEREBROS DE RATÓN}

La espectroscopía Raman es una técnica no destructiva que permite obtener información del orden molecular de una estructura además de aportar información sobre su composición. Para el estudio conformacional de los DMR por espectroscopía Raman se secó la fracción 3 (balsa lipídica) obtenida del gradiente de sacarosa de membranas de cerebro de ratón WT y ApoDKO. El espectro muestra diferencias estructurales en los DRM ante la falta de ApoD (Fig. 44).

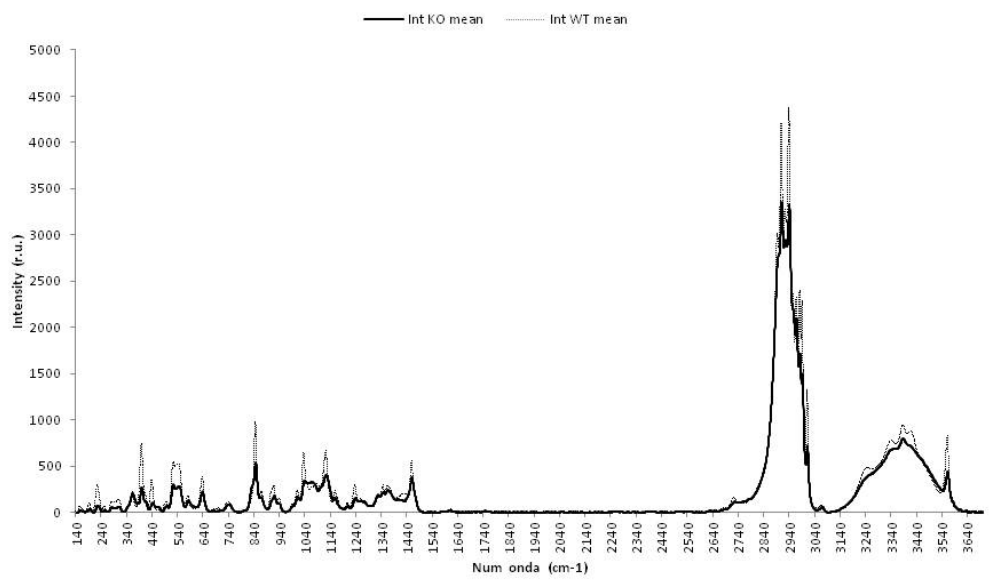

Figura 44. La falta de ApoD modifica el espectro Raman de las DMR de cerebro de ratón.

La sustracción del espectro KO al espectro WT para bajas frecuencias, ambos obtenidos por FTRaman (que permite obtener información promedio de la muestra) presenta picos correspondientes a tirosinas $\left(850 \mathrm{~cm}^{-1}\right)$, cisteínas $\left(640 \mathrm{~cm}^{-1}\right)$ y enlaces disulfuro $\left(540 \mathrm{~cm}^{-1}\right)$ en el WT que no aparecen en el KO lo que concuerda con la ausencia de ApoD en las muestras KO (Fig. 45A). Los espectros obtenidos con micro-Raman (asociado a un microscopio) (que permiten estudiar las heterogeneidades de la muestra) realizados sobre tres puntos al azar tanto de la muestra KO como de la WT presentan diferencias en la situación KO y no en la WT (Fig. 45B). Esto significa que la muestra KO no es homogénea a la escala de micro-Raman. Los espectros muestran diferencias en las regiones de bajas frecuencias propias de los enlaces responsables de las conformaciónes protéicas (C-S, C-N, etc.) y de las altas frecuencias correspondientes a $-\mathrm{OH}$ formando enlaces de hidrógeno $\left(3200-3500 \mathrm{~cm}^{-1}\right)$. También se observan variaciones en la anchura de las bandas que implican diferencias en el orden estructural de las muestras. El orden de empaquetamiento molecular de la muestra KO es menor que el orden molecular de la muestra WT (Fig. 45B). La comparación de los espectros de bajas frecuencias de muestras WT y KO en puntos de espectros similares y en puntos de espectros diferentes mostraron que tanto en las regiones similares como en las más diferentes las muestras WT y KO presentan importantes diferencias (Fig. 45C). 
B
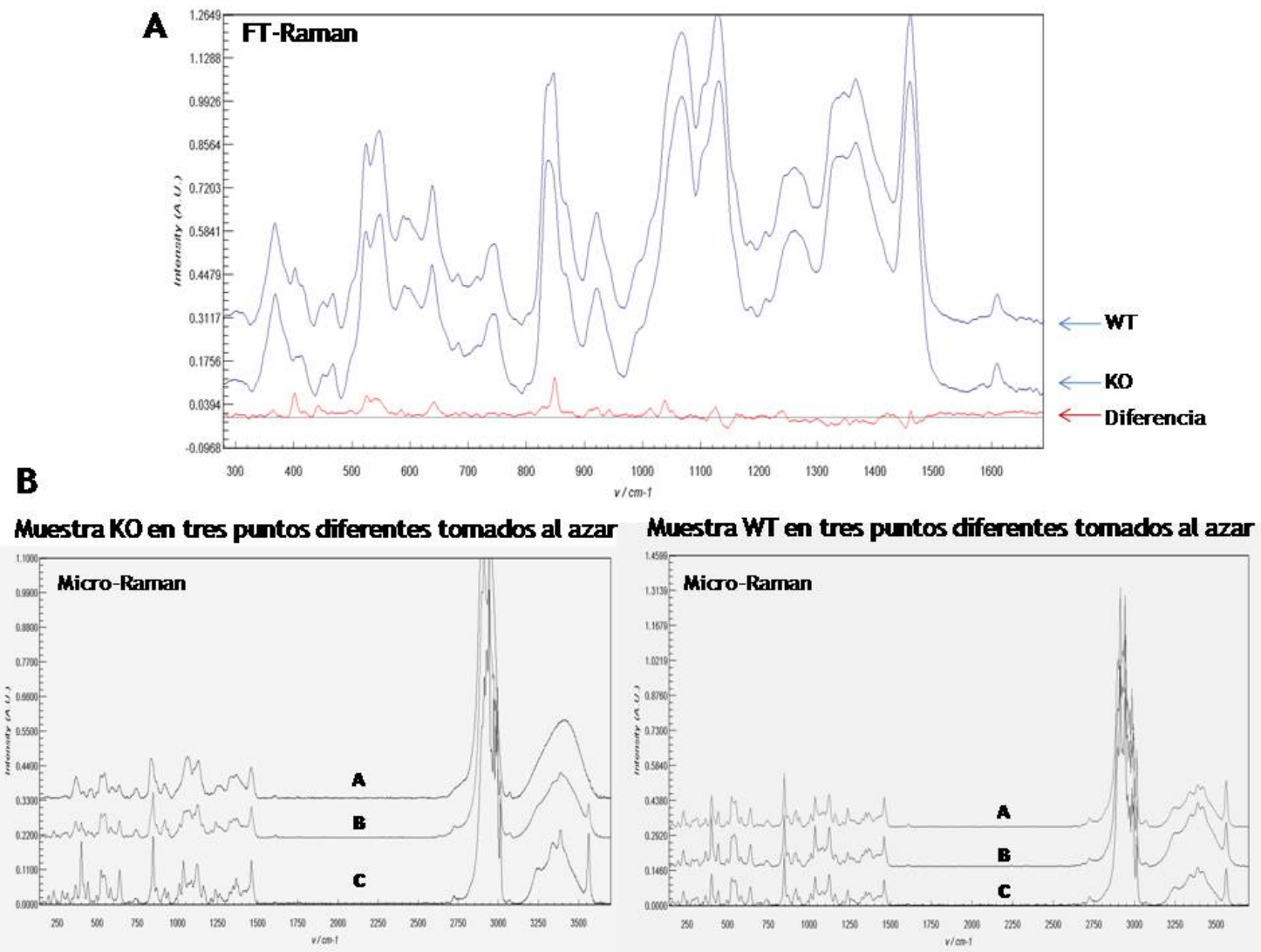

C

Diferencias entre WT y KO (en rojo) en un punto de espectros similares.

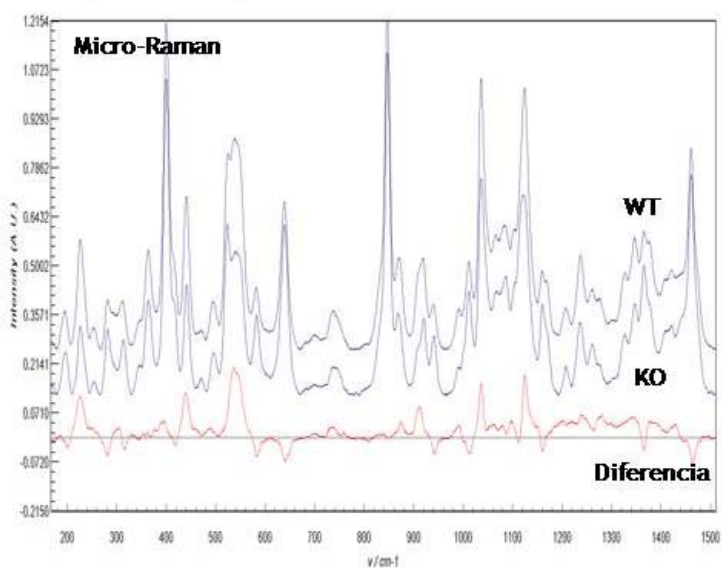

Diferencias entre WT y KO (en rojo) en un punto de espectros diferentes.

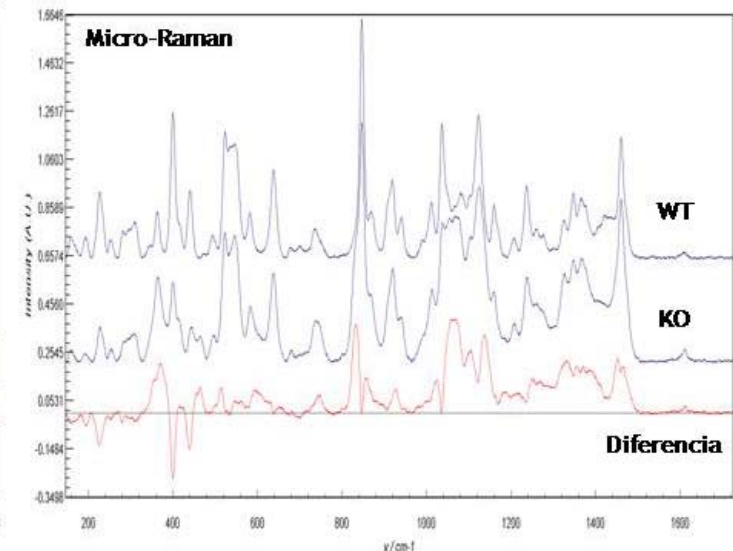

Figura 45. Estudio comparativo de los espectros Raman de los DRMs WT y KO.

A. Espectro obtenido por FT Raman para bajas frecuencias de DRMs de cerebro de ratón (análisis promedio de la muestra: spot de $1 \mathrm{~mm}$ de diámetro). La línea roja inferior, resultado de la sustracción del espectro KO al espectro WT, muestra picos correspondientes a tirosinas, cisteínas y enlaces disulfuro en el WT y no en el KO que corresponden a la ausencia de ApoD en las muestras KO.B. Espectros micro-Raman para DRMs de cerebro de ratón (Análisis micro de la muestra: spot de $20 \mu \mathrm{m}$ de diámetro) para tres puntos al azar de la muestra KO y de la WT. Se observan diferencias entre los espectros A, B y C de la muestra KO lo que significa que la muestra no es homogénea a la escala micro. Se observan diferencias en las regiones de bajas frecuencias propias de los enlaces $\mathrm{C}-\mathrm{S}$ y de las altas frecuencias correspondientes a - $\mathrm{OH}$ formando puentes de hidrógeno. Se observa además que el orden estructural no es el mismo (anchura de las bandas). C. Comparativa entre espectros de bajas frecuencias de muestras WT y KO en puntos de espectros similares y entre espectros de muestras WT y KO en puntos de espectros diferentes. Se observan diferencias entre WT y KO tanto en las regiones similares como en las más diferentes. 
Todos estos datos indican que existe un mayor desorden estructural en los DRM carentes de ApoD. Este desorden estructural podría deberse a cambios conformacionales o de composición de los lípidos o de las proteínas que los forman. Dado que los lípidos son los componentes mayoritarios de los dominios de membranas, estos cambios podrían implicar variaciones en la distribución de los lípidos y por tanto diferencias en las interacciones entre ellos o ser reflejo de cambios en la composición o de sus estados de oxidación.

\subsection{ApoD NO MODIFICA LA DISTRIBUCIÓN DEL MARCADOR GENÉRICO DE BALSAS LIPÍDICAS FLOTILINA}

No todas las proteínas de membrana asociadas a las balsas lipídicas permanecen en ellas de forma inmutable. Algunas proteínas entran o salen de las balsas en respuesta a eventos intracelulares o extracelulares como unión a ligandos, fosforilación u oxidación [214]. Si ApoD está modificando la conformación de los lípidos que forman las balsas, también podría estar modificando la distribución de las proteínas presentes en ellos.

Para el estudio de la influencia de ApoD sobre la distribución de Flotilina en la membrana, se comparó por inmunoblot el perfil de flotilina en el gradiente de sacarosa de membranas de cerebros de ratón WT tratadas con Triton X-114 con el perfil generado por las membranas de cerebros ApoD-KO en las mismas condiciones. Para la cuantificación se refirió la densidad de cada banda a la suma total de bandas en el gradiente. No se encontraron diferencias significativas en la distribución de flotilina a lo largo del gradiente ante la falta de ApoD (Fig. 46)

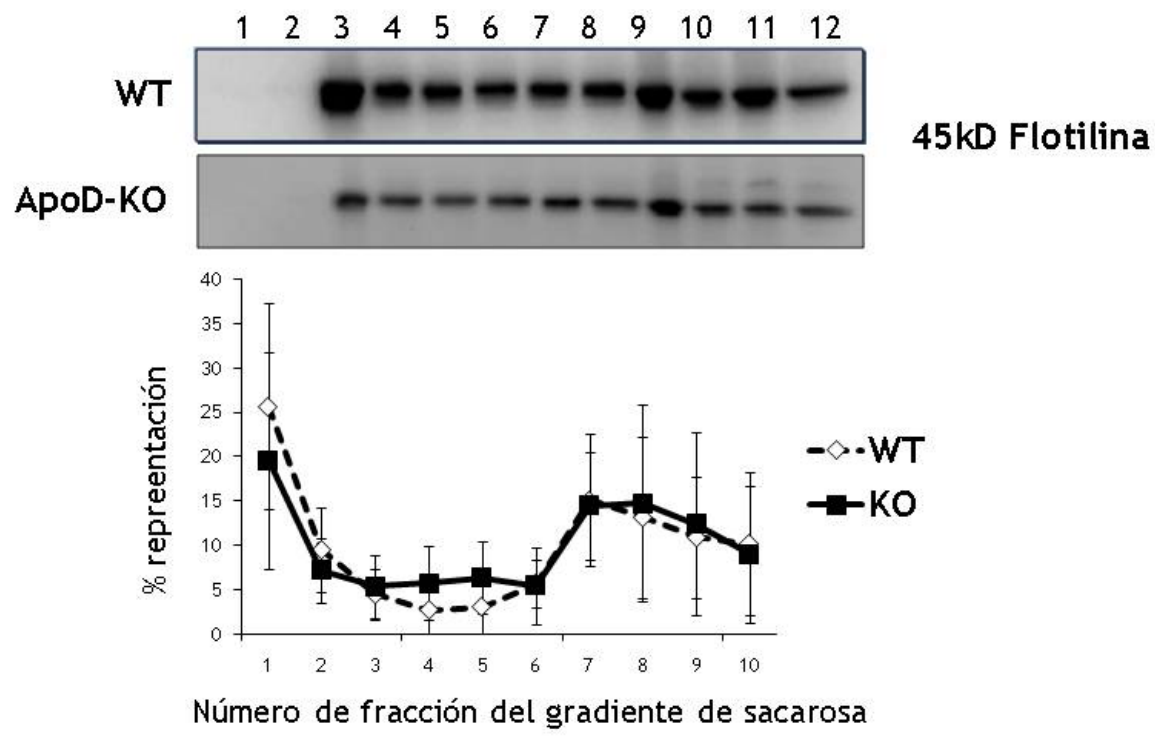

Figura 46. ApoD no altera la distribución de flotilina en el gradiente de sacarosa de membranas de cerebro de ratón. Inmunoblot para flotilina de las fracciones obtenidas en el gradiente de sacarosa tras el tratamiento de membranas de cerebros de ratones WT y KO con Triton X-114 y posterior centrifugación. Cuantificación realizada refiriendo la densidad de evaluaron por el test de $t$ de Student. ${ }^{*} P<0,05$. 


\subsection{LA FALTA DE ApoD MODIFICA LA RESPUESTA ANTE EL ESTRÉS OXIDATIVO DE LOS LÍPIDOS DE LOS DOMINIOS DE MEMBRANA RESISTENTES A DETERGENTE DE MEMBRANAS DE HIPOCAMPOS DE RATÓN}

El hipocampo es una de las regiones del cerebro más sensibles a la oxidación, y por tanto es un área clave para el estudio del estrés oxidativo [433, 434, 490]. Además está implicado en importantes funciones como la memoria explícita y memoria espacial que ayuda a la navegación. Los ratones nulos para ApoD muestran un estrés oxidativo basal, una disminución de la resistencia a paraquat, un aumento de los lípidos peroxidados en el cerebro y un mayor fracaso en pruebas comportamentales como la disminución en la actividad locomotora y exploratoria y déficit de memoria [89]. El hecho de no haber encontrado diferencias ante la falta de ApoD ni en la composición proteica ni en los dos componentes lipídicos mayoritarios de los DRM en condiciones basales, la estrecha relación que parece existir entre ApoD y el estrés oxidativo, y los fenotipos observados en los ratones ApoD-KO relacionados con el hipocampo, apoyaron la realización de un estudio lipidómico en respuesta al estrés oxidativo en DRM de membranas de hipocampos de ratones WT y ApoD-KO.

Para la caracterización lipídica se aislaron DRM de hipocampos de 5 ratones adultos silvestres y5 nulos para ApoD en condición control y sometidos a estrés oxidativo por PQ. Los lípidos de las muestras se solubilizaron con cloroformo/metanol y se analizaron por cromatografía líquida de ultra-rendimiento acoplada a espectrometría de masas (UPLC-MS) que permitió determinar glicerolípidos, esteroles, esfingolípidos y glicerofosfolípidos.

\subsubsection{LOSDOMINIOS DE MEMBRANA RESISTENTES A TRITON X-114 DE HIPOCAMPO DE RATÓN SON ALTAMENTE SENSIBLES AL ESTRÉS OXIDATIVO Y SU COMPOSICIÓN VARÍA ANTE LA FALTA DE APOD ÚNICAMENTE BAJO ESTRÉS OXIDATIVO.}

El primer componente del análisis multivariante dirigido, teniendo en cuenta todos los datos obtenidos (por quintuplicado) para las cuatro condiciones (WT-CTRL, KO-CTRL, WT-PQ, KO$P Q$ ), permitió una clara separación entre el grupo de ratones tratados con PQ (WT-PQ y KO-PQ) (izquierda) frente a los no tratados (WT-CTRL y KO-CTRL) (derecha). Esto indica que las mayores diferencias se encuentran al comparar la situación control con el tratamiento con $P Q$, es decir, demuestra que la composición lipídica de los DRM del hipocampo es altamente sensible al estrés oxidativo(Fig. 47A). Esta sensibilidad frente al estrés oxidativo generado por el PQ se observa tanto en los hipocampos de individuos WT como en los ApoD-KO.

El segundo componente del análisis multivariante permitió separarlos individuos WT-PQ de los $\mathrm{KO}-\mathrm{PQ}$, pero no tanto los WT de los KO lo que indica que la composición de los dominios de membrana se ve alterada ante la falta de ApoD predominantemente cuando se encuentran en situación de estrés (Fig. 47A).

Varios estudios sobre las diferencias de extracción de distintos detergentes y la caracterización de los tipos de microdominios que aíslan, describen los DMRs resistentes a Triton X-114 como microdominios de membranas internas ricas en cerebrósidos (glucoesfingolípidos) [392, 584, 585] y es en este tipo de dominios donde aparece ApoD. 
Del total de especies detectadas, el DHA y el AA aparecen mayoritariamente en las familias lipídicas que contienen ácidos grasos insaturados. Todas las PC que contenían DHA y AA sufrieron cambios significativos ante el estrés oxidativo, lo que corrobora la alta sensibilidad de los lípidos insaturados a la oxidación. Los DRM de hipocampo de ratón extraídos con Triton X114 presentan, por tanto, una alta representación de DHA y AA concordando con el enriquecimiento en AA y DHA descrito en otros tipos de DRMs que les confiere una alta sensibilidad al estrés oxidativo $[145,586]$.

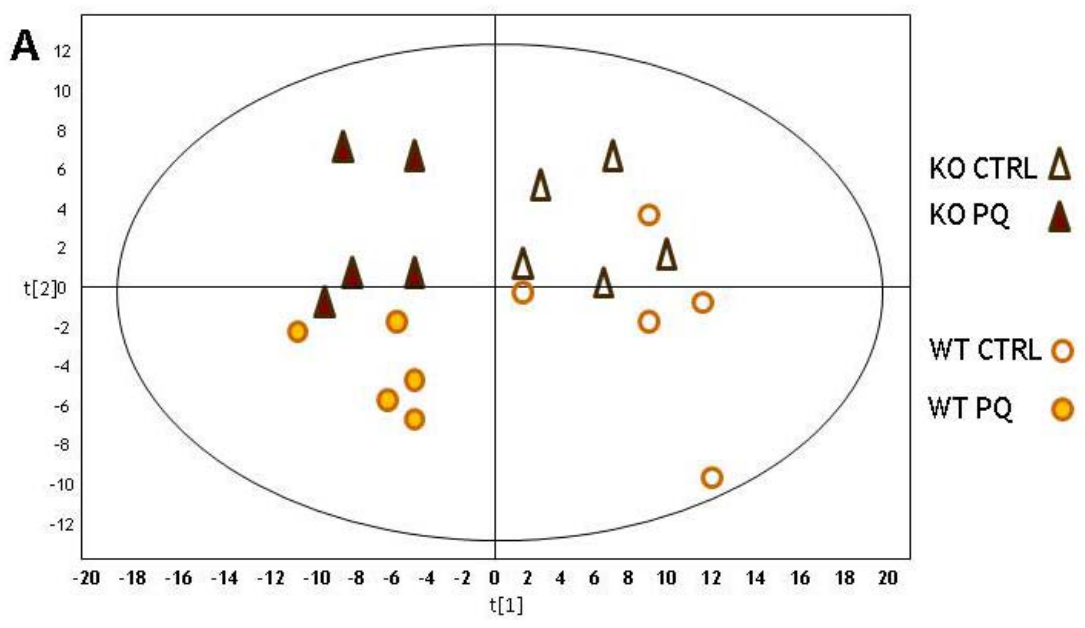

B

WT

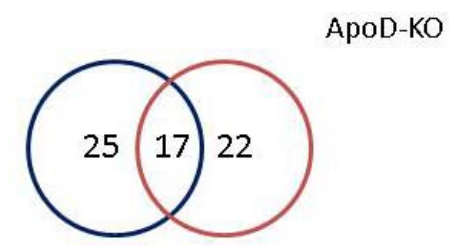

Lípidos modificados por $\mathrm{PQ}$

Figura 47. Los DRMs de hipocampos de ratón se alteran por la acción de ApoD en situación de estrés oxidativo.

A. Análisis multivariante dirigido de los datos obtenidos del análisis lipidómico por cromatografía líquida de ultra-rendimiento acoplada a espectrometría de masas (UPLC-MS) de dominios de membranas de hipocampos de 5 ratones adultos silvestres y5 nulos para ApoD en condición control y sometidos a estrés oxidativo por PQ. EI primer componente $t[1]$ separa los individuos en situación control de los individuos tratados con $\mathrm{PQ}$. El segundo componente $\mathrm{t}[2]$ separa mejor los individuos $\mathrm{WT}$ de los ApoD-KO si han sufrido tratamiento con PQ que en situación control. B. Diagrama de Venn de los lípidos alterados por el tratamiento con PQ en DRMs de hipocampos de ratón WT y ApoD-KO.

\subsubsection{LA FALTA DE ApOD PROVOCA UN AUMENTO DE MONOHEXOSILCERAMIDAS EN LOS DOMINIOS DE MEMBRANA RESISTENTES A DETERGENTE DE MEMBRANAS DE HIPOCAMPOS DE RATONES SOMETIDOS A ESTRÉS OXIDATIVO.}

La existencia de diferencias entre los niveles de cada metabolito en las condiciones experimentales se analizaron aplicando dos aproximaciones estadísticas: test ANOVA 
(considerando la interrelación de los cuatro grupos de estudio (WT-KO-CTRL-PQ) y $t$ de Student (comparando dos grupos independientemente de los otros) generando, con los datos obtenidos, un heatmap o mapa de calor (Fig.48).

De los 117 lípidos detectados 69 mostraron diferencias significativas ante el tratamiento con $\mathrm{PQ}, 42$ metabolitos cambiaron significativamente ante el tratamiento con $\mathrm{PQ}$ en los individuos WT y 39 en los KO ante el mismo tratamiento. Únicamente 17 de estos lípidos fueron comunes a ambas situaciones (Fig.47B).

De los metabolitos que cambian ante el $P Q$ específicamente cuando falta $A p o D, 11$ son monohexosilceramidas (CMH), 7 PC poliinsaturadas, dos PE con AA, 1 esfingomielina y 1 ceramida (Tabla 4). Las monohexosilceramidas responden al estrés oxidativo de manera específica a la ausencia de ApoD.

16 metabolitos experimentaron cambios significativos al comparar la composición de los DRMs con o sin ApoD. Al comparar los DRMs WT frente a los ApoD-KO, cuatro monohexosilceramidas, tres ceramidas y dos $\mathrm{PC}$ poliinsaturadas aparecen disminuidas en los hipocampos sin ApoD, todas ellas (salvo una $\mathrm{CMH}$ ) aparecen también alteradas ante el PQ de forma dependiente de ApoD. Únicamente la PE 16:1e/18:2 aumenta ante la falta de ApoD (aumenta también ante el tratamiento con PQ). Seis componentes diferencian ambos genotipos después del tratamiento con $\mathrm{PQ}$, tres PE y tres PC (Tabla 5). ApoD parece ejercer su influencia fundamentalmente sobre las monohexosilceramidas y sus derivados frente al estrés oxidativo aunque algunas especies lipídicas también se ven alteradas en situación de estrés oxidativo ante la pérdida de función de la lipocalina. Estos datos concuerdan con la ausencia de diferencias en las medidas de colesterol y esfingomielinas de los DRMs ante la falta de ApoD.

De entre todos los lípidos alterados con el $\mathrm{PQ}$, los lípidos comunes a ambos genotipos son de cadena más corta, sobre todo si se compara con los lípidos afectados específicamente por la falta de $A p o D$, en su mayoría, aminoácidos de cadena larga con un alto grado de insaturación ( $P C$ y $P E$ ) teóricamente más sensibles al estrés oxidativo. 


\begin{tabular}{|c|c|c|c|c|c|c|c|c|}
\hline \multicolumn{3}{|c|}{ Sólo en WT } & \multicolumn{3}{|c|}{ Comunes } & \multicolumn{3}{|c|}{ Sólo en ApoD- KO } \\
\hline Lípido & $\log 2(F . C)$ & $\begin{array}{l}\text { Student(p- } \\
\text { valor) }\end{array}$ & Lípido & $\log 2($ F.C.) & $\begin{array}{l}\text { t- } \\
\text { Student( } \\
\text { p-valor) }\end{array}$ & Lípido & $\log 2(F . C)$. & $\begin{array}{l}\text { St- } \\
\text { Student(p- } \\
\text { valor) }\end{array}$ \\
\hline \multicolumn{3}{|l|}{ COLESTEROL } & \multicolumn{3}{|l|}{ MONOHEXOSILCERAMIDA } & \multicolumn{3}{|l|}{ MONOHEXOSILCERAMIDA } \\
\hline Colesterol & 0,12 & $3,95 \mathrm{E}-03$ & d18:2/22:0(2OH) & 1,13 & $8,77 \mathrm{E}-05$ & $d 18: 1 / 25: 1(2 \mathrm{OH})$ & 1,33 & $1,77 \mathrm{E}-03$ \\
\hline \multicolumn{3}{|l|}{ FOSFATIDILETANOLAMINA } & $\mathrm{d} 18: 1 / 24: 2$ & 1,27 & $7,05 \mathrm{E}-05$ & $\mathrm{~d} 18: 1 / 23: 1$ & 1,10 & 4,90E-04 \\
\hline $18: 1 e / 22: 4$ & 0,31 & $2,90 \mathrm{E}-02$ & FOSFATIDILETANOLAMINA & & & $\mathrm{d} 18: 1 / 24: 1(2 \mathrm{OH})$ & 0,81 & $1,01 \mathrm{E}-04$ \\
\hline 18:0/18:1 & 0,20 & $5,12 \mathrm{E}-03$ & $16: 1 e / 18: 2$ & 0,55 & $3,59 \mathrm{E}-02$ & $d 18: 1 / 20: 0(2 O H)$ & 0,80 & $2,04 \mathrm{E}-03$ \\
\hline \multicolumn{3}{|l|}{ FOSFATIDILCOLINA } & $18: 1 e / 18: 2$ & 0,65 & 6,07E-03 & $\mathrm{d} 18: 1 / 23: 0(2 \mathrm{OH})$ & 0,79 & $9,74 \mathrm{E}-03$ \\
\hline $16: 0 / 22: 6$ & $-0,20$ & $2,36 \mathrm{E}-02$ & \multicolumn{3}{|l|}{ FOSFATIDILCOLINA } & $\mathrm{d} 18: 1 / 25: 1$ & 0,68 & $2,02 \mathrm{E}-02$ \\
\hline $16: 0 / 20: 4$ & $-0,25$ & $4,77 \mathrm{E}-02$ & $20: 4 / 20: 4+18: 2 / 22: 6+18: 0 / 22: 8$ & $-0,34$ & $3,46 \mathrm{E}-03$ & $\mathrm{~d} 18: 1 / 24: 1$ & 0,57 & $4,91 \mathrm{E}-03$ \\
\hline $16: 0 / 18: 2$ & $-0,25$ & $1,85 \mathrm{E}-02$ & $17: 0 / 20: 4$ & $-0,24$ & $1,09 \mathrm{E}-02$ & $d 18: 1 / 22: 0(2 O H)$ & 0,54 & $2,60 \mathrm{E}-02$ \\
\hline $16: 0 / 14: 0+14: 0 / 16: 0$ & $-0,29$ & $2,90 \mathrm{E}-03$ & $18: 0 / 22: 6$ & $-0,13$ & $4,70 \mathrm{E}-02$ & $\mathrm{~d} 18: 1 / 23: 0$ & 0,53 & $3,86 \mathrm{E}-02$ \\
\hline $18: 0 / 20: 4$ & $-0,30$ & $1,31 \mathrm{E}-02$ & $15: 0 / 20: 4$ & $-0,41$ & $1,90 \mathrm{E}-03$ & $\mathrm{~d} 18: 0 / 22: 0(2 \mathrm{OH})$ & $-0,54$ & $3,05 \mathrm{E}-02$ \\
\hline $18: 0 / 22: 5$ & $-0,30$ & $3,94 \mathrm{E}-03$ & $0-16: 0 / 14: 0$ & $-0,53$ & $1,28 \mathrm{E}-03$ & $\mathrm{~d} 18: 1 / 25: 0$ & $-0,67$ & $5,63 \mathrm{E}-03$ \\
\hline 18:0/18:2 & $-0,31$ & $3,82 \mathrm{E}-03$ & $0-16: 0 / 16: 0$ & $-0,46$ & $2,69 \mathrm{E}-03$ & CERAMIDA & & \\
\hline $17: 1 / 20: 4+15: 0 / 22: 5$ & $-0,33$ & $4,74 \mathrm{E}-02$ & $18: 1 e / 20: 4$ & $-0,48$ & $1,11 \mathrm{E}-03$ & $\mathrm{~d} 18: 1 / 24: 1+\mathrm{d} 18: 2 / 24: 0$ & 0,56 & $2,21 \mathrm{E}-03$ \\
\hline $18: 1 / 20: 4+16: 0 / 22: 5$ & $-0,33$ & $1,52 \mathrm{E}-02$ & $16: 0 / 18: 0$ & $-0,30$ & $6,08 \mathrm{E}-03$ & \multicolumn{3}{|l|}{ FOSFATIDILETANOLAMINA } \\
\hline $16: 0 / 16: 0$ & $-0,34$ & $1,57 \mathrm{E}-03$ & $14: 0 / 18: 2$ & $-0,44$ & $1,73 \mathrm{E}-04$ & $18: 0 / 20: 4$ & $-0,08$ & $1,98 \mathrm{E}-02$ \\
\hline $18: 1 / 22: 6$ & $-0,34$ & $6,09 E-04$ & $14: 0 / 20: 4$ & $-0,53$ & $5,27 \mathrm{E}-03$ & $16: 0 / 20: 4$ & $-0,17$ & $1,05 \mathrm{E}-02$ \\
\hline $16: 0 / 20: 3$ & $-0,35$ & $2,28 \mathrm{E}-02$ & $0-16: 0 / 18: 0+0-18: 0 / 16: 0$ & $-0,59$ & $1,90 \mathrm{E}-03$ & FOSFATIDILCOLINA & & \\
\hline $18: 1 / 18: 2$ & $-0,38$ & $2,05 E-02$ & ESFINGOMIELINA & & & $18: 0 / 22: 4$ & $-0,21$ & $2,99 \mathrm{E}-02$ \\
\hline $18: 0 / 20: 5+16: 0 / 22: 5$ & $-0,40$ & $2,59 \mathrm{E}-03$ & $\mathrm{~d} 18: 0 / 18: 0$ & $-0,67$ & $3,00 \mathrm{E}-03$ & $0-16: 0 / 18: 1+18: 1 e / 16: 0$ & $-0,22$ & $2,26 \mathrm{E}-02$ \\
\hline $20: 3 / 20: 4$ & $-0,50$ & $3,59 \mathrm{E}-03$ & $\mathrm{~d} 18: 0 / 16: 0$ & $-0,63$ & $1,01 \mathrm{E}-02$ & $16: 0 / 20: 5$ & $-0,33$ & $2,89 \mathrm{E}-03$ \\
\hline \multicolumn{3}{|l|}{ ESFINGOMIELINA } & & & & $16: 1 / 20: 4$ & $-0,35$ & $1,09 \mathrm{E}-02$ \\
\hline $\mathrm{d} 18: 1 / 16: 0$ & $-0,53$ & $6,09 E-03$ & & & & $18: 3 / 18: 3$ & $-0,39$ & $2,68 \mathrm{E}-02$ \\
\hline $\mathrm{d} 18: 1 / 18: 0$ & $-0,55$ & $1,78 \mathrm{E}-03$ & & & & $0-16: 0 / 20: 4$ & $-0,39$ & $3,92 \mathrm{E}-03$ \\
\hline $\mathrm{d} 17: 1 / 16: 0+\mathrm{d} 18: 1 / 15: 0$ & $-0,55$ & $2,67 \mathrm{E}-02$ & & & & $18: 2 / 20: 4$ & $-0,66$ & $8,41 \mathrm{E}-04$ \\
\hline $\mathrm{d} 18: 1 / 20: 0+16: 1 / 22: 0$ & $-0,94$ & $3,21 \mathrm{E}-04$ & & & & \multicolumn{3}{|l|}{ ESFINGOMIELINA } \\
\hline \multicolumn{3}{|l|}{ CERAMIDA } & & & & \multirow[t]{4}{*}{$d 18: 1 / 23: 0$} & \multirow[t]{4}{*}{$-0,98$} & \multirow[t]{4}{*}{$6,59 \mathrm{E}-03$} \\
\hline $\mathrm{d} 18: 1 / 23: 0$ & $-0,51$ & $1,61 \mathrm{E}-02$ & & & & & & \\
\hline $\mathrm{d} 18: 1 / 24: 0$ & $-0,60$ & $3,10 \mathrm{E}-02$ & & & & & & \\
\hline $\mathrm{d} 18: 1 / 20: 0$ & $-0,79$ & $7,74 \mathrm{E}-03$ & & & & & & \\
\hline \multicolumn{9}{|c|}{$\begin{array}{l}\text { TABLA 4B. Diferencias lipídicas entre DRMs de membranas de hipocampo de ratón con y sin ApoD en situación control y tras tratamiento } \\
\text { con PQ }\end{array}$} \\
\hline \multicolumn{4}{|c|}{ WT vs. ApoD-KO } & \multicolumn{5}{|c|}{ WT-PQ vs. ApoD-KO-PQ } \\
\hline Lípido & \multicolumn{2}{|c|}{ log2(fold change) } & Student's t-test (p) & & lípido & $\log 2$ (fold change) & Student' & t-test (p) \\
\hline FOSFATIDILETANOLAMINA & & & & FOSFATID & LETANOLAM & & & \\
\hline $16: 1 \mathrm{e} / 18: 2^{\mathrm{c}}$ & 0 & & $1,77 \mathrm{E}-02$ & & $: 0 / 20: 4^{\mathrm{a}}$ & $-0,12$ & 1,1 & $=-02$ \\
\hline FOSFATIDILCOLINA & & & & & $: 1 \mathrm{e} / 18: 1$ & $-0,41$ & 4,7 & $=-02$ \\
\hline $14: 0 / 18: 2^{c}$ & -0 , & & $2,50 \mathrm{E}-02$ & & $1 e / 22: 4^{a}$ & $-0,36$ & 2,7 & $=-02$ \\
\hline $18: 0 / 20: 5+16: 0 / 22: 5^{a}$ & -0 , & & $2,82 \mathrm{E}-02$ & FOSFA & TIDILCOLINA & & & \\
\hline CERAMIDA & & & & & $: 3 / 18: 3^{b}$ & $-0,48$ & 1,4 & $E-03$ \\
\hline $\mathrm{d} 18: 1 / 20: 0^{\mathrm{a}}$ & -0 , & & $3,72 \mathrm{E}-02$ & & $: 2 / 20: 4^{b}$ & $-0,44$ & 2,1 & $=-02$ \\
\hline $\mathrm{d} 18: 1 / 24: 0^{\mathrm{a}}$ & -0 , & & $4,42 \mathrm{E}-02$ & & $: 1 / 22: 6^{a}$ & 0,15 & 3,5 & $=-02$ \\
\hline $\mathrm{d} 18: 1 / 24: 1+\mathrm{d} 18: 2 / 24: 0^{b}$ & -0 , & & 4,07E-02 & & & & & \\
\hline MONOHEXOSILCERAMIDA & & & & & & & & \\
\hline $\mathrm{d} 18: 1 / 20: 0(2 \mathrm{OH})^{\mathrm{b}}$ & -0 , & & $3,40 \mathrm{E}-02$ & & & & & \\
\hline $\mathrm{d} 18: 1 / 22: 0(2 \mathrm{OH})^{\mathrm{b}}$ & -0 , & & 4,67E-02 & & & & & \\
\hline $\mathrm{d} 18: 2 / 22: 0(2 \mathrm{OH})^{\mathrm{b}}$ & 0 & & $4,29 \mathrm{E}-02$ & & & & & \\
\hline d18:1/24:0(2OH) & -0 , & & $3,37 \mathrm{E}-02$ & & & & & \\
\hline
\end{tabular}

TABLA 4. Listado de especies lipídicas que modifican su concentración respecto a los controles ante el tratamiento con PQ. Especies lipídicas de DRMs de membranas de hipocampo de ratón analizadas por cromatografía líquida de ultra-rendimiento acoplada a espectrometría de masas (UPLC-MS) que muestran diferencias a) ante el tratamiento con $\mathrm{PQ}$ sólo en la situación WT, especies lipídicas que cambian en ambas situaciones y especies lipídicas que cambian sólo en la situación ApoD-KO, b) al comparar muestras WT frente a ApoD-KO en situación control y ante el tratamiento con PQ. Los lípidos aparecen ordenados por familias y según su factor de cambio. Para la caracterización lipídica se aislaron dominios de membranas de hipocampos de 5 ratones adultos silvestres y 5 nulos para ApoD en condición control y sometidos a estrés oxidativo por PQ. Los diferentes niveles de cada metabolito se analizaron aplicando la aproximación estadística $t$ de Student. 


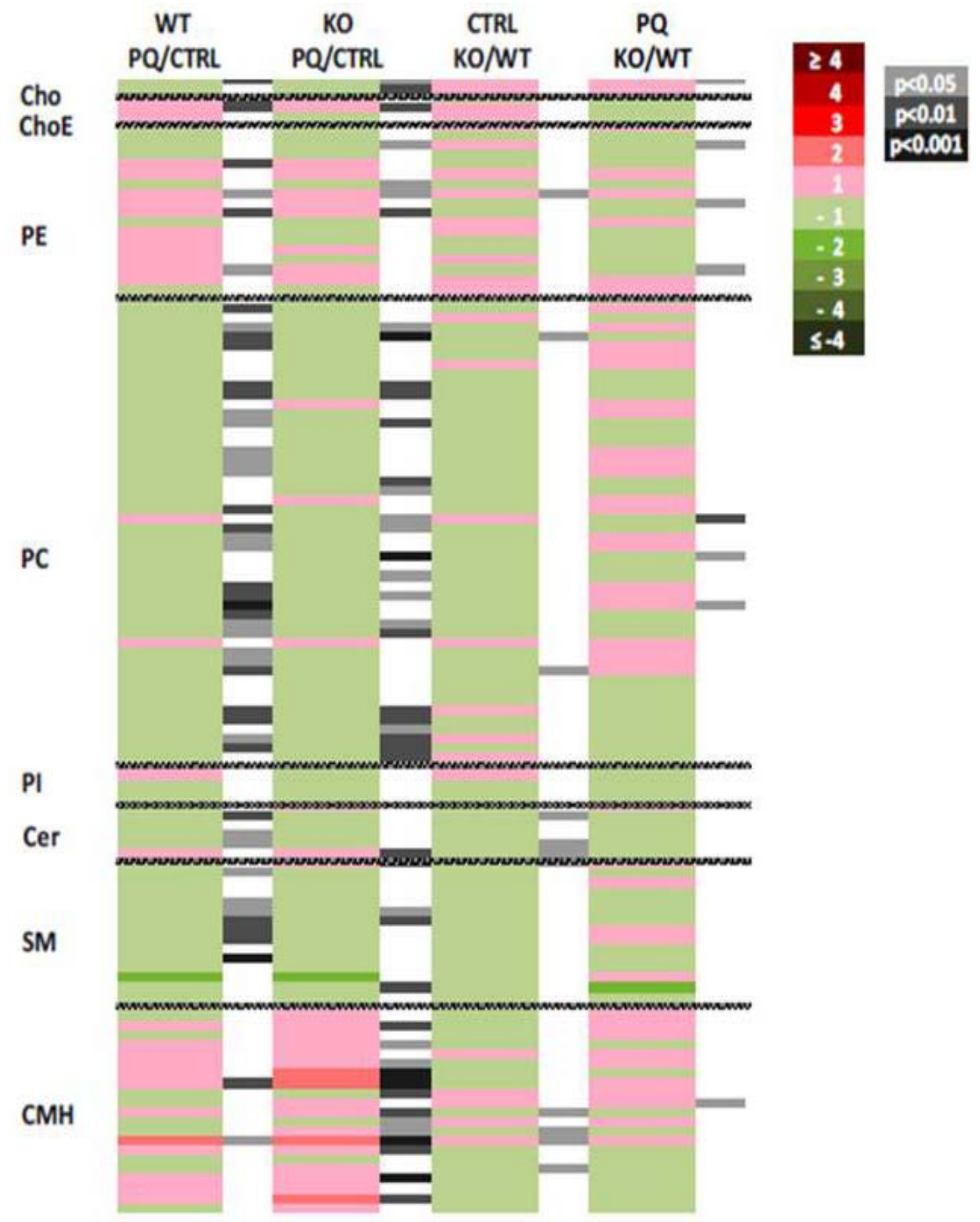

Figura 48. Heatmap del estudio lipidómico obtenido de DRMs de membranas de hipocampos de ratón WT y ApoD-KO en situación control o tras tratamiento con Paraquat.

El código de color muestra el factor de cambio de las distintas especies lipídicas (las tonalidades rojas indican aumento y las tonalidades verdes disminución). Las bandas en tonos grises muestran los $p$ valores obtenidos del test $t$ de Student. Datos obtenidos del análisis por cromatografía líquida de ultra-rendimiento acoplada a espectrometría de masas (UPLC-MS) de membranas de hipocampos de 5 ratones adultos silvestres y5 nulos para $A p o D$ en condición control y sometidos a estrés oxidativo por $P Q$. 
El estudio de los datos que generan el heatmap permitió comparar el comportamiento de cada familia de lípidos de los DRMs frente a la oxidación en presencia o ausencia de ApoD.

\section{Monohexosilceramidas}

Los cambios más significativos del estudio lipidómico de los DRMs se encuentran entre las monohexosilceramidas (CMH). Todas las monohexosilceramidas afectadas por el tratamiento con $\mathrm{PQ}$ en los DRMs de hipocampos de ratón aumentan, comportamiento contrario al del resto de lípidos de los DRMs detectados. 11 monohexosilceramidas presentan un comportamiento significativamente diferente ante el PQ en la condición ApoD-KO respecto al comportamiento de los DRMs control. Nueve aumentan significativamente mientras que las 2 restantes disminuyen (Fig.49A). Destacado es el cambio del 69\% tras el tratamiento con PQ experimentado por la CMH (d18:1/25:1(2OH)) en los DRMs ApoD-KO respecto al control, el experimentado por $\mathrm{CMH}(\mathrm{d} 18: 1 / 20: 0(2 \mathrm{OH}))$ del $49 \%$ y el de $\mathrm{CMH}(\mathrm{d} 18: 1 / 22: 0(2 \mathrm{OH})) 50 \%$ (Fig.49B). Otras dos $\mathrm{CMH}, \mathrm{CMH}$ (d18:1/24:2) y $\mathrm{CMH}$ (d18:2/22:0(2OH)), ambas poliinsaturadas, responden significativamente al $P Q$ de manera común en ambos genotipos aunque únicamente $\mathrm{CMH}$ (d18:1/24:2) aumenta un 35\% más en los DRMs ApoD-KO ante el PQ (Fig. 49C).

\begin{tabular}{|c|c|c|c|c|c|}
\hline A & \multicolumn{2}{|c|}{ WT PQ vs. CTRL } & \multicolumn{2}{|c|}{ KOPQ vs. CTRL } & \\
\hline $\mathrm{CMH}$ & $\begin{array}{l}\log 2 \\
\text { (F.C.) }\end{array}$ & t-test (p) & $\begin{array}{l}\log 2 \\
\text { (F.C.) }\end{array}$ & t-test $(p)$ & \\
\hline $\mathrm{CMH}(\mathrm{d} 18: 1 / 24: 2)$ & 0,83 & $6,60 \mathrm{E}-03$ & 1,27 & $7,05 E-05$ & \\
\hline $\mathrm{CMH}(\mathrm{d} 18: 2 / 22: 0(2 \mathrm{OH}))$ & 1,12 & $3,43 \mathrm{E}-02$ & 1,13 & $8,77 E-05$ & Cambian en WT yKo \\
\hline $\mathrm{CMH}(\mathrm{d} 18: 1 / 24: 1(2 \mathrm{OH}))$ & 0,29 & $2,77 E-01$ & 0,81 & $1,01 E-04$ & \\
\hline $\mathrm{CMH}(\mathrm{d} 18: 1 / 23: 1)$ & 0,74 & $5,26 \mathrm{E}-02$ & 1,10 & $4,90 E-04$ & \\
\hline $\mathrm{CMH}(\mathrm{d} 18: 1 / 25: 1(2 \mathrm{OH}))$ & 0,59 & $7,48 \mathrm{E}-02$ & 1,33 & $1,77 \mathrm{E}-03$ & \\
\hline $\mathrm{CMH}(\mathrm{d} 18: 1 / 20: 0(2 \mathrm{OH}))$ & 0,22 & $3,13 \mathrm{E}-01$ & 0,80 & $2,04 \mathrm{E}-03$ & \\
\hline $\mathrm{CMH}(\mathrm{d} 18: 1 / 24: 1)$ & 0,40 & $1,23 \mathrm{E}-01$ & 0,57 & $4,91 E-03$ & \\
\hline $\mathrm{CMH}(\mathrm{d} 18: 1 / 25: 0)$ & $-0,49$ & $1,34 \mathrm{E}-01$ & $-0,67$ & $5,63 E-03$ & Cambian sólo en KO \\
\hline $\mathrm{CMH}(\mathrm{d} 18: 1 / 23: 0(2 \mathrm{OH}))$ & 0,28 & $3,05 E-01$ & 0,79 & $9,74 \mathrm{E}-03$ & \\
\hline $\mathrm{CMH}(\mathrm{d} 18: 1 / 25: 1)$ & 0,69 & $8,15 E-02$ & 0,68 & $2,02 E-02$ & \\
\hline $\mathrm{CMH}(\mathrm{d} 18: 1 / 22: 0(2 \mathrm{OH}))$ & $-0,04$ & $8,70 \mathrm{E}-01$ & 0,54 & $2,60 \mathrm{E}-02$ & \\
\hline $\mathrm{CMH}(\mathrm{d} 18: 0 / 22: 0(2 \mathrm{OH}))$ & $-0,48$ & $6,28 \mathrm{E}-02$ & $-0,54$ & $3,05 E-02$ & \\
\hline $\mathrm{CMH}(\mathrm{d} 18: 1 / 23: 0)$ & 0,24 & $3,51 E-01$ & 0,53 & $3,86 E-02$ & \\
\hline $\mathrm{CMH}(\mathrm{d} 18: 1 / 24: 0(2 \mathrm{OH}))$ & $-0,17$ & $5,56 \mathrm{E}-01$ & 0,42 & $6,03 E-02$ & \\
\hline $\mathrm{CMH}(\mathrm{d} 18: 1 / 25: 0(2 \mathrm{OH}))$ & 0,12 & $6,46 \mathrm{E}-01$ & 0,38 & 1,51E-01 & \\
\hline $\mathrm{CMH}(\mathrm{d} 18: 0 / 24: 0(2 \mathrm{OH}))$ & $-0,60$ & $1,18 \mathrm{E}-01$ & $-0,31$ & $2,74 \mathrm{E}-01$ & \\
\hline $\mathrm{CMH}(\mathrm{d} 18: 1 / 18: 0)$ & $-0,47$ & $1,20 \mathrm{E}-01$ & 0,26 & $3,44 \mathrm{E}-01$ & \\
\hline $\mathrm{CMH}(\mathrm{d} 18: 1 / 24: 0)$ & $-0,25$ & $1,05 E-01$ & 0,09 & $4,84 \mathrm{E}-01$ & No cambian ante el $P Q$ \\
\hline $\mathrm{CMH}(\mathrm{d} 38: 1)$ & 0,03 & $8,73 E-01$ & 0,17 & $4,92 \mathrm{E}-01$ & \\
\hline $\mathrm{CMH}(\mathrm{d} 44: 2)$ & $-0,20$ & $3,42 \mathrm{E}-01$ & 0,10 & $5,45 \mathrm{E}-01$ & \\
\hline $\mathrm{CMH}(\mathrm{d} 18: 1 / 22: 0)$ & $-0,08$ & 6,99E-01 & 0,08 & $5,70 \mathrm{E}-01$ & \\
\hline $\mathrm{CMH}(\mathrm{d} 44: 2(\mathrm{OH}))$ & 0,00 & $9,95 \mathrm{E}-01$ & 0,15 & 6,57E-01 & \\
\hline
\end{tabular}



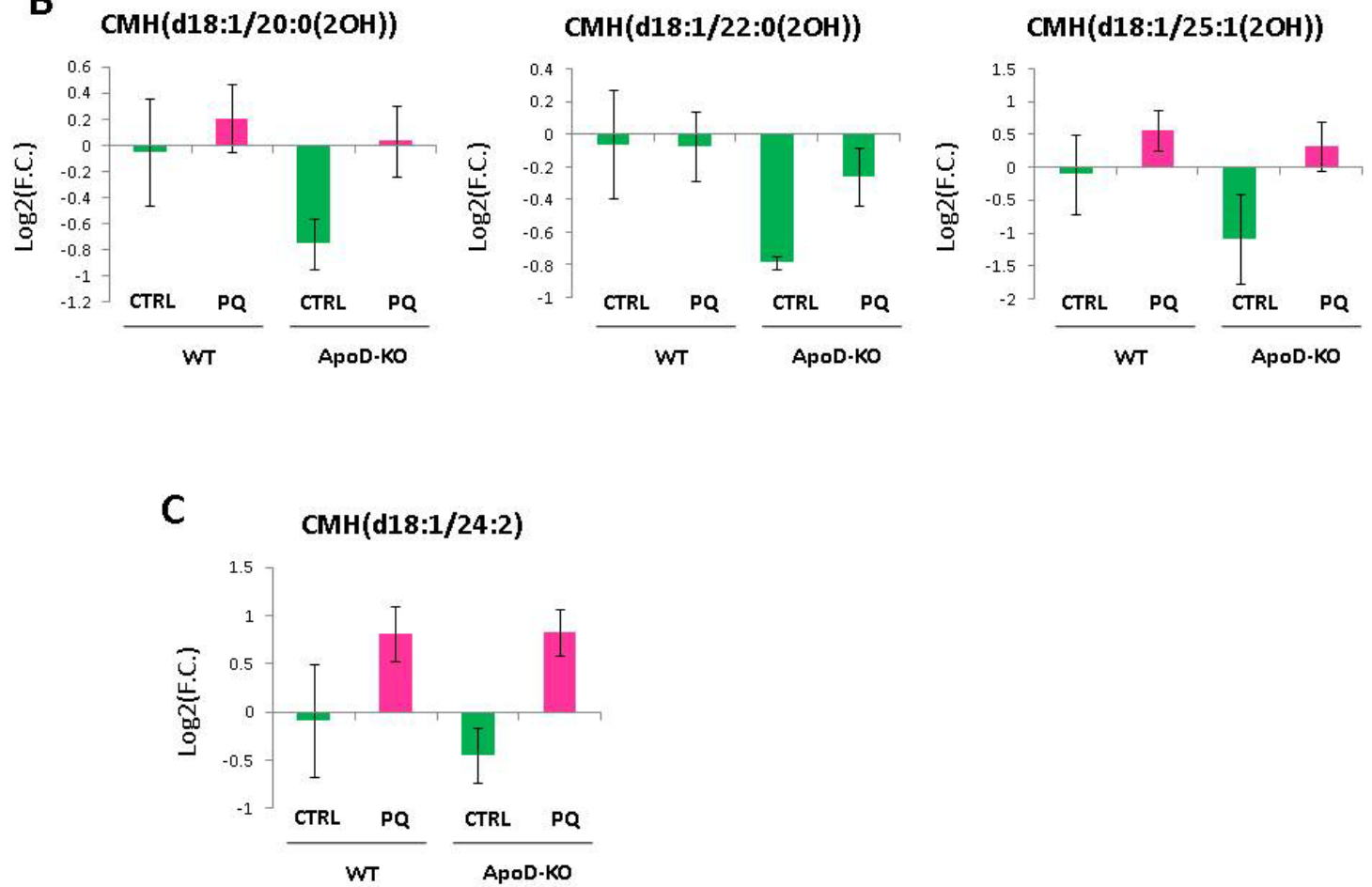

Figura 49. Las monohexosilceramidas experimentan mayor aumento en los DRMs de hipocampos de ratones ApoD-KO ante el tratamiento con PQ.

A.Zona del heatmap de las CMH amplificado.B. $\mathrm{CMH}(\mathrm{d} 18: 1 / 20: 0(2 \mathrm{OH}))$, (d18:1/22:0(2OH)) y (d18:1/25:1(2OH)) registran una relación de factor de cambio (ratio fold change) superior a 1,5 al comparar el comportamieno de los DRMs ApoD-KO ante el PQ respecto a la situación control. C.CMH (d18:1/24:2) y (d18:2/22:0(2OH)) responden significativamente al PQ de manera común en ambos genotipos. $\mathrm{CMH}$ (d18:1/24:2) aumenta un 35\% más en los DRMs ApoD-KO ante el PQ. Ambas monohexosilceramidas son poliinsaturadas.

Las monohexosilceramidas (cerebrósidos) son intermediarios del metabolismo de los gangliósidos (componentes importantes de los dominios de membrana no analizados en este estudio lipidómico por no ser extraídos con metanol/cloroformo). Se producen en los lisosomas como productos del catabolismo de los gangliósidos a través de la acción de enzimas como la GM1- $\beta$-galactosidasa o la GalCer- $\beta$-galactosidasa [154] (Fig. 49A) o en la membrana a partir de ceramida como base para generar glicoesfingolípidos complejos. Poseen funciones bioquímicas como el transporte intracelular de membrana, proliferación o supervivencia celular. No solo contribuyen a las propiedades de la superficie de la membrana plasmática sino que interactúan con proteínas de la superficie modulando su función. Son componentes esenciales de la mielina donde establecen interacciones entre ellos o con otras proteínas (MAG) pudiendo influir en su compactación. La falta de ApoD provoca una menor compactación de la mielina del SNC $[42,530]$. Los niveles de monohexosilceramidas se alteran en enfermedades cardiovasculares, cáncer, diabetes... [152].

En los DRM de hipocampos de ratón estudiados, las monohexosilceramidas aumentan en respuesta a PQ lo que podría indicar un incremento de la degradación de gangliósidos o una síntesis de sus precursores. Las CMH forman la familia de lípidos que más específicamente responde a la falta de ApoD en condiciones de estrés oxidativo, y los gangliósidos podrían ser el nexo entre ApoD y las membranas o el blanco de su mecanismo de acción. ApoD podría 
estar protegiendo a los gangliósidos de la oxidación por PQ de tal manera que su falta provocaría o bien su degradación o bien la generación de nuevos gangliósidos para su sustitución. Algunos gangliósidos que contienen ácido siálico contienen cabezas muy grandes y pueden crear superficies o barreras de propiedades biofísicas importantes para la membrana $[230,587]$ de gran importancia en funciones cerebrales como la memoria [588]. ApoD podría promover la generación de estas barreras como sistemas de protección ante es estrés oxidativo.

\section{Ceramidas}

Tres ceramidas saturadas de las 6 detectadas en los DRMs de hipocampo, las 18:1/23:0, 18:1/24:0 y 18:1/20:0, disminuyen de forma significativa con el tratamiento con PQ de forma específica en las muestras WT. Esto podría indicar que la falta de ApoD podría impedir, o al menos dificultar, la correcta degradación de ceramidas o su transformación en otras especies lipídicas (Fig. 50) [589].

Una ceramida se altera en los DRMs ApoD-KO y no en los WT (d18:1/24:1+d18:2/24:0) es una ceramida di-insaturada que se comporta de manera contraria, aumenta tras el tratamiento con PQ. Este metabolito podría seguir la misma vía mencionada para las monohexosilceramidas, siendo un producto de la degradación de glucosilceramidas o esfingomielinas insaturadas (más sensibles a la oxidación). Este comportamiento concuerda con el hecho de que el radical superóxido (ROS generado por $P Q$ ) induce la expresión de mRNA de esfingomielinasa y por tanto favorece la degradación de esfingomielina a ceramida [590].

Las ceramidas son la base de la biosíntesis de las esfingomielinas, galactoceramidas y glucosilceramidas que a su vez pueden convertirse en cientos de glucoesfinglípidos complejos.

Las ceramidas pueden producirse de novo a partir de serina y palmitoil CoA, siendo intermediarios de vida corta ante la necesidad de producción de esfingolípidos de membranas. A su vez, la degradación de esfingomielina y glucosilceramidas supone una fuente alternativa de ceramidas (Fig. 51). Estas reacciones pueden ocurrir tanto en organelas internas, como el aparato de Golgi, como en la membrana plasmática. Las ceramidas participan en el control de los niveles de colesterol y están implicadas en la regulación de procesos celulares como la apoptosis, la generación de endosomas multivesiculares o de exosomas [591] (Fig. 51C). Este complejo sistema de síntesis y su papel precursor de otras especies, síntoma del importante papel que desempeñan en la señalización en la membrana plasmática, hace difícil el estudio de las ceramidas [152].

Por lo tanto, la familia de las ceramidas, íntimamente relacionadas con las monohexosilceramidas y los gangliósidos, también responde a la presencia o no de ApoD. 

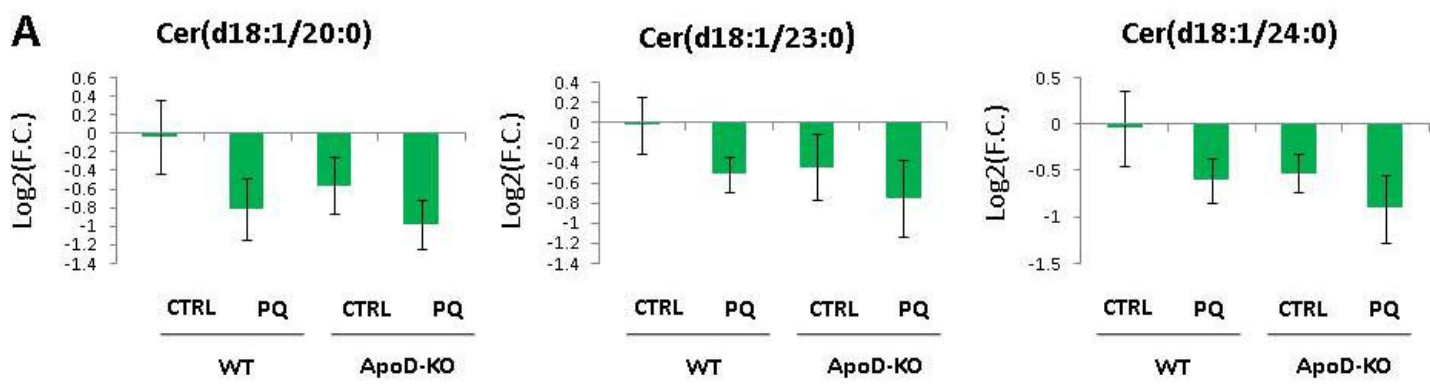

B

$\operatorname{Cer}(18: 1 / 24: 1)+\operatorname{Cer}(18: 2 / 24: 0)$

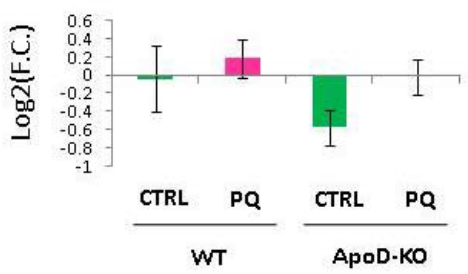

Figura 50. La familia de las ceramidas también responde a la falta de ApoD.

4 de las 6 ceramidas detectadas en los DRMs de membranas de hipocampos de ratón responden a la falta de ApoD. A.3 de las ceramidas saturadas (18:1/23:0, 18:1/24:0, 18:1/20:0) que disminuyen de forma significativa con el tratamiento con PQ de forma específica en las muestras WT. B. Ceramida di-insaturada que se comporta de manera contraria en los DRMs ApoD-KO y no en los WT (d18:1/24:1+d18:2/24:0), aumenta tras el tratamiento con PQ. 
A

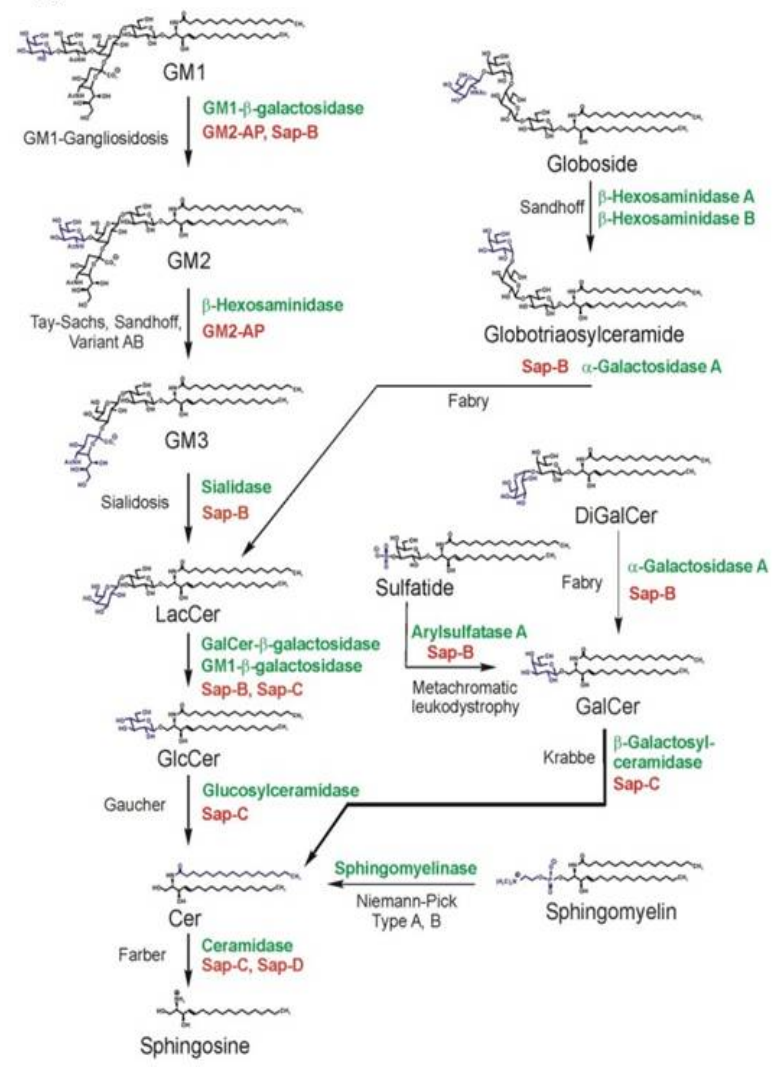

B

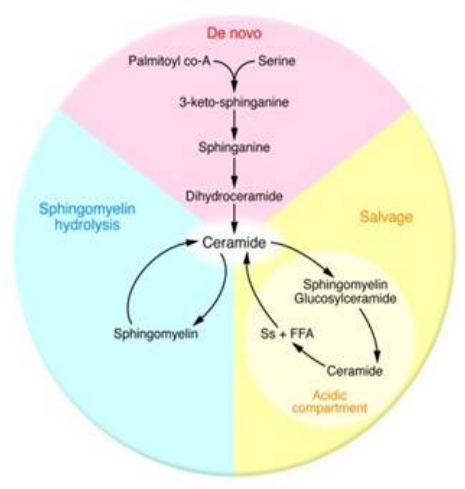

C

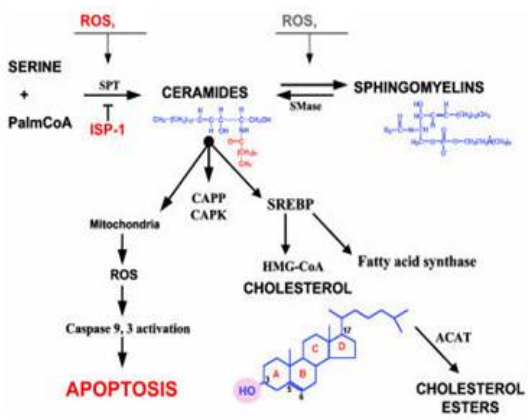

Figura 51. Vias de metabolismo de gangliosidos, esfingomielinas, ceramidas y colesterol.

A.Vías de degradación de esfingolípidos en el lisosoma (Konrad Sandhoff, 2013). B. Metabolismo de ceramidas (Benjamin T. Bikman, 2011). C. Vías del metabolismo de esfingomielinas, ceramidas y colesterol, su modulación ante el estrés oxidativo y su papel en la muerte neuronal (Cutler, RG.,2004). La producción de esfingomielinas a partir de serina y palmitoil CoA está catalizada por la enzima serina palmitoil CoA transferasa (SPT). Las ceramidas se sintetizan como precursoras de esfingomielina y también se generan por su hidrólisis por las esfingomielinasas.

\section{Esfingomielinas}

De las 13 esfingomielinas detectadas en los DRMs, 7responden de manera diferente ante el PQ en función de la presencia o no de ApoD. Cuatro de ellas (todas poseen ácido oleico (18:1)) disminuyen únicamente en los DRMs WT (Fig.52A). Sólo la esfingomielina d18:1/23:0 disminuye específicamente ante la falta de ApoD (Fig.52C). Dos esfingomielinas saturadas(18:0/18:0, 18:0/16:0) disminuyen en ambos genotipos, aunque disminuyen un $9 \% \mathrm{y}$ un 15\% más respetivamente en los DRMs ApoD-KO (Fig. 52B). Esto concuerda con el aumento de mRNA de esfingomielinasa y por tanto la pérdida de SM descrita en situaciones de estrés oxidativo por radical superóxido [590] y corrobora la hipótesis de que ApoD está relacionado con el metabolismo de los gangliósidos. 

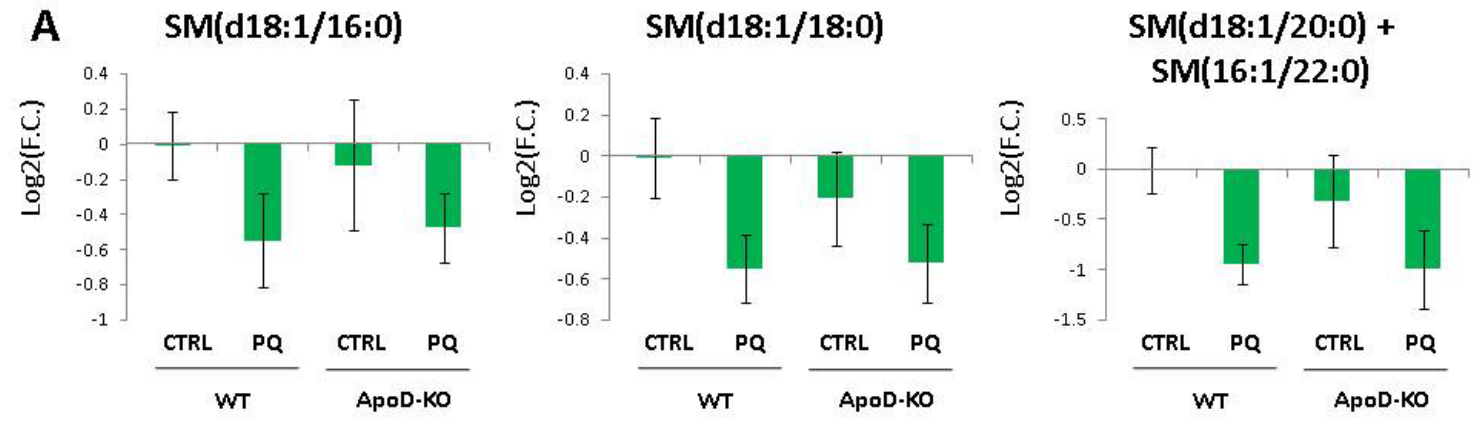

B

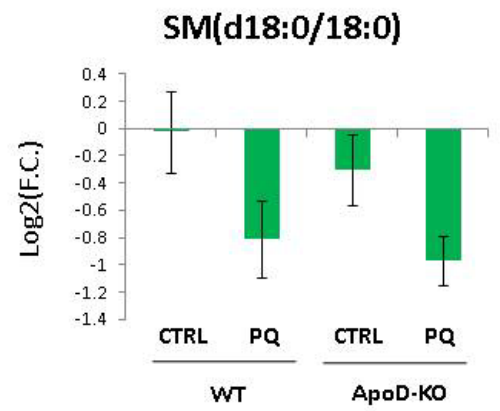

C

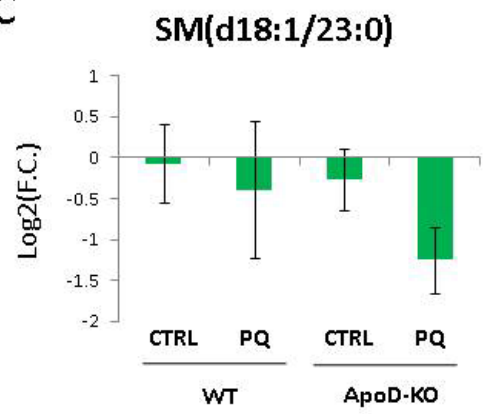

Figura 52. Algunos miembros de la familia de esfingomielinas responden ante la presencia o ausencia de ApoD.

A. 3 de las esfingomielinas que cambian significativamente ante el PQ exclusivamente en la situación WT. B. Una de las dos esfingomielinas que responde al tratamiento con PQ tanto en presencia como en ausencia de ApoD. C. Esfingomielina que disminuye significativamente de forma específica ante la falta de ApoD.

\section{Fosfatidiletanolaminas}

De las 18 PE detectadas, dos PE, (18:0/20:4 y 16:0/20:4),están alteradas específicamente en los DRMs ApoD-KO disminuyendo ante el tratamiento con PQ. Ambos metabolitos poseían AA. Por el contrario, las dos PE (18:0/18:1 y 18:1e/22.4) alteradas específicamente en los WT aumentaron frente al PQ. Dos PE de cadena corta se vieron alteradas de forma común a ambos genotipos (PE (16:1e/18:2 y 18:1e/18:2), aumentando significativamente. Ninguna de las PE con DHA alteró su comportamiento ante el PQ ni en presencia de ApoD ni en su ausencia (Fig. 53).
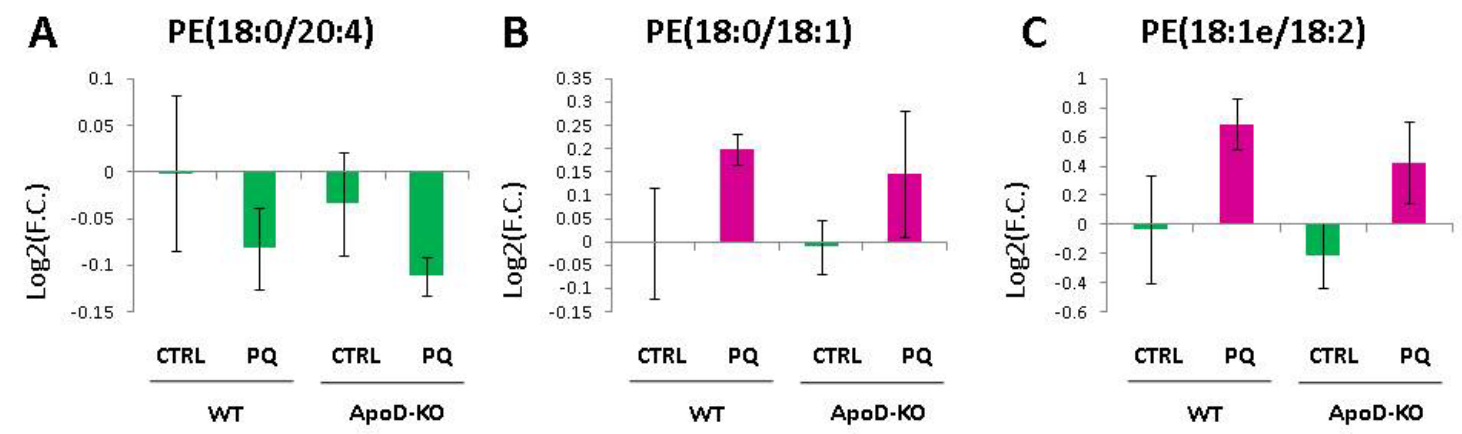

Figura 53. Algunas fosfatidiletanolaminas de los DRMs afectadas por ApoD ante el tratamiento con PQ.

A. PE (18:0/20:4) disminuye significativamente ante el PQ en ausencia de ApoD. B. PE (18:0/18:1) aumenta significativamente ante el PQ en presencia de ApoD. C. PE (18:1e/18:2) aumenta significativamente ante el PQ tanto en presencia como en ausencia de ApoD. 


\section{Fosfatidilcolinas}

Varias fosfatidilcolinas se alteran tanto en la situación WT como en ApoD-KO como en ambas ante el tratamiento con PQ. Sin embargo, las fosfatidilcolinas saturadas o monoinsaturadas de cadena corta permanecen constantes. Ninguna de las fosfatidilcolinas con DHA se altera de forma específica ante la falta de $A p o D$, mientras que sí aparecen modificaciones en algunas fosfatidilcolinas con AA. En todos los casos las fosfatidilcolinas disminuyen tras el tratamiento con $P Q$ lo que indicaría que las fosfatidilcolinas se oxidan y/o degradan. Este comportamiento concuerda con la sensibilidad a la oxidación que supone su alto grado de insaturaciones (Fig.54).

\begin{tabular}{|c|c|c|c|c|c|}
\hline & \multicolumn{2}{|c|}{ WTPOUS.CTRI } & \multicolumn{2}{|c|}{ KOPQus. CTRL } & \\
\hline PC & $\log 2\left(F . C_{C}\right)$ & $t-\operatorname{test}(p)$ & $\log 2$ (F.C.) & $t-\operatorname{test}(D)$ & \\
\hline$P C(14: 0 / 16: 1)$ & & $9,72 E-01$ & $-0,31$ & $5,36 \mathrm{E}-02$ & \\
\hline $\mathrm{PC}(32: 1)$ & $-0,12$ & $1,09 E-01$ & $-0,02$ & $7,11 E-01$ & \\
\hline$P C(16: 0 / 17: 0)$ & $-0,56$ & $1,18 \mathrm{E}-01$ & $-0,51$ & $2,42 \mathrm{E}-01$ & \\
\hline $\mathrm{PC}(33: 1)$ & $-0,11$ & $1,75 E-01$ & $-0,10$ & 1,74E-01 & \\
\hline$P C(16: 0 / 19: 1)$ & $-0,26$ & 1,73E-01 & $-0,10$ & $2,37 \mathrm{E}-01$ & \\
\hline $\mathrm{PC}(17: 1 / 18: 1)$ & $-0,18$ & $3,16 \mathrm{E}-01$ & $-0,27$ & $1,07 \mathrm{E}-01$ & \\
\hline$P C(16: 0 / 18: 1\}$ & $-0,21$ & $7,06 E-02$ & 0,07 & $6,48 \mathrm{E}-01$ & \\
\hline $\mathrm{PC}(18: 0 / 18: 1)$ & $-0,17$ & $1,09 \mathrm{E}-01$ & 0,02 & 7,53E-01 & No cambian ante el $P Q$ \\
\hline$P C(40: 1)$ & 0,48 & $1,26 \mathrm{E}-01$ & 0,22 & $3,89 \mathrm{E}-01$ & \\
\hline$P C(20: 0 / 18: 2)$ & $-0,13$ & 4,34E-01 & $-0,08$ & $2,89 E-01$ & \\
\hline$P C(16: 1 e / 16: 0)$ & $-0,16$ & $4,99 E-01$ & $-0,26$ & $7,30 E-02$ & \\
\hline $\mathrm{PC}(16: 1 \mathrm{e} / 18: 1)$ & $-0,16$ & 6,15E-01 & $-0,13$ & $6,16 \mathrm{E}-01$ & \\
\hline$P C(16: 1 e / 20: 4)$ & $-0,32$ & $2,97 \mathrm{E}-01$ & $-0,47$ & $1,41 \mathrm{E}-01$ & \\
\hline$P C(14: 0 / 14: 0)$ & $-0,26$ & $1,24 \mathrm{E}-01$ & $-0,31$ & $1,65 \mathrm{E}-01$ & \\
\hline$P C(16: 0 / 18: 2)$ & $-0,25$ & $1,85 E-02$ & $-0,11$ & $2,35 E-01$ & \\
\hline $\mathrm{PC}(18: 1 / 18: 2)$ & $-0,38$ & $2,05 E-02$ & $-0,25$ & $5,17 E-02$ & \\
\hline$P C(16: 0 / 20: 3)$ & $-0,35$ & $2,28 \mathrm{E}-02$ & $-0,17$ & $1,09 \mathrm{E}-01$ & \\
\hline $\mathrm{PC}(16: 0 / 20: 4)$ & $-0,25$ & $4,77 E-02$ & $-0,02$ & $8,70 E-01$ & \\
\hline $\mathrm{PC}(18: 0 / 18: 2)$ & $-0,31$ & $3,82 E-03$ & $-0,05$ & $6,58 \mathrm{E}-01$ & \\
\hline$P C(16: 0 / 22: 6)$ & $-0,20$ & $2,36 E-02$ & $-0,03$ & $7,66 \mathrm{E}-01$ & \\
\hline$P C(18: 0 / 20: 4)$ & $-0,30$ & $1,31 \mathrm{E}-02$ & $-0,02$ & $9,07 E-01$ & \\
\hline$P C(18: 0 / 22: 5)$ & $-0,30$ & $3,94 E-03$ & $-0,11$ & $4,16 \mathrm{E}-01$ & Cambian sólo en WT \\
\hline$P C(18: 1 / 22: 6)$ & $-0,34$ & $6,09 E-04$ & $-0,13$ & $1,09 \mathrm{E}-01$ & \\
\hline $\mathrm{PC}(20: 3 / 20: 4)$ & $-0,50$ & $3,59 E-03$ & $-0,38$ & $9,94 \mathrm{E}-02$ & \\
\hline$P C(16: 0 / 16: 0)$ & $-0,34$ & $1,57,03$ & $-0,08$ & $5,22 \mathrm{E}-01$ & \\
\hline$P C(37: 5)$ & $-0,33$ & $4,74 \mathrm{E}-02$ & $-0,20$ & $7,08 \mathrm{E}-02$ & \\
\hline $\mathrm{PC}(38: 5)$ & $-0,33$ & $1,52 \mathrm{E}-02$ & $-0,13$ & $2,67 E-01$ & \\
\hline $\mathrm{PC}(38: 5)$ & $-0,40$ & $2,59 E-03$ & $-0,15$ & $1,12 \mathrm{E}-01$ & \\
\hline$P C(30: 0)$ & $-0,29$ & $2,90 E-03$ & $-0,18$ & $9,48 E-02$ & \\
\hline $\mathrm{PC}(31: 0)$ & $-0,47$ & $2,89 E-02$ & $-0,32$ & $2,08 E-02$ & \\
\hline$P C(14: 0 / 18: 2)$ & $-0,46$ & $5,50 E-03$ & $-0,44$ & $1,73 \mathrm{E}-04$ & \\
\hline $\mathrm{PC}(18: 1 \mathrm{e} / 20: 4)$ & $-0,44$ & $5,04 E-03$ & $-0,48$ & $1,11 \mathrm{E}, 03$ & \\
\hline $\mathrm{PC}(40: 5)$ & $-0,32$ & $3,85 E-02$ & $-0,23$ & $2,60 E-02$ & \\
\hline$P C(40: 8)$ & $-0,25$ & $2,71 \mathrm{E}-02$ & $-0,34$ & $3,46 E-03$ & \\
\hline$P C(18: 0 / 22: 6)$ & $-0,34$ & $2,90 E-03$ & $-0,13$ & $4,70 E-02$ & \\
\hline$P C(0-16: 0 / 16: 0)$ & $-0,43$ & $1,22 \mathrm{E}-03$ & $-0,46$ & $2,69 E-03$ & \\
\hline$P C(34: 0 e)$ & $-0,64$ & $5,50 E-03$ & $-0,59$ & $1,90 E-03$ & Cambiah en wi y \\
\hline$P C(17: 0 / 20: 4)$ & $-0,26$ & $7,52 E-03$ & $-0,24$ & $1,09 \mathrm{E}-02$ & \\
\hline$P C(0-16: 0 / 14: 0)$ & $-0,37$ & $3,83 E-02$ & $-0,53$ & $1,28 \mathrm{E}-03$ & \\
\hline$P C(14: 0 / 20: 4)$ & $-0,59$ & $1,53 \mathrm{E}-03$ & $-0,53$ & $5,27 E-03$ & \\
\hline$P C(15: 0 / 20: 4)$ & $-0,35$ & $2,35 E-02$ & $-0,41$ & $1,90 E-03$ & \\
\hline$P C(16: 0 / 18: 0)$ & $-0,44$ & 7,62E-03 & $-0,30$ & $6,08 E-03$ & \\
\hline $\mathrm{PC}(16: 0 / 20: 5)$ & $-0,21$ & $1,67 \mathrm{E}-01$ & $-0,33$ & $2,89 \mathrm{E}-03$ & \\
\hline$P C(16: 1 / 20: 4)$ & $-0,21$ & $2,50 E-01$ & $-0,35$ & $1,09 \mathrm{E}-02$ & \\
\hline$P C(34: 1 e)$ & $-0,14$ & $3,40 E-01$ & $-0,22$ & $2,26 \mathrm{E}-02$ & \\
\hline$P C(18: 2 / 20: 4)$ & $-0,30$ & $1,48 E-01$ & $-0,66$ & $8,41 E-04$ & \\
\hline$P C(18: 0 / 22: 4)$ & $-0,18$ & $2,57 E-01$ & $-0,21$ & $2,99 E-02$ & Cambian solo en KO \\
\hline$P C(0-16: 0 / 20: 4)$ & $-0,20$ & $5,00 \mathrm{E}-02$ & $-0,39$ & $3,92 E-03$ & \\
\hline$P C(18: 3 / 18: 3)$ & 0,28 & $1,29 \mathrm{E}-01$ & $-0,39$ & $2,68 E-02$ & \\
\hline
\end{tabular}

Figura 54.Región del heatmap de las fosfatidilcolinas ampliado.

\section{Colesterol}

El colesterol aumenta en los DRMs WT ante la oxidación pero no en situación ApoD-KO (Fig. 55). Un aumento de colesterol en los DRMs tras el tratamiento con PQ implicaría una mayor estabilidad de los dominios y por tanto un mayor control de las vías de protección y reparación puestas en juego. El hecho de que la falta de ApoD bloquee este aumento de colesterol ante la oxidación podría indicar una mayor pérdida de colesterol en las membranas o una menor captación del colesterol procedente de las LDL o HDL. Un desequilibrio en la composición química de las membranas (pérdida de gangliósidos por ejemplo) podría desestabilizar el 
colesterol existente favoreciendo la salida de este de las membranas o bien podría impedir la correcta interacción de los transportadores de colesterol y su absorción.

El colesterol presente en el cerebro es independiente del colesterol circulante por el plasma sanguíneo dado que no puede atravesar la barrera hematoencefálica, por lo que su presencia en este órgano depende en su mayoría de la síntesis de novo [592]. Ante el estrés oxidativo los niveles de colesterol aumentan y disminuye la fluidez de membrana en las neuronas hipocampales [591]. Esto podría considerarse un sistema de defensa que intentaría aumentar la estabilidad de las membranas que están siendo modificadas por la oxidación. Además, un aumento en la fluidez de las membranas podría amplificar el efecto destructivo del estrés oxidativo al favorecer la agrupación de balsas lipídicas que elevarían la producción de ROS por activación de las PLC [593]. Por otro lado, con la edad incrementan los niveles de CYP46, enzima que provoca la disminución del colesterol en las neuronas hipocampales activando vías de supervivencia (TrkBB/Akt) [592].

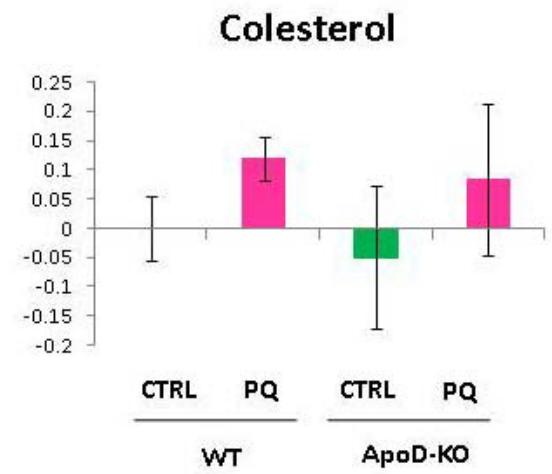

Figura 55. Comportamiento del colesterol en los DRMs de membrana de hipocampos de ratón.

El colesterol aumenta en los DRMs WT ante la oxidación pero no en situación ApoD-KO.

\section{Fosfatidilinositoles}

De los 4 fosfatidilinositoles detectados en los DRMs ninguno muestra alteraciones ni ante el $P Q$ ni ante la presencia o ausencia de ApoD. Los fosfatidilinositoles se sintetizan exclusivamente en el ER por la misma vía que la fosfatidilserina, no poseen ninguna amina protonable porque derivan del inositol y presentan múltiples opciones de fosforilación (Fig. 56) [594]. Esto concuerda con que ApoD pudiera estar implicado en el metabolismo de los gangliósidos de forma específica y con el hecho de que no tuviera relación con la expresión de Vibrator (Vib) una proteína transportadora de fosfatidilinositol. 


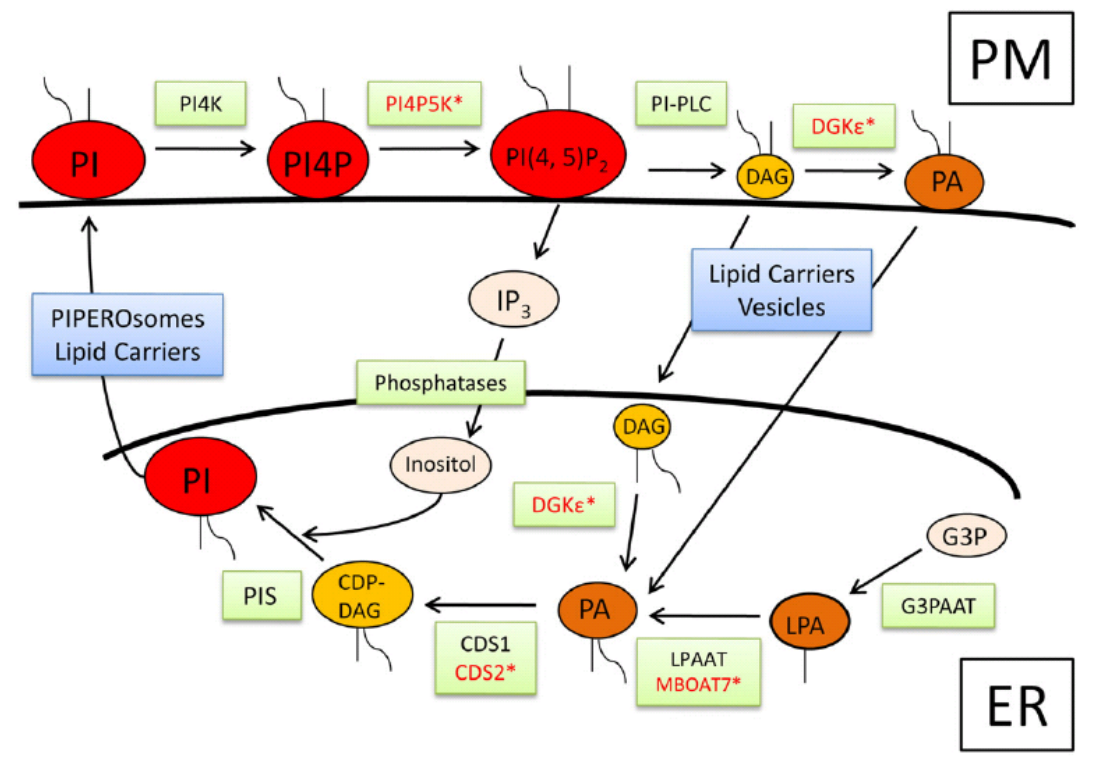

Figura 56. Vía metabólica de los fosfatidilinositoles [594].

En resumen, ApoD parece estar implicado en las vías del metabolismo de esfingolípidos, concretamente en la ruta de los gangliósidos, activadas ante el estrés oxidativo. La falta de ApoD modifica la respuesta de las monohexosilceramidas de los DRMs de membranas de hipocampo de ratón ante el tratamiento con $P Q$, provocando su aumento posiblemente como consecuencia de la oxidación y degradación de gangliósidos o de la síntesis de novo. También altera la respuesta de algunas ceramidas y esfingomielinas frente al estrés oxidativo y controla los niveles de colesterol. 


\section{DISCUSIÓN}

Los efectos neuroprotectores de ApoD y sus homólogos frente a daños oxidativos sitúan a esta familia de proteínas dentro de la respuesta protectora del sistema nervioso contra la oxidación. Hasta el momento, todos los trabajos realizados dirigían el estudio de ApoD hacia el control de lípidos peroxidados y una función unidora de lípidos libres propia de la superfamilia a la que pertenecen, las Lipocalinas [15]. Los efectos protectores de GLaz y NLaz observados en diferentes entornos oxidantes como el envejecimiento, estrés oxidativo experimental o una enfermedad neurodegenerativa basada en una disfunción mitocondrial, la Ataxia de Friedreich [97], confirman su actuación sobre el mecanismo común a estos procesos, la generación de ROS.

El estudio de la función de un homólogo de $A p o D$ en un entorno neurodegenerativo causado por la expresión de proteínas poliglutaminadas pretende determinar si el mecanismo de acción de ApoD actúa exclusivamente sobre los procesos derivados de la generación de ROS o si el grupo de "proteínas ApoD" podría ejercer un efecto protector similar, ante un daño de naturaleza primaria no oxidativa, enfocando su función hacia el otro mecanismo común a la neurodegeneración, el deterioro de los sistemas de control de calidad de las proteínas.

En primer lugar, se ha demostrado que tanto GLaz como NLaz forman parte de la respuesta transcripcional endógena ante la neurodegeneración provocada por la expresión de la proteína poliglutaminada Ataxina 1 humana. La misma respuesta se había observado para ApoD en otras enfermedades neurodegenerativas pero no para una neurodegenerativa basada en proteínas poliQ [49, 51-53]. Por lo tanto, la sobreexpresión de ApoD, común a otras neurodegenerativas, está conservada y es también característica de la neurodegeneración por proteínas poliglutaminadas.

En segundo lugar se ha determinado que ambas proteínas son capaces de contrarrestar el daño generado por una proteína poliQ, manteniendo la viabilidad celular y la integridad del tejido pero dejando inalterados los agregados de la proteína. Dicho efecto protector es persistente en el tiempo e independiente de la naturaleza autocrina o paracrina de la expresión del rescatador en relación al foco de daño. La mejora inducida por GLaz y NLaz no es debida a una actuación directa sobre la proteína poliglutaminada defectuosa, o sobre los agregados que genera sino sobre las consecuencias patológicas de su expresión y acumulación. Por ello, asumiendo que un mecanismo de rescate implica la actuación directa sobre el foco del problema, el efecto beneficioso observado debería definirse no como rescate sino como un mecanismo protector o una mejora de la respuesta protectora celular puesta en marcha ante el daño provocado por la proteína defectuosa.

Por primera vez se ha determinado que la lipocalina GLaz es capaz de mejorar, hasta el punto de impedir la muerte celular, la respuesta ante la degeneración por poliQs, a través de la mejora en la eficacia del flujo de la autofagia, promoviendo así una mejor y más efectiva eliminación del material dañado. La posibilidad de que una lipocalina secretada pueda alterar 
la autofagia tiene un precedente en células embrionarias murinas las cuales experimentan una inhibición de la autofagia ante la falta de la lipocalina Lcn2 [595].

Este estudio también ha mostrado que la inducción de la autofagia forma parte de la respuesta al daño generado por este modelo de degeneración. Otros modelos de expresión de proteínas mutadas como la huntingtina también responden a la degeneración con una inducción de la autofagia [510]. Sin embargo, el complejo proceso autofágico requiere del correcto funcionamiento de todas y cada una de sus etapas, resultando ineficaz su activación si no se produce un correcto desenlace de las etapas finales.

La pérdida de función de GLaz altera negativamente el flujo de la autofagia pero no modifica su inducción, situando su actuación en los procesos finales del proceso.

La sobreexpresión de GLaz en el contexto neurodegenerativo promueve la eliminación de proteínas ubiquitinadas junto al receptor de carga autofágica p62, sin necesidad de inducir la transcripción de Atg8 (LC3), gen relacionado con la activación de la autofagia. Este resultado confirma la actuación de la lipocalina sobre los procesos posteriores a la inducción autofágica en los que participa la proteína p62.

Dada la relación de ApoD y sus homólogos con los ligandos hidrofóbicos, es lógico pensar que su actuación recaiga sobre alguno de los procesos autofágicos en los que estén involucrados los lípidos. La degradación de los sustratos por autofagia requiere de la confluencia de la carga del autofagosoma y las enzimas del lisosoma en un mismo compartimento. Para ello debe producirse la fusión de las membranas de ambas vesículas. El contenido lipídico tanto de los autofagosomas como de los lisosomas modula la fusión vesicular en la autofagia [401]. GLaz podría modular dicha fusión a través de cambios en los lípidos de las membranas de tal manera que su pérdida de función implique un bloqueo de la etapa final de la autofagia y por tanto, una acumulación de los elementos que deberían ser degradados. Su sobreexpresión natural frente a una patología podría favorecer y promover la eficacia de la fusión entre las membranas autofagosomales y lisosomales, y por tanto contribuir a la eliminación de los productos citotóxicos sin necesidad de aumentar la inducción del proceso completo.

Este resultado clasificaría a las proteínas de la familia de ApoD como elementos reguladores de los procesos finales de la autofagia (hasta el momento escasos y poco estudiados) y los convertiría en eficaces dianas terapéuticas que permitirían potenciar los efectos beneficiosos de la autofagia, sin necesidad de aumentar su activación o combinándolos con elementos inductores.

La autofagia está relacionada con un gran número de procesos como el envejecimiento celular [410] o la fagocitosis $[596,597]$ y con numerosas patologías no necesariamente relacionadas con proteínas poliglutaminadas (ver sección 3.2) [334]. Esto confiere a las proteínas con capacidad promotora del flujo de la autofagia como ApoD un amplio radio de acción. Por ello, los resultados obtenidos en este modelo aportan nuevas explicaciones a muchos de los variados fenómenos relacionados con la función de ApoD y sus homólogos. La actuación sobre la autofagia podría estar detrás, o al menos contribuir, en los fenotipos característicos de esta familia de proteínas como la modulación de la longevidad [75, 83, 542, 562] o los procesos de 
degradación de mielina implicados en la regeneración del sistema nervioso periférico tras un daño, también afectados por ApoD (García-Mateo, resultados no publicados).

Por otro lado se ha comprobado que el nexo entre GLaz y el estrés oxidativo se mantiene, aunque también esté actuando sobre otros procesos como la autofagia, al establecer una relación entre la expresión de un gen implicado en los mecanismos protectores contra el estrés oxidativo, GstS1 y GLaz. Ambas proteínas forman parte de la respuesta celular a la oxidación lipídica y modifican el fenotipo del modelo de SCA1 en los fotorreceptores [541]. La sobreexpresión de GLaz en el entorno degenerativo provoca una disminución en la expresión de GstS1. Esto podría indicar que GLaz controlaría la oxidación de los lípidos mientras que GstS1 eliminaría los ya oxidados, de tal manera que una mayor y más eficaz actuación de GLaz implicaría una menor necesidad del paso siguiente y por tanto una disminución de su expresión. La relación de GLaz/ApoD con el estrés oxidativo entronca con el mecanismo de la autofagia ya que las reacciones en cadena de la peroxidación lipídica podrían dañar los sistemas de degradación de la célula [442] y la protección ejercida por GLaz contra la oxidación de las membranas también permitiría modular los mecanismos de fusión de las vesículas autofágicas [598].

Esta dualidad funcional, sobre la autofagia y sobre el estrés oxidativo, en una misma situación patológica confiere a la familia de ApoD un importante y eficaz papel dentro de la respuesta protectora ante el daño que concuerda con la conservada sobreexpresión de ApoD en la anteriormente mencionada amplia lista de situaciones patológicas de diversa naturaleza (ver sección 1.4).

Por otra parte, se ha detectado la endocitosis de GLaz (expresada en las células gliales) por parte de los fotorreceptores sometidos al estrés provocado por el modelo neurodegenerativo de SCA1. Los primeros estudios sobre la distribución de ApoD también defendían una posible endocitosis de ApoD por parte de tipos celulares que no la expresan [5]. Los astrocitos de ratón en cultivo también son capaces de endocitar $A p o D$ humana del medio extracelular y acumularla en vesículas citosólicas [543].

Este fenómeno permite ampliar las hipótesis que permitirían explicar la acción de una proteína extracelular unidora de lípidos sobre un proceso intracelular como la autofagia.

Una posibilidad sería explicar la función de ApoD/GLaz a través del mecanismo de acción común a todas las lipocalinas, el transporte de lípidos, considerando por tanto que GLaz podría gestionar los lípidos de la membrana plasmática desde el medio extracelular [599]. GLaz, desde el exterior, podría influir sobre las membranas que intervienen en la autofagia aceptando que el origen de la membrana del fagóforo fuera la membrana plasmática (ver sección 3.1) o bien asumiendo que el tráfico vesicular podría distribuir los efectos ejercidos por GLaz en la membrana plasmática hacia el resto de membranas internas. También podría considerarse la posibilidad de formación de un anfisoma fruto de la fusión del autofagosoma (cuya membrana podría tener un origen diferente a la membrana plasmática) y endosomas procedentes de la membrana plasmática que portarían los cambios lipídicos provocados por la lipocalina [600]. 
Otra posibilidad sería proponer que ApoD y sus homólogos, a pesar de ser proteínas secretadas, pudieran tener acceso a las membranas del interior celular y por tanto, ejercer su función, o al menos parte de ella, dentro de la célula. Los experimentos que muestran la endocitosis de GLaz o hApoD permiten considerar esta posibilidad.

Según la interpretación de los resultados anteriores, GLaz podría favorecer el flujo de la autofagia a través de un mecanismo con efectos en la fusión entre las membranas del autofagosoma y del lisosoma. Para que ApoD pudiera actuar sobre esta fusión desde el interior de la célula debería poder tener acceso, o bien a la membrana del autofagosoma o bien a la del lisosoma. Dado que el origen de la membrana del autofagosoma no es claro o incluso podría ser dependiente de condiciones y tipos celulares, se estudió la posibilidad de que fueran los lisosomas las vesículas citosólicas que contuvieran ApoD endocitado.

Los experimentos de colocalización con marcadores específicos de lisosomas confirman la presencia mayoritaria de ApoD endocitada en los lisosomas. Esto no solo permitiría explicar el efecto sobre la autofagia sino que también colocaría a ApoD en uno de los compartimentos celulares más sensibles al estrés oxidativo (centro de mayor producción de la reacción de Fenton), relacionado con la supervivencia y la longevidad, centros fundamentales en el metabolismo lipídico [377, 384]. Por tanto, los lisosomas podrían ser el punto de intersección entre los efectos de ApoD sobre la autofagia, los efectos sobre estrés oxidativo y su relación con la homeostasis lipídica (ver sección 1.5).

A pesar de que algunos indicios señalaban que la endocitosis de ApoD podría estar inducida por una situación de estrés en la célula que endocita, estudios preliminares confirmados posteriormente en el laboratorio (Pascua-Maestro, R. Tesis) no han mostrado una relación directa entre la presencia de ApoD en los lisosomas y el estrés oxidativo generado por $\mathrm{PQ}$. Esto, junto con el alto grado de glicosilación de ApoD, indica una estancia estable en estos compartimentos, en contraposición a un destino de ApoD en los lisosomas como centros de eliminación de proteínas inservibles. Los últimos estudios del laboratorio indican una permanencia de ApoD en los lisosomas de larga duración (más de 48h) (Pascua-Maestro, R. Tesis).

Desde los lisosomas, ApoD podría controlar el estado de oxidación de la membrana lisosomal favoreciendo su fusión con el autofagosoma y con ello la eficacia autofágica, una correcta homeostasis lipídica y un eficaz reciclado de la membrana dañada. Todo ello contribuiría a mantener la integridad lisosomal favoreciendo la supervivencia celular. Como se ha comentado, la autofagia también podría ser parte de los mecanismos de control de la oxidación de la célula (ver sección 3.2) [405]. Esto concordaría con el descenso de la reactividad y la mejor resistencia al estrés mostrada por los astrocitos murinos tras la endocitosis de hApoD [543].

Muchas de las proteínas de la membrana lisosomal son proteínas glicosiladas relacionadas con el transporte lipídico que acceden al lisosoma por endocitosis de la membrana plasmática (ver sección 2.2). La internalización de ApoD implica su participación en alguna de las vías de endocitosis y plantea una nueva línea de investigación, el tráfico intracelular de ApoD y sus homólogos, que actualmente se sigue en el laboratorio. 
A su vez, la participación de $A p o D$ en los sistemas de endocitosis implicaría algún tipo de interacción entre la lipocalina y la membrana. Sin embargo, no se conoce ningún receptor ni para ApoD ni para ninguno de sus homólogos.

El homólogo de ApoD en el saltamontes, Lazarillo, mantiene una interacción estable con la membrana a través de una cola GPI. Lazarillo, se definió como una lipocalina involucrada en la guía de axones. Su pérdida de función genera un defecto en el crecimiento axónico durante el desarrollo del sistema nervioso del saltamontes [36]. Muchos experimentos han demostrado que tanto ApoD como sus homólogos en invertebrados (incluyendo Lazarillo expresado en mosca) conservan la función protectora frente a diferentes tipos de estrés y varios de sus fenotipos de pérdida de función. Incluso algunos de estos fenotipos pueden ser rescatados por la sobreexpresión de alguno de sus homólogos [563]. Sin embargo, el principal efecto sobre el crecimiento axónico (origen del nombre de estas lipocalinas) observado en saltamontes no había sido demostrado en el resto de los homólogos.

La generación de cultivos primarios neuronales de Drosophila permitió estudiar el efecto de la pérdida de función de las dos lipocalinas (NLaz y GLaz) en el crecimiento axónico. Además permitió estudiar su efecto en la generación de sinapsis.

La falta de NLaz y GLaz provoca la disminución de la longitud del axón acompañado de anomalías en la distribución de los microtúbulos. Esto demuestra por primera vez que el fenotipo de saltamontes en el crecimiento axónico, está conservado en sus homólogos de Drosophila. En el proceso de crecimiento axónico, el tráfico vesicular juega un papel importante, controlando la formación de nueva membrana, generando polaridad, y transportando moléculas señalizadoras que transmiten tanto la información del exterior necesaria para la orientación espacial y temporal como la respuesta interna a dichos estímulos [516, 601]. El metabolismo lipídico es un factor esencial de este proceso. La correcta formación de microtúbulos está relacionada con interacciones entre la actina y la membrana [131, 521].

El transporte axónico supone interacciones entre las membranas de las vesículas, las proteínas transportadoras, el citoesqueleto y otros elementos que dependen de una correcta composición y organización de membrana [513]. Al igual que GLaz podría estar controlando el flujo autofágico a través de la regulación de la fusión entre membranas, GLaz y NLaz podrían ejercer el mismo efecto durante el proceso de crecimiento axónico.

La disminución del número y superficie de sinapsis, observadas ante la pérdida de función de GLaz y NLaz, podría indicar deficiencias en la generación de vesículas, en su transporte hacia su localización final o en las fusiones entre ellas o con la membrana plasmática.La transmisión sináptica se basa en procesos de exo-endocitosis en los que intervienen diferentes proteínas (SNARE (sintaxina), sinaptogmina, etc. en la exocitosis y clatrina, anfifisina, dinamina o Hsc70 en la endocitosis) y en los que algunos lípidos juegan un papel crítico (colesterol, fosfoinosítidos, ácidos grasos poliinsaturados) $[262,602,603]$ que pueden afectar a la sinapsis bien actuando como ligandos de proteínas efectoras y moléculas señalizadoras, bien modificando las propiedades fisicoquímicas y la organización molecular de sus membranas [521]. Las membranas sinápticas contienen dominios de membrana resistentes a detergente. Es en estos dominios donde podría tener lugar la fusión de la vesícula sináptica [604, 605]. 
La reducción del número de sinapsis concuerda con los defectos comportamentales observados en los ratones ApoD-KO que afectan a la memoria y a la actividad locomotora y exploratoria [606, 607].

La confirmación de la conservación del fenotipo de saltamontes en sus homólogos de Drosophila, junto con el resto de fenotipos compartidos demuestran que tanto los efectos protectores como el mecanismo de acción de ApoD podrían estar conservados en sus homólogos incluso en el caso del que contiene la cola GPI, es decir, podrían realizarse desde la membrana. Esto permite extrapolar la interacción de Lazarillo de saltamontes con la membrana, a través de su cola GPI, al resto de sus homólogos, incluido ApoD, carentes de dicho anclaje. Hasta el momento, la falta de este sistema de anclaje a la membrana o de cualquier otro había descartado esta posibilidad.

La estructura de ApoD presenta un parche inusualmente hidrofóbico capaz de interaccionar con la bicapa lipídica. La ApoD humana también contiene una cisteína libre. Las cisteínas pueden sufrir una S-palmitoilación (tioacilación) estableciendo uniones tioester con ácidos grasos saturados. Dicha modificación es reversible lo que le permitiría volver a su estado soluble [216, 217]. El bolsillo hidrofóbico de la estructura de ApoD también podría servirle como mecanismo de anclaje a los lípidos de la membrana. Por lo tanto, existen elementos en la estructura de ApoD que podrían servirle de unión a la membrana sin necesidad de conservar su cola GPI, e incluso le permitirían establecer una unión mucho más dinámica, funcional y reversible que dicha cola.

Tanto la cola GPI, como la S-palmitoilación, son elementos íntimamente ligados a los dominios de membrana. La mayoría de los sistemas biológicos estudiados implicados en la función de ApoD también están relacionados con los dominios de membrana. Los dominios de membrana afectan la polaridad de las membranas, muy importante en la génesis y transporte sináptico y en la estabilización de los puntos de contacto neurona-diana; estabilizan la F-actina estimulando el crecimiento axonal; controlan el tráfico de membranas y la fusión vesicular; son importantes para la señalización de factores de crecimiento, adhesión celular y guía de axones. Además, son puntos de anclaje de las lipoproteínas (ver sección 4.5.4). La función de ApoD parece estar implicada en todos estos procesos y por consiguiente, en los dominios de membrana.

La detección de ApoD en los extractos de membrana de hipocampos de ratón estableció por primera vez una interacción estable entre esta lipocalina y las membranas celulares.

El análisis por inmunoblot de los dominios de membrana resistentes a Triton X-114 extraídos a partir de membranas de hipocampo de ratón y de una línea celular humana de astrocitoma, ha demostrado que ApoD se une, de manera estable e independiente de especie, a dichos dominios e incluso con mayor especificidad que el marcador de dominios flotilina.

Recientemente $A p o D$ ha aparecido en un listado de proteínas encontradas en dominios de membrana de tejido cardiaco humano [608]. También se ha observado marcaje de ApoD en preparaciones de mielina (García-Mateo, resultados no publicados) lo que confirma la 
posibilidad de unión a la membrana de esta proteína de forma estable e independiente de tejido y especie.

La cisteína libre que posee hApoD no está conservada en el ratón, que en su lugar posee una treonina con capacidad para generar enlaces de hidrógeno con grupos fosfato o cadenas de oligosacáridos [13]. Ambos aminoácidos se clasifican dentro del mismo grupo: polares sin carga. El hecho de que la unión a la membrana esté conservada en ambas especies podría indicar que el sistema de anclaje no sea a través de estos residuos sino a través de su bolsillo o de sus cadenas hidrocarbonadas del parche hidrofóbico. Sin embargo, sería necesario un estudio sobre el tipo de unión a membrana para descartar totalmente una posible unión con cualquiera de los dos residuos, cisteína o treonina.

La extracción con Triton X-114 se ha relacionado con dominios de membrana internos, ricos en cerebrósidos (por ejemplo LAMP 2, marcador lisosomal, se extrae específicamente en dominios resistentes a Triton X-114) [392]. Por lo tanto, podría considerarse que ApoD estaría enriquecido en los dominios de membranas internas, como los lisosomas o en los dominios de la membrana plasmática con destino citosólico.

La unión a la membrana concuerda con el marcaje de membrana punteado observado en las células de astrocitoma humano. Varias podrían ser las explicaciones de por qué no aparece este marcaje al añadir ApoD humana a los astrocitos primarios de ratón. En primer lugar, en el experimento con células humanas es la propia célula la que secreta y endocita la proteína, mientras que en el caso de los astrocitos de ratón, la proteína marcada no es la endógena sino hApoD añadida al medio extracelular. Esto podría indicar que la proteína secretada podría tener mayor tendencia a permanecer en la membrana, mientras que la libre en el citosol podría ser la endocitada. Esto podría explicarse teniendo en cuenta el estado de oxidación de la proteína. Es posible que la proteína añadida al medio extracelular se oxidara con más facilidad que la recién sintetizada unida a la membrana. La oxidación de metioninas es un sistema de regulación de la actividad de ciertas proteínas [102, 463]. ApoA-1 es una de las proteínas que ve afectada su actividad por la oxidación de alguna de sus metioninas [609]. La metionina M93 de ApoD aparece oxidada en el plasma de pacientes de Alzheimer. En las proteínas de membrana, las metioninas interaccionan con la bicapa protegiéndose de la oxidación. En la estructura de ApoD la metionina M93 se encuentra cerca del bolsillo, en la región hidrofóbica con capacidad de inserción en la bicapa [18]. Podría ser que ApoD en la membrana se encuentre en su forma reducida, y que su oxidación provoque la activación de mecanismos como su endocitosis. La ApoD añadida al medio podría oxidarse más fácilmente y endocitarse rápidamente. Por otro lado, las diferencias en la estructura de las dos proteínas homólogas podrían haber evolucionado en paralelo a diferencias entre los otros elementos de su mecanismo, manteniendo su función pero variando su comportamiento o localización. Por ejemplo, en la membrana de los astrocitos humanos podría existir una molécula con mayor tendencia a unirse a la cisteína de hApoD y menos a la treonina de mApoD y viceversa estabilizando su posición. También podría considerarse la idea de que las pequeñas vesículas cerca de la superficie celular fueran vesículas de secreción que en el caso de los astrocitos de ratón no se verían con el anticuerpo contra la proteína humana que únicamente sería endocitada y no secretada. 
Por otro lado, también se han observado diferencias entre estas dos proteínas en los resultados de los inmunoblots (Fig.57). En el caso de las membranas de astrocitos humanos, el anticuerpo marca una segunda banda correspondiente al doble tamaño de ApoD, mientras que en el ratón únicamente aparece la banda correspondiente a la proteína monomérica. Es posible que la cisteína libre del homólogo humano pudiera oxidarse y formar dímeros en la membrana que se distribuyen por igual en todas las regiones del gradiente excepto en las que aparece la banda de menor peso, la banda correspondiente al dominio resistente a detergente, lo que podría indicar que en dominios de membrana la proteína se encuentra no oxidada o unida a otra molécula mientras que fuera de ellos se dimeriza por oxidación o por encontrarse libre. Si hApoD formara dímeros a través de interacciones entre sus cisteínas y aún así permanece unido a la membrana podría indicar nuevamente que la interacción de ApoD con la membrana se realiza a través del bolsillo o de su parche hidrofóbico.

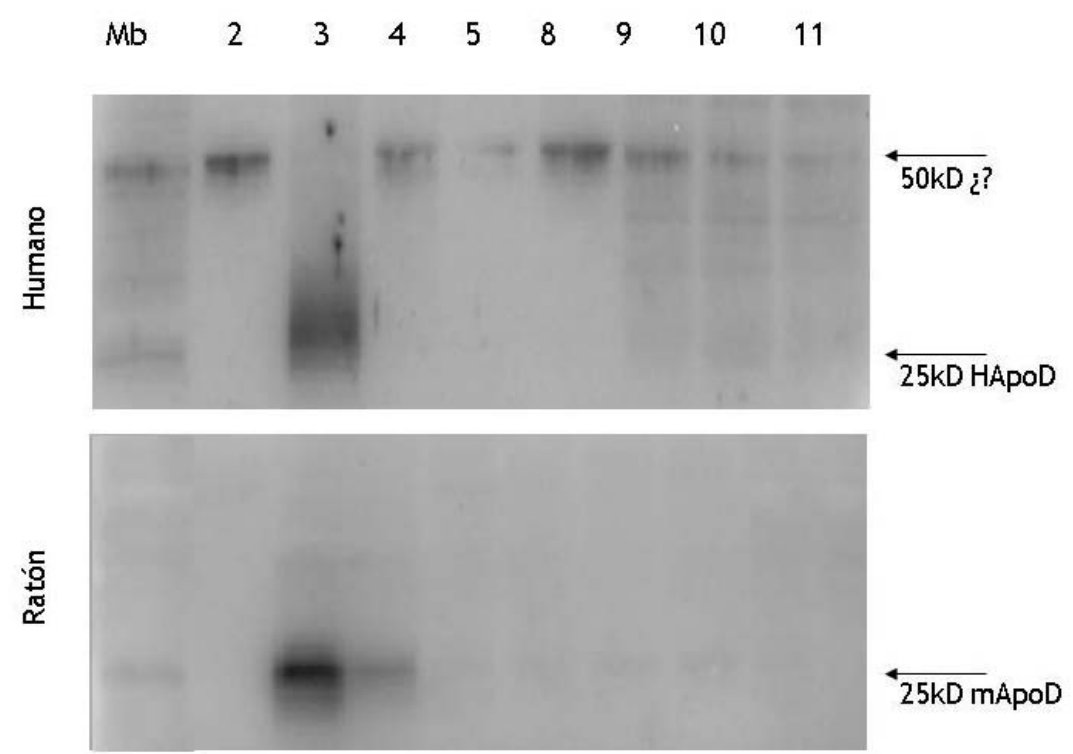

Figura 57. hApoD podría formar dímeros fuera de los DRMs.

Inmunoblot de hApoD y mApoD de DRMs de la línea de astrocitoma humana $1321 \mathrm{~N} 1$ y cultivos primarios de astrocitos de ratón respectivamente. La banda de $25 \mathrm{kD}$ corresponde a ApoD localizado en el extracto de membrana ( $\mathrm{Mb}$ ) y en la fracción de los dominios de membrana. Una segunda banda aparece a $50 \mathrm{kD}$ en las fracciones no-rafts.

El análisis de estos DRMs de membranas de hipocampo ha mostrado que la falta de ApoD no modifica ni la composición en colesterol y esfingomielina, ni el patrón proteico de estos dominios, ni la distribución del marcador de DRMs flotilina. Por el contrario sí se han observado diferencias en su conformación estructural a través de espectrometría Raman. Dado que los lípidos son los componentes mayoritarios de los dominos de membrana y que no existe una variación importante en las proteínas que los forman es lógico pensar que la disminución en el orden de dichas estructuras y los cambios conformacionales detectados sean debidos a cambios lipídicos, bien en composición, bien en su estructura (oxidación, distribución, empaquetamiento). 
El análisis por espectrometría de masas de los DRMs de hipocampo extraídos por Triton X-114 muestra una importante representación del ácido araquidónico y DHA en las familias de lípidos que pueden contener aminoácidos insaturados (PE y PC). Es importante recordar que ApoD presenta una alta afinidad in vitro por la unión a AA.

El estudio comparativo de la lipidómica de los DRMs de hipocampos de ratones WT frente a ApoD-KO en situación control y sometidos a tratamiento con PQ muestra una alta sensibilidad de los lípidos que conforman estas estructuras ante la oxidación, especialmente los lípidos poliinsaturados. El efecto de la pérdida de función de ApoD sobre los DRMs afecta mayoritariamente a la respuesta de estas estructuras frente al estrés oxidativo. Esto corroboraría la hipótesis de una función protectora de ApoD frente a una situación de estrés.

Las monohexosilceramidas son la familia de lípidos que responde más específicamente a la falta de ApoD en situación de estrés oxidativo. Las monohexosilceramidas estudiadas aumentan en respuesta al tratamiento con $P Q$ cuando $A p o D$ no realiza su función. Esto indica que esta familia de lípidos está íntimamente influenciada por la función de ApoD. Las monohexosilceramidas son el producto del catabolismo de los gangliósidos, el tercer componente mayoritario de los dominios de membrana. ApoD podría estar protegiendo a los gangliósidos de la oxidación. Ante la falta de ApoD, los gangliósidos podrían oxidarse o bien podrían activarse proteínas que promueven su catabolismo dando como resultado un aumento de las monohexosilceramidas (como producto de degradación o como base para la nueva síntesis) (ver sección 4.6.3).

ApoD también varía la respuesta al PQ de la familia de las esfingomielinas pero en este caso disminuyen en los DMRs ante la presencia de ApoD y permanecen inalteradas en su ausencia. Las ceramidas saturadas también disminuyen específicamente en ausencia de ApoD ante el $P Q$. El radical superóxido, en este caso generado por el $P Q$, induce la expresión de la esfingomielinasa que provoca la degradación de la esfingomielina a ceramida. La ceramida a su vez es un intermediario tanto de la síntesis de esfingomielina como de los gangliósidos (Fig.58). Por lo tanto se concluye que el mecanismo de acción de ApoD está relacionado con el complejo metabolismo de la ceramida en respuesta al estrés oxidativo generado por ROS posiblemente a través del control de la oxidación de los gangliósidos ${ }^{27}$.

Los últimos estudios realizados apuntan hacia que la distribución de ApoD en los DRMs de membranas de astrocitoma humano se modifica ante el tratamiento con PQ pero no ante el bajo suero y de manera similar al comportamiento de caveolina bajo las mismas condiciones. Por el contrario Flotilina ve alterada su distribución en ambas condiciones de estrés. Caveolina, al igual que ApoD podría estar apareciendo en otros tipos de balsas lipídicas que no se extraen por Triton X-114 ante el tratamiento con PQ, como por ejemplo dominios o caveolas de membrana plasmática. El estudio de la distribución de ApoD en dominios extraídos con diferentes detergentes podría generar un mapa de la distribución de ApoD en las membranas en respuesta a estrés oxidativo.

\footnotetext{
${ }^{27}$ Durante la escritura de esta tesis se está procediendo al estudio lipidómico de una plataforma diferente a la utilizada con anterioridad en la que podrán estudiarse con detalle los gangliósidos y los sulfátidos, experimentos que permitirán la confirmación de esta hipótesis.
} 


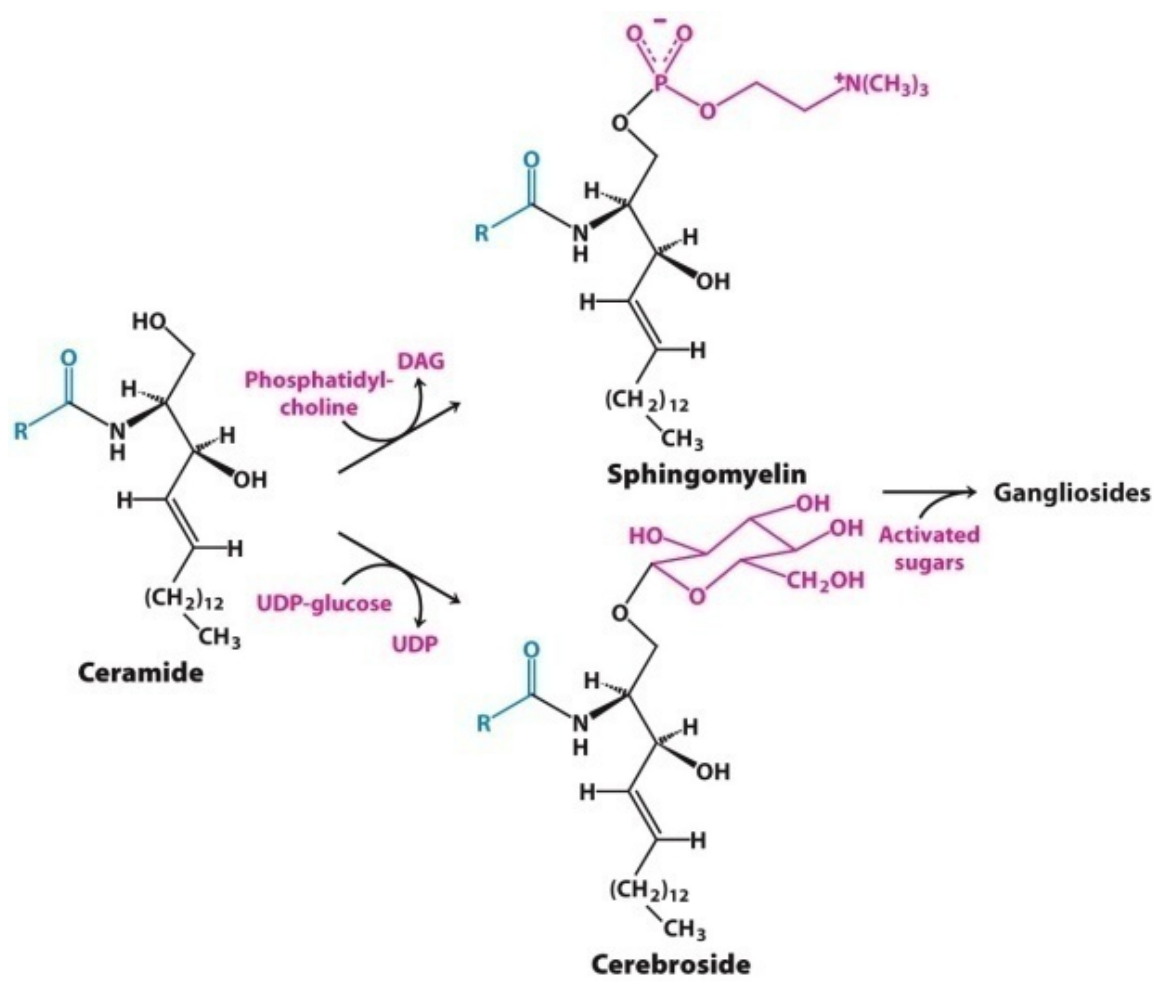

Figura 58. Cadena de los esfingolípidos[610]

Los resultados de esta Tesis demuestran que ApoD interacciona con los dominios de membrana resistentes a detergente, donde participa en la respuesta celular frente al estrés oxidativo modulando el metabolismos de los esfingolípidos y más concretamente la vía de los gangliósidos. Está presente tanto en la membrana celular como en membranas de organelas internas, y específicamente en los lisosomas. La modulación que ejerce sobre estas membranas tiene efectos sobre los dos mecanismos fundamentales alterados en las enfermedades neurodegenerativas y la edad: la generación de ROS y los mecanismos de control de calidad de proteínas. En concreto ApoD protege frente a daño provocado por la expresión de proteínas poliglutaminadas al fomentar la eficacia del flujo de la autofagia, durante el proceso de fusión entre la membrana del lisosoma y el autofagosoma. ApoD también mantiene una correcta actividad de los mecanismos en los que intervienen las membranas como el crecimiento axonal o la formación de sinapsis.

Intentando aunar todos los resultados obtenidos y los conocimientos sobre ApoD, se propone un posible mecanismo de acción:

Anclaje:

ApoD interacciona con la membrana a través de su parche hidrofóbico y su bolsillo atrapando a los "bigotes" de lípidos oxidados, o estableciendo interacciones con las cabezas de los gangliósidos. Por lo tanto el "receptor" de ApoD podría no ser una proteína sino un lípido de la membrana. 
Desde la membrana ApoD podría realizar diferentes funciones

Reducción:

Tanto su metionina (al lado del bolsillo) como la cisteína teóricamente tienen poder reductor. En un ambiente oxidante podrían oxidarse y actuar como enzimas reductoras de los lípidos contiguos siempre que existiera algún sistema para revertir su propia oxidación permitiéndole repetir la operación con más lípidos. Esto podrían hacerlo las metioninasulfóxidoreductasas (se ha encontrado un tipo en las membranas). ApoD, por tanto podría reducir los lípidos peroxidados, favorecer la estabilidad de las membranas y fomentar el correcto funcionamiento de los procesos en los que están implicados. La oxidación de la metionina también podría producir cambios conformacionales en la estructura de ApoD que afectaran a una posible función posterior de ApoD o a su afinidad por sus ligandos.

\section{Activación de enzimas:}

La modulación del metabolismo de los esfingolípidos por parte de ApoD podría indicar una indirecta acción sobre enzimas implicadas en el metabolismo lipídico. De hecho, prácticamente todas las apolipoproteínas están asociadas a la actividad de alguna enzima (lipasa LPL, LCAT). ApoD también podría estar asociada a alguna enzima del metabolismo lipídico. Aunque se encontró asociada a LCAT en las HDL, otras proteínas también podrían ser candidatas. Se han observado cambios en las PLAs en los nervios de ratones ApoD-KO. Además ciertas fosfolipasas son las encargadas de la eliminación de colas GPI (relacionadas con dominios de membrana y con el homólogo de ApoD en saltamontes). ApoD podría modular la actividad de alguna de estas fosfolipasas cuya función provoca cambios en lípidos que derivan en procesos de endocitosis, cascadas de señalización o liberación de mensajeros al medio extracelular. SPT (serinapalmitoiltransferasa), enzima que sintetiza ceramida, se encuentra en la membrana del retículo endoplásmico y en otras regiones como adhesiones focales. Curiosamente SPT1 es el gen más cercano a la secuencia de GLaz en Drosophila [75]. La ceramida sintasa (CerS), dada su participación en el metabolismo de los esfingolípidos, también podría modular su actividad en función de ApoD. La pérdida de su actividad catalítica causa ataxia cerebelosa, neurodegeneración y defectos lisosomales. Las esfingomielinasas y glicosiltransferasas involucradas en la cascada de los gangliósidos también podrían ver modificada su actividad por la presencia de ApoD.

El control por parte de ApoD de las enzimas implicadas en el metabolismo lipídico también podría conectar a ApoD con los fenómenos de fusión y tráfico vesicular, autofagosomas, cuerpos multivesiculares, y liberación de partículas de membrana (exosomas).

Modulación de membranas:

Los efectos que ApoD tiene sobre las membranas, y en concreto sobre los dominios de membrana podrían influir en la entrada o salida de proteínas de estas estructuras modulando su actividad. Los receptores tipo Toll requieren de su translocación a los dominios de 
membrana para su activación. Las ceramidas juegan un papel fundamental en su función. Están implicados en la expresión de citoquinas y quimioquinas y en la resistencia a la insulina. La falta de ApoD presenta fenotipos relacionados con estos mecanismos por lo que se ha sugerido que la función de ApoD podría modular a estos receptores y los mecanismos que regulan.

Tráfico vesicular:

Los dominios de membrana están implicados en los procesos de endocitosis, tanto los mediados por caveolina como los que no. ApoD participa en este transporte vesicular ya que ella misma es endocitada. Cuenta con dos posibles sistemas de anclaje, la cisteína y el bolsillo hidrofóbico lo que le confiere un hipotético papel estabilizador. Podría estar unido a la bicapa por una de sus partes y unirse a una proteína de otra membrana o incluso a otra bicapa por la otra. Esto podría suceder también en la recepción de las HDL. ApoD podría unirse a los dominios de membrana de la célula a través de su bolsillo mientras permanece unida a otras apolipoproteínas de las HDL por su cisteína, favoreciendo la endocitosis de la lipoproteína y dirigiéndola a los lisosomas donde se producirá la liberación de sus lípidos. De la misma manera ApoD podría estabilizar vesículas favoreciendo su fusión. Los lisosomas no son únicamente centros de degradación sino que también pueden actuar como plataformas de secreción. Se ha detectado la presencia de ApoD en exosomas. ApoD podría ejercer de "receptor" estabilizando la unión entre el exosoma y la célula aceptora y favoreciendo su fusión.

Muchas son las hipótesis por contrastar y muchas las preguntas que aún quedan por resolver sobre la función y el mecanismo de acción de ApoD.

Sin embargo, la confirmación de una unión con la membrana y su presencia en dominios concretos de la membrana ha abierto un amplio abanico de posibilidades y vías de investigación: el estudio del comportamiento de ApoD ante la extracción selectiva de diferentes dominios de membrana con diferentes detergentes y en diferentes condiciones; la determinación del tipo de unión de ApoD con la membrana; un estudio proteómico profundo de la composición de los dominios enriquecidos en ApoD y los cambios que su actuación pueda provocar; la confirmación de la conservación de GLaz y NLaz en dominios de membrana de Drosophila y su posible clasificación en diferentes dominios que explicarían las diferencias entre ellos; la monitorización de la actividad de diferentes enzimas relacionadas con los dominios de membranas ante la presencia de ApoD; los estudios del efecto de ApoD en las sinapsis y el tráfico axónico; la endocitosis de ApoD y los factores de su regulación; y muchos otros análisis quedan en el laboratorio a la espera de su estudio.

Las membranas son la cara de las células, espejo de su alma, a través de las cuales expresan su identidad, su función, su estado; sistemas de comunicación directa o indirecta con el entorno; contenedoras del mayor y más sutil sistema de regulación, los lípidos, con cientos de elementos diferentes que cual teclas de un gran piano pueden tocarse una a una o en acordes para generar la armonía celular. Son un importante campo en el que queda mucho por explorar y que seguro que dará, en un futuro no muy lejano, grandes sorpresas. 
ApoD forma parte de este complejo sistema, compartiendo con él su gran potencialidad. Cual pianista en un concierto, ApoD toca las teclas de la membrana en función de las necesidades "armónicas" de la célula. Su implicación en importantes y variados procesos ha convertido el estudio de ApoD realizado durante esta Tesis doctoral en una apasionante aventura a través de los diversos misterios que esconden las células, en los que este investigador ha sido un ciego que ha ido descubriendo las maravillas de la biología de la mano de su Lazarillo. 


\section{CONCLUSIONES}

1. GLaz y NLaz forman parte de la respuesta transcripcional endógena a la degeneración provocada por una proteína poliglutaminada contrarrestando el daño celular y manteniendo la integridad del tejido de manera estable con el tiempo.

2. GLaz ejerce su función protectora desde dentro de la neurona en degeneración, o de manera paracrina.

3. GstS1, proteína implicada en el aclaramiento de lípidos peroxidados, también es inducida en el modelo de SCA1. Esta inducción se altera con la sobreexpresión de GLaz.

4. GLaz contrarresta la muerte celular apoptótica inducida por la SCA1 promoviendo el flujo de la autofagia selectiva y no su inducción, favoreciendo la eliminación de los agregados proteicos. Esta protección se mantiene al inducir la autofagia farmacológicamente.

5. ApoD y el resto de lipocalinas Lazarillo forman parte del sistema de protección endógena contra los dos factores involucrados en la neurodegeneración y el envejecimiento: daño generado por ROS y el deterioro de la proteostasis.

6. ApoD se endocita y se localiza en los lisosomas, desde donde puede actuar sobre procesos que ocurren en el interior celular.

7. La falta de GLaz y NLaz provoca defectos en el crecimiento axonal, disminuyendo la longitud del axón y provocando la desorganización de los microtúbulos. También altera el proceso de formación de sinapsis reduciendo su número y su área.

8. ApoD, a pesar de ser una proteína secretada, presenta una fuerte interacción con las membranas. ApoD se une, de manera estable e independiente de especie, a los dominios de membrana resistentes a detergente e incluso con mayor especificidad que el marcador genérico de dominios flotilina. De manera específica ApoD se encuentra en los dominios de membrana extraídos por Triton X-114 caracterizados como dominios de membranas del interior celular ricos en gangliósidos.

9. ApoD no modifica sustancialmente ni el perfil proteico ni el perfil lipídico de los dominios de membrana en situación control.

10. ApoD modifica, específicamente y ante el estrés oxidativo, la composición en monohexosilceramidas, esfingomielinas y ceramidas de los dominios de membrana por lo que participa en el metabolismo de los cerebrósidos en respuesta a estrés oxidativo. 


\section{CONCLUSIONS}

1. GLaz and NLaz are part of the endogenous transcriptional response to degeneration caused by a poliglutaminated protein, counteracting cellular damage and maintaining tissue integrity. This neuroprotection is persistent with age.

2. GLaz exerts its protective function both, from within the degenerating neuron and in a paracrine manner.

3. GstS1, a protein involved in the lipid peroxide clearance, is also induced in the SCA1 model. This induction is altered by GLaz overexpression.

4. GLaz counteracts apoptotic cell death induced by SCA1 promoting flow of selective autophagy, not its induction, favoring the clearance of aggregation-prone proteins. This protection remains even when combining SCA1-dependent with pharmacological inductions of autophagy.

5. ApoD and the Lazarillo-related Lipocalins are part of the endogenous protection system against the two major factors involved in neurodegeneration and aging: ROSdependent damage and proteostasis deterioration.

6. ApoD is endocytosed and localized in lysosomes where it can act on processes occurring inside the cell.

7. The absence of NLaz and GLaz provokes axonal growth defects, decreasing the length of the axon and causing disorganization of microtubules. It also alters the process of synapse formation by reducing their number and area.

8. Despite being a secreted protein, ApoD has a strong interaction with membranes. ApoD is associated to detergent-resistant membrane domains in a stable and independent of species manner and even more specific than the generic membrane domains marker Flotillin. ApoD has a specifically interaction with membrane domains extracted by Triton X-114 characterized as intracellular membrane domains rich in gangliosides.

9. ApoD does not substantially modify the global protein profile of membrane domains in a control situation.

10. ApoD alters the response of membrane domains to oxidative stress specifically in their composition of monohexosylceramides, sphingomyelins and ceramides. Therefore, ApoD participates in the metabolism of cerebrosides in response to oxidative stress. 


\section{BIBLIOGRAFÍA}

1. Arai, H., Oxidative modification of lipoproteins. Subcell Biochem, 2014. 77: p. 103-14.

2. McConathy, W.J. and P. Alaupovic, Isolation and partial characterization of apolipoprotein D: a new protein moiety of the human plasma lipoprotein system. FEBS Lett, 1973. 37(2): p. 178-82.

3. O'Byrne, S.M. and W.S. Blaner, Retinol and retinyl esters: biochemistry and physiology. J Lipid Res. 54(7): p. 1731-43.

4. Drayna, D., et al., Cloning and expression of human apolipoprotein D cDNA. J Biol Chem, 1986. 261(35): p. 16535-9.

5. Weech, P.K., et al., Apolipoprotein D--an atypical apolipoprotein. Prog Lipid Res, 1991. 30(2-3): p. 259-66.

6. Flower, D.R., A.C. North, and C.E. Sansom, The lipocalin protein family: structural and sequence overview. Biochim Biophys Acta, 2000. 1482(1-2): p. 9-24.

7. Grzyb, J., D. Latowski, and K. Strzalka, Lipocalins - a family portrait. J Plant Physiol, 2006. 163(9): p. 895-915.

8. Blanco-Vaca, F., et al., Characterization of disulfide-linked heterodimers containing apolipoprotein D in human plasma lipoproteins. J Lipid Res, 1992. 33(12): p. 1785-96.

9. Akerstrom, B., et al., The lipocalin alpha1-microglobulin has radical scavenging activity. J Biol Chem, 2007. 282(43): p. 31493-503.

10. Steyrer, E. and G.M. Kostner, Activation of lecithin-cholesterol acy/transferase by apolipoprotein D: comparison of proteoliposomes containing apolipoprotein $D, A-I$ or $C$ I. Biochim Biophys Acta, 1988. 958(3): p. 484-91.

11. Dubovy, P., Schwann cells and endoneurial extracellular matrix molecules as potential cues for sorting of regenerated axons: a review. Anat Sci Int, 2004. 79(4): p. 198-208.

12. Sanchez, D., et al., Exon-intron structure and evolution of the Lipocalin gene family. Mol Biol Evol, 2003. 20(5): p. 775-83.

13. Eichinger, A., et al., Structural insight into the dual ligand specificity and mode of high density lipoprotein association of apolipoprotein D. J Biol Chem, 2007. 282(42): p. 31068-75.

14. Yang, C.Y., et al., Structure of human apolipoprotein D: locations of the intermolecular and intramolecular disulfide links. Biochemistry, 1994. 33(41): p. 12451-5.

15. Rassart, E., et al., Apolipoprotein D. Biochim Biophys Acta, 2000. 1482(1-2): p. 185-98.

16. Blanco-Vaca, F. and H.J. Pownall, Disulfide linked dimers of apolipoprotein $D$ in urine. Electrophoresis, 1993. 14(10): p. 1086-7.

17. Oakley, A.J., et al., Molecular dynamics analysis of apolipoprotein-D-lipid hydroperoxide interactions: mechanism for selective oxidation of Met-93. PLoS One, 2012. 7(3): p. e34057.

18. Bhatia, S., et al., Selective reduction of hydroperoxyeicosatetraenoic acids to their hydroxy derivatives by apolipoprotein D: implications for lipid antioxidant activity and Alzheimer's disease. Biochem J, 2011. 442(3): p. 713-21.

19. Kamboh, M.I., et al., Genetic studies of human apolipoproteins. IX. Apolipoprotein D polymorphism and its relation to serum lipoprotein lipid levels. Am J Hum Genet, 1989. 45(1): p. 147-54.

20. Desai, P.P., et al., Genetic variation in the apolipoprotein D gene among African blacks and its significance in lipid metabolism. Atherosclerosis, 2002. 163(2): p. 329-38.

21. Ruiz, M., et al., Lipid-binding properties of human ApoD and Lazarillo-related lipocalins: functional implications for cell differentiation. FEBS J, 2013. 280(16): p. 3928-43. 
22. Haagensen, D.E., Jr., et al., Breast gross cystic disease fluid analysis. I. Isolation and radioimmunoassay for a major component protein. J Natl Cancer Inst, 1979. 62(2): p. 239-47.

23. Pearlman, W.H., J.L. Gueriguian, and M.E. Sawyer, A specific progesterone-binding component of human breast cyst fluid. J Biol Chem, 1973. 248(16): p. 5736-41.

24. Vogt, M. and A. Skerra, Bacterially produced apolipoprotein D binds progesterone and arachidonic acid, but not bilirubin or E-3M2H. J Mol Recognit, 2001. 14(1): p. 79-86.

25. Patel, R.C., et al., Probing the structure of the ligand binding cavity of lipocalins by fluorescence spectroscopy. Protein Eng, 1997. 10(6): p. 621-5.

26. Morais Cabral, J.H., et al., Arachidonic acid binds to apolipoprotein D: implications for the protein's function. FEBS Lett, 1995. 366(1): p. 53-6.

27. Blankman, J.L. and B.F. Cravatt, Chemical probes of endocannabinoid metabolism. Pharmacol Rev. 65(2): p. 849-71.

28. Breustedt, D.A., D.L. Schonfeld, and A. Skerra, Comparative ligand-binding analysis of ten human lipocalins. Biochim Biophys Acta, 2006. 1764(2): p. 161-73.

29. Zeng, C., et al., A human axillary odorant is carried by apolipoprotein D. Proc Natl Acad Sci U S A, 1996. 93(13): p. 6626-30.

30. Salles, A., A. Romano, and R. Freudenthal, Synaptic NF-kappa B pathway in neuronal plasticity and memory. J Physiol Paris.

31. Do Carmo, S., et al., Modulation of apolipoprotein D and apolipoprotein E mRNA expression by growth arrest and identification of key elements in the promoter. J Biol Chem, 2002. 277(7): p. 5514-23.

32. Levros, L.C., Jr., et al., Binding and repressive activities of apolipoprotein E3 and E4 isoforms on the human ApoD promoter. Mol Neurobiol, 2013. 48(3): p. 669-80.

33. Sasaki, Y., et al., p53 family members regulate the expression of the apolipoprotein $D$ gene. J Biol Chem, 2009. 284(2): p. 872-83.

34. Seguin, D., M. Desforges, and E. Rassart, Molecular characterization and differential mRNA tissue distribution of mouse apolipoprotein D. Brain Res Mol Brain Res, 1995. 30(2): p. 242-50.

35. Ganfornina, M.D., et al., Molecular characterization and developmental expression pattern of the chicken apolipoprotein $D$ gene: implications for the evolution of vertebrate lipocalins. Dev Dyn, 2005. 232(1): p. 191-9.

36. Ganfornina, M.D., D. Sanchez, and M.J. Bastiani, Lazarillo, a new GPI-linked surface lipocalin, is restricted to a subset of neurons in the grasshopper embryo. Development, 1995. 121(1): p. 123-34.

37. Sanchez, D., et al., Characterization of two novel lipocalins expressed in the Drosophila embryonic nervous system. Int J Dev Biol, 2000. 44(4): p. 349-59.

38. Navarro, A., E. Del Valle, and J. Tolivia, Differential expression of apolipoprotein d in human astroglial and oligodendroglial cells. J Histochem Cytochem, 2004. 52(8): p. 1031-6.

39. Boyles, J.K., et al., Identification, characterization, and tissue distribution of apolipoprotein D in the rat. J Lipid Res, 1990. 31(12): p. 2243-56.

40. Spreyer, P., et al., Regeneration-associated high level expression of apolipoprotein $D$ mRNA in endoneurial fibroblasts of peripheral nerve. EMBO J, 1990. 9(8): p. 2479-84.

41. Schaeren-Wiemers, N., P. van der Bijl, and M.E. Schwab, The UDP-galactose:ceramide galactosyltransferase: expression pattern in oligodendrocytes and Schwann cells during myelination and substrate preference for hydroxyceramide. J Neurochem, 1995. 65(5): p. 2267-78.

42. Nadia Garcia-Mateo, M.D.G., Olimpio Montero, and Diego Sanchez, Schwann cellderived Apolipoprotein $D$ controls the dynamics of post-injury myelin breakdown through the control of lipid mediators. . 2014: p. (en preparación). 
43. Loerch, P.M., et al., Evolution of the aging brain transcriptome and synaptic regulation. PLoS One, 2008. 3(10): p. e3329.

44. Verheijen, M.H., et al., Local regulation of fat metabolism in peripheral nerves. Genes Dev, 2003. 17(19): p. 2450-64.

45. de Magalhaes, J.P., J. Curado, and G.M. Church, Meta-analysis of age-related gene expression profiles identifies common signatures of aging. Bioinformatics, 2009. 25(7): p. 875-81.

46. Sohal, R.S. and W.C. Orr, The redox stress hypothesis of aging. Free Radic Biol Med, 2011. 52(3): p. 539-55.

47. Bajo-Graneras, R., et al., Apolipoprotein D mediates autocrine protection of astrocytes and controls their reactivity level, contributing to the functional maintenance of paraquat-challenged dopaminergic systems. Glia. 59(10): p. 1551-66.

48. Bajo-Graneras, R., et al., Apolipoprotein $D$ alters the early transcriptional response to oxidative stress in the adult cerebellum. J Neurochem. 117(6): p. 949-60.

49. Ordonez, C., et al., Apolipoprotein D expression in substantia nigra of Parkinson disease. Histol Histopathol, 2006. 21(4): p. 361-6.

50. Thomas, E.A. and J.K. Yao, Clozapine specifically alters the arachidonic acid pathway in mice lacking apolipoprotein D. Schizophr Res, 2007. 89(1-3): p. 147-53.

51. Kroksveen, A.C., et al., Discovery and initial verification of differentially abundant proteins between multiple sclerosis patients and controls using iTRAQ and SID-SRM. J Proteomics, 2012. 78: p. 312-25.

52. Terrisse, L., et al., Increased levels of apolipoprotein $D$ in cerebrospinal fluid and hippocampus of Alzheimer's patients. J Neurochem, 1998. 71(4): p. 1643-50.

53. Suresh, S., et al., Cellular cholesterol storage in the Niemann-Pick disease type C mouse is associated with increased expression and defective processing of apolipoprotein D. J Neurochem, 1998. 70(1): p. 242-51.

54. Bajo-Graneras, R., Apolipoproteina-D/Lazarillo, una pieza clave en el envejecimiento. Fisiología. Revista Oficial de la Sociedad Española de Ciencias Fisiológicas (SECF), 2010. 12(1889-397X).

55. Glockner, F. and T.G. Ohm, Hippocampal apolipoprotein D level depends on Braak stage and APOE genotype. Neuroscience, 2003. 122(1): p. 103-10.

56. Kalman, J., et al., Apolipoprotein $D$ in the aging brain and in Alzheimer's dementia. Neurol Res, 2000. 22(4): p. 330-6.

57. Ganfornina, M.D., et al., ApoD, a glia-derived apolipoprotein, is required for peripheral nerve functional integrity and a timely response to injury. Glia, 2010. 58(11): p. 132034.

58. Desai, P.P., et al., Apolipoprotein $D$ is a component of compact but not diffuse amyloidbeta plaques in Alzheimer's disease temporal cortex. Neurobiol Dis, 2005. 20(2): p. 574-82.

59. Martinez, E., et al., Amyloid-beta25-35 induces apolipoprotein D Synthesis and growth arrest in HT22 hippocampal cells. J Alzheimers Dis, 2012. 30(2): p. 233-44.

60. Cordy, J.M., N.M. Hooper, and A.J. Turner, The involvement of lipid rafts in Alzheimer's disease. Mol Membr Biol, 2006. 23(1): p. 111-22.

61. Thomas, E.A., et al., Apolipoprotein D mRNA expression is elevated in PDAPP transgenic mice. J Neurochem, 2001. 79(5): p. 1059-64.

62. Rickhag, M., et al., Apolipoprotein D is elevated in oligodendrocytes in the peri-infarct region after experimental stroke: influence of enriched environment. J Cereb Blood Flow Metab, 2008. 28(3): p. 551-62.

63. Perdomo, G. and H. Henry Dong, Apolipoprotein D in lipid metabolism and its functional implication in atherosclerosis and aging. Aging (Albany NY), 2009. 1(1): p. 17-27. 
64. Vijayaraghavan, S., G.A. Hitman, and P.G. Kopelman, Apolipoprotein-D polymorphism: a genetic marker for obesity and hyperinsulinemia. J Clin Endocrinol Metab, 1994. 79(2): p. 568-70.

65. Bajo-Graneras, R., et al., Expression and potential role of apolipoprotein D on the death-survival balance of human colorectal cancer cells under oxidative stress conditions. Int J Colorectal Dis, 2013. 28(6): p. 751-66.

66. Carrillo-Esper, R., Lipocalina asociada con la gelatinasa de neutrófilos, un nuevo marcador de lesión renal aguda en el enfermo grave.Cirujía y cirujanos, 2011. 79.

67. Kurano, M., et al., Induction of insulin secretion by apolipoprotein $M$, a carrier for sphingosine 1-phosphate. Biochim Biophys Acta, 2014. 1841(9): p. 1217-1226.

68. Arkensteijn, B.W., et al., The apolipoprotein m-sphingosine-1-phosphate axis: biological relevance in lipoprotein metabolism, lipid disorders and atherosclerosis. Int J Mol Sci, 2013. 14(3): p. 4419-31.

69. Christoffersen, C. and L.B. Nielsen, Apolipoprotein M: bridging HDL and endothelial function. Curr Opin Lipidol, 2013. 24(4): p. 295-300.

70. Elsoe, S., et al., Apolipoprotein M promotes mobilization of cellular cholesterol in vivo. Biochim Biophys Acta, 2013. 1831(7): p. 1287-92.

71. Trojer, P., et al., Complement component C8gamma is expressed in human fetal and adult kidney independent of C8alpha. FEBS Lett, 1999. 446(2-3): p. 243-6.

72. Mohri, I., et al., Lipocalin-type prostaglandin D synthase is up-regulated in oligodendrocytes in lysosomal storage diseases and binds gangliosides. J Neurochem, 2006. 97(3): p. 641-51.

73. Gemelli, C., et al., The Orosomucoid 1 protein is involved in the vitamin $D$ - mediated macrophage de-activation process. Exp Cell Res, 2013. 319(20): p. 3201-13.

74. Ruiz, M., Lazarillo and related Lipocalins: ligands and functions, in Departamento de Bioquímica Biología Molecular y Fisiología. 2013, Universidad de Valladolid: Valladolid. p. 250.

75. Sanchez, D., et al., Loss of glial lazarillo, a homolog of apolipoprotein $D$, reduces lifespan and stress resistance in Drosophila. Curr Biol, 2006. 16(7): p. 680-6.

76. Colomb, J., et al., Architecture of the primary taste center of Drosophila melanogaster larvae. J Comp Neurol, 2007. 502(5): p. 834-47.

77. Boca, S., et al., Arabidopsis lipocalins AtCHL and AtTIL have distinct but overlapping functions essential for lipid protection and seed longevity. Plant Cell Environ, 2013. 37(2): p. 368-81.

78. Frenette Charron, J.B., et al., Molecular and structural analyses of a novel temperature stress-induced lipocalin from wheat and Arabidopsis. FEBS Lett, 2002. 517(1-3): p. 12932.

79. Axler, O., J. Ahnstrom, and B. Dahlback, Apolipoprotein M associates to lipoproteins through its retained signal peptide. FEBS Lett, 2008. 582(5): p. 826-8.

80. Pasco, M.Y. and P. Leopold, High sugar-induced insulin resistance in Drosophila relies on the lipocalin Neural Lazarillo. PLoS One, 2012. 7(5): p. e36583.

81. Muffat, J., D.W. Walker, and S. Benzer, Human ApoD, an apolipoprotein up-regulated in neurodegenerative diseases, extends lifespan and increases stress resistance in Drosophila. Proc Natl Acad Sci U S A, 2008. 105(19): p. 7088-93.

82. Oltmanns, U., et al., Role of c-jun N-terminal kinase in the induced release of GM-CSF, RANTES and IL-8 from human airway smooth muscle cells. Br J Pharmacol, 2003. 139(6): p. 1228-34.

83. Hull-Thompson, J., et al., Control of metabolic homeostasis by stress signaling is mediated by the lipocalin NLaz. PLoS Genet, 2009. 5(4): p. e1000460.

84. Ceriani, M.F., et al., Genome-wide expression analysis in Drosophila reveals genes controlling circadian behavior. J Neurosci, 2002. 22(21): p. 9305-19. 
85. Gates, M.A., R. Kannan, and E. Giniger, A genome-wide analysis reveals that the Drosophila transcription factor Lola promotes axon growth in part by suppressing expression of the actin nucleation factor Spire. Neural Dev, 2011. 6: p. 37.

86. Rynes, J., et al., Activating transcription factor 3 regulates immune and metabolic homeostasis. Mol Cell Biol, 2012. 32(19): p. 3949-62.

87. Allen, A.K. and A.C. Spradling, The Sf1-related nuclear hormone receptor Hr39 regulates Drosophila female reproductive tract development and function.

Development, 2008. 135(2): p. 311-21.

88. Berry, C., C. La Vecchia, and P. Nicotera, Paraquat and Parkinson's disease. Cell Death Differ, 2010. 17(7): p. 1115-25.

89. Ganfornina, M.D., et al., Apolipoprotein $D$ is involved in the mechanisms regulating protection from oxidative stress. Aging Cell, 2008. 7(4): p. 506-15.

90. Rajput, P.S., et al., Expression of somatostatin and somatostatin receptor subtypes in Apolipoprotein $D(A p o D)$ knockout mouse brain: An immunohistochemical analysis. J Chem Neuroanat, 2009. 38(1): p. 20-33.

91. Boer, S., et al., Decreased kainate receptors in the hippocampus of apolipoprotein $D$ knockout mice. Prog Neuropsychopharmacol Biol Psychiatry, 2009. 34(2): p. 271-8.

92. Jimenez-Palomares, M., et al., Genetic deficiency of apolipoprotein D in the mouse is associated with nonfasting hypertriglyceridemia and hyperinsulinemia. Metabolism, 2011. 60(12): p. 1767-74.

93. Ruiz, M., et al., Ligand binding-dependent functions of the lipocalin NLaz: an in vivo study in Drosophila. FASEB J, 2013. 28(4): p. 1555-67.

94. Do Carmo, S., et al., Neuroprotective effect of apolipoprotein D against human coronavirus OC43-induced encephalitis in mice. J Neurosci, 2008. 28(41): p. 10330-8.

95. Do Carmo, S., et al., Human apolipoprotein D overexpression in transgenic mice induces insulin resistance and alters lipid metabolism. Am J Physiol Endocrinol Metab, 2009. 296(4): p. E802-11.

96. Tsukamoto, K., et al., Identification of apolipoprotein $D$ as a cardioprotective gene using a mouse model of lethal atherosclerotic coronary artery disease. Proc Natl Acad Sci U S A, 2013. 110(42): p. 17023-8.

97. Navarro, J.A., et al., Altered lipid metabolism in a Drosophila model of Friedreich's ataxia. Hum Mol Genet, 2010. 19(14): p. 2828-40.

98. Sabio, G. and R.J. Davis, TNF and MAP kinase signalling pathways. Semin Immunol.

99. Simard, J., et al., Additive stimulatory action of glucocorticoids and androgens on basal and estrogen-repressed apolipoprotein-D messenger ribonucleic acid levels and secretion in human breast cancer cells. Endocrinology, 1992. 130(3): p. 1115-21.

100. Lopez-Boado, Y.S., J. Tolivia, and C. Lopez-Otin, Apolipoprotein D gene induction by retinoic acid is concomitant with growth arrest and cell differentiation in human breast cancer cells. J Biol Chem, 1994. 269(43): p. 26871-8.

101. Pajaniappan, M., et al., Endothelial cells downregulate apolipoprotein D expression in mural cells through paracrine secretion and Notch signaling. Am J Physiol Heart Circ Physiol, 2011. 301(3): p. H784-93.

102. Zhang, $\mathrm{C}$., et al., Methionine sulfoxide reductase $A$ (MsrA) protects cultured mouse embryonic stem cells from H2O2-mediated oxidative stress. J Cell Biochem, 2010. 111(1): p. 94-103.

103. Nicolson, G.L., The Fluid-Mosaic Model of Membrane Structure: Still relevant to understanding the structure, function and dynamics of biological membranes after more than 40years. Biochim Biophys Acta, 2013.

104. Lodish H., B.A., Zipursky SL., et al., Molecular Cell Biology 4th edition, ed. W.H. Freeman. 2000, New York.

105. Shi, Z. and T. Baumgart, Dynamics and instabilities of lipid bilayer membrane shapes. Adv Colloid Interface Sci, 2014. 
106. Bogdanov, M., W. Dowhan, and H. Vitrac, Lipids and topological rules governing membrane protein assembly. Biochim Biophys Acta, 2013. 1843(8): p. 1475-1488.

107. Komura, S. and D. Andelman, Physical aspects of heterogeneities in multi-component lipid membranes. Adv Colloid Interface Sci, 2014.

108. Mouritsen, O.G., Model answers to lipid membrane questions. Cold Spring Harb Perspect Biol, 2011. 3(9): p. a004622.

109. Singer, S.J., A fluid lipid-globular protein mosaic model of membrane structure. Ann N Y Acad Sci, 1972. 195: p. 16-23.

110. http://melhorbiologia.blogspot.com.es/2012/11/membrana-plasmatica.html.

111.

http://eportfoliosusana.webnode.pt/products/obten\%C3\%A7\%C3\%A30\%20de \%20materia\%20pelos\%20seres\%20heterotroficos/http://www.personal.kent.edu/ cea rley/ChemWrld/lipids/lipids.htm

112. http://www.expertsmind.com/questions/fluid-mosaic-model-30116225.aspx.

113. Bagatolli, L.A. and O.G. Mouritsen, Is the fluid mosaic (and the accompanying raft hypothesis) a suitable model to describe fundamental features of biological membranes? What may be missing? Front Plant Sci, 2013. 4: p. 457.

114. Goni, F.M., The basic structure and dynamics of cell membranes: An update of the Singer-Nicolson model. Biochim Biophys Acta, 2014.

115. Morange, M., What history tells us XXX. The emergence of the fluid mosaic model of membranes. J Biosci, 2013. 38(1): p. 3-7.

116. Engelman, D.M., Membranes are more mosaic than fluid. Nature, 2005. 438(7068): p. 578-80.

117. Yalovsky, S., M. Rodr Guez-Concepcion, and W. Gruissem, Lipid modifications of proteins - slipping in and out of membranes. Trends Plant Sci, 1999. 4(11): p. 439-445.

118. Campelo, F., et al., Helfrich model of membrane bending: From Gibbs theory of liquid interfaces to membranes as thick anisotropic elastic layers. Adv Colloid Interface Sci, 2014.

119. Mouritsen, O.G., Lipids, curvature, and nano-medicine. Eur J Lipid Sci Technol, 2011. 113(10): p. 1174-1187.

120. Contreras, F.X., et al., Transbilayer (flip-flop) lipid motion and lipid scrambling in membranes. FEBS Lett, 2010. 584(9): p. 1779-86.

121. Gummadi, S.N. and K.S. Kumar, The mystery of phospholipid flip-flop in biogenic membranes. Cell Mol Biol Lett, 2005. 10(1): p. 101-21.

122. Semrau, S., et al., Membrane-mediated interactions measured using membrane domains. Biophys J, 2009. 96(12): p. 4906-15.

123. Eeman, M.a.D., M., From biological membranes to biomimetic model membranes. Biotechmol.Agrom.Soc.Environ., 2010: p. 719-736.

124. Magee, T. and M.C. Seabra, Fatty acylation and prenylation of proteins: what's hot in fat. Curr Opin Cell Biol, 2005. 17(2): p. 190-6.

125. Pechlivanis, M. and J. Kuhlmann, Hydrophobic modifications of Ras proteins by isoprenoid groups and fatty acids--More than just membrane anchoring. Biochim Biophys Acta, 2006. 1764(12): p. 1914-31.

126. Corbalan-Garcia, S. and J.C. Gomez-Fernandez, Signaling through C2 domains: more than one lipid target. Biochim Biophys Acta, 2014. 1838(6): p. 1536-47.

127. Lhor, M., et al., Comparison between the behavior of different hydrophobic peptides allowing membrane anchoring of proteins. Adv Colloid Interface Sci, 2014.

128. Resh, M.D., Targeting protein lipidation in disease. Trends Mol Med, 2012. 18(4): p. 206-14.

129. Granger, E., et al., The role of the cytoskeleton and molecular motors in endosomal dynamics. Semin Cell Dev Biol, 2014. 31C: p. 20-29. 
130. McMorran, L.M., D.J. Brockwell, and S.E. Radford, Mechanistic studies of the biogenesis and folding of outer membrane proteins in vitro and in vivo: What have we learned to date? Arch Biochem Biophys, 2014.

131. Head, B.P., H.H. Patel, and P.A. Insel, Interaction of membrane/lipid rafts with the cytoskeleton: impact on signaling and function: membrane/lipid rafts, mediators of cytoskeletal arrangement and cell signaling. Biochim Biophys Acta, 2013. 1838(2): p. 532-45.

132. Clary, D.O. and J.E. Rothman, Purification of three related peripheral membrane proteins needed for vesicular transport. J Biol Chem, 1990. 265(17): p. 10109-17.

133. Kahya, N., Targeting membrane proteins to liquid-ordered phases: molecular selforganization explored by fluorescence correlation spectroscopy. Chem Phys Lipids, 2006. 141(1-2): p. 158-68.

134. Lee, A.G., How lipids affect the activities of integral membrane proteins. Biochim Biophys Acta, 2004. 1666(1-2): p. 62-87.

135. Rossy, J., Y. Ma, and K. Gaus, The organisation of the cell membrane: do proteins rule lipids? Curr Opin Chem Biol, 2014. 20C: p. 54-59.

136. Yeagle, P.L., Non-covalent binding of membrane lipids to membrane proteins. Biochim Biophys Acta, 2013. 1838(6): p. 1548-59.

137. Ernst, A.M. and B. Brugger, Sphingolipids as modulators of membrane proteins. Biochim Biophys Acta, 2013. 1841(5): p. 665-70.

138. https://wikispaces.psu.edu/display/Biol230WFall09/Membrane +Structure+and+Function.

139. http://quizlet.com/3043074/cell-membranes-flash-cards.

140. van Meer, G., D.R. Voelker, and G.W. Feigenson, Membrane lipids: where they are and how they behave. Nat Rev Mol Cell Biol, 2008. 9(2): p. 112-24.

141. Cronan, J.E., Jr. and E.P. Gelmann, Physical properties of membrane lipids: biological relevance and regulation. Bacteriol Rev, 1975. 39(3): p. 232-56.

142. Fave, G., T.C. Coste, and M. Armand, Physicochemical properties of lipids: new strategies to manage fatty acid bioavailability. Cell Mol Biol (Noisy-le-grand), 2004. 50(7): p. 815-31.

143. Marangoni, A.G., physical properties of lipids, ed. T.F. Inc. 2002.

144. Fahy, E., et al., A comprehensive classification system for lipids. J Lipid Res, 2005. 46(5): p. 839-61.

145. Pike, L.J., et al., Lipid rafts are enriched in arachidonic acid and plasmenylethanolamine and their composition is independent of caveolin-1 expression: a quantitative electrospray ionization/mass spectrometric analysis. Biochemistry, 2002. 41(6): p. 2075-88.

146. Weete, J.D., Acylglycerides, Glycosylglycerides, and Simple Esters, in Fungal Lipid Biochemistry S. US, Editor. 1974. p. 209-238.

147. Roth, M.G. and P.C. Sternweis, The role of lipid signaling in constitutive membrane traffic. Curr Opin Cell Biol, 1997. 9(4): p. 519-26.

148. Kim, H.Y., B.X. Huang, and A.A. Spector, Phosphatidy/serine in the Brain: Metabolism and Function. Prog Lipid Res, 2014.

149. Schink, K.O., C. Raiborg, and H. Stenmark, Phosphatidylinositol 3-phosphate, a lipid that regulates membrane dynamics, protein sorting and cell signalling. Bioessays, 2013. 35(10): p. 900-12.

150. Larijani, B. and D.L. Poccia, Effects of phosphoinositides and their derivatives on membrane morphology and function. Curr Top Microbiol Immunol, 2012. 362: p. 99110.

151. Oliver, P.M., et al., Localization of anionic phospholipids in Escherichia coli cells. J Bacteriol, 2014. 
152. Merrill, A.H., Jr., Sphingolipid and glycosphingolipid metabolic pathways in the era of sphingolipidomics. Chem Rev, 2011. 111(10): p. 6387-422.

153. Ishibashi, Y., A. Kohyama-Koganeya, and Y. Hirabayashi, New insights on glucosylated lipids: metabolism and functions. Biochim Biophys Acta, 2013. 1831(9): p. 1475-85.

154. Sandhoff, K. and K. Harzer, Gangliosides and gangliosidoses: principles of molecular and metabolic pathogenesis. J Neurosci, 2013. 33(25): p. 10195-208.

155. Schnaar, R.L., R. Gerardy-Schahn, and H. Hildebrandt, Sialic acids in the brain: gangliosides and polysialic acid in nervous system development, stability, disease, and regeneration. Physiol Rev, 2014. 94(2): p. 461-518.

156. Ariga, T. and R.K. Yu, The role of globo-series glycolipids in neuronal cell differentiation-a review. Neurochem Res, 1998. 23(3): p. 291-303.

157. Castro, B.M., M. Prieto, and L.C. Silva, Ceramide: a simple sphingolipid with unique biophysical properties. Prog Lipid Res, 2014. 54: p. 53-67.

158. Ohvo-Rekila, H., et al., Cholesterol interactions with phospholipids in membranes. Prog Lipid Res, 2002. 41(1): p. 66-97.

159. Slotte, J.P., Biological functions of sphingomyelins. Prog Lipid Res, 2013. 52(4): p. 42437.

160. Chakraborty, M. and X.C. Jiang, Sphingomyelin and its role in cellular signaling. Adv Exp Med Biol, 2013. 991: p. 1-14.

161. Taniguchi, M. and T. Okazaki, The role of sphingomyelin and sphingomyelin synthases in cell death, proliferation and migration-from cell and animal models to human disorders. Biochim Biophys Acta, 2013. 1841(5): p. 692-703.

162. Crane, J.M. and L.K. Tamm, Role of cholesterol in the formation and nature of lipid rafts in planar and spherical model membranes. Biophys J, 2004. 86(5): p. 2965-79.

163. Bieberich, E., It's a lipid's world: bioactive lipid metabolism and signaling in neural stem cell differentiation. Neurochem Res, 2012. 37(6): p. 1208-29.

164. http://images.flatworldknowledge.com/ballgob/ballgob-fig17 009.jpg.

165. Kraut, R., Roles of sphingolipids in Drosophila development and disease. J Neurochem, 2011. 116(5): p. 764-78.

166. Goni, F.M. and A. Alonso, Effects of ceramide and other simple sphingolipids on membrane lateral structure. Biochim Biophys Acta, 2009. 1788(1): p. 169-77.

167. Guan, X.L., et al., Biochemical membrane lipidomics during Drosophila development. Dev Cell, 2012. 24(1): p. 98-111.

168. Zhai, L., D. Chaturvedi, and S. Cumberledge, Drosophila wnt-1 undergoes a hydrophobic modification and is targeted to lipid rafts, a process that requires porcupine. J Biol Chem, 2004. 279(32): p. 33220-7.

169. Hebbar, S., et al., A fluorescent sphingolipid binding domain peptide probe interacts with sphingolipids and cholesterol-dependent raft domains. J Lipid Res, 2008. 49(5): p. 1077-89.

170. Stuermer, C.A., et al., Glycosylphosphatidyl inositol-anchored proteins and fyn kinase assemble in noncaveolar plasma membrane microdomains defined by reggie-1 and -2 . Mol Biol Cell, 2001. 12(10): p. 3031-45.

171. Hoehne, M., et al., Loss- and gain-of-function analysis of the lipid raft proteins Reggie/Flotillin in Drosophila: they are posttranslationally regulated, and misexpression interferes with wing and eye development. Mol Cell Neurosci, 2005. 30(3): p. 326-38.

172. Karpen, H.E., et al., The sonic hedgehog receptor patched associates with caveolin-1 in cholesterol-rich microdomains of the plasma membrane. J Biol Chem, 2001. 276(22): p. 19503-11.

173. Rietveld, A., et al., Association of sterol- and glycosylphosphatidylinositol-linked proteins with Drosophila raft lipid microdomains. J Biol Chem, 1999. 274(17): p. 1204954. 
174. Rodrigues, F., I. Schmidt, and C. Klambt, Comparing peripheral glial cell differentiation in Drosophila and vertebrates. Cell Mol Life Sci, 2010. 68(1): p. 55-69.

175. Schmitt, F., et al., A plural role for lipids in motor neuron diseases: energy, signaling and structure. Front Cell Neurosci, 2014. 8: p. 25.

176. Shevchenko, A. and K. Simons, Lipidomics: coming to grips with lipid diversity. Nat Rev Mol Cell Biol, 2010. 11(8): p. 593-8.

177. Wenk, M.R., Lipidomics: new tools and applications. Cell, 2010. 143(6): p. 888-95.

178. Simons, K. and J.L. Sampaio, Membrane organization and lipid rafts. Cold Spring Harb Perspect Biol, 2011. 3(10): p. a004697.

179. Sprong, H., P. van der Sluijs, and G. van Meer, How proteins move lipids and lipids move proteins. Nat Rev Mol Cell Biol, 2001. 2(7): p. 504-13.

180. Mouritsen, O.G. and M.J. Zuckermann, What's so special about cholesterol? Lipids, 2004. 39(11): p. 1101-13.

181. Ye, J. and R.A. DeBose-Boyd, Regulation of cholesterol and fatty acid synthesis. Cold Spring Harb Perspect Biol, 2011. 3(7).

182. Todd P.W. McMullen, R.N.A.H.L., Ronald N. McElhaney, Cholesterol-phospholipid interactions, the liquid-ordered phase and lipid rafts in model and biological membranes. Cholesterol-phospholipid interactions, the liquid-ordered phase and lipid rafts in model and biological membranes, 2004. 8(6): p. 459-468.

183. Pomorski, T., et al., Tracking down lipid flippases and their biological functions. J Cell Sci, 2004. 117(Pt 6): p. 805-13.

184. Ryan, V.H., et al., Coordination of Gene Expression of Arachidonic and Docosahexaenoic Acid Cascade Enzymes during Human Brain Development and Aging. PLoS One, 2014. 9(6): p. e100858.

185. Burkhardt, U., et al., Impaired brain development and reduced cognitive function in phospholipase D-deficient mice. Neurosci Lett, 2014. 572: p. 48-52.

186. Collins, M.A., et al., Alcohol, Phospholipase A-associated Neuroinflammation, and omega3 Docosahexaenoic Acid Protection. Mol Neurobiol, 2014.

187. Bae, E.J., et al., Phospholipase D1 regulates autophagic flux and clearance of alphasynuclein aggregates. Cell Death Differ, 2014. 21(7): p. 1132-41.

188. Jang, H.J., et al., Phospholipase C-gamma1 involved in brain disorders. Adv Biol Regul, 2012. 53(1): p. 51-62.

189. Allyson, J., et al., Maintenance of synaptic stability requires calcium-independent phospholipase A(2) activity. Neural Plast, 2012. 2012: p. 569149.

190. Rapoport, S.I., E. Ramadan, and M. Basselin, Docosahexaenoic acid (DHA) incorporation into the brain from plasma, as an in vivo biomarker of brain DHA metabolism and neurotransmission. Prostaglandins Other Lipid Mediat, 2011. 96(1-4): p. 109-13.

191. Basselin, M., E. Ramadan, and S.I. Rapoport, Imaging brain signal transduction and metabolism via arachidonic and docosahexaenoic acid in animals and humans. Brain Res Bull, 2011. 87(2-3): p. 154-71.

192. Hannun, Y.A. and L.M. Obeid, Principles of bioactive lipid signalling: lessons from sphingolipids. Nat Rev Mol Cell Biol, 2008. 9(2): p. 139-50.

193. Riehle, R.D., S. Cornea, and A. Degterev, Role of phosphatidylinositol 3,4,5trisphosphate in cell signaling. Adv Exp Med Biol, 2013. 991: p. 105-39.

194. http://biowiki.ucdavis.edu/Biochemistry/Lipids/Lipids as Biological Signals.

195. van Meer, G. and K. Simons, Lipid polarity and sorting in epithelial cells. J Cell Biochem, 1988. 36(1): p. 51-8.

196. Brown, D.A. and J.K. Rose, Sorting of GPI-anchored proteins to glycolipid-enriched membrane subdomains during transport to the apical cell surface. Cell, 1992. 68(3): p. 533-44. 
197. Simons, K. and E. Ikonen, Functional rafts in cell membranes. Nature, 1997. 387(6633): p. 569-72.

198. Munro, S., Lipid rafts: elusive or illusive? Cell, 2003. 115(4): p. 377-88.

199. Brown, D.A. and E. London, Functions of lipid rafts in biological membranes. Annu Rev Cell Dev Biol, 1998. 14: p. 111-36.

200. Lingwood, D. and K. Simons, Lipid rafts as a membrane-organizing principle. Science, 2010. 327(5961): p. 46-50.

201. Zurzolo, C., G. van Meer, and S. Mayor, The order of rafts. Conference on microdomains, lipid rafts and caveolae. EMBO Rep, 2003. 4(12): p. 1117-21.

202. Brown, D.A. and K. Jacobson, Microdomains, lipid rafts and caveolae (San Feliu de Guixols, Spain, 19-24 May 2001). Traffic, 2001. 2(9): p. 668-72.

203. Gkantiragas, I., et al., Sphingomyelin-enriched microdomains at the Golgi complex. Mol Biol Cell, 2001. 12(6): p. 1819-33.

204. Smart, E.J., et al., A detergent-free method for purifying caveolae membrane from tissue culture cells. Proc Natl Acad Sci U S A, 1995. 92(22): p. 10104-8.

205. Schnitzer, J.E., P. Oh, and D.P. McIntosh, Role of GTP hydrolysis in fission of caveolae directly from plasma membranes. Science, 1996. 274(5285): p. 239-42.

206. Bist, A., P.E. Fielding, and C.J. Fielding, Two sterol regulatory element-like sequences mediate up-regulation of caveolin gene transcription in response to low density lipoprotein free cholesterol. Proc Natl Acad Sci U S A, 1997. 94(20): p. 10693-8.

207. Murata, M., et al., VIP21/caveolin is a cholesterol-binding protein. Proc Natl Acad Sci U S A, 1995. 92(22): p. 10339-43.

208. Anderson, H.A., Y. Chen, and L.C. Norkin, MHC class I molecules are enriched in caveolae but do not enter with simian virus 40. J Gen Virol, 1998. 79 ( Pt 6): p. 1469-77.

209. Smart, E.J., et al., Caveolins, liquid-ordered domains, and signal transduction. Mol Cell Biol, 1999. 19(11): p. 7289-304.

210. Jin, S., et al., Lipid raft redox signaling: molecular mechanisms in health and disease. Antioxid Redox Signal, 2011. 15(4): p. 1043-83.

211. Shvets, E., A. Ludwig, and B.J. Nichols, News from the caves: update on the structure and function of caveolae. Curr Opin Cell Biol, 2014. 29C: p. 99-106.

212. Bickel, P.E., et al., Flotillin and epidermal surface antigen define a new family of caveolae-associated integral membrane proteins. J Biol Chem, 1997. 272(21): p. 13793802.

213. Lang, D.M., et al., Identification of reggie-1 and reggie-2 as plasmamembraneassociated proteins which cocluster with activated GPI-anchored cell adhesion molecules in non-caveolar micropatches in neurons. J Neurobiol, 1998. 37(4): p. 50223.

214. Paratcha, G. and C.F. Ibanez, Lipid rafts and the control of neurotrophic factor signaling in the nervous system: variations on a theme. Curr Opin Neurobiol, 2002. 12(5): p. 5429.

215. Foster, L.J., C.L. De Hoog, and M. Mann, Unbiased quantitative proteomics of lipid rafts reveals high specificity for signaling factors. Proc Natl Acad Sci U S A, 2003. 100(10): p. 5813-8.

216. Patterson, S.I., Posttranslational protein S-palmitoylation and the compartmentalization of signaling molecules in neurons. Biol Res, 2002. 35(2): p. 13950.

217. Linder, M.E. and R.J. Deschenes, Palmitoylation: policing protein stability and traffic. Nat Rev Mol Cell Biol, 2007. 8(1): p. 74-84.

218. Nadolski, M.J. and M.E. Linder, Protein lipidation. FEBS J, 2007. 274(20): p. 5202-10.

219. Zajchowski, L.D. and S.M. Robbins, Lipid rafts and little caves. Compartmentalized signalling in membrane microdomains. Eur J Biochem, 2002. 269(3): p. 737-52. 
220. Hirsch, T.Z., et al., PrP signalling in neurons: From basics to clinical challenges. Biochimie, 2014.

221. Rege, T.A. and J.S. Hagood, Thy-1 as a regulator of cell-cell and cell-matrix interactions in axon regeneration, apoptosis, adhesion, migration, cancer, and fibrosis. FASEB J, 2006. 20(8): p. 1045-54.

222. Puig, B., H. Altmeppen, and M. Glatzel, The GPI-anchoring of PrP: Implications in sorting and pathogenesis. Prion, 2014. 8(1).

223. Lewis, V. and N.M. Hooper, The role of lipid rafts in prion protein biology. Front Biosci (Landmark Ed), 2011. 16: p. 151-68.

224. Salzer, U. and R. Prohaska, Stomatin, flotillin-1, and flotillin-2 are major integral proteins of erythrocyte lipid rafts. Blood, 2001. 97(4): p. 1141-3.

225. de Marco, M.C., et al., BENE, a novel raft-associated protein of the MAL proteolipid family, interacts with caveolin-1 in human endothelial-like ECV304 cells. J Biol Chem, 2001. 276(25): p. 23009-17.

226. McNiven, M.A., et al., Regulated interactions between dynamin and the actin-binding protein cortactin modulate cell shape. J Cell Biol, 2000. 151(1): p. 187-98.

227. Huttner, W.B. and A. Schmidt, Lipids, lipid modification and lipid-protein interaction in membrane budding and fission--insights from the roles of endophilin A1 and synaptophysin in synaptic vesicle endocytosis. Curr Opin Neurobiol, 2000. 10(5): p. 54351.

228. Hinzpeter, A., et al., Membrane cholesterol content modulates CIC-2 gating and sensitivity to oxidative stress. J Biol Chem, 2007. 282(4): p. 2423-32.

229. Stancevic, B. and R. Kolesnick, Ceramide-rich platforms in transmembrane signaling. FEBS Lett, 2010. 584(9): p. 1728-40.

230. Hakomori, S. and K. Handa, Glycosphingolipid-dependent cross-talk between glycosynapses interfacing tumor cells with their host cells: essential basis to define tumor malignancy. FEBS Lett, 2002. 531(1): p. 88-92.

231. Heffer-Lauc, M., et al., Membrane redistribution of gangliosides and glycosylphosphatidylinositol-anchored proteins in brain tissue sections under conditions of lipid raft isolation. Biochim Biophys Acta, 2005. 1686(3): p. 200-8.

232. Sonnino, S., et al., Gangliosides as components of lipid membrane domains. Glycobiology, 2007. 17(1): p. 1R-13R.

233. Sonnino, S., et al., Gangliosides as regulators of cell signaling: ganglioside-protein interactions or ganglioside-driven membrane organization? J Neurochem, 2013. 124(4): p. 432-5.

234. Galbiati, F., B. Razani, and M.P. Lisanti, Emerging themes in lipid rafts and caveolae. Cell, 2001. 106(4): p. 403-11.

235. Patel, H.H. and P.A. Insel, Lipid rafts and caveolae and their role in compartmentation of redox signaling. Antioxid Redox Signal, 2009. 11(6): p. 1357-72.

236. Douglass, A.D. and R.D. Vale, Single-molecule microscopy reveals plasma membrane microdomains created by protein-protein networks that exclude or trap signaling molecules in T cells. Cell, 2005. 121(6): p. 937-50.

237. Anderson, R.G. and K. Jacobson, A role for lipid shells in targeting proteins to caveolae, rafts, and other lipid domains. Science, 2002. 296(5574): p. 1821-5.

238. Abrami, L., et al., Cross-talk between caveolae and glycosylphosphatidylinositol-rich domains. J Biol Chem, 2001. 276(33): p. 30729-36.

239. Pike, L.J., Lipid rafts: heterogeneity on the high seas. Biochem J, 2004. 378(Pt 2): p. 281-92.

240. Pike, L.J., Rafts defined: a report on the Keystone Symposium on Lipid Rafts and Cell Function. J Lipid Res, 2006. 47(7): p. 1597-8.

241. Seeds, M.C. and D.A. Bass, Regulation and metabolism of arachidonic acid. Clin Rev Allergy Immunol, 1999. 17(1-2): p. 5-26. 
242. Contreras, F.X., et al., Specificity of intramembrane protein-lipid interactions. Cold Spring Harb Perspect Biol, 2011. 3(6).

243. Lichtenberg, D., F.M. Goni, and H. Heerklotz, Detergent-resistant membranes should not be identified with membrane rafts. Trends Biochem Sci, 2005. 30(8): p. 430-6.

244. Staneva, G., et al., Making a tool of an artifact: the application of photoinduced Lo domains in giant unilamellar vesicles to the study of Lo/Ld phase spinodal decomposition and its modulation by the ganglioside GM1. Langmuir, 2011. 27(24): p. 15074-82.

245. Chen, Y., et al., Cold induces micro- and nano-scale reorganization of lipid raft markers at mounds of T-cell membrane fluctuations. PLoS One, 2009. 4(4): p. e5386.

246. Friedrichson, T. and T.V. Kurzchalia, Microdomains of GPI-anchored proteins in living cells revealed by crosslinking. Nature, 1998. 394(6695): p. 802-5.

247. Reeves, V.L., C.M. Thomas, and E.J. Smart, Lipid rafts, caveolae and GPI-linked proteins. Adv Exp Med Biol, 2012. 729: p. 3-13.

248. Jacobson, K., O.G. Mouritsen, and R.G. Anderson, Lipid rafts: at a crossroad between cell biology and physics. Nat Cell Biol, 2007. 9(1): p. 7-14.

249. Heffer-Lauc, M., et al., Effects of detergents on the redistribution of gangliosides and GPI-anchored proteins in brain tissue sections. J Histochem Cytochem, 2007. 55(8): p. 805-12.

250. Pizzo, P. and A. Viola, Lymphocyte lipid rafts: structure and function. Curr Opin Immunol, 2003. 15(3): p. 255-60.

251. Prior, I.A., R.G. Parton, and J.F. Hancock, Observing cell surface signaling domains using electron microscopy. Sci STKE, 2003. 2003(177): p. PL9.

252. Shogomori, H. and D.A. Brown, Use of detergents to study membrane rafts: the good, the bad, and the ugly. Biol Chem, 2003. 384(9): p. 1259-63.

253. George, S., et al., A novel approach to examining compositional heterogeneity of detergent-resistant lipid rafts. Immunol Cell Biol, 2006. 84(2): p. 192-202.

254. Brown, D.A., Lipid rafts, detergent-resistant membranes, and raft targeting signals. Physiology (Bethesda), 2006. 21: p. 430-9.

255. Skwarek, M., Recent controversy surrounding lipid rafts. Arch Immunol Ther Exp (Warsz), 2004. 52(6): p. 427-31.

256. Chamberlain, L.H., Detergents as tools for the purification and classification of lipid rafts. FEBS Lett, 2004. 559(1-3): p. 1-5.

257. Vidal, A. and T.J. McIntosh, Transbilayer peptide sorting between raft and nonraft bilayers: comparisons of detergent extraction and confocal microscopy. Biophys J, 2005. 89(2): p. 1102-8.

258. Sonnino, S. and A. Prinetti, Membrane domains and the "lipid raft" concept. Curr Med Chem. 20(1): p. 4-21.

259. Schuck, S., et al., Resistance of cell membranes to different detergents. Proc Natl Acad Sci U S A, 2003. 100(10): p. 5795-800.

260. Drobnik, W., et al., Apo Al/ABCA1-dependent and HDL3-mediated lipid efflux from compositionally distinct cholesterol-based microdomains. Traffic, 2002. 3(4): p. 268-78.

261. Persaud-Sawin, D.A., S. Lightcap, and G.J. Harry, Isolation of rafts from mouse brain tissue by a detergent-free method. J Lipid Res, 2009. 50(4): p. 759-67.

262. Maekawa, S., S. lino, and S. Miyata, Molecular characterization of the detergentinsoluble cholesterol-rich membrane microdomain (raft) of the central nervous system. Biochim Biophys Acta, 2003. 1610(2): p. 261-70.

263. Ohtani, Y., et al., Differential effects of alpha-, beta- and gamma-cyclodextrins on human erythrocytes. Eur J Biochem, 1989. 186(1-2): p. 17-22.

264. Bang, B., R. Gniadecki, and B. Gajkowska, Disruption of lipid rafts causes apoptotic cell death in HaCaT keratinocytes. Exp Dermatol, 2005. 14(4): p. 266-72. 
265. Gniadecki, R., Depletion of membrane cholesterol causes ligand-independent activation of Fas and apoptosis. Biochem Biophys Res Commun, 2004. 320(1): p. 165-9.

266. Algeciras-Schimnich, A., et al., Molecular ordering of the initial signaling events of CD95. Mol Cell Biol, 2002. 22(1): p. 207-20.

267. Li, N., et al., Monocyte lipid rafts contain proteins implicated in vesicular trafficking and phagosome formation. Proteomics, 2003. 3(4): p. 536-48.

268. Li, X.M., et al., Sterol structure and sphingomyelin acyl chain length modulate lateral packing elasticity and detergent solubility in model membranes. Biophys J, 2003. 85(6): p. 3788-801.

269. Hofsass, C., E. Lindahl, and O. Edholm, Molecular dynamics simulations of phospholipid bilayers with cholesterol. Biophys J, 2003. 84(4): p. 2192-206.

270. Niemela, P., M.T. Hyvonen, and I. Vattulainen, Structure and dynamics of sphingomyelin bilayer: insight gained through systematic comparison to phosphatidylcholine. Biophys J, 2004. 87(5): p. 2976-89.

271. Niemela, P.S., M.T. Hyvonen, and I. Vattulainen, Influence of chain length and unsaturation on sphingomyelin bilayers. Biophys J, 2006. 90(3): p. 851-63.

272. Niemela, P.S., M.T. Hyvonen, and I. Vattulainen, Atom-scale molecular interactions in lipid raft mixtures. Biochim Biophys Acta, 2009. 1788(1): p. 122-35.

273. Pandit, S.A., et al., Sphingomyelin-cholesterol domains in phospholipid membranes: atomistic simulation. Biophys J, 2004. 87(2): p. 1092-100.

274. Zaraiskaya, T. and K.R. Jeffrey, Molecular dynamics simulations and $2 H$ NMR study of the GalCer/DPPG lipid bilayer. Biophys J, 2005. 88(6): p. 4017-31.

275. Bhide, S.Y., Z. Zhang, and M.L. Berkowitz, Molecular dynamics simulations of SOPS and sphingomyelin bilayers containing cholesterol. Biophys J, 2007. 92(4): p. 1284-95.

276. Aittoniemi, J., et al., Insight into the putative specific interactions between cholesterol, sphingomyelin, and palmitoyl-oleoyl phosphatidylcholine. Biophys J, 2007. 92(4): p. 1125-37.

277. Komura, S. and D. Andelman, Physical aspects of heterogeneities in multi-component lipid membranes. Adv Colloid Interface Sci, 2014. 208: p. 34-46.

278. Dluhy, R.A., et al., Interaction of dipalmitoy/phosphatidylcholine and dimyristoy/phosphatidy/choline-d54 mixtures with glycophorin. A fourier transform infrared investigation. Biochemistry, 1983. 22(5): p. 1170-7.

279. Hooper, N.M., Detergent-insoluble glycosphingolipid/cholesterol-rich membrane domains, lipid rafts and caveolae (review). Mol Membr Biol, 1999. 16(2): p. 145-56.

280. El Kirat, K. and S. Morandat, Cholesterol modulation of membrane resistance to Triton $X-100$ explored by atomic force microscopy. Biochim Biophys Acta, 2007. 1768(9): $p$. 2300-9.

281. Chiantia, S., et al., Role of ceramide in membrane protein organization investigated by combined AFM and FCS. Biochim Biophys Acta, 2008. 1778(5): p. 1356-64.

282. Pralle, A., et al., Sphingolipid-cholesterol rafts diffuse as small entities in the plasma membrane of mammalian cells. J Cell Biol, 2000. 148(5): p. 997-1008.

283. Gulbins, E., Highlight: sphingolipids - signals and disease. Biol Chem, 2008. 389(11): p. 1347-8.

284. Lingwood, D., et al., Lipid rafts as functional heterogeneity in cell membranes. Biochem Soc Trans, 2009. 37(Pt 5): p. 955-60.

285. Brugger, B., et al., Quantitative analysis of biological membrane lipids at the low picomole level by nano-electrospray ionization tandem mass spectrometry. Proc Natl Acad Sci U S A, 1997. 94(6): p. 2339-44.

286. Klymchenko, A.S. and R. Kreder, Fluorescent probes for lipid rafts: from model membranes to living cells. Chem Biol, 2013. 21(1): p. 97-113.

287. Pike, L.J., Lipid rafts: bringing order to chaos. J Lipid Res, 2003. 44(4): p. 655-67. 
288. Kirkham, M. and R.G. Parton, Clathrin-independent endocytosis: new insights into caveolae and non-caveolar lipid raft carriers. Biochim Biophys Acta, 2005. 1746(3): p. 349-63.

289. Simons, K. and G. van Meer, Lipid sorting in epithelial cells. Biochemistry, 1988. 27(17): p. 6197-202.

290. Seveau, S., et al., Cytoskeleton-dependent membrane domain segregation during neutrophil polarization. Mol Biol Cell, 2001. 12(11): p. 3550-62.

291. Cheng, Z.J., et al., Membrane microdomains, caveolae, and caveolar endocytosis of sphingolipids. Mol Membr Biol, 2006. 23(1): p. 101-10.

292. Mukherjee, S., T.T. Soe, and F.R. Maxfield, Endocytic sorting of lipid analogues differing solely in the chemistry of their hydrophobic tails. J Cell Biol, 1999. 144(6): p. 1271-84.

293. Levental, I., et al., Palmitoylation regulates raft affinity for the majority of integral raft proteins. Proc Natl Acad Sci U S A, 2010. 107(51): p. 22050-4.

294. Tsui-Pierchala, B.A., et al., Lipid rafts in neuronal signaling and function. Trends Neurosci, 2002. 25(8): p. 412-7.

295. Gielen, E., et al., Rafts in oligodendrocytes: evidence and structure-function relationship. Glia, 2006. 54(6): p. 499-512.

296. Debruin, L.S. and G. Harauz, White matter rafting--membrane microdomains in myelin. Neurochem Res, 2007. 32(2): p. 213-28.

297. George, K.S. and S. Wu, Lipid raft: $A$ floating island of death or survival. Toxicol Appl Pharmacol, 2012. 259(3): p. 311-9.

298. Chamberlain, L.H., et al., The synaptic vesicle protein, cysteine-string protein, is associated with the plasma membrane in 3T3-L1 adipocytes and interacts with syntaxin 4. J Cell Sci, 2001. 114(Pt 2): p. 445-55.

299. Tillman, T.S. and M. Cascio, Effects of membrane lipids on ion channel structure and function. Cell Biochem Biophys, 2003. 38(2): p. 161-90.

300. Landman, N. and T.W. Kim, Got RIP? Presenilin-dependent intramembrane proteolysis in growth factor receptor signaling. Cytokine Growth Factor Rev, 2004. 15(5): p. 33751.

301. Vetrivel, K.S., et al., Spatial segregation of gamma-secretase and substrates in distinct membrane domains. J Biol Chem, 2005. 280(27): p. 25892-900.

302. Hammond, A.T., et al., Crosslinking a lipid raft component triggers liquid ordered-liquid disordered phase separation in model plasma membranes. Proc Natl Acad Sci U S A, 2005. 102(18): p. 6320-5.

303. Klionsky, D.J., Autophagy: from phenomenology to molecular understanding in less than a decade. Nat Rev Mol Cell Biol, 2007. 8(11): p. 931-7.

304. Tanida, I., Autophagosome formation and molecular mechanism of autophagy. Antioxid Redox Signal, 2010. 14(11): p. 2201-14.

305. Mulakkal, N.C., et al., Autophagy in : From Historical Studies to Current Knowledge. Biomed Res Int, 2014. 2014: p. 273473.

306. Shen, H.M. and N. Mizushima, At the end of the autophagic road: an emerging understanding of lysosomal functions in autophagy. Trends Biochem Sci, 2013. 39(2): p. 61-71.

307. Wang, C.W. and D.J. Klionsky, The molecular mechanism of autophagy. Mol Med, 2003. 9(3-4): p. 65-76.

308. Mijaljica, D., M. Prescott, and R.J. Devenish, Microautophagy in mammalian cells: revisiting a 40-year-old conundrum. Autophagy, 2011. 7(7): p. 673-82.

309. Koga, H. and A.M. Cuervo, Chaperone-mediated autophagy dysfunction in the pathogenesis of neurodegeneration. Neurobiol Dis, 2010. 43(1): p. 29-37.

310. He, C. and D.J. Klionsky, Regulation mechanisms and signaling pathways of autophagy. Annu Rev Genet, 2009. 43: p. 67-93. 
311. Nakatogawa, H., et al., Dynamics and diversity in autophagy mechanisms: lessons from yeast. Nat Rev Mol Cell Biol, 2009. 10(7): p. 458-67.

312. Yen, W.L. and D.J. Klionsky, How to live long and prosper: autophagy, mitochondria, and aging. Physiology (Bethesda), 2008. 23: p. 248-62.

313. Hain, A.U. and J. Bosch, Autophagy in Plasmodium, a multifunctional pathway? Comput Struct Biotechnol J, 2013. 8: p. e201308002.

314. Ryter, S.W., S.M. Cloonan, and A.M. Choi, Autophagy: a critical regulator of cellular metabolism and homeostasis. Mol Cells, 2013. 36(1): p. 7-16.

315. Liang, X.H., et al., Induction of autophagy and inhibition of tumorigenesis by beclin 1. Nature, 1999. 402(6762): p. 672-6.

316. Kihara, A., et al., Two distinct Vps34 phosphatidylinositol 3-kinase complexes function in autophagy and carboxypeptidase Y sorting in Saccharomyces cerevisiae. J Cell Biol, 2001. 152(3): p. 519-30.

317. Lamb, C.A., H.C. Dooley, and S.A. Tooze, Endocytosis and autophagy: Shared machinery for degradation. Bioessays, 2012. 35(1): p. 34-45.

318. Ravikumar, B., et al., Regulation of mammalian autophagy in physiology and pathophysiology. Physiol Rev, 2010. 90(4): p. 1383-435.

319. Noda, T., et al., Apg9p/Cvt7p is an integral membrane protein required for transport vesicle formation in the Cvt and autophagy pathways. J Cell Biol, 2000. 148(3): p. 46580.

320. Hailey, D.W., et al., Mitochondria supply membranes for autophagosome biogenesis during starvation. Cell, 2010. 141(4): p. 656-67.

321. Kim, J. and D.J. Klionsky, Autophagy, cytoplasm-to-vacuole targeting pathway, and pexophagy in yeast and mammalian cells. Annu Rev Biochem, 2000. 69: p. 303-42.

322. Mizushima, N., Autophagy: process and function. Genes Dev, 2007. 21(22): p. 2861-73.

323. Mizushima, N., et al., A protein conjugation system essential for autophagy. Nature, 1998. 395(6700): p. 395-8.

324. Fujita, N., et al., The Atg16L complex specifies the site of LC3 lipidation for membrane biogenesis in autophagy. Mol Biol Cell, 2008. 19(5): p. 2092-100.

325. Kaufmann, A. and T. Wollert, Scaffolding the expansion of autophagosomes. Autophagy, 2014. 10(7): p. 1343-1345.

326. Xie, Z., U. Nair, and D.J. Klionsky, Atg8 controls phagophore expansion during autophagosome formation. Mol Biol Cell, 2008. 19(8): p. 3290-8.

327. Dancourt, J. and T.J. Melia, Lipidation of the autophagy proteins LC3 and GABARAP is a membrane-curvature dependent process. Autophagy, 2014. 10(8).

328. Tanida, I., T. Ueno, and E. Kominami, LC3 and Autophagy. Methods Mol Biol, 2008. 445: p. 77-88.

329. Abada, A. and Z. Elazar, Getting ready for building: signaling and autophagosome biogenesis. EMBO Rep, 2014.

330. Lippai, M. and P. Low, The Role of the Selective Adaptor $p 62$ and Ubiquitin-Like Proteins in Autophagy. Biomed Res Int, 2014. 2014: p. 832704.

331. Wang, X., et al., Proteasome functional insufficiency in cardiac pathogenesis. Am J Physiol Heart Circ Physiol, 2011. 301(6): p. H2207-19.

332. Komatsu, M., S. Kageyama, and Y. Ichimura, p62/SQSTM1/A170: physiology and pathology. Pharmacol Res, 2012. 66(6): p. 457-62.

333. Moscat, J. and M.T. Diaz-Meco, Feedback on fat: p62-mTORC1-autophagy connections. Cell, 2011. 147(4): p. 724-7.

334. Narendra, D., et al., p62/SQSTM1 is required for Parkin-induced mitochondrial clustering but not mitophagy; VDAC1 is dispensable for both. Autophagy, 2010. 6(8): p. 1090-106.

335. Geisler, S., et al., PINK1/Parkin-mediated mitophagy is dependent on VDAC1 and p62/SQSTM1. Nat Cell Biol, 2010. 12(2): p. 119-31. 
336. Pankiv, S., et al., $p 62 / S Q S T M 1$ binds directly to Atg8/LC3 to facilitate degradation of ubiquitinated protein aggregates by autophagy. J Biol Chem, 2007. 282(33): p. 2413145.

337. Komatsu, M., et al., Constitutive autophagy: vital role in clearance of unfavorable proteins in neurons. Cell Death Differ, 2007. 14(5): p. 887-94.

338. Nezis, I.P. and I. Papassideri, Monitoring autophagy in insect eggs. Methods Enzymol, 2008. 451: p. 669-83.

339. Bitto, A., et al., p62/SQSTM1 at the interface of aging, autophagy, and disease. Age (Dordr), 2014. 36(3): p. 9626.

340. Bjorkoy, G., et al., p62/SQSTM1 forms protein aggregates degraded by autophagy and has a protective effect on huntingtin-induced cell death. J Cell Biol, 2005. 171(4): p. 603-14.

341. Lamark, T. and T. Johansen, Autophagy: links with the proteasome. Curr Opin Cell Biol, 2009. 22(2): p. 192-8.

342. Lamark, T., et al., NBR1 and p62 as cargo receptors for selective autophagy of ubiquitinated targets. Cell Cycle, 2009. 8(13): p. 1986-90.

343. Kirkin, V., et al., A role for ubiquitin in selective autophagy. Mol Cell, 2009. 34(3): p. 259-69.

344. Kirkin, V., et al., NBR1 cooperates with $p 62$ in selective autophagy of ubiquitinated targets. Autophagy, 2009. 5(5): p. 732-3.

345. Webb, J.L., B. Ravikumar, and D.C. Rubinsztein, Microtubule disruption inhibits autophagosome-lysosome fusion: implications for studying the roles of aggresomes in polyglutamine diseases. Int J Biochem Cell Biol, 2004. 36(12): p. 2541-50.

346. Noda, T. and Y. Ohsumi, Tor, a phosphatidylinositol kinase homologue, controls autophagy in yeast. J Biol Chem, 1998. 273(7): p. 3963-6.

347. Lorin, S., et al., Evidence for the interplay between JNK and p53-DRAM signalling pathways in the regulation of autophagy. Autophagy, 2009. 6(1): p. 153-4.

348. Sui, X., et al., p38 and JNK MAPK pathways control the balance of apoptosis and autophagy in response to chemotherapeutic agents. Cancer Lett, 2013. 344(2): p. 1749.

349. Haberzettl, P. and B.G. Hill, Oxidized lipids activate autophagy in a JNK-dependent manner by stimulating the endoplasmic reticulum stress response. Redox Biol, 2013. 1(1): p. 56-64.

350. Petrovski, G. and D.K. Das, Does autophagy take a front seat in lifespan extension? J Cell Mol Med, 2010. 14(11): p. 2543-51.

351. Tracy, K. and E.H. Baehrecke, The role of autophagy in Drosophila metamorphosis. Curr Top Dev Biol, 2013. 103: p. 101-25.

352. Jin, M. and D.J. Klionsky, Regulation of autophagy: Modulation of the size and number of autophagosomes. FEBS Lett. 588(15): p. 2457-2463.

353. de Duve, C., The peroxisome in retrospect. Ann N Y Acad Sci, 1996. 804: p. 1-10.

354. DiCiccio, J.E. and B.E. Steinberg, Lysosomal $\mathrm{pH}$ and analysis of the counter ion pathways that support acidification. J Gen Physiol, 2011. 137(4): p. 385-90.

355. Doherty, G.J. and H.T. McMahon, Mechanisms of endocytosis. Annu Rev Biochem, 2009. 78: p. 857-902.

356. Sorkin, A. and M. von Zastrow, Endocytosis and signalling: intertwining molecular networks. Nat Rev Mol Cell Biol, 2009. 10(9): p. 609-22.

357. Hohn, A. and T. Grune, Lipofuscin: formation, effects and role of macroautophagy. Redox Biol, 2013. 1(1): p. 140-4.

358. Appelqvist, H., et al., The lysosome: from waste bag to potential therapeutic target. J Mol Cell Biol, 2013. 5(4): p. 214-26.

359. Huynh, C., et al., Defective lysosomal exocytosis and plasma membrane repair in Chediak-Higashi/beige cells. Proc Natl Acad Sci U S A, 2004. 101(48): p. 16795-800. 
360. McNeil, P.L. and T. Kirchhausen, An emergency response team for membrane repair. Nat Rev Mol Cell Biol, 2005. 6(6): p. 499-505.

361. Blott, E.J. and G.M. Griffiths, Secretory lysosomes. Nat Rev Mol Cell Biol, 2002. 3(2): p. 122-31.

362. Yu, L., et al., Termination of autophagy and reformation of lysosomes regulated by mTOR. Nature, 2010. 465(7300): p. 942-6.

363. Sardiello, M., et al., A gene network regulating lysosomal biogenesis and function. Science, 2009. 325(5939): p. 473-7.

364. Sardiello, M. and A. Ballabio, Lysosomal enhancement: a CLEAR answer to cellular degradative needs. Cell Cycle, 2009. 8(24): p. 4021-2.

365. Settembre, C., et al., TFEB links autophagy to lysosomal biogenesis. Science, 2011. 332(6036): p. 1429-33.

366. Luzio, J.P., et al., Lysosome-endosome fusion and lysosome biogenesis. J Cell Sci, 2000. 113 ( Pt 9): p. 1515-24.

367. González, S.R.S., http://kk.convdocs.org/docs/index-325832.htm/?page=31, .

368. Hussain, M.M., Structural, biochemical and signaling properties of the low-density lipoprotein receptor gene family. Front Biosci, 2001. 6: p. D417-28.

369. Marino, M. and R.T. McCluskey, Role of thyroglobulin endocytic pathways in the control of thyroid hormone release. Am J Physiol Cell Physiol, 2000. 279(5): p. C1295306.

370. Ferrer, M., et al., MMP2 and acrosin are major proteinases associated with the inner acrosomal membrane and may cooperate in sperm penetration of the zona pellucida during fertilization. Cell Tissue Res, 2012. 349(3): p. 881-95.

371. Lacombe, J., G. Karsenty, and M. Ferron, Regulation of lysosome biogenesis and functions in osteoclasts. Cell Cycle, 2013. 12(17): p. 2744-52.

372. DeSelm, C.J., et al., Autophagy proteins regulate the secretory component of osteoclastic bone resorption. Dev Cell, 2011. 21(5): p. 966-74.

373. Coutinho, M.F., M.J. Prata, and S. Alves, Mannose-6-phosphate pathway: a review on its role in lysosomal function and dysfunction. Mol Genet Metab, 2012. 105(4): p. 54250.

374. Bonten, E.J., I. Annunziata, and A. d'Azzo, Lysosomal multienzyme complex: pros and cons of working together. Cell Mol Life Sci, 2013. 71(11): p. 2017-32.

375. Shayman, J.A., Sphingolipids: their role in intracellular signaling and renal growth. J Am Soc Nephrol, 1996. 7(2): p. 171-82.

376. Shayman, J.A., et al., Group XV phospholipase A(2), a lysosomal phospholipase A(2). Prog Lipid Res, 2010. 50(1): p. 1-13.

377. Hamer, I., et al., Lipids and lysosomes. Curr Drug Metab, 2012. 13(10): p. 1371-87.

378. Lakhan, S.E., S. Sabharanjak, and A. De, Endocytosis of glycosylphosphatidylinositolanchored proteins. J Biomed Sci, 2009. 16: p. 93.

379. Mann, K.J., et al., Effect of glycosylphosphatidylinositol (GPI)-phospholipase D overexpression on GPI metabolism. Biochem J, 2004. 378(Pt 2): p. 641-8.

380. Hari, T., et al., Subcellular distribution of glycosylphosphatidylinositol-specific phospholipase D in rat liver. Biochem J, 1996. 320 ( Pt 1): p. 315-9.

381. Lu, J., et al., Activation of synoviocytes by the secreted phospholipase A2 motif in the VP1-unique region of parvovirus B19 minor capsid protein. J Infect Dis, 2006. 193(4): $p$. 582-90.

382. Boya, P., M.A. Mellen, and E.J. de la Rosa, How autophagy is related to programmed cell death during the development of the nervous system. Biochem Soc Trans, 2008. 36(Pt 5): p. 813-7.

383. Boya, P. and G. Kroemer, Lysosomal membrane permeabilization in cell death. Oncogene, 2008. 27(50): p. 6434-51. 
384. Cesen, M.H., et al., Lysosomal pathways to cell death and their therapeutic applications. Exp Cell Res, 2012. 318(11): p. 1245-51.

385. Matsui, T. and M. Fukuda, Methods of analysis of the membrane trafficking pathway from recycling endosomes to lysosomes. Methods Enzymol, 2013. 534: p. 195-206.

386. Hunziker, W. and H.J. Geuze, Intracellular trafficking of lysosomal membrane proteins. Bioessays, 1996. 18(5): p. 379-89.

387. Braulke, T. and J.S. Bonifacino, Sorting of lysosomal proteins. Biochim Biophys Acta, 2009. 1793(4): p. 605-14.

388. Cheruku, S.R., et al., Mechanism of cholesterol transfer from the Niemann-Pick type C2 protein to model membranes supports a role in lysosomal cholesterol transport. J Biol Chem, 2006. 281(42): p. 31594-604.

389. Ikonen, E., Cellular cholesterol trafficking and compartmentalization. Nat Rev Mol Cell Biol, 2008. 9(2): p. 125-38.

390. Guillaumot, P., et al., Pdro, a protein associated with late endosomes and lysosomes and implicated in cellular cholesterol homeostasis. PLoS One, 2010. 5(6): p. e10977.

391. Eskelinen, E.L., Roles of LAMP-1 and LAMP-2 in lysosome biogenesis and autophagy. Mol Aspects Med, 2006. 27(5-6): p. 495-502.

392. Kaushik, S., A.C. Massey, and A.M. Cuervo, Lysosome membrane lipid microdomains: novel regulators of chaperone-mediated autophagy. EMBO J, 2006. 25(17): p. 3921-33.

393. Kolter, T. and K. Sandhoff, Principles of lysosomal membrane digestion: stimulation of sphingolipid degradation by sphingolipid activator proteins and anionic lysosomal lipids. Annu Rev Cell Dev Biol, 2005. 21: p. 81-103.

394. Hayashi, K., et al., SMAD1 signaling is critical for initial commitment of germ cell lineage from mouse epiblast. Mech Dev, 2002. 118(1-2): p. 99-109.

395. Gruenberg, J. and H. Stenmark, The biogenesis of multivesicular endosomes. Nat Rev Mol Cell Biol, 2004. 5(4): p. 317-23.

396. Abdul-Hammed, M., et al., Role of endosomal membrane lipids and NPC2 in cholesterol transfer and membrane fusion. J Lipid Res, 2010. 51(7): p. 1747-60.

397. Trajkovic, K., et al., Ceramide triggers budding of exosome vesicles into multivesicular endosomes. Science, 2008. 319(5867): p. 1244-7.

398. Wickner, W., Membrane fusion: five lipids, four SNAREs, three chaperones, two nucleotides, and a Rab, all dancing in a ring on yeast vacuoles. Annu Rev Cell Dev Biol, 2010. 26: p. 115-36.

399. Idone, V., et al., Repair of injured plasma membrane by rapid Ca2+-dependent endocytosis. J Cell Biol, 2008. 180(5): p. 905-14.

400. Idone, V., C. Tam, and N.W. Andrews, Two-way traffic on the road to plasma membrane repair. Trends Cell Biol, 2008. 18(11): p. 552-9.

401. Kaushik, S., R. Singh, and A.M. Cuervo, Autophagic pathways and metabolic stress. Diabetes Obes Metab, 2010. 12 Suppl 2: p. 4-14.

402. Wang, X. and E.J. Terpstra, Ubiquitin receptors and protein quality control. J Mol Cell Cardiol, 2012. 55: p. 73-84.

403. Tukaj, C., The significance of macroautophagy in health and disease. Folia Morphol (Warsz), 2013. 72(2): p. 87-93.

404. Pietrocola, F., et al., Regulation of autophagy by stress-responsive transcription factors. Semin Cancer Biol, 2013. 23(5): p. 310-22.

405. Giordano, S., V. Darley-Usmar, and J. Zhang, Autophagy as an essential cellular antioxidant pathway in neurodegenerative disease. Redox Biol, 2014. 2: p. 82-90.

406. Schneider, J.L. and A.M. Cuervo, Autophagy and human disease: emerging themes. Curr Opin Genet Dev, 2014. 26C: p. 16-23.

407. Metcalf, D.J., et al., Autophagy and misfolded proteins in neurodegeneration. Exp Neurol, 2010. 238(1): p. 22-8. 
408. Garcia-Arencibia, M., et al., Autophagy, a guardian against neurodegeneration. Semin Cell Dev Biol, 2010. 21(7): p. 691-8.

409. Merenlender-Wagner, A., et al., Autophagy has a key role in the pathophysiology of schizophrenia. Mol Psychiatry, 2013.

410. Cuervo, A.M., et al., Autophagy and aging: the importance of maintaining "clean" cells. Autophagy, 2005. 1(3): p. 131-40.

411. Hannigan, A.M. and S.M. Gorski, Macroautophagy: the key ingredient to a healthy diet? Autophagy, 2009. 5(2): p. 140-51.

412. Wang, X. and E.K. Michaelis, Selective neuronal vulnerability to oxidative stress in the brain. Front Aging Neurosci. 2: p. 12.

413. Bowie, A. and L.A. O'Neill, Oxidative stress and nuclear factor-kappaB activation: a reassessment of the evidence in the light of recent discoveries. Biochem Pharmacol, 2000. 59(1): p. 13-23.

414. Packer, M., New concepts in the pathophysiology of heart failure: beneficial and deleterious interaction of endogenous haemodynamic and neurohormonal mechanisms. J Intern Med, 1996. 239(4): p. 327-33.

415. Liu, Z.Q. and H.Y. Shan, Cholesterol, not polyunsaturated fatty acids, is target molecule in oxidation induced by reactive oxygen species in membrane of human erythrocytes. Cell Biochem Biophys, 2006. 45(2): p. 185-93.

416. Schroeder, F., et al., Sterol carrier protein-2: new roles in regulating lipid rafts and signaling. Biochim Biophys Acta, 2007. 1771(6): p. 700-18.

417. Strobel, N.A., et al., Oxidative stress biomarkers as predictors of cardiovascular disease. Int J Cardiol, 2010. 147(2): p. 191-201.

418. Kamsler, A. and M. Segal, Hydrogen peroxide as a diffusible signal molecule in synaptic plasticity. Mol Neurobiol, 2004. 29(2): p. 167-78.

419. Kamsler, A. and M. Segal, Control of neuronal plasticity by reactive oxygen species. Antioxid Redox Signal, 2007. 9(2): p. 165-7.

420. Serrano, F. and E. Klann, Reactive oxygen species and synaptic plasticity in the aging hippocampus. Ageing Res Rev, 2004. 3(4): p. 431-43.

421. Kishida, K.T. and E. Klann, Sources and targets of reactive oxygen species in synaptic plasticity and memory. Antioxid Redox Signal, 2007. 9(2): p. 233-44.

422. Valko, M., et al., Free radicals and antioxidants in normal physiological functions and human disease. Int J Biochem Cell Biol, 2007. 39(1): p. 44-84.

423. Schafer, F.Q. and G.R. Buettner, Redox environment of the cell as viewed through the redox state of the glutathione disulfide/glutathione couple. Free Radic Biol Med, 2001. 30(11): p. 1191-212.

424. Jones, D.P., Redox potential of GSH/GSSG couple: assay and biological significance. Methods Enzymol, 2002. 348: p. 93-112.

425. Gumulec, J., et al., Determination of oxidative stress and activities of antioxidant enzymes in guinea pigs treated with haloperidol. Exp Ther Med, 2013. 5(2): p. 479-484.

426. Mates, J.M., et al., Roles of dioxins and heavy metals in cancer and neurological diseases using ROS-mediated mechanisms. Free Radic Biol Med, 2010. 49(9): p. 132841.

427. Halliwell, B., Role of free radicals in the neurodegenerative diseases: therapeutic implications for antioxidant treatment. Drugs Aging, 2001. 18(9): p. 685-716.

428. Nagy, I.Z., On the true role of oxygen free radicals in the living state, aging, and degenerative disorders. Ann N Y Acad Sci, 2001. 928: p. 187-99.

429. Chinopoulos, C. and V. Adam-Vizi, Calcium, mitochondria and oxidative stress in neuronal pathology. Novel aspects of an enduring theme. FEBS J, 2006. 273(3): p. 43350. 
430. Butterfield, D.A., Amyloid beta-peptide (1-42)-induced oxidative stress and neurotoxicity: implications for neurodegeneration in Alzheimer's disease brain. A review. Free Radic Res, 2002. 36(12): p. 1307-13.

431. Farkas, E., et al., Tumor necrosis factor-alpha increases cerebral blood flow and ultrastructural capillary damage through the release of nitric oxide in the rat brain. Microvasc Res, 2006. 72(3): p. 113-9.

432. Wang, X. and E.K. Michaelis, Selective neuronal vulnerability to oxidative stress in the brain. Front Aging Neurosci, 2010. 2: p. 12.

433. Wilde, G.J., et al., Differential vulnerability of the CA1 and CA3 subfields of the hippocampus to superoxide and hydroxyl radicals in vitro. J Neurochem, 1997. 69(2): p. 883-6.

434. Wang, X., et al., High intrinsic oxidative stress may underlie selective vulnerability of the hippocampal CA1 region. Brain Res Mol Brain Res, 2005. 140(1-2): p. 120-6.

435. Wang, X., et al., Genome-wide transcriptome profiling of region-specific vulnerability to oxidative stress in the hippocampus. Genomics, 2007. 90(2): p. 201-12.

436. Wang, X., et al., Genomic and biochemical approaches in the discovery of mechanisms for selective neuronal vulnerability to oxidative stress. BMC Neurosci, 2009. 10: p. 12.

437. Schmidt-Kastner, R. and T.F. Freund, Selective vulnerability of the hippocampus in brain ischemia. Neuroscience, 1991. 40(3): p. 599-636.

438. Olsson, T., T. Wieloch, and M.L. Smith, Brain damage in a mouse model of global cerebral ischemia. Effect of NMDA receptor blockade. Brain Res, 2003. 982(2): p. 260-9.

439. Mueller, S.G., et al., Measurement of hippocampal subfields and age-related changes with high resolution MRI at 4T. Neurobiol Aging, 2007. 28(5): p. 719-26.

440. Dubinina, E.E. and V.A. Dadali, Role of 4-hydroxy-trans-2-nonenal in cell functions. Biochemistry (Mosc), 2010. 75(9): p. 1069-87.

441. Farooqui, A.A. and L.A. Horrocks, Phospholipase A2-generated lipid mediators in the brain: the good, the bad, and the ugly. Neuroscientist, 2006. 12(3): p. 245-60.

442. Farout, L., et al., Inactivation of the proteasome by 4-hydroxy-2-nonenal is site specific and dependant on $20 S$ proteasome subtypes. Arch Biochem Biophys, 2006. 453(1): p. 135-42.

443. Bentz, A.B., A Review of Quercetin: Chemistry, Antioxidant Properties, and Bioavailability. jourl of young investigators, 2009(1539-4026).

444. Jellinger, K.A., Alzheimer's disease: a challenge for modern neuropathobiology. Acta Neuropathol, 2009. 118(1): p. 1-3.

445. Koudinov, A., et al., Amyloid-beta, tau protein, and oxidative changes as a physiological compensatory mechanism to maintain CNS plasticity under Alzheimer's disease and other neurodegenerative conditions. J Alzheimers Dis, 2009. 18(2): p. 381400.

446. Radak, Z. and I. Boldogh, 8-Oxo-7,8-dihydroguanine: links to gene expression, aging, and defense against oxidative stress. Free Radic Biol Med, 2010. 49(4): p. 587-96.

447. Esiri, M.M., Ageing and the brain. J Pathol, 2007. 211(2): p. 181-7.

448. Head, E., Oxidative damage and cognitive dysfunction: antioxidant treatments to promote healthy brain aging. Neurochem Res, 2009. 34(4): p. 670-8.

449. Martin, M.G., et al., Cholesterol loss enhances TrkB signaling in hippocampal neurons aging in vitro. Mol Biol Cell, 2008. 19(5): p. 2101-12.

450. Adibhatla, R.M. and J.F. Hatcher, Altered lipid metabolism in brain injury and disorders. Subcell Biochem, 2008. 49: p. 241-68.

451. Martin, L.J., et al., Neurodegeneration in excitotoxicity, global cerebral ischemia, and target deprivation: A perspective on the contributions of apoptosis and necrosis. Brain Res Bull, 1998. 46(4): p. 281-309. 
452. Zhuang, S., et al., Extracellular signal-regulated kinase activation mediates mitochondrial dysfunction and necrosis induced by hydrogen peroxide in renal proximal tubular cells. J Pharmacol Exp Ther, 2008. 325(3): p. 732-40.

453. Zhao, Z., et al., Protection of pancreatic beta-cells by group VIA phospholipase A(2)mediated repair of mitochondrial membrane peroxidation. Endocrinology, 2010. 151(7): p. 3038-48.

454. Hoda, M.N., et al., Reduction of lipoxidative load by secretory phospholipase A2 inhibition protects against neurovascular injury following experimental stroke in rat. J Neuroinflammation, 2009. 6: p. 21.

455. Nigam, S. and T. Schewe, Phospholipase A(2)s and lipid peroxidation. Biochim Biophys Acta, 2000. 1488(1-2): p. 167-81.

456. Iannilli, F., et al., Oxidative stress activates the pro-survival TrkA pathway through membrane cholesterol loss. Neurobiol Aging, 2009. 32(6): p. 1033-42.

457. Greenberg, M.E., et al., The lipid whisker model of the structure of oxidized cell membranes. J Biol Chem, 2008. 283(4): p. 2385-96.

458. Buettner, G.R., E.E. Kelley, and C.P. Burns, Membrane lipid free radicals produced from L1210 murine leukemia cells by photofrin photosensitization: an electron paramagnetic resonance spin trapping study. Cancer Res, 1993. 53(16): p. 3670-3.

459. Niforou, K., C. Cheimonidou, and I.P. Trougakos, Molecular chaperones and proteostasis regulation during redox imbalance. Redox Biol, 2014. 2: p. 323-32.

460. Held, J.M. and B.W. Gibson, Regulatory control or oxidative damage? Proteomic approaches to interrogate the role of cysteine oxidation status in biological processes. Mol Cell Proteomics, 2011. 11(4): p. R111 013037.

461. Lim, J.C., et al., Methionine sulfoxide reductase $A$ is a stereospecific methionine oxidase. Proc Natl Acad Sci U S A, 2011. 108(26): p. 10472-7.

462. Drazic, A. and J. Winter, The physiological role of reversible methionine oxidation. Biochim Biophys Acta, 2014. 1844(8): p. 1367-82.

463. Stadtman, E.R., et al., Methionine oxidation and aging. Biochim Biophys Acta, 2005. 1703(2): p. 135-40.

464. Salmon, A.B., et al., Lack of methionine sulfoxide reductase $A$ in mice increases sensitivity to oxidative stress but does not diminish life span. FASEB J, 2009. 23(10): p. 3601-8.

465. Zhao, C., et al., Role of methionine sulfoxide reductases $A$ and $B$ of Enterococcus faecalis in oxidative stress and virulence. Infect Immun, 2010. 78(9): p. 3889-97.

466. Souza, J.M., G. Peluffo, and R. Radi, Protein tyrosine nitration--functional alteration or just a biomarker? Free Radic Biol Med, 2008. 45(4): p. 357-66.

467. Levine, R.L. and E.R. Stadtman, Oxidative modification of proteins during aging. Exp Gerontol, 2001. 36(9): p. 1495-502.

468. Stadtman, E.R., Protein oxidation in aging and age-related diseases. Ann N Y Acad Sci, 2001. 928: p. 22-38.

469. Stadtman, E.R., Protein oxidation and aging. Free Radic Res, 2006. 40(12): p. 1250-8.

470. Chao, C.C., Y.S. Ma, and E.R. Stadtman, Modification of protein surface hydrophobicity and methionine oxidation by oxidative systems. Proc Natl Acad Sci U S A, 1997. 94(7): p. 2969-74.

471. Shringarpure, R., et al., Ubiquitin conjugation is not required for the degradation of oxidized proteins by proteasome. J Biol Chem, 2003. 278(1): p. 311-8.

472. Hsieh, H.L. and C.M. Yang, Role of redox signaling in neuroinflammation and neurodegenerative diseases. Biomed Res Int, 2014. 2013: p. 484613.

473. Nakamura, A., et al., Biological significance of protein modifications in aging and calorie restriction. Ann N Y Acad Sci, 2010. 1197: p. 33-9. 
474. Terman, A., et al., Mitochondrial turnover and aging of long-lived postmitotic cells: the mitochondrial-lysosomal axis theory of aging. Antioxid Redox Signal, 2009. 12(4): p. 503-35.

475. Tydlacka, S., et al., Differential activities of the ubiquitin-proteasome system in neurons versus glia may account for the preferential accumulation of misfolded proteins in neurons. J Neurosci, 2008. 28(49): p. 13285-95.

476. Fischer, D.F., et al., Long-term proteasome dysfunction in the mouse brain by expression of aberrant ubiquitin. Neurobiol Aging, 2009. 30(6): p. 847-63.

477. Kuczera, T., et al., The anaphase promoting complex is required for memory function in mice. Learn Mem, 2010. 18(1): p. 49-57.

478. Szabo, Z., et al., Voluntary exercise may engage proteasome function to benefit the brain after trauma. Brain Res, 2009. 1341: p. 25-31.

479. http://www.hindawi.com/journals/omcl/2011/213686/fig6/.

480. Sharma, R., et al., Carbonyl modification in rat liver histones: decrease with age and increase by dietary restriction. Free Radic Biol Med, 2006. 40(7): p. 1179-84.

481. Norris, K.L. and T.P. Yao, Lysine modifications and autophagy. Essays Biochem, 2012. 52: p. 65-77.

482. Maluf, S.W., et al., DNA damage and oxidative stress in human disease. Biomed Res Int, 2013. 2013: p. 696104.

483. Bohr, V., et al., Oxidative DNA damage processing and changes with aging. Toxicol Lett, 1998. 102-103: p. 47-52.

484. Schmitz, C., et al., Age-related changes of DNA repair and mitochondrial DNA synthesis in the mouse brain. Acta Neuropathol, 1999. 97(1): p. 71-81.

485. Cardozo-Pelaez, F., et al., Effects of diethylmaleate on DNA damage and repair in the mouse brain. Free Radic Biol Med, 2002. 33(2): p. 292-8.

486. Choi, J.E. and R. Mostoslavsky, Sirtuins, metabolism, and DNA repair. Curr Opin Genet Dev, 2014. 26C: p. 24-32.

487. Brooks, A.I., et al., Paraquat elicited neurobehavioral syndrome caused by dopaminergic neuron loss. Brain Res, 1999. 823(1-2): p. 1-10.

488. Bus, J.S. and J.E. Gibson, Paraquat: model for oxidant-initiated toxicity. Environ Health Perspect, 1984. 55: p. 37-46.

489. Prasad, K., et al., Toxicokinetics and toxicodynamics of paraquat accumulation in mouse brain. Exp Neurol, 2009. 215(2): p. 358-67.

490. Vornov, J.J., J. Park, and A.G. Thomas, Regional vulnerability to endogenous and exogenous oxidative stress in organotypic hippocampal culture. Exp Neurol, 1998. 149(1): p. 109-22.

491. Wang, L., et al., Effects of extracellular delta-aminolaevulinic acid on sodium currents in acutely isolated rat hippocampal CA1 neurons. Eur J Neurosci, 2005. 22(12): p. 3122-8.

492. Satoh, T., et al., Oxygen toxicity induces apoptosis in neuronal cells. Cell Mol Neurobiol, 1998. 18(6): p. 649-66.

493. Siskova, Z., et al., Brain region specific pre-synaptic and post-synaptic degeneration are early components of neuropathology in prion disease. PLoS One, 2013. 8(1): p. e55004.

494. Bayer, T.A., Proteinopathies, a core concept for understanding and ultimately treating degenerative disorders? Eur Neuropsychopharmacol, 2013.

495. Sipe, J.D. and A.S. Cohen, Review: history of the amyloid fibril. J Struct Biol, 2000. 130(2-3): p. 88-98.

496. Haass, C. and D.J. Selkoe, Soluble protein oligomers in neurodegeneration: lessons from the Alzheimer's amyloid beta-peptide. Nat Rev Mol Cell Biol, 2007. 8(2): p. 101-12.

497. Colby, D.W. and S.B. Prusiner, De novo generation of prion strains. Nat Rev Microbiol, 2011. 9(11): p. 771-7. 
498. Kordower, J.H. and C.W. Olanow, Regulatable promoters and gene therapy for Parkinson's disease: is the only thing to fear, fear itself? Exp Neurol, 2008. 209(1): p. 34-40.

499. $\mathrm{Li}, \mathrm{X} ., \mathrm{H} . \mathrm{Li}$, and X.J. Li, Intracellular degradation of misfolded proteins in polyglutamine neurodegenerative diseases. Brain Res Rev, 2008. 59(1): p. 245-52.

500. Meyer-Luehmann, M., et al., Rapid appearance and local toxicity of amyloid-beta plaques in a mouse model of Alzheimer's disease. Nature, 2008. 451(7179): p. 720-4.

501. Bertram, L. and R.E. Tanzi, The genetic epidemiology of neurodegenerative disease. J Clin Invest, 2005. 115(6): p. 1449-57.

502. Walker, L.C., et al., Apolipoprotein E4 promotes the early deposition of Abeta42 and then Abeta40 in the elderly. Acta Neuropathol, 2000. 100(1): p. 36-42.

503. DeKosky, S.T., M.D. Ikonomovic, and S. Gandy, Traumatic brain injury: football, warfare, and long-term effects. Minn Med, 2011. 93(12): p. 46-7.

504. Cohen-Carmon, D. and E. Meshorer, Polyglutamine (polyQ) disorders: the chromatin connection. Nucleus, 2012. 3(5): p. 433-41.

505. Seidel, K., et al., Brain pathology of spinocerebellar ataxias. Acta Neuropathol, 2012. 124(1): p. 1-21.

506. Orr, H.T., Polyglutamine neurodegeneration: expanded glutamines enhance native functions. Curr Opin Genet Dev, 2012. 22(3): p. 251-5.

507. Robertson, A.L. and S.P. Bottomley, Molecular pathways to polyglutamine aggregation. Adv Exp Med Biol, 2012. 769: p. 115-24.

508. Ransome, M.I., T. Renoir, and A.J. Hannan, Hippocampal neurogenesis, cognitive deficits and affective disorder in Huntington's disease. Neural Plast, 2012. 2012: p. 874387.

509. Rub, U., et al., Clinical features, neurogenetics and neuropathology of the polyglutamine spinocerebellar ataxias type 1, 2, 3, 6 and 7. Prog Neurobiol, 2013. 104: p. 38-66.

510. Heng, M.Y., et al., Early autophagic response in a novel knock-in model of Huntington disease. Hum Mol Genet, 2010. 19(19): p. 3702-20.

511. Jimenez-Sanchez, M., et al., Autophagy and polyglutamine diseases. Prog Neurobiol, 2011. 97(2): p. 67-82.

512. Nisoli, I., et al., Neurodegeneration by polyglutamine Atrophin is not rescued by induction of autophagy. Cell Death Differ, 2010. 17(10): p. 1577-87.

513. Bouquet, C. and F. Nothias, Molecular mechanisms of axonal growth. Adv Exp Med Biol, 2007. 621: p. 1-16.

514. Tojima, T., Intracellular signaling and membrane trafficking control bidirectional growth cone guidance. Neurosci Res, 2012. 73(4): p. 269-74.

515. Lee, S.K. and P.J. Hollenbeck, Organization and translation of mRNA in sympathetic axons. J Cell Sci, 2003. 116(Pt 21): p. 4467-78.

516. Bloom, O.E. and J.R. Morgan, Membrane trafficking events underlying axon repair, growth, and regeneration. Mol Cell Neurosci, 2011. 48(4): p. 339-48.

517. Bridgman, P.C. and M.E. Dailey, The organization of myosin and actin in rapid frozen nerve growth cones. J Cell Biol, 1989. 108(1): p. 95-109.

518. Dehmelt, L. and S. Halpain, Actin and microtubules in neurite initiation: are MAPs the missing link? J Neurobiol, 2004. 58(1): p. 18-33.

519. Learte, A.R. and A. Hidalgo, The role of glial cells in axon guidance, fasciculation and targeting. Adv Exp Med Biol, 2007. 621: p. 156-66.

520. Vitriol, E.A. and J.Q. Zheng, Growth cone travel in space and time: the cellular ensemble of cytoskeleton, adhesion, and membrane. Neuron, 2012. 73(6): p. 1068-81.

521. Guirland, C. and J.Q. Zheng, Membrane lipid rafts and their role in axon guidance. Adv Exp Med Biol, 2007. 621: p. 144-55. 
522. Golub, T., S. Wacha, and P. Caroni, Spatial and temporal control of signaling through lipid rafts. Curr Opin Neurobiol, 2004. 14(5): p. 542-50.

523. Nakai, Y. and H. Kamiguchi, Migration of nerve growth cones requires detergentresistant membranes in a spatially defined and substrate-dependent manner. J Cell Biol, 2002. 159(6): p. 1097-108.

524. Dickson, B.J., Molecular mechanisms of axon guidance. Science, 2002. 298(5600): p. 1959-64.

525. Pollerberg, G.E., et al., The role of cell adhesion molecules for navigating axons: density matters. Mech Dev, 2012. 130(6-8): p. 359-72.

526. Craig, A.M., R.J. Wyborski, and G. Banker, Preferential addition of newly synthesized membrane protein at axonal growth cones. Nature, 1995. 375(6532): p. 592-4.

527. Ye, B., et al., Growing dendrites and axons differ in their reliance on the secretory pathway. Cell, 2007. 130(4): p. 717-29.

528. Verkade, P. and K. Simons, Robert Feulgen Lecture 1997. Lipid microdomains and membrane trafficking in mammalian cells. Histochem Cell Biol, 1997. 108(3): p. 211-20.

529. Itofusa, R. and H. Kamiguchi, Polarizing membrane dynamics and adhesion for growth cone navigation. Mol Cell Neurosci, 2011. 48(4): p. 332-8.

530. McKerracher, L., Ganglioside rafts as MAG receptors that mediate blockade of axon growth. Proc Natl Acad Sci U S A, 2002. 99(12): p. 7811-3.

531. Suzuki, S., et al., BDNF-induced recruitment of TrkB receptor into neuronal lipid rafts: roles in synaptic modulation. J Cell Biol, 2004. 167(6): p. 1205-15.

532. Ming, G., et al., Phospholipase C-gamma and phosphoinositide 3-kinase mediate cytoplasmic signaling in nerve growth cone guidance. Neuron, 1999. 23(1): p. 139-48.

533. Brand, A.H. and N. Perrimon, Targeted gene expression as a means of altering cell fates and generating dominant phenotypes. Development, 1993. 118(2): p. 401-15.

534. Duffy, J.B., GAL4 system in Drosophila: a fly geneticist's Swiss army knife. Genesis, 2002. 34(1-2): p. 1-15.

535. Rong, Y.S., et al., Targeted mutagenesis by homologous recombination in D. melanogaster. Genes Dev, 2002. 16(12): p. 1568-81.

536. Tayler, T.D., M.B. Robichaux, and P.A. Garrity, Compartmentalization of visual centers in the Drosophila brain requires Slit and Robo proteins. Development, 2004. 131(23): p. 5935-45.

537. Ihara, R., et al., RNA binding mediates neurotoxicity in the transgenic Drosophila model of TDP-43 proteinopathy. Hum Mol Genet, 2013. 22(22): p. 4474-84.

538. Kaminker, J.S., et al., Control of photoreceptor axon target choice by transcriptional repression of Runt. Nat Neurosci, 2002. 5(8): p. 746-50.

539. Li, W.Z., et al., A broad expression profile of the GMR-GAL4 driver in Drosophila melanogaster. Genet Mol Res, 2012. 11(3): p. 1997-2002.

540. Han, C., L.Y. Jan, and Y.N. Jan, Enhancer-driven membrane markers for analysis of nonautonomous mechanisms reveal neuron-glia interactions in Drosophila. Proc Natl Acad Sci U S A, 2011. 108(23): p. 9673-8.

541. Fernandez-Funez, P., et al., Identification of genes that modify ataxin-1-induced neurodegeneration. Nature, 2000. 408(6808): p. 101-6.

542. Walker, D.W., et al., Overexpression of a Drosophila homolog of apolipoprotein D leads to increased stress resistance and extended lifespan. Curr Biol, 2006. 16(7): p. 674-9.

543. Bajo-Graneras, R., et al., Apolipoprotein D mediates autocrine protection of astrocytes and controls their reactivity level, contributing to the functional maintenance of paraquat-challenged dopaminergic systems. Glia, 2011. 59(10): p. 1551-66.

544. Bajo-Graneras, R., et al., Apolipoprotein D alters the early transcriptional response to oxidative stress in the adult cerebellum. J Neurochem, 2011. 117(6): p. 949-60.

545. Sanchez-Soriano, N., et al., Drosophila growth cones: a genetically tractable platform for the analysis of axonal growth dynamics. Dev Neurobiol, 2009. 70(1): p. 58-71. 
546. Sanchez-Soriano, N., et al., Are dendrites in Drosophila homologous to vertebrate dendrites? Dev Biol, 2005. 288(1): p. 126-38.

547. Campos-Ortega, J.A., Neurogenesis in Drosophila: an historical perspective and some prospects. Perspect Dev Neurobiol, 1997. 4(4): p. 267-71.

548. Livak, K.J. and T.D. Schmittgen, Analysis of relative gene expression data using realtime quantitative PCR and the 2(-Delta Delta C(T)) Method. Methods, 2001. 25(4): p. 402-8.

549. Yuan, J.S., et al., Statistical analysis of real-time PCR data. BMC Bioinformatics, 2006. 7: p. 85.

550. Gorg, A., et al., Two-dimensional electrophoresis with immobilized pH gradients of leaf proteins from barley (Hordeum vulgare): method, reproducibility and genetic aspects. Electrophoresis, 1988. 9(11): p. 681-92.

551. Hojjati, M.R. and X.C. Jiang, Rapid, specific, and sensitive measurements of plasma sphingomyelin and phosphatidylcholine. J Lipid Res, 2006. 47(3): p. 673-6.

552. Arroyo, A.I., et al., Pharmacological reversion of sphingomyelin-induced dendritic spine anomalies in a Niemann Pick disease type A mouse model. EMBO Mol Med, 2014. 6(3): p. 398-413.

553. E Hoffmann, V.S., Mass espectroscopy, priciples y aplications. Second Edition ed, ed. J.W. Sons. 1999, s Ltd, The Atrium, Southern Gate, Chichester,

West Sussex PO19 8SQ, England.

554. Seppänen-Laakso, T., How to study lipidomes. Journal of Molecular Endocrinology 2009. 42: p. $185-190$

555. Roberts, L.D., et al., A matter of fat: an introduction to lipidomic profiling methods. J Chromatogr B Analyt Technol Biomed Life Sci, 2008. 871(2): p. 174-81.

556. Barr, J., et al., Obesity-dependent metabolic signatures associated with nonalcoholic fatty liver disease progression. J Proteome Res, 2012. 11(4): p. 2521-32.

557. http://antoine.frostburg.edu/chem/senese/101/glossary/m.shtml.

558. Di Zou, A.-h.Z., Guang-li Yan, Yun-long Tan, Hui Suna and Xi-jun Wang, UPLC-MS coupled with a dynamic multiple data processing method for the comprehensive detection of the chemical constituents of the herbal formula San-Miao-Wan. Anal. Methods, 2014. 6: p. 2848-2854.

559. De Gelder, J., et al., Raman spectroscopic study of bacterial endospores. Anal Bioanal Chem, 2007. 389(7-8): p. 2143-51.

560. Brauchle, E. and K. Schenke-Layland, Raman spectroscopy in biomedicine - non-invasive in vitro analysis of cells and extracellular matrix components in tissues. Biotechnol J, 2012. 8(3): p. 288-97.

561. triplenlace.com. 2014 [cited.

562. Ruiz, M., et al., Sex-dependent modulation of longevity by two Drosophila homologues of human Apolipoprotein D, GLaz and NLaz. Exp Gerontol, 2011. 46(7): p. 579-89.

563. Ruiz, M., et al., Grasshopper Lazarillo, a GPI-anchored Lipocalin, increases Drosophila longevity and stress resistance, and functionally replaces its secreted homolog NLaz. Insect Biochem Mol Biol, 2012. 42(10): p. 776-89.

564. Kanai, M., A. Raz, and D.S. Goodman, Retinol-binding protein: the transport protein for vitamin $A$ in human plasma. J Clin Invest, 1968. 47(9): p. 2025-44.

565. Thomas, E.A., R.C. George, and J.G. Sutcliffe, Apolipoprotein D modulates arachidonic acid signaling in cultured cells: implications for psychiatric disorders. Prostaglandins Leukot Essent Fatty Acids, 2003. 69(6): p. 421-7.

566. Gasymov, O.K., et al., Tear lipocalin: evidence for a scavenging function to remove lipids from the human corneal surface. Invest Ophthalmol Vis Sci, 2005. 46(10): p. 3589-96. 
567. Bhatia, S., et al., Selective reduction of hydroperoxyeicosatetraenoic acids to their hydroxy derivatives by apolipoprotein D: implications for lipid antioxidant activity and Alzheimer's disease. Biochem J, 2012. 442(3): p. 713-21.

568. Sanchez, D., et al., Molecular interactions of the neuronal GPI-anchored lipocalin Lazarillo. J Mol Recognit, 2008. 21(5): p. 313-23.

569. Muffat, J. and D.W. Walker, Apolipoprotein D: an overview of its role in aging and agerelated diseases. Cell Cycle, 2009. 9(2): p. 269-73.

570. Gladyshev, V.N., On the cause of aging and control of lifespan: heterogeneity leads to inevitable damage accumulation, causing aging; control of damage composition and rate of accumulation define lifespan. Bioessays, 2012. 34(11): p. 925-9.

571. Cano-Espinel, M.A., J.R. Sanchez, D. Ganfornina, M.D., Lazarillo-related Lipocalinsconfer long-term protection againsttype I Spinocerebellar Ataxia degeneration by promoting autophagy flow. Molecular Neurodegeneration, 2014: $\mathrm{p}$. (en revision).

572. Branco, J., et al., Comparative analysis of genetic modifiers in Drosophila points to common and distinct mechanisms of pathogenesis among polyglutamine diseases. Hum Mol Genet, 2008. 17(3): p. 376-90.

573. Milton, V.J. and S.T. Sweeney, Oxidative stress in synapse development and function. Dev Neurobiol, 2012. 72(1): p. 100-10.

574. Simonsen, A., et al., Promoting basal levels of autophagy in the nervous system enhances longevity and oxidant resistance in adult Drosophila. Autophagy, 2008. 4(2): p. $176-84$.

575. Costa-Mattioli, M. and L.M. Monteggia, mTOR complexes in neurodevelopmental and neuropsychiatric disorders. Nat Neurosci, 2013. 16(11): p. 1537-43.

576. Komatsu, M. and Y. Ichimura, Physiological significance of selective degradation of $p 62$ by autophagy. FEBS Lett, 2010. 584(7): p. 1374-8.

577. Bartlett, B.J., et al., p62, Ref(2)P and ubiquitinated proteins are conserved markers of neuronal aging, aggregate formation and progressive autophagic defects. Autophagy, 2011. 7(6): p. 572-83.

578. Bjorkoy, G., et al., Monitoring autophagic degradation of p62/SQSTM1. Methods Enzymol, 2009. 452: p. 181-97.

579. Tang, B.L., Emerging aspects of membrane traffic in neuronal dendrite growth. Biochim Biophys Acta, 2008. 1783(2): p. 169-76.

580. Ryu, J., et al., Proteomic analysis of osteoclast lipid rafts: the role of the integrity of lipid rafts on V-ATPase activity in osteoclasts. J Bone Miner Metab, 2010. 28(4): p. 4107.

581. Wilkins, M.R., et al., Two-dimensional gel electrophoresis for proteome projects: the effects of protein hydrophobicity and copy number. Electrophoresis, 1998. 19(8-9): p. 1501-5.

582. Santoni, V., M. Molloy, and T. Rabilloud, Membrane proteins and proteomics: un amour impossible? Electrophoresis, 2000. 21(6): p. 1054-70.

583. Vandewalle, B., et al., Further characterization of the light breast cyst fluid protein, GCDFP-15. Biochimie, 1986. 68(5): p. 649-56.

584. Williamson, R., et al., Isolation of detergent resistant microdomains from cultured neurons: detergent dependent alterations in protein composition. BMC Neurosci, 2010. 11: p. 120.

585. Uruse, M., et al., Phase separation of myelin sheath in Triton X-114 solution: predominant localization of the 21.5-kDa isoform of myelin basic protein in the lipid raft-associated domain. J Biochem, 2014. 155(4): p. 265-71.

586. Fabelo, N., et al., Severe alterations in lipid composition of frontal cortex lipid rafts from Parkinson's disease and incidental Parkinson's disease. Mol Med, 2011. 17(9-10): p. 1107-18. 
587. Wang, B., et al., Sialic acid concentration of brain gangliosides: variation among eight mammalian species. Comp Biochem Physiol A Mol Integr Physiol, 1998. 119(1): p. 4359.

588. Rahmann, H., Brain gangliosides and memory formation. Behav Brain Res, 1995. 66(12): p. 105-116.

589. Bikman, B.T. and S.A. Summers, Ceramides as modulators of cellular and whole-body metabolism. J Clin Invest, 2011. 121(11): p. 4222-30.

590. Catalgol, B. and N. Kartal Ozer, Lipid rafts and redox regulation of cellular signaling in cholesterol induced atherosclerosis. Curr Cardiol Rev, 2011. 6(4): p. 309-24.

591. Cutler, R.G., et al., Involvement of oxidative stress-induced abnormalities in ceramide and cholesterol metabolism in brain aging and Alzheimer's disease. Proc Natl Acad Sci U S A, 2004. 101(7): p. 2070-5.

592. Martin, M., C.G. Dotti, and M.D. Ledesma, Brain cholesterol in normal and pathological aging. Biochim Biophys Acta, 2010. 1801(8): p. 934-44.

593. Nourissat, A., et al., Estimation of the risk for nutritional state degradation in patients with cancer: development of a screening tool based on results from a cross-sectional survey. Ann Oncol, 2007. 18(11): p. 1882-6.

594. D'Souza, K. and R.M. Epand, Enrichment of phosphatidylinositols with specific acyl chains. Biochim Biophys Acta, 2013. 1838(6): p. 1501-8.

595. Jin, D., Y. Zhang, and X. Chen, Lipocalin 2 deficiency inhibits cell proliferation, autophagy, and mitochondrial biogenesis in mouse embryonic cells. Mol Cell Biochem, 2011. 351(1-2): p. 165-72.

596. Vural, A. and J.H. Kehrl, Autophagy in macrophages: impacting inflammation and bacterial infection. Scientifica (Cairo), 2014. 2014: p. 825463.

597. Hale, A.N., et al., Autophagy: regulation and role in development. Autophagy, 2013. 9(7): p. 951-72.

598. Ammar, M.R., et al., Lipids in Regulated Exocytosis: What are They Doing? Front Endocrinol (Lausanne), 2013. 4: p. 125.

599. Li, X., A.G. Garrity, and H. Xu, Regulation of membrane trafficking by signalling on endosomal and lysosomal membranes. J Physiol, 2013. 591(Pt 18): p. 4389-401.

600. Fader, C.M. and M.I. Colombo, Autophagy and multivesicular bodies: two closely related partners. Cell Death Differ, 2009. 16(1): p. 70-8.

601. Bronfman, F.C., et al., Endosomal transport of neurotrophins: roles in signaling and neurodegenerative diseases. Dev Neurobiol, 2007. 67(9): p. 1183-203.

602. Zonta, B. and L. Minichiello, Synaptic membrane rafts: traffic lights for local neurotrophin signaling? Front Synaptic Neurosci, 2013. 5: p. 9.

603. Pfrieger, F.W., Role of cholesterol in synapse formation and function. Biochim Biophys Acta, 2003. 1610(2): p. 271-80.

604. Linetti, A., et al., Cholesterol reduction impairs exocytosis of synaptic vesicles. J Cell Sci, 2010. 123(Pt 4): p. 595-605.

605. Rosa, P. and A. Fratangeli, Cholesterol and synaptic vesicle exocytosis. Commun Integr Biol, 2010. 3(4): p. 352-3.

606. Kandel, E.R., Y. Dudai, and M.R. Mayford, The molecular and systems biology of memory. Cell, 2014. 157(1): p. 163-86.

607. van der Zee, E.A., Synapses, spines and kinases in mammalian learning and memory, and the impact of aging. Neurosci Biobehav Rev, 2014.

608. Wang, X.L., et al., Autoimmunoreactive IgGs against cardiac lipid raft-associated proteins in patients with postural orthostatic tachycardia syndrome. Transl Res. 162(1): p. 34-44.

609. Weissbach, H., et al., Peptide methionine sulfoxide reductase: structure, mechanism of action, and biological function. Arch Biochem Biophys, 2002. 397(2): p. 172-8. 
610. Jeremy M. Beg, J.L.T., Lubert Stryer, Biochemistry, Seventh Edition ed. W.H.F.a. Company. 2012.

ANEXO

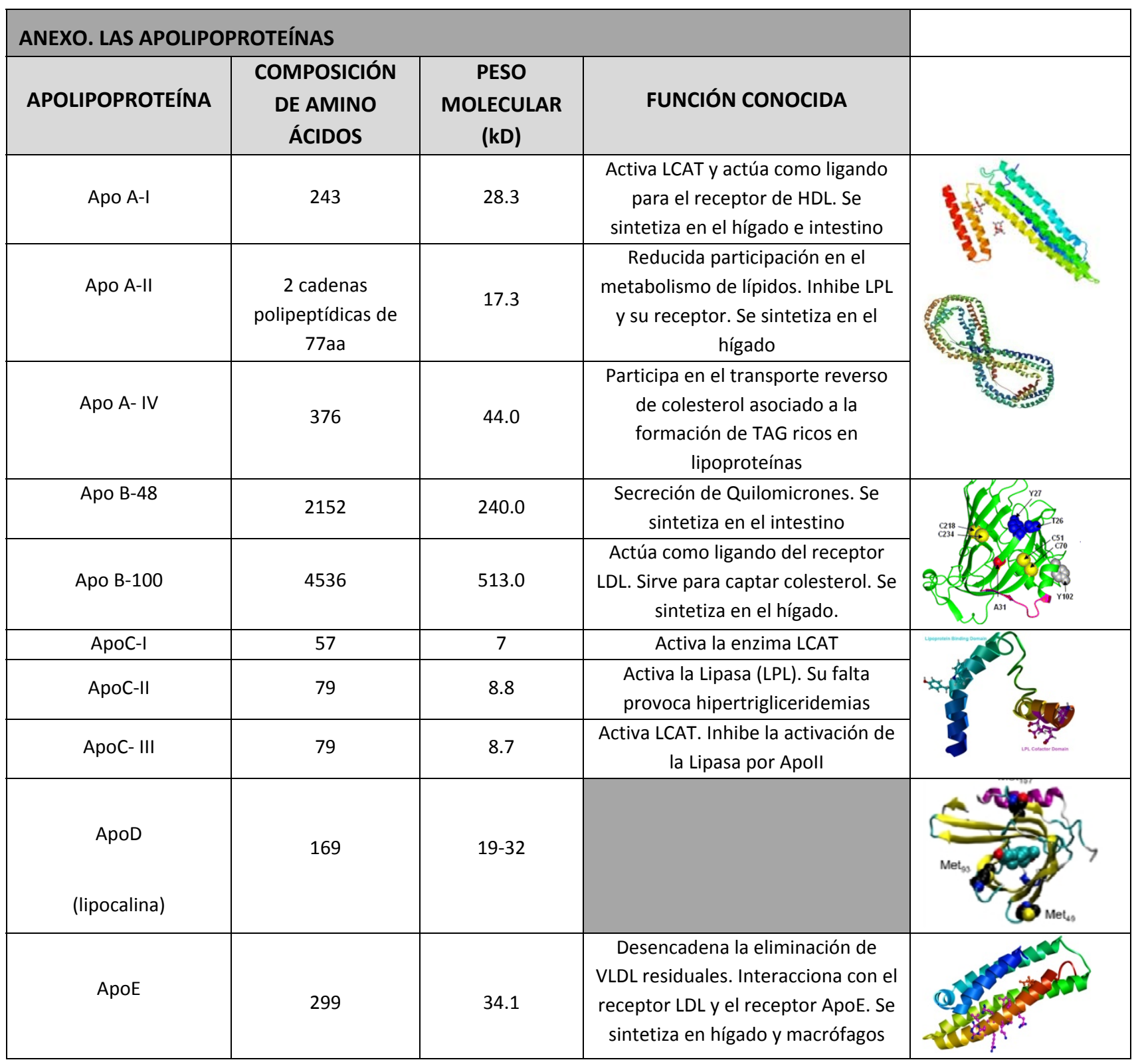




\begin{tabular}{|c|c|c|c|}
\hline ApoM & 188 & 25 & $\begin{array}{c}\text { Actúa como una chaperona } \\
\text { modulando la actividad del lípido } \\
\text { bioactivo esfingosina-1 fosfato } \\
\text { (S1P) }\end{array}$
\end{tabular}


NOTAS 
